\author{
UNIVERSIDADE DE SÃO PAULO \\ ESCOLA DE EDUCAÇÃO FÍSICA E ESPORTE
}

\title{
BIOMECÂNICA DA ATERRISSAGEM DE DUPLO MORTAL ESTENDIDO NA BARRA FIXA
}

Franklin de Camargo Junior

São Paulo

2019 
FRANKLIN DE CAMARGO JUNIOR

\section{BIOMECÂNICA DA ATERRISSAGEM DE DUPLO MORTAL ESTENDIDO NA BARRA FIXA}

Tese submetida à Defesa de Título de Doutor em Ciências na Escola de Educação Física e Esporte da Universidade de São Paulo

Área de Concentração: Estudos Biodinâmicos da Educação Física e Esporte

Orientador: Prof. Dr. Alberto Carlos Amadio

São Paulo 
Catalogação da Publicação

Serviço de Biblioteca

Escola de Educação Física e Esporte da Universidade de São Paulo

Camargo Junior, Franklin de

Biomecânica da aterrissagem de duplo mortal estendido na barra fixa / Franklin de Camargo Junior. - São Paulo: [s.n.], 2019.

$135 p$.

Tese (Doutorado)- -Escola de Educação Física e Esporte da Universidade de São Paulo.

Orientador: Prof. Dr. Alberto Carlos Amadio

1. Biomecânica 2. Ginástica artística 3. Duplo mortal I. Título. 


\section{FOLHA DE APROVAÇÃO}

Autor: CAMARGO JUNIOR, Franklin de.

Título: Biomecânica da aterrissagem de duplo mortal estendido na barra fixa.

Tese apresentada ao Programa de PósGraduação da Escola de Educação Física e Esporte da Universidade de São Paulo, como requisito para obtenção do título de Doutor em Ciências.

Aprovado em:

\section{Banca Examinadora}

Prof. Dr.

Instituição: Julgamento:

Prof. Dr.

Instituição: Julgamento:

Prof. Dr.

Instituição: Julgamento: 
À minha esposa, Julieta, e aos meus filhos, Lucas e Júlia. 


\section{AGRADECIMENTOS}

Alberto Carlos Amadio / EEFE-USP

Arturo Forner-Cordero / EP-USP

Fabrizio Leonardi / FEI

Júlio Cerca Serrão / EEFE-USP

Letícia Martins Raposo / COPPE-UFRJ

Luciano Luporini Menegaldo / COPPE-UFRJ

Luis Mochizuki / EACH-USP

Marko Ackermann / FEI

Rafael Traldi Moura / EP-USP

Rosimary Terezinha de Almeida / COPPE-UFRJ

Comitê Olímpico do Brasil

Confederação Brasileira de Ginástica

Ginástica Artística / São Caetano do Sul 
"O que sabemos é uma gota; o que ignoramos é um oceano." Isaac Newton (1642-1727) 


\section{RESUMO}

CAMARGO-JUNIOR, F. Biomecânica da aterrissagem de duplo mortal estendido na barra fixa. [Tese de Doutorado] - Escola de Educação Física e Esporte, Universidade de São Paulo, São Paulo, 2019.

A aterrissagem na saída de um aparelho em ginástica artística é uma das habilidades de maior desafio dessa modalidade. Entre os atletas de alto rendimento, uma falha nessa fase do movimento, como um passo ou queda na finalização, pode retirar as chances de pódio nas competições. Para diminuir as chances de erro, como em toda habilidade de precisão, as saídas de aparelho são realizadas repetidas vezes durante as sessões de treinamento. O efeito danoso disso é o aumento da exposição ao risco de lesão musculoesquelética por sobrecarga mecânica ou trauma por falha de execução. O objetivo desse estudo foi elucidar os fatores biomecânicos determinantes para uma aterrissagem ideal em ginástica artística (i.e., sem a necessidade de passos para atingir uma condição de repouso após o contato com o solo). Para tanto, foi proposto um modelo de interpretação analítica para os fatores biomecânicos que regem essa habilidade, com base em um sistema de pêndulo invertido no qual o ginasta foi representado pelo segmento que une o centro articular do tornozelo ao centro de massa corporal (ank-com) no instante de colisão. Selecionada por conveniência amostral (7 ginastas da elite nacional com ranking internacional) e metodológica (modelagem e experimental), a saída de barra fixa em duplo mortal estendido para trás foi caracterizada em 109 variáveis biomecânicas. A Análise de Componentes Principais foi adotada para medir o potencial preditivo das variáveis de estado definidas pelo modelo biomecânico para a discriminação das condições de sucesso e falha. Por fim, um conjunto de configurações de sucesso foi interpretado com base no modelo analítico proposto. Revelou-se pela Análise de Componentes Principais uma capacidade de discriminação entre as condições praticamente absoluta (91\% dos casos) no acumulado de três eixos de variabilidade. Foram consideradas suficientes para configurar as condições ideais de aterrissagem do duplo mortal estendido na pré-colisão, as combinações das variáveis no modelo ank-com: quantidade de movimento angular do corpo, ângulo do corpo, velocidade angular do corpo e velocidades horizontal e vertical do centro de massa. Espera-se com a presente investigação, poder contribuir para o desenvolvimento de estratégias de controle e correção das habilidades de saída de barra, com potencial de transferência para outros aparelhos ginásticos, em condições de menor risco de lesões por impacto e maior domínio dos fatores biomecânicos de intervenção.

Palavras-chave: biomecânica, ginástica artística, duplo mortal, aterrissagem e modelagem. 


\begin{abstract}
CAMARGO-JUNIOR, F. Biomechanics of the landing for double salto backward stretched in the horizontal bar. [Doctoral Thesis]. Sao Paulo: School of Physical Education and Sport, University of Sao Paulo, 2019.

The landing on the dismount of an apparatus in artistic gymnastics is one of the most challenging skills in this sport. Among high performance athletes, a failure in this movement phase, such as a step or fall, can take chances of podium in championships. In order to reduce the chance of errors, as in any precision motor skills, dismounts are performed repeatedly during training sessions. The side effect of this practice is the increased exposure to the risk of musculoskeletal injury by mechanical overload or trauma due to execution failure. The aim of this study was to clarify the determining biomechanical factors for optimal landing in artistic gymnastics (i.e., no step needed to achieve a rest state after contact with the ground). Therefore, an analytical interpretation model was proposed for the biomechanical factors governing this ability, based on an inverted pendulum system in which the gymnast was represented by the segment connecting the ankle joint center to the body center of mass (ankcom) at the instant of collision. Selected by sampling (seven national elite gymnasts with international ranking) and methodological convenience (modeling and experimental), the double salto backward stretched dismount on the horizontal bar was characterized in 109 biomechanical variables. The Principal Component Analysis was adopted to measure the predictive potential of the state variables defined by the biomechanical model for discriminating the success and failure conditions. Finally, a set of successful configurations was interpreted based on the proposed analytical model. An almost absolute ability to discriminate between conditions (91\% of cases) in the cumulative three axes of variability was revealed by the Principal Component Analysis. The combinations of angular momentum, angular position, angular velocity of the body and horizontal and vertical velocities of the center of mass were considered sufficient to establish the ideal conditions for the double salto backward stretched in the pre-collision by ank-com model. This research is expected to contribute to the development of control strategies and correction of horizontal bar dismount skills, with transfer potential to other gymnastics apparatus, under conditions of lower risk of impact injuries and greater mastery of biomechanical intervention factors.
\end{abstract}

Keywords: biomechanics, artistic gymnastics, double salto, landing and modeling. 


\section{LISTA DE FIGURAS}

Figura 1. Exemplos de grupos de habilidades ginásticas $\left(^{*}\right)$ por demanda mecânica. Legenda: (a) apoio, (b) suspensão, (c) locomoção, (d) rotação, (e) repulsão e (f) aterrissagem (adaptado de FIG, 2017)....................................................... 24

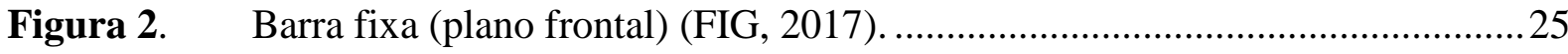

Figura 3. Movimentações de largada-retomada e saída em barra fixa. Legenda: (a) salto carpado para trás com $1 / 2$ pirueta (balanço, largada, rotação no eixo longitudinal, rotação no eixo médio-lateral e retomada); (b) saída de duplo mortal para frente, sem ou com $1 / 2$ pirueta, e aterrissagem (adaptado de FIG, 2017).

Figura 4. Posturas corporais em elementos ginásticos. Legenda: (a) grupado, (b) carpado e (c) estendido (adaptado de FIG, 2017). .26

Figura 5. Saídas de barra fixa de maior complexidade de acordo com o Código de Pontuação (FIG, 2017). 26

Figura 6. Saídas de barra fixa: (a) duplo mortal para trás (superior) e single mortal para trás (inferior) e (b) Tsukahara (FIG, 2017).

Figura 7. Ângulos articulares, energia mecânica, momentos articulares e potência mecânica em função dos ângulos de giro gigante para saídas da barra fixa (ARAMPATZIS; BRUGGEMANN, 1998).

Figura 8. Energia elástica da barra para saída (esquerda superior) e largada-retomada (direita superior) (ARAMPATZIS; BRUGGEMANN, 1998). 30

Figura 9. Técnica de giro gigante para saída de barra fixa em mortal grupado para trás: tradicional (conventional technique) e carpado (power technique) (ARAMPATZIS; BRÜGGEMANN, 1999). 30

Figura 10. Energia corporal, quantidade de movimento angular, momentos articulares durante o giro gigante (ARAMPATZIS; BRUGGEMANN, 1999).

Figura 11. Diagrama de corpo livre das forças atuantes nos 4 segmentos corporais (membros superiores, tronco, coxa e perna) (HILEY; YEADON, 2003a)........ 32

Figura 12. Caraterização angular das técnicas tradicional e carpado durante o giro gigante para saída em duplo mortal estendido com pirueta (HILEY; YEADON, 2003b).

Figura 13. Saída de barra fixa em mortal para trás: giros gigantes (superior), duplo grupado (inferior esquerdo), estendido com pirueta (inferior centro) e duplo estendido (inferior direito) (FIG, 2017). 
Figura 14. Momentos articulares durante o giro gigante para três saídas de barra em mortal para trás: grupado (double tucked), estendido com pirueta (twisted) e duplo estendido (double stretched) (SERBEST; BERISHA; CILLI, 2018). ... 36

Figura 15. Ajustes posturais de quadril para saídas de barra fixa (KERWIN; YEADON; LEE, 1990): (a) duplo mortal estendido e (b) triplo mortal grupado.

Figura 16. Kickout (3): (A) posições antecipada e (B) atrasada de extensão articular (joelho e quadril).

Figura 17. Sequência de posturais corporais e resultados de altura do centro de massa e momento de inércia normalizado na saída de duplo mortal carpado para trás $\left[* * \mathrm{p}<0,005 \mathrm{e}^{* * *} \mathrm{p}<0,001\right]$ (adaptado de TAKEI; DUNN, 1997).

Figura 18. Tempo de voo, distância horizontal do centro de massa e distância angular nas fases da saída de duplo mortal carpado para trás $(* \mathrm{p}<0,005$ e **p $<0,001)$ (TAKEI; DUNN, 1997).

Figura 19. Rotações em mortal (som), inclinação (tilt) e piruetas (twist) (YEADON, 1997).

Figura 20. Sequência de movimento para as técnicas de controle de pirueta: decolagem (superior) e assimetria de membros (inferior) (YEADON, 1997).

Figura 21. Posição angular nas chegadas de paralelas assimétricas em três condições: falha, sucesso e modificada para o sucesso em função do momento nos ombros (REQUEJO; MCNITT-GRAY; FLASHNER, 2002).

Figura 22. Cinemática da aterrissagem na saída de paralelas assimétricas. Dados experimentais (esquerda) e simulação de controle modificada (direita) para satisfazer as condições de sucesso (R-angle) (REQUEJO; MCNITT-GRAY; FLASHNER, 2004) 45

Figura 23. Fases e sequência de movimentos para o mortal grupado para frente (HEINEN; NICOLAUS, 2016).

Figura 24. Limites críticos para a subdivisão das fases de voo (esquerda) e intervalo de momento de inércia assumido pelo corpo durante a simulação do mortal grupado para frente (HEINEN; NICOLAUS, 2016). 46

Figura 25. Projeção do potencial de aterrissagem (sucesso $=0,00$; falha $=1,00$ ) em mortal para frente grupado com quantidade de movimento de 39 Nms (HEINEN; NICOLAUS, 2016).

Figura 26. (A) representa a sequência de movimentos durante o mortal para trás. (B) deslocamentos e velocidades angulares do pescoço ( $\alpha$ e $\left.\alpha^{\prime}\right)$, quadril ( $\beta$ e $\beta^{\prime}$ ), tronco $\left(\gamma\right.$ e $\left.\gamma^{\prime}\right)$ e cabeça $\left(\theta\right.$ e $\left.\theta^{\prime}\right)$. O movimento foi dividido em 4 fases considerando os períodos de estabilização relativa da cabeça (I e III) (BERTHOZ; POZZO, 1994). 48 
Figura 27. Ângulo e velocidade angular do (a) joelho, (b) quadril e (c) tronco durante o salto mortal para trás com variação visual temporal (vision - normal; first half - normal na $1^{\text {a }}$ metade do voo; second half - normal na $2^{\text {a }}$ metade do voo; no vision - vedado) (DAVLIN; SANDS; SHULTZ, 2001b).

Figura 28. Ativação EMG normalizada durante aterrissagens em 3 alturas $(1,0,1,5$ e 2,0 m). A linha vertical representa o tempo de contato com o solo. GM gastrocnêmio medial, TA - tibial anterior, PL - fibular longo, VL - vasto lateral e HA - isquiotibiais (ARAMPATZIS; MOREY-KLAPSING; BRÜGGEMANN, 2003).

Figura 29. Padrão de atividade muscular durante aterrissagem em profundidade $(0,6 \mathrm{~m})$ (Adaptado de DYHRE-POULSEN; SIMONSEN; VOIGT, 1991).

Figura 30. Regiões de velocidade angular pós-impacto $\left(\omega_{\mathrm{i}}\right)$ resultantes de ângulo corporal de pré-impacto $\left(\theta_{0}\right)$ para as condições de equilíbrio nas aterrissagens de barras assimétricas, em mortal simples e duplo mortal (SHEETS; HUBBARD, 2007).

Figura 31. Fases aérea e de impacto na saída de trave em mortal para trás: carpado (superior) e grupado (inferior). Orientação corporal representada pelo segmento que une o centro articular metatarsofalangeano ao centro de massa (®) (GITTOES; IRWIN; KERWIN, 2013).

Figura 32. Sequência de movimentos para a saída de barra fixa em duplo mortal estendido para trás (DSBS): giro gigante (balanço em barra fixa), lançamento, voo (rotação em torno do CM) e chegada (ou aterrissagem).

Figura 33. Saída de barra em DSBS (FIG, 2017). Quadrantes da fase de barra (1 a $\left.4^{\mathrm{a}}\right)$ e rotações no plano sagital em ambas as fases: GG - giro gigante; MEPT mortal estendido para trás).

Figura 34. Posição da câmera $(\mathrm{m})$, posição do colchão $(\mathrm{m})$, dimensões da barra fixa $(\mathrm{m}) \mathrm{e}$ sistema de referência global (X, Y). .58

Figura 35. Hardwares do sistema para análise cinemática: (a) câmera OptiTrack: Flex3 e

(b) marcadores retrorreflexivos.

Figura 36. Modelo cinemático 2D para saída de barra em DSBS. 61

Figura 37. Solução por dinâmica inversa. 63

Figura 38. Diagrama de corpo livre para o DSBS. .64

Figura 39. Modelo biomecânico de aterrissagem em DSBS. 66

Figura 40. Etapas de desenvolvimento do estudo. Legenda: (DSBS) Double Salto Backward Stretched, (2D) bidimensional e (PCA) Principal Component Analysis. 
Figura 41. Sequência de movimentos para a saída de DSBS no percentual do período: início do primeiro giro gigante (0), início do segundo giro gigante (37), postura carpado sobre a barra (62), lançamento (79), duplo mortal (79-100) e préimpacto (100).

Figura 42. Representação segmentar e trajetória do centro de massa $(C o M)$ durante o DSBS (superior). Primeira subfase do giro gigante: postura quasi-estendida; período de 630 graus com rotação de 0 à 3 h no sentido anti-horário (centroesquerda). Segunda subfase do giro gigante: postura carpado (entre 3 e $9 \mathrm{~h}$ ); período de 360 graus com rotação iniciando em 3h no sentido anti-horário (centro-direita). Fase de voo: rotação em torno do CM; período de 630 graus (inferior-esquerda). Posturas de início do giro gigante (1), lançamento (2) e chegada (3) (inferior-direita). Legenda: (i) posição inicial e (f) final da sequência de movimentos.

Figura 43. Trajetória do CM durante o DSBS (superior). Primeira subfase do giro gigante (centro-esquerda). Segunda subfase do giro gigante (centro-direita). Fase completa de giro gigante (inferior-esquerda). Fase de voo (inferior-direita). Legenda: $(\circ)$ posição inicial e $(\bullet)$ final da sequência de movimentos. 76

Figura 44. Movimento rotacional do corpo representado por: (1) wri-com, segmento que une o centro articular do punho (azul) ao centro de massa (preto) no instante de lançamento; (2) ank-com, segmento que une o centro articular do tornozelo ao centro de massa durante a fase aérea.

Figura 45. Histórico angular da movimentação corporal durante o DSBS. Legenda: (ankcom) segmento que une o centro articular do tornozelo ao centro de massa; ( $\square$ ) instante de lançamento.

Figura 46. Histórico de velocidade linear média no período de DSBS. Legenda: (vx) velocidade horizontal do CM; (vy) componente vertical do CM; ( $\square$ ) instante de lançamento. 78

Figura 47. Ações articulares no DSBS: (1) instante de máxima flexão de quadril e máxima extensão de ombro; (2) instante de máxima extensão de quadril e máxima flexão de ombro. Legenda: ( $\uparrow f l x)$ ação flexora; ( $\uparrow e x t)$ ação extensora; ( $\square$ ) instante de lançamento.

Figura 48. Velocidades articulares durante o DSBS. Legenda: (kne) joelho, (hip) quadril e (sho) ombro; ( flx) ação flexora; ( $\uparrow$ ext) ação extensora; ( $\square$ ) instante de lançamento.

Figura 49. Velocidades articulares em função da posição angular durante o DSBS. Legenda: (ank-com) segmento que une o centro articular do tornozelo ao centro de massa; (०) posição inicial e (•) final da sequência de movimentos; ( $\square$ ) instante de lançamento.

Figura 50. Quantidade movimento angular em relação ao centro de massa durante o DSBS. Legenda: $\left(\mathrm{H}_{\mathrm{g}}\right)$ quantidade de movimento angular em relação ao centro de massa; $(\square)$ instante de lançamento. 
Figura 51. Histórico de energia mecânica durante o DSBS. Legenda: ( $\square$ ) instante de lançamento.

Figura 52. Momentos articulares durante o DSBS: ombro (superior), quadril (centro) e joelho (inferior). Legenda: ( $\uparrow f l x)$ ação flexora; ( $\square$ ) instante de lançamento. ... 85

Figura 53. Perfil biomecânico do DSBS baseado em instantes críticos. 86

Figura 54. Trajetória do CM (média \pm desvio padrão) no período de DSBS de cada sujeito. Legenda: ( $)$ posição inicial e (•) final da sequência de movimentos. 87

Figura 55. Velocidade linear do CM (média \pm desvio padrão) no período de DSBS de cada sujeito. Legenda: ( $\square$ ) instante de lançamento.

Figura 56. Histórico da posição angular do corpo (média \pm desvio padrão) no período de DSBS de cada sujeito. Legenda: (ank-com) segmento que ume o centro articular do tornozelo ao $\mathrm{CM}$; $(\square)$ instante de lançamento. 88

Figura 57. Posição articular (média \pm desvio padrão) no período de DSBS de cada sujeito. Legenda: (k) joelho, (h) quadril e (s) ombro; ( $\uparrow f l x)$ ação flexora; ( $\square$ ) instante de lançamento. 88

Figura 58. Velocidade angular do corpo (média \pm desvio padrão) em função da posição angular, no período de DSBS de cada sujeito. Legenda: (ank-com) segmento que une o centro articular do tornozelo ao centro de massa; ( $($ ) posição inicial e $(\bullet)$ final da sequência de movimentos; ( $\square$ ) instante de lançamento.

Figura 59. Quantidade de movimento angular $\left(\mathrm{H}_{\mathrm{g}}\right)$ em relação do centro de massa (média \pm desvio padrão) no período de DSBS de cada sujeito. Legenda: ( $\square)$ instante de lançamento.

Figura 60. Energia mecânica (média \pm desvio padrão) no período de DSBS de cada sujeito. Legenda: $(\square)$ instante de lançamento.

Figura 61. Momento de ombro $(\tau)$ (média \pm desvio padrão) no período de DSBS de cada sujeito. Legenda: ( $\uparrow$ flx) ação flexora; ( $\square$ ) instante de lançamento. 90

Figura 62. Momento de quadril $(\tau)$ (média \pm desvio padrão) no período de DSBS de cada sujeito. Legenda: ( $\uparrow f l x)$ ação flexora; $(\square)$ instante de lançamento.

Figura 63. Momento de joelho $(\tau)$ (média \pm desvio padrão) no período de DSBS de cada sujeito. Legenda: ( $\uparrow f l x)$ ação flexora; $(\square)$ instante de lançamento.

Figura 64. Análise de componentes principais para condições de sucesso ou falha (7 sujeitos (S), em 7 tentativas cada) nas saídas de barra fixa em duplo mortal estendido, considerando 77 variáveis biomecânicas. 
Figura 65. Componentes Principais 1 e 2 para condições de sucesso ou falha nas saídas de barra fixa em duplo mortal estendido. Legenda: $(\mathrm{S})$ sucesso, $(\mathrm{Fb})$ falha com deslocamento para trás e (Ff) falha com deslocamento para frente.

Figura 66. Componentes Principais 2 e 3 para condições de sucesso ou falha nas saídas de barra fixa em duplo mortal estendido. Legenda: $(\mathrm{S})$ sucesso, $(\mathrm{Fb})$ falha com deslocamento para trás e $(\mathrm{Ff})$ falha com deslocamento para frente.

Figura 67. Ângulo de aterrissagem $(\theta)$ em relação à quantidade de movimento angular $\left(\mathrm{H}_{\mathrm{o}}\right)$ em relação ao eixo de controle (tornozelo) para o impulso estacionário. Conjunto representativo das configurações de sucesso (área tracejada). Legenda: $(\mathrm{S})$ sucesso, $(\mathrm{Fb})$ falha com deslocamento para trás; $(\mathrm{Ff})$ falha com deslocamento para frente e (S4) caso particular de sucesso.

Figura 68. Velocidade angular $(\omega)$ em relação ao ângulo $(\theta)$ de pré-impacto. Linha de tendência associada ao sucesso da aterrissagem. Legenda: $(\mathrm{S})$ sucesso, $(\mathrm{Fb})$ falha com deslocamento para trás, $(\mathrm{Ff})$ falha com deslocamento para frente, (GC) linha de tendência central para o sucesso com caso particular (S4) e (RC) linha de tendência central para o sucesso somente com casos regulares. 95

Figura 69. Velocidade horizontal (vx) em relação à velocidade angular $(\omega)$ no préimpacto. Linha de tendência associada ao sucesso da aterrissagem. Legenda: (S) sucesso, $(\mathrm{Fb})$ falha com deslocamento para trás, ( $\mathrm{Ff}$ ) falha com deslocamento para frente, (GC) linha de tendência central para o sucesso com caso particular (S4) e (RC) linha de tendência central para o sucesso somente com casos regulares. 96

Figura 70. Velocidade vertical (vy) em relação à velocidade angular ( $\omega)$ no pré-impacto. Linha de tendência associada ao sucesso da aterrissagem. Legenda: (S) sucesso, $(\mathrm{Fb})$ falha com deslocamento para trás, $(\mathrm{Ff})$ falha com deslocamento para frente, (GC) linha de tendência central para o sucesso com caso particular (S4) e (RC) linha de tendência central para o sucesso somente com casos regulares. .96

Figura 71. Velocidade angular $(\theta)$ em relação à quantidade de movimento angular $\left(\mathrm{H}_{\mathrm{o}}\right)$ no pré-impacto, de cada sujeito. Legenda: (S) sucesso, (Fb) falha com deslocamento para trás e (Ff) falha com deslocamento para frente.

Figura 72. Ângulo de aterrissagem $(\theta)$ em relação à quantidade de movimento angular $\left(\mathrm{H}_{\mathrm{o}}\right)$ no pré-impacto, de cada sujeito. Legenda: $(\mathrm{S})$ sucesso, $(\mathrm{Fb})$ falha com deslocamento para trás e $(\mathrm{Ff})$ falha com deslocamento para frente.

Figura 73. Velocidade angular $(\omega)$ em relação ao ângulo $(\theta)$ no pré-impacto, de cada sujeito. Legenda: $(\mathrm{S})$ sucesso, $(\mathrm{Fb})$ falha com deslocamento para trás e $(\mathrm{Ff})$ falha com deslocamento para frente.

Figura 74. Velocidade horizontal (vx) em relação à velocidade angular $(\omega)$ no préimpacto, de cada sujeito. Legenda: $(\mathrm{S})$ sucesso, $(\mathrm{Fb})$ falha com deslocamento para trás e $(\mathrm{Ff})$ falha com deslocamento para frente. 
Figura 75. Velocidade vertical (vy) em função da velocidade angular ( $\omega)$ no pré-impacto, de cada sujeito. Legenda: $(\mathrm{S})$ sucesso, $(\mathrm{Fb})$ falha com deslocamento para trás e (Ff) falha com deslocamento para frente.

Figura 76. Esquema representativo das condições necessárias para aterrissagem de DSBS, sem passo ou queda. 


\section{LISTA DE TABELAS}

Tabela 1. Características dos instantes de lançamento para saídas de barra fixa (adaptado de BRÜGGEMANN et al., 1994).

Tabela 2. Contribuição segmentar para quantidade de movimento angular nas saídas de barra fixa (adaptado de BRÜGGEMANN et al., 1994). 28

Tabela 3. Caraterísticas dinâmicas da saída de barra em mortal grupado para trás (ARAMPATZIS; BRUGGEMANN, 1999)

Tabela 4. Janela de lançamento de cada quantidade de movimento angular, com restrição de momento (redução de 25\%) (HILEY; YEADON, 2005).

Tabela 5. Caraterísticas dos voos e janelas de lançamento para a saída em duplo mortal estendido de um ginasta de elite (HILEY; YEADON, 2016a).

Tabela 6. Diferença RMS nos ângulos articulares, deslocamento da barra e ângulos de rotação corporal entre as soluções ótimas e experimentais (HILEY; YEADON, 2016).

Tabela 7. Ajuste postural simulado para saída de barra fixa em GA (KERWIN; YEADON; LEE, 1990).

Tabela 8. Resultados das saídas de duplo mortal estendido (saltos $=2$ ) e triplo mortal grupado (saltos $=3)($ KERWIN; YEADON; LEE, 1990)

Tabela 9. Parâmetros de entrada para a simulação das possibilidades de sucesso para aterrissagem de mortal grupado para frente (adaptado de HEINEN; NICOLAUS, 2016).

Tabela 10. Cinemática e condições de aterrissagem para mortal grupado para trás com variação do campo visual (vision - normal; peripheral - restrito em $100^{\circ}$ ou $60^{\circ}$; no vision - vedado) (DAVLIN; SANDS; SHULTZ, 2001a).

Tabela 11. Tempo de estabilização da aterrissagem no salto mortal para trás com variação visual temporal (vision - normal; first half - normal na $1^{\text {a }}$ metade do voo; second half - normal na $2^{\mathrm{a}}$ metade do voo; no vision - vedado) (DAVLIN; SANDS; SHULTZ, 2001b).

Tabela 12. Comparação das latências EMG (ms) para três condições de aterrissagens (DUNCAN; MCDONAGH, 2000).

Tabela 13. Parâmetros antropométricos segmentares (HILEY; YEADON, 2016).

Tabela 14. Fases e subfases, ciclos de movimento, posições e posturas características do DSBS 
Tabela 15. Percentual do período de DSBS para instante de pico de momento articular $(\tau)$. Diferença de instantes entre articulações adjacentes.

Tabela 16. Resultados da proporção acumulada na PCA para as variáveis que configuram a hipótese de pesquisa (velocidade linear, ângulo do corpo, velocidade angular e quantidade de movimento angular).

Tabela 17. Resultados da contribuição da variabilidade de cada variável nos eixos que compõem o espaço multidimensional na PCA. 94

Tabela 18. Resumo dos fatores determinates de sucesso para aterrissagem de DSBS.......99

Tabela 19. Variáveis atribuídas à hipótese alternativa para o instante de pré-impacto.... 101 


\section{SUMÁRIO}

1 INTRODUÇÃO

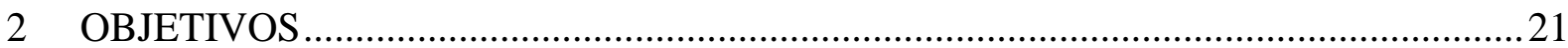

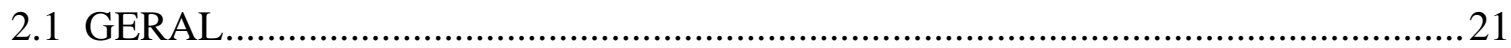

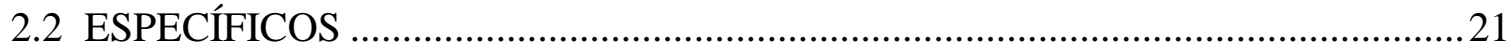

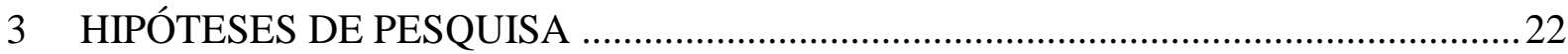

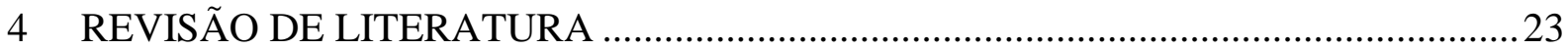

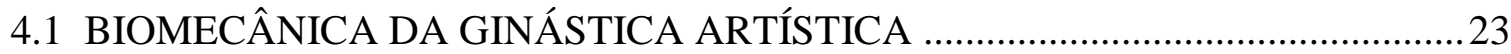

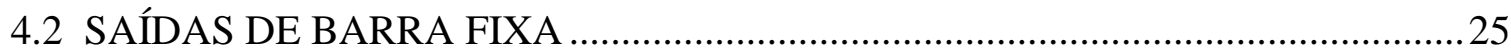

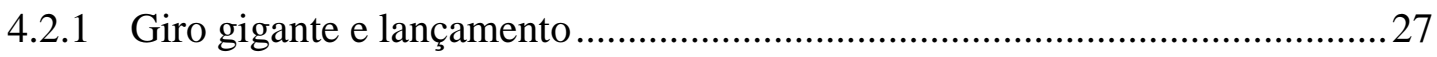

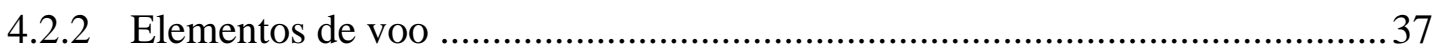

4.3 CHEGADAS E CONDIÇÕES DE ATERRISSAGEM .......................................... 43

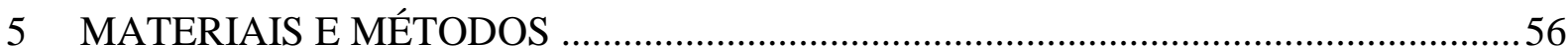

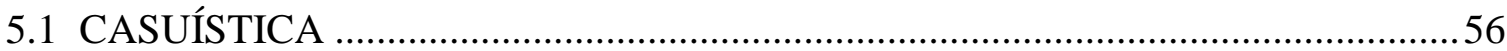

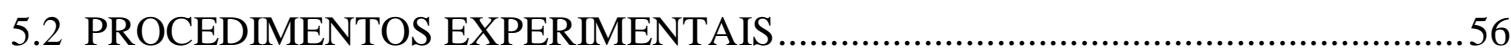

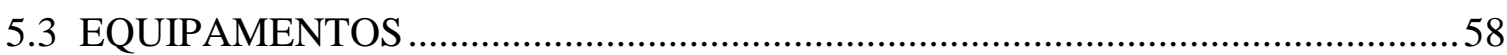

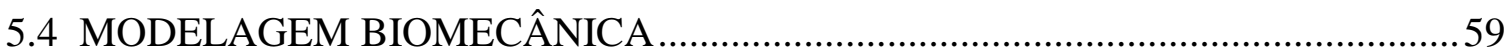

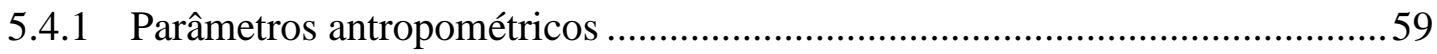

5.4.2 Cinemática do Duplo Mortal Estendido para Trás ......................................... 60

5.4.3 Cinética do Duplo Mortal Estendido para Trás ..............................................62

5.4.3.1 Quantidade de movimento e energia mecânica................................62

5.4.3.2 Solução por dinâmica inversa....................................................... 63

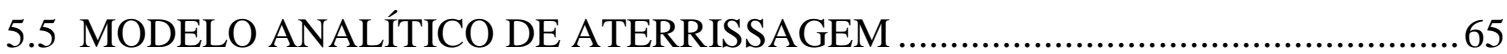

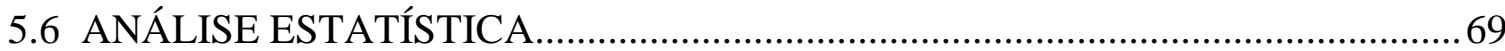

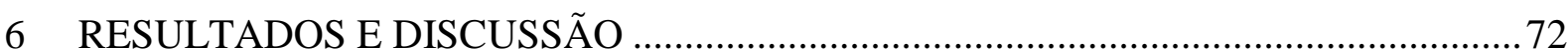

6.1 PERFIL BIOMECÂNICO DESCRITIVO DA SAÍDA DE BARRA FIXA EM

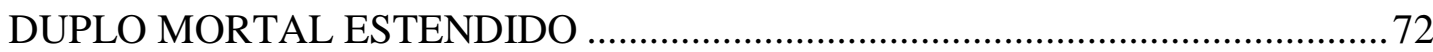

6.2 CONDIÇÕES DE ATERRISSAGEM DO DUPLO MORTAL ESTENDIDO PARA TRÁS SEGUNDO MODELO ANALÍTICO .......................................................... 91

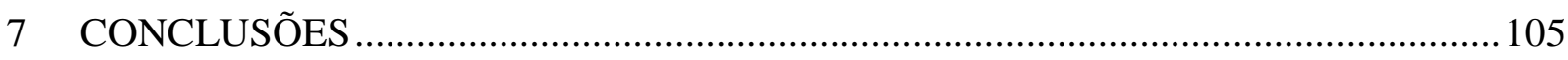

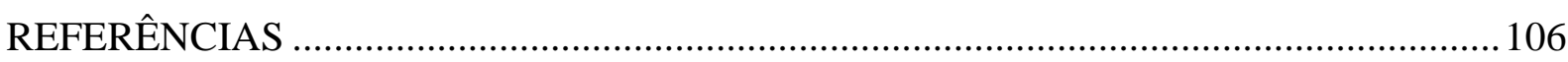

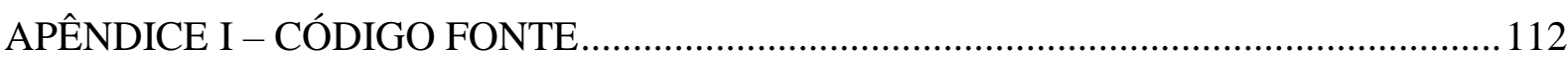

ANEXO I - TERMO DE CONSENTIMENTO LIVRE E ESCLARECIDO ........................ 133

ANEXO II - TERMO DE COMPROMISSO / COMITÊ DE ÉTICA LOCAL …................. 135 


\section{INTRODUÇÃO}

A busca pelo melhor desempenho na ginástica artística (GA) invariavelmente abrange as propriedades biomecânicas que regem o movimento dos corpos (IRWIN; WILLIAMS; KERWIN, 2014). Fatores cinemáticos (posição dos segmentos, velocidade do centro de massa, quantidade de movimento...) e dinâmicos (forças de contato, momentos articulares, energia mecânica...) permitem, respectivamente, descrever e explicar os mais complexos gestos esportivos, entre os quais estão as habilidades ginásticas de alto rendimento (ATIKOVIC; SMAJLOVIC, 2011; FARANA; VAVERKA, 2012).

Motivada pela necessidade de se destacar nas competições esportivas, a evolução das séries de movimentos ginásticos implica em saltos cada vez mais altos, números de giros cada vez maiores, combinações de elementos cada vez mais complexas, provocando uma estreita separação entre o acerto e o erro, o eficaz e o arriscado. Para Brüggemann (2005), de maneira cada vez mais acentuada, os ginastas têm se aproximado dos limites mecânicos do corpo para as demandas, tanto de carga, quanto de execução. No primeiro caso, isso pode explicar os altos índices de lesões (43\%, sendo 58-62\% traumáticas e 29-30\% graves) (KIRIALANIS et al., 2003; AMARAL; SANTOS; FERREIRINHA, 2009), observados em temporadas competitivas de GA. E, no segundo, pode justificar a rara manifestação de saltos mortais quádruplos em competições, ainda que os ginastas apresentem momentos articulares suficientes para isso do ponto de vista teórico (BRUGGEMANN, 2005).

Entre os elementos de maior desafio para os ginastas estão as habilidades precedidas por fase aérea. Presentes em ambas as categorias (masculino e feminino) e em todos os aparelhos ginásticos, ao menos na finalização, as aterrissagens exercem grande influência nos resultados de uma série (ou rotina) ginástica. Enquanto finalizações precisas podem garantir um valor de destaque ao competidor, uma queda na execução do elemento ginástico pode colocar um fim às chances de pódio desse atleta.

Previstas no Código de Pontuação da Fédération Internationale de Gymnastique (FIG, 2017), órgão normativo dessa modalidade esportiva, as deduções na nota de execução de uma série ginástica são proporcionais às falhas observadas nas aterrissagens. Quanto menos controlada a chegada, maior a dedução. No alto rendimento, em tempos de uma ginástica cada vez mais definida no detalhe, a menor falha $(0,1$ ponto) pode mudar a cor da medalha num pódio Olímpico e uma queda (1,0 ponto) retirar as chances de participar de uma final esportiva. 
Nos Jogos Olímpicos de 2016, diferença de 0,1 ponto separou o medalhista de prata do $4^{\text {o }}$ colocado $(15,500$ e 15,400) na prova de barra fixa, por exemplo. E mesmo na disputa individual geral, onde o resultado representa a soma das notas dos seis aparelhos, no caso da ginástica masculina, a diferença entre as notas para o lugar mais alto no pódio não superou 0,1 ponto $(92,365$ e 92,266$)$.

Diminuir as consequências do impacto recorrendo a estratégias de movimento para frenagem e amortecimento faz das aterrissagens um dos maiores desafios no esporte de alto rendimento. Mas no caso da ginástica artística, isso não basta. É necessário ainda que essa habilidade seja desenvolvida com precisão, de tal maneira que nenhum passo seja exigido para atingir a posição de repouso na chegada ao solo. No jargão da GA, a meta é "cravar".

Para tanto, e como em qualquer habilidade de precisão, o ginasta investe em intensivos treinamentos por repetição. Afinal, como diz o ditado, "a prática leva à perfeição". De fato, o treinamento por repetição num sistema retroalimentado por tentativa e erro permite a automatização de movimentos complexos gerando padrões de execução mais eficientes. Como é o caso de uma cobrança de falta no futebol ou o arremesso em lance livre no basquete. Porém, o complicador no caso da ginástica é que a repetição de um movimento de saída de aparelho traz como efeito indesejado o aumento do risco de lesão por sobrecarga ou trauma mecânico.

Como estratégia para redução dos impactos nas aterrissagens, os técnicos têm optado por finalizações de elementos ginásticos em superfícies com diferentes níveis de rigidez. E assim, alternam entre chegadas em fosso preenchido com espuma, a condição mais suave, e no colchão oficial de competição, o solo mais rígido. $O$ fato é que, tipicamente, as aterrissagens em solo de maior suavidade têm menor foco nas aterrissagens. Retornando ao problema de repetição com alto impacto.

Mas, uma vez preservadas as características do gesto técnico nos treinamentos de saídas de aparelhos ginásticos, ainda que em solo suave como no fosso, as propriedades biomecânicas pré-impacto podem servir de métrica para o sucesso nas aterrissagens em GA. O presente trabalho propõe-se à exploração dessa temática na saída de barra fixa, devido aos potenciais de transferência para o aparelho feminino correspondente (barras assimétricas) e de aproveitamento dos elementos ginásticos em fase aérea.

Assim, considerando a relevância das aterrissagens no desempenho esportivo do ginasta, a pergunta motivadora deste estudo foi: quais os fatores biomecânicos determinantes de sucesso na chegada de barra fixa em GA? Conforme será apresentado no capítulo de Revisão de Literatura, diferentes estudos exploraram os fatores biomecânicos para a execução 
do duplo mortal estendido na saída de barra fixa. No entanto, a discriminação dos fatores biomecânicos para as condições de sucesso (sem passo ou queda) na chegada de barra fixa incluindo a diferenciação entre os tipos de falha (recuo ou avanço) foi entendida como lacuna a ser preenchida. Esperamos, com a realização deste trabalho, ampliar o entendimento sobre as possibilidades de movimento para o sucesso nas aterrissagens e, assim, contribuir com o desenvolvimento das estratégias de intervenção para a melhora de desempenho dessa habilidade esportiva. 


\section{OBJETIVOS}

\subsection{GERAL}

Elucidar os fatores biomecânicos que configuram a aterrissagem de sucesso (i.e., sem passos ou queda) na saída de barra fixa, em ginástica artística.

\subsection{ESPECÍFICOS}

Foram estabelecidos os seguintes objetivos específicos para esta pesquisa:

- caracterizar o perfil biomecânico da saída de duplo mortal estendido para trás na barra fixa;

- identificar os fatores determinantes para as condições de chegada de duplo mortal estendido para trás;

- propor um modelo físico-matemático para as investigações do sucesso nas chegadas de barra fixa;

- definir as configurações de sucesso e falha para as chegadas de barra fixa. 


\section{HIPÓTESES DE PESQUISA}

As finalizações (ou saídas) de sucesso na ginástica artística dependem da configuração de um conjunto de variáveis biomecânicas que permitam uma aterrissagem sem passo ou queda. Para essa condição, assumimos como:

- Hipótese nula $\left(\mathbf{H}_{\mathbf{0}}\right)$ : a indefinição de variáveis biomecânicas determinantes em virtude das variabilidades antropométricas e/ou coordenativas dos ginastas.

- Hipótese alternativa $\left(\mathbf{H}_{1}\right)$ : a definição de uma combinação de variáveis determinantes no instante imediatamente anterior à aterrissagem. Destacam-se entre essas: a posição angular do corpo em relação ao solo, a velocidade linear do centro de massa, a velocidade angular do corpo e a quantidade de movimento angular em relação ao ponto de colisão.

As variáveis definidas em $\mathrm{H}_{1}$ foram selecionadas com base nos princípios de impulso e conservação da quantidade de movimento angular para as condições de estado do fenômeno investigado. Assim, a posição angular expressa que o corpo não pode atingir o solo de cabeça para baixo, por exemplo. A velocidade linear representa as condições de lançamento para altura mínima de voo. E por fim, a velocidade angular e a quantidade de movimento angular garantem que o ginasta realize o duplo giro ainda em fase aérea, e seja capaz de compensar a tendência rotacional após o contato com o solo. 


\section{REVISÃO DE LITERATURA}

\subsection{BIOMECÂNICA DA GINÁSTICA ARTÍSTICA}

Os estudos biomecânicos podem ser divididos em duas categorias: teóricos e experimentais (SMITH, 1998). Nas análises teóricas alguns pressupostos são assumidos para fins de representação do fenômeno a ser estudado. Segmentos anatômicos inelásticos, resistência do ar desprezível e ausência de dissipação de energia na forma de calor são exemplos dessas aceitações. Em geral, busca-se uma simplificação da realidade sem perda das propriedades fundamentais que regem o gesto esportivo.

Nos estudos experimentais o foco é extrair dados da realidade preservando ao máximo o contexto do fenômeno investigado. Especialmente no campo GA, com movimentações e aparelhos muito específicos, essas duas abordagens necessitam ser cada vez mais complementares. Idealmente, numa contínua substituição, do estudo teórico ao prático, do prático à formulação de novas hipóteses.

A ginástica artística é uma modalidade que exige grande mobilidade articular, força muscular e precisão de movimentos. Com foco na prevenção de lesões e/ou no desempenho atlético, a abordagem biomecânica tem despertado interesse de diferentes pesquisadores (ZATSIORSKY, 2004; WINTER, 2009). Nos últimos 45 anos, entre as principais contribuições desses estudos estão as elucidações sobre os limites de críticos (clínicos e/ou esportivos) para as diferentes demandas mecânicas durante a prática da modalidade.

Considerando a diversidade de movimentos, as habilidades ginásticas podem ser classificadas em seis grupos de acordo com demanda mecânica (Figura 1):

(1) apoio, no qual o CM encontra-se acima da base de sustentação (ex: volteios no cavalo com alças);

(2) suspensão, quando o CM está abaixo da base de sustentação (ex: crucifixo nas argolas);

(3) locomoção, no qual o corpo se desloca em translação (ex: corrida em diagonal no solo);

(4) rotação, quando há deslocamento do corpo em torno de um eixo (ex: balanço na barra fixa); 
(5) repulsão, amortecimento seguido de abrupta propulsão (ex: ataque ao aparelho no salto) e

(6) aterrissagem, finalização dos elementos de voo (ex: saída de barras paralelas).

Um único elemento ginástico pode incluir um ou mais grupos nas diferentes fases de execução. É o caso do objeto de estudo do presente trabalho: saída de barra fixa. Independente do tipo de saída, esse elemento ginástico pode ser dividido em quatro fases: (1) apoio; (2) suspensão e rotação, em torno da barra fixa; (3) rotação em torno do centro de massa e (4) aterrisagem. No capítulo seguinte, esse tema será abordado em maiores detalhes.

Ainda que fora do escopo do presente estudo, sinalizamos a importância da abordagem dos fatores de risco de lesão por falhas na aterrissagem durante a prática dessa modalidade esportiva (BRÜGGEMANN, 2000; MCNITT-GRAY, 2000; MCNITT-GRAY et al., 2001; SEEGMILLER; MCCAW, 2003; GITTOES; IRWIN, 2012; SLATER et al., 2015; MCNITT-GRAY; YOKOI; MILLWARD, 2016; DESAI et al., 2019). Diferenças técnicas e/ou de condições, como altura e tipo de salto por exemplo, podem elevar a carga mecânica a limites críticos de resistência tecidual.

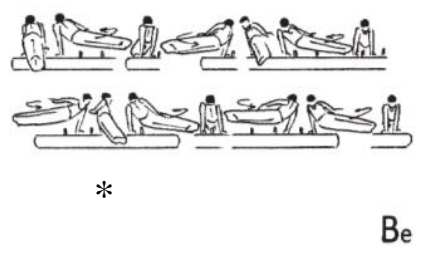

a

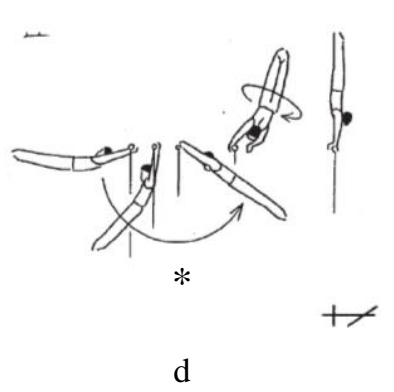

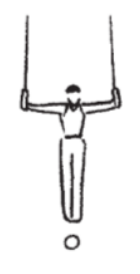

*

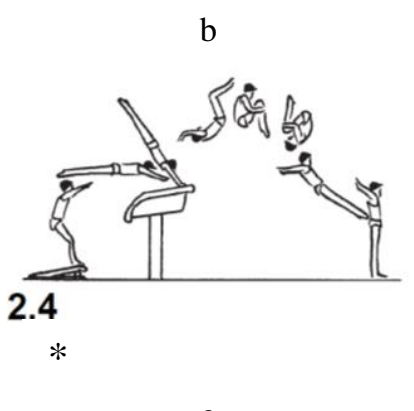

$\mathrm{e}$

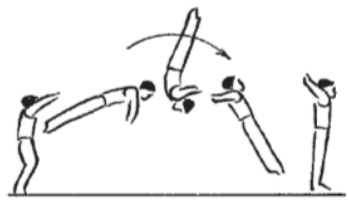

c

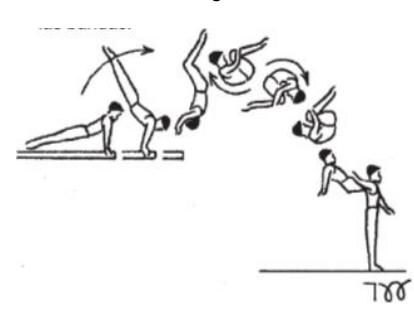

f

Figura 1. Exemplos de grupos de habilidades ginásticas $\left(^{*}\right)$ por demanda mecânica. Legenda: (a) apoio, (b) suspensão, (c) locomoção, (d) rotação, (e) repulsão e (f) aterrissagem (adaptado de FIG, 2017). 


\subsection{SAÍDAS DE BARRA FIXA}

A barra fixa é um dos seis aparelhos que compõe o programa de ginástica artística masculina (Figura 2). As rotinas nesse aparelho são caracterizadas por movimentos contínuos com largadas (i.e., perdas de contato com a barra), retomadas, mortais (rotações no eixo médio-lateral), piruetas (rotações no eixo longitudinal) e aterrissagem (Figura 3).

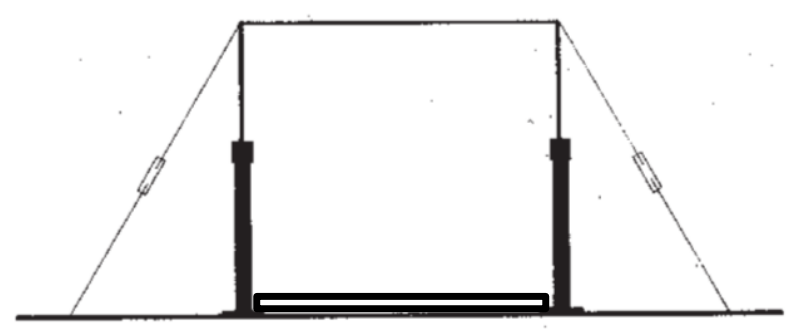

Figura 2. Barra fixa (plano frontal) (FIG, 2017).

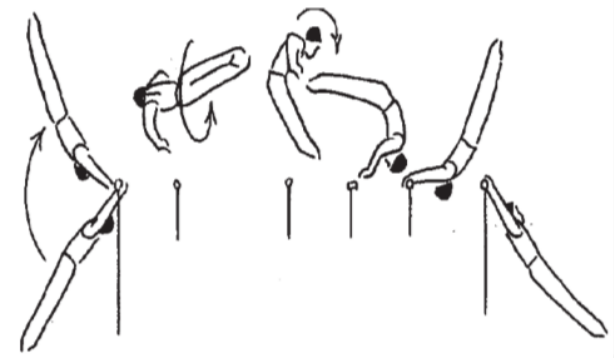

a

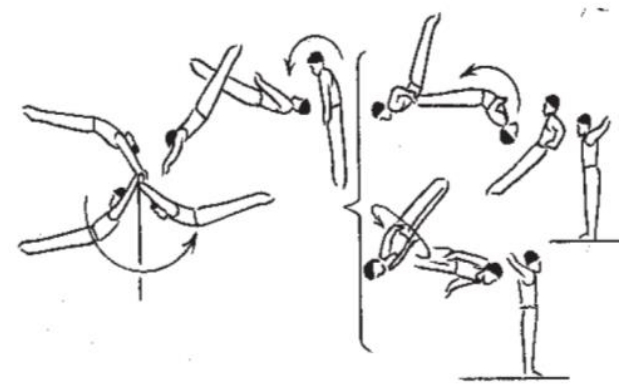

b

Figura 3. Movimentações de largada-retomada e saída em barra fixa. Legenda: (a) salto carpado para trás com 1/2 pirueta (balanço, largada, rotação no eixo longitudinal, rotação no eixo médio-lateral e retomada); (b) saída de duplo mortal para frente, sem ou com $1 \frac{1}{2}$ pirueta, e aterrissagem (adaptado de FIG, 2017).

Ao executar uma série ginástica, o atleta pode assumir 3 posturas corporais: grupado (joelho e quadril flexionados), carpado (joelho estendido e quadril flexionado) e estendido (joelho e quadril estendidos) (Figura 4). As saídas do aparelho podem ser: para frente (com face corporal voltada para o solo no instante de lançamento, Figura 3b) ou para trás (com dorso para o solo no instante de lançamento).

Em conjunto, essa sequência de movimentos e posturas corporais configuram elementos ginásticos de diferentes níveis de complexidade na barra fixa (Pontuação: de $\mathrm{A}=$ $0,1$ a $\mathrm{G}=0,7)$. Elementos na postura estendida e com maior número de rotações em voo são considerados de maior grau de dificuldade, independente do sentido da rotação. 


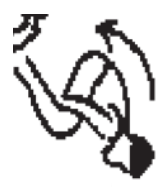

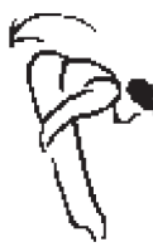

b

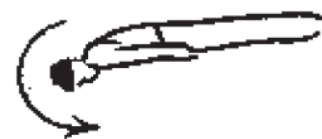

Figura 4. Posturas corporais em elementos ginásticos. Legenda: (a) grupado, (b) carpado e (c) estendido (adaptado de FIG, 2017).

Até a década de 50, o hecht e o mortal estendido para trás com variações representavam as mais difíceis saídas de barra fixa (TAKEI; DUNN, 1997b). Nos dez anos seguintes, esse posto foi ocupado por mortal estendido para trás com pirueta, duplo mortal grupado para trás e hecht com pirueta. Em 1995, o Fedorchenko foi apresentado pela primeira vez em campeonato mundial. Atualmente, o Código de Pontuação da FIG (2017) registra 32 tipos de saída de barra fixa, sendo Rumbutis, Fardan e Belle os elementos de maior complexidade (Figura 5).

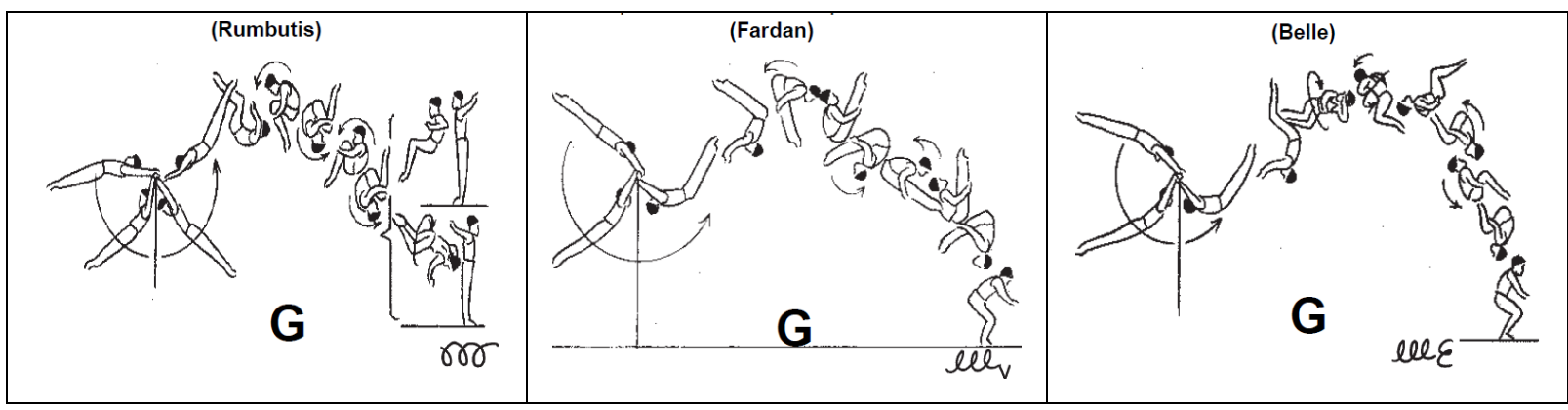

Figura 5. Saídas de barra fixa de maior complexidade de acordo com o Código de Pontuação (FIG, 2017).

As saídas de barra fixa representam uma típica habilidade esportiva de movimento aéreo. De acordo com Yeadon (1997), a dinâmica desses movimentos inclui três etapas: abordagem, decolagem (ou lançamento) e voo. Durante a abordagem ocorre a produção de energia cinética responsável a amplitude de deslocamento aéreo. No caso da barra fixa, isso decorre de balanços circulares entorno do aparelho conhecidos por giros gigantes. Para o lançamento, busca-se atingir a velocidade vertical e a quantidade de movimento necessárias para cumprir os deslocamentos aéreos. A fase de voo é destinada ao controle dos movimentos que caracterizam elemento ginástico em execução, incluindo as condições finalização (ou chegada) para as aterrissagens. Os aspectos biomecânicos associados a cada uma dessas fases serão discutidos a seguir. 


\subsubsection{Giro gigante e lançamento}

Brüggemann et al., (1994) apresentaram os perfis biomecânicos de giro gigante e lançamento para um conjunto de largadas-retomadas e saídas de barra fixa. Foram selecionadas as séries ginásticas acima da média ou perfeitas dos competidores dos Jogos Olímpicos de Barcelona 1992 (70 tentativas). No caso das saídas, os elementos ginásticos foram: duplo mortal grupado para trás $(n=6)$, duplo mortal estendido para trás $(n=6)$, triplo mortal grupado para trás $(n=3)$ e duplo mortal grupado com $1 \frac{1}{2}$ pirueta $(n=3)$.

Em todos os casos, os autores observaram elevados níveis de energia cinética (acima de $1200 \mathrm{~J}$ ) durante o giro gigante. No instante de lançamento, destaque para o duplo mortal estendido que apresentou menor ângulo de saída (352 graus, sendo zero no plano horizontal), menor velocidade vertical $(4,04 \mathrm{~m} / \mathrm{s})$ e maior quantidade de movimento angular $(65,1$ $\mathrm{kgm}^{2} / \mathrm{s}$ ); esses últimos com diferença estatística ( $\left.\mathrm{p}<0,05\right)$ (Tabela 1 e Tabela 2).

Tabela 1. Características dos instantes de lançamento para saídas de barra fixa (adaptado de BRÜGGEMANN et al., 1994).

\begin{tabular}{|c|c|c|c|c|c|c|c|c|}
\hline & \multicolumn{2}{|c|}{$\begin{array}{c}\text { VXCM-R } \\
(\mathrm{m} / \mathrm{s})\end{array}$} & \multicolumn{2}{|c|}{$\begin{array}{c}\text { VYCM-R } \\
(\mathrm{m} / \mathrm{s})\end{array}$} & \multicolumn{2}{|c|}{$\begin{array}{c}\text { НTOT } \\
\left(\mathrm{kg} \cdot \mathrm{m}^{2} / \mathrm{s}\right)\end{array}$} & \multicolumn{2}{|c|}{$\begin{array}{c}\text { ACML-R } \\
\left({ }^{\circ}\right)\end{array}$} \\
\hline & $M$ & $S D$ & $M$ & $S D$ & $M$ & $S D$ & $M$ & $S D$ \\
\hline \multicolumn{9}{|c|}{ Backward rotation, Category I } \\
\hline DBSC & 1.04 & 0.31 & 4.79 & 0.33 & 46.6 & 6.7 & 363 & 4 \\
\hline DBSA & 1.34 & 0.67 & 4.04 & 0.1 & 65.1 & 16.0 & 352 & 30 \\
\hline TBSC & 1.19 & 0.39 & 5.06 & 0.28 & 47.6 & 4.1 & 362 & 41 \\
\hline \multicolumn{9}{|c|}{ Forward rotation, Category I } \\
\hline FLIFF & -1.48 & 0.85 & 4.26 & 0.42 & 51.4 & 8.6 & 356 & 17 \\
\hline
\end{tabular}

Legenda: (R) movimento de largada-retomada na barra fixa, (VXCM) velocidade horizontal do centro de massa, (VYCM) velocidade vertical do centro de massa, (HTOT) quantidade de movimento angular do corpo e (ACML) ângulo definido pelo segmento que une o eixo da barra ao centro de massa do ginasta em relação ao plano horizontal. (M) média e (SD) desvio padrão. Elementos ginásticos: (DBSC) double backward somersault, tuck; (DBSA) double backward somersault, layout; (TBSC) triple backward somersault e (FLIFF) Fliffes. 
Tabela 2. Contribuição segmentar para quantidade de movimento angular nas saídas de barra fixa (adaptado de BRÜGGEMANN et al., 1994).

\begin{tabular}{|c|c|c|c|c|c|c|c|c|c|c|c|}
\hline & \multicolumn{2}{|c|}{ HTOT-R } & \multicolumn{3}{|c|}{ HLEG-R } & \multicolumn{3}{|c|}{ HTRU-R } & \multicolumn{3}{|c|}{ HARM-R } \\
\hline & $M$ & $S D$ & $M$ & $S D$ & $\%$ & $M$ & $S D$ & $\%$ & $M$ & $S D$ & $\%$ \\
\hline DBSA & 65.0 & 16.0 & 42.0 & 13.0 & 64.6 & 12.0 & 2 & 18.5 & 11.0 & 2.0 & 16.9 \\
\hline DBSC & 46.6 & 6.7 & 28.4 & 5.4 & 60.8 & 8.6 & 0.9 & 18.5 & 9.6 & 2.1 & 20.6 \\
\hline TBSC & 47.6 & 4.1 & 29.5 & 3.4 & 62.0 & 8.7 & 0.6 & 18.3 & 9.4 & 1.7 & 19.7 \\
\hline FLIFF & 51.4 & 8.6 & 28.8 & 6.6 & 56.0 & 8.4 & 1.1 & 16.3 & 14.1 & 1.2 & 27.4 \\
\hline
\end{tabular}

Legenda: (R) movimento de largada-retomada na barra fixa, (HTOT) quantidade de movimento angular do corpo, (HLEG) quantidade de movimento angular dos membros inferiores, (HTRU) quantidade de movimento angular do tronco e (HARM) quantidade de movimento angular dos membros superiores. (M) média, (SD) desvio padrão e (\%) percentual de contribuição segmentar. Elementos ginásticos: (DBSA) double backward somersault, layout; (DBSC) double backward somersault, tuck; (TBSC) triple backward somersault e (FLIFF) Fliffes.

Arampatzis e Brüggemann (1998) caracterizaram a dinâmica do giro gigante a partir do registro de dados cinemáticos dos elementos ginásticos de atletas experientes $(n=3)$ e dados cinéticos da curvatura de barra coletados de forma isolada. Os autores representaram o corpo humano em 15 segmentos rígidos e por dinâmica inversa determinaram: a potência mecânica das saídas de single mortal para trás, duplo moral para trás e Tsukahara (mortal para trás com pirueta); a energia mecânica e os momentos articulares (quadril e ombro) para esse último elemento ginástico (Figura 6).

O programa de simulação alaska (advanced lagrangian solver in kinetic analysis) foi utilizado para modelar o comportamento elástico da barra. Os autores ainda definiram um índice de aproveitamento da energia da barra baseados: (1) na diferença entre a energia transferida para a barra e a redução da energia corporal total e (2) na diferença entre o aumento da energia corporal total e a energia retornada da barra.

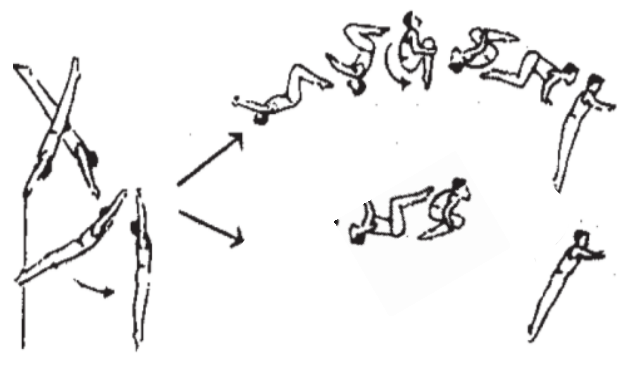

$\ell$

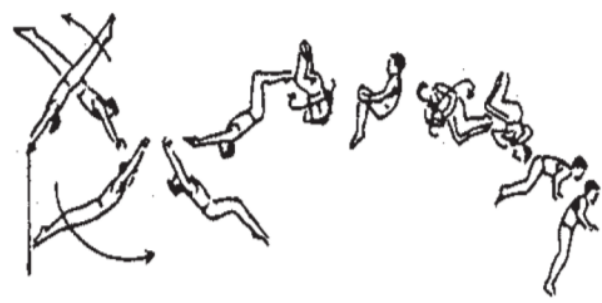

le

b

Figura 6. Saídas de barra fixa: (a) duplo mortal para trás (superior) e single mortal para trás (inferior) e (b) Tsukahara (FIG, 2017). 
Os resultados indicaram maior potência mecânica nos ombros ( 2500W) para a saída em single mortal. Maiores momentos para o ombro para o duplo mortal ( 500Nm). Menor aproveitamento de energia para as largadas-retomadas comparadas às saídas. Por fim concluíram que uma redução nos ângulos dos quadris e dos ombros durante o giro gigante pode aumentar: a energia mecânica corporal em 15\%, a velocidade vertical do CM em $10 \%$ e a quantidade de movimento angular em 35\% (Figura 7 e Figura 8).

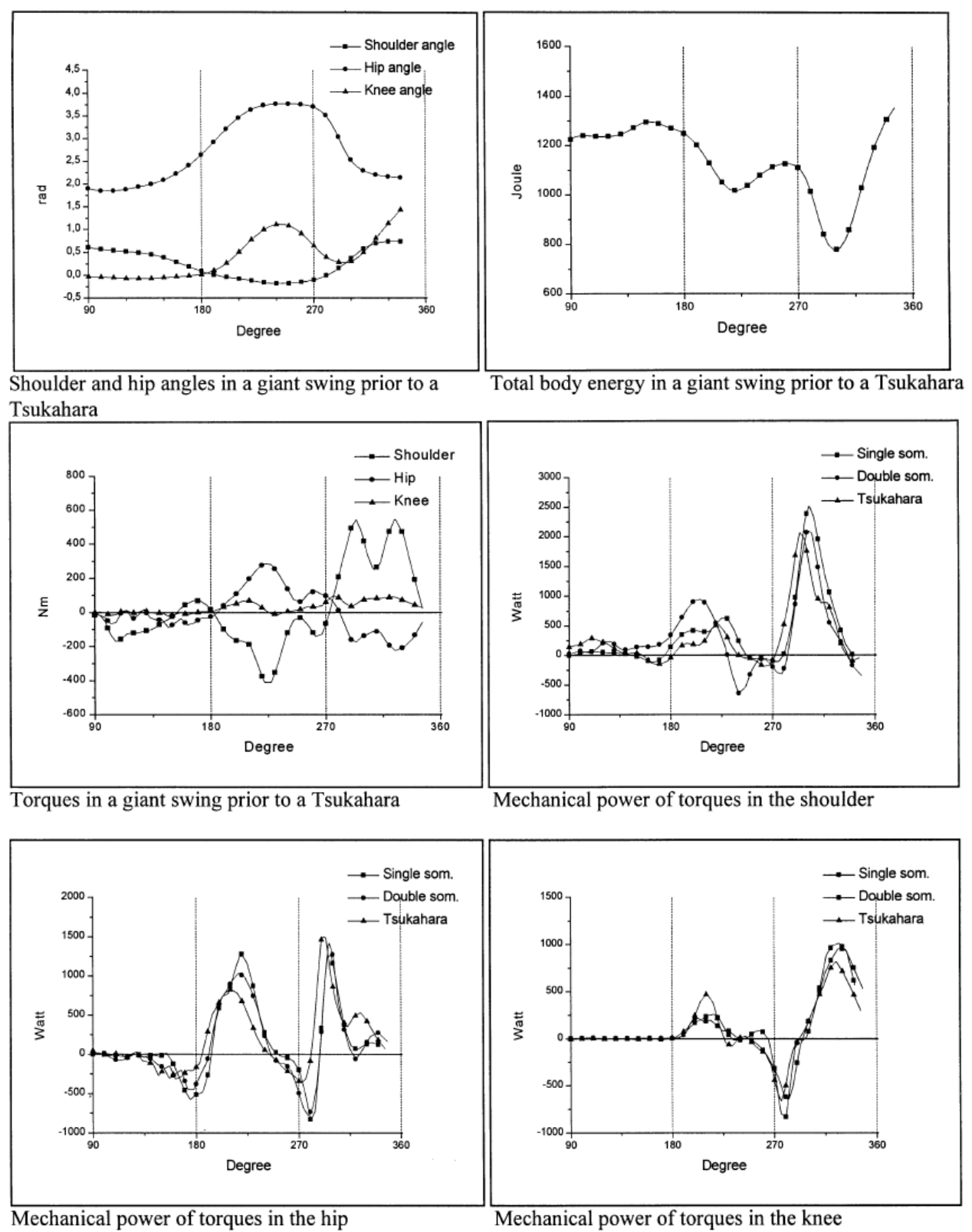

Figura 7. Ângulos articulares, energia mecânica, momentos articulares e potência mecânica em função dos ângulos de giro gigante para saídas da barra fixa (ARAMPATZIS; BRUGGEMANN, 1998). 

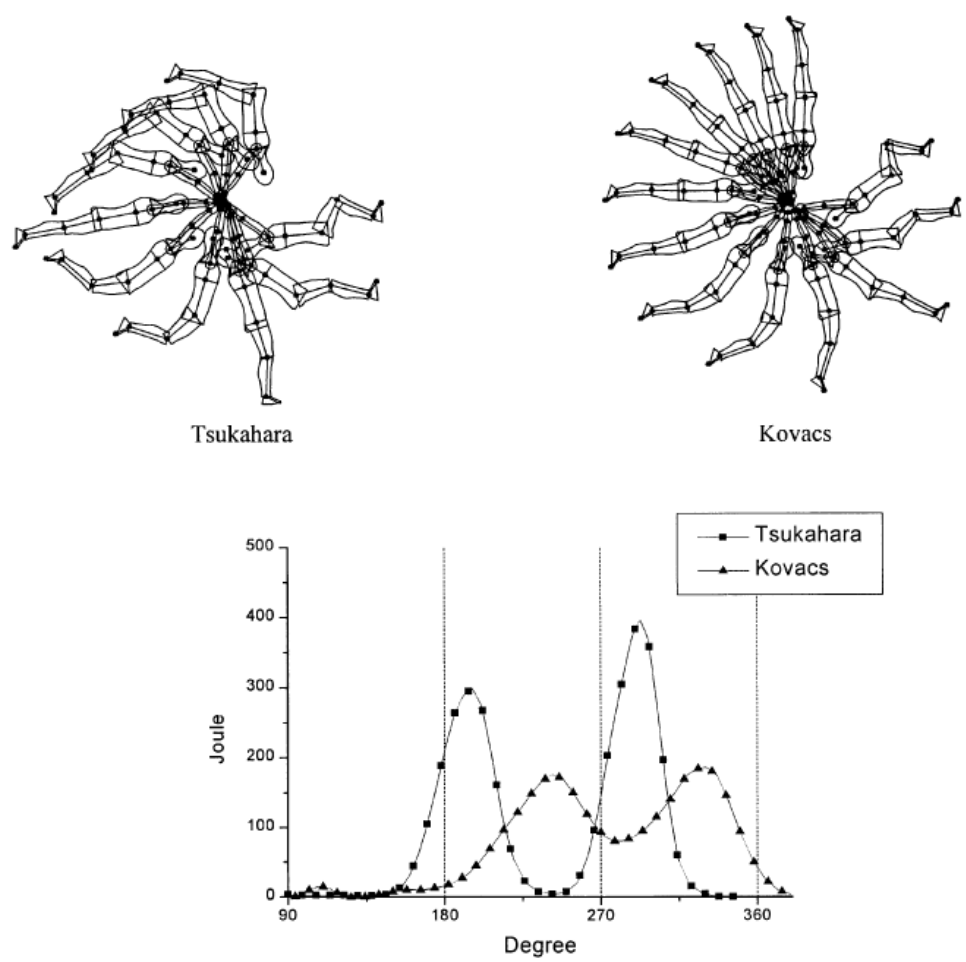

Figura 8. Energia elástica da barra para saída (esquerda superior) e largada-retomada (direita superior) (ARAMPATZIS; BRUGGEMANN, 1998).

Num segundo estudo, os autores (ARAMPATZIS; BRUGGEMANN, 1999) investigaram algumas características dinâmicas para saídas de barra fixa, paralelas assimétricas, largadas e retomadas. Na barra fixa foram avaliadas as saídas de mortal grupado de 33 ginastas $(62,2 \pm 4,2 \mathrm{~kg} ; 1,66 \pm 0,07 \mathrm{~m})$ nas técnicas tradicional (postura estendida) e carpado (Figura 9). Destaca-se entre os achados valores mais elevados na técnica carpado, exceto para velocidade vertical do centro de massa corporal (Tabela 3 e Figura 10).

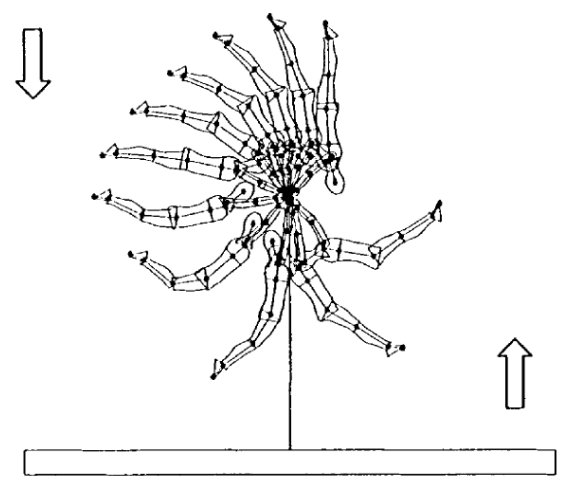

Dismount, Conventional Technique

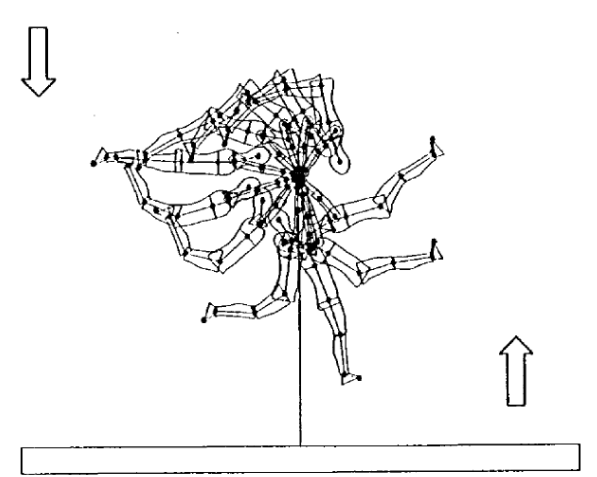

Dismount, Power Technique

Figura 9. Técnica de giro gigante para saída de barra fixa em mortal grupado para trás: tradicional (conventional technique) e carpado (power technique) (ARAMPATZIS; BRÜGGEMANN, 1999). 
Tabela 3. Caraterísticas dinâmicas da saída de barra em mortal grupado para trás (ARAMPATZIS; BRUGGEMANN, 1999).

\begin{tabular}{|c|c|c|c|c|c|c|}
\hline Técnica & $\begin{array}{c}\mathrm{vx}\left(\mathrm{t}_{\mathrm{l}}\right) \\
{[\mathrm{m} / \mathrm{s}]}\end{array}$ & $\begin{array}{c}\mathrm{vy}\left(\mathrm{t}_{\mathrm{l}}\right) \\
{[\mathrm{m} / \mathrm{s}]}\end{array}$ & $\begin{array}{c}\mathrm{H}\left(\mathrm{t}_{\mathrm{f}}\right) \\
{\left[\mathrm{kgm}^{2} / \mathrm{s}\right]}\end{array}$ & $\begin{array}{c}\mathrm{E}_{\mathrm{M}}\left(\mathrm{t}_{\mathrm{l}}\right) \\
{[\mathrm{J} / \mathrm{kg}]}\end{array}$ & $\begin{array}{c}\text { Quadril: } \mathrm{M}_{\mathrm{flx}} \\
(\text { pico })[\mathrm{Nm} / \mathrm{kg}]\end{array}$ & $\begin{array}{c}\text { Ombro: } \mathrm{M}_{\mathrm{flx}} \\
(\mathrm{pico})[\mathrm{Nm} / \mathrm{kg}]\end{array}$ \\
\hline $\begin{array}{c}\text { Tradicional } \\
(\mathrm{n}=9)\end{array}$ & $0,82 \pm 0,45$ & $4,91 \pm 0,36$ & $61,06 \pm 6,66$ & $14,77 \pm 1,50$ & $\sim 2,0$ & $\sim 3,50$ \\
\hline $\begin{array}{c}\text { Carpado } \\
(\mathrm{n}=19)\end{array}$ & $1,40 \pm 0,40$ & $4,91 \pm 0,32$ & $68,94 \pm 9,44$ & $16,81 \pm 1,01$ & $\sim 2,8$ & $\sim 4,00$ \\
\hline
\end{tabular}

Legenda: vx - velocidade horizontal do centro de massa corporal, vy - velocidade vertical do centro de massa corporal, $\mathrm{H}$ - quantidade de movimento angular, $\mathrm{E}_{\mathrm{M}}$ - energia mecânica corporal total, $\mathrm{M}_{\mathrm{flx}}-$ momento flexor, $\mathrm{t}_{\mathrm{l}}$ - instante de lançamento, $\mathrm{t}_{\mathrm{f}}$ - fim do balanço em giro gigante.
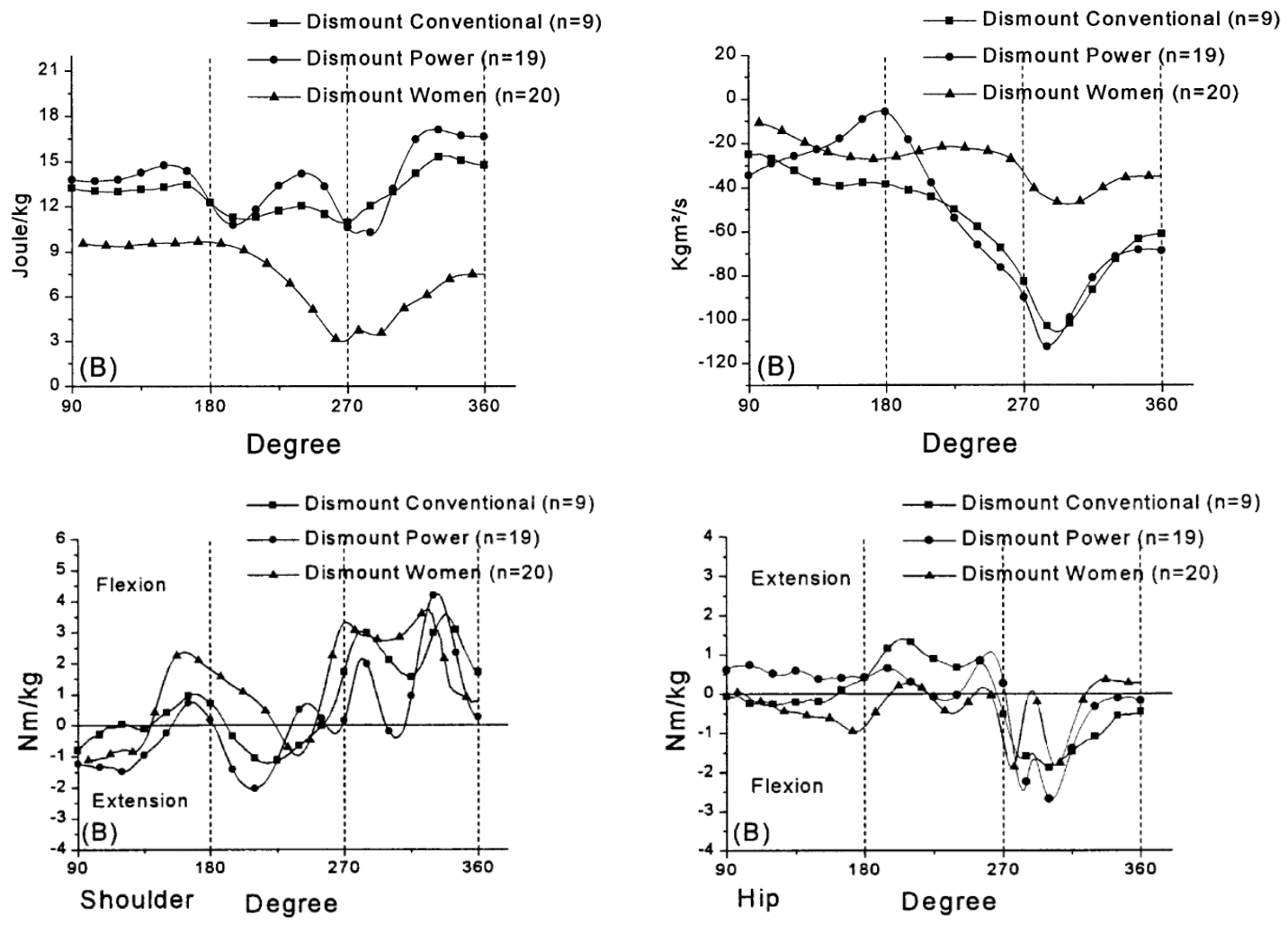

Figura 10. Energia corporal, quantidade de movimento angular, momentos articulares durante o giro gigante (ARAMPATZIS; BRUGGEMANN, 1999).

Hiley e Yeadon (HILEY; YEADON, 2003a) exploraram o potencial de cada técnica de giro gigante (tradicional e carpado) na produção da quantidade de movimento angular na saída de duplo mortal esticado para trás de um ginasta de elite. Para tanto, foi adotado um modelo 2D de 4 segmentos (perna, coxa, tronco e membros superiores) sendo a barra e o ombro do ginasta um sistema de mola (Figura 11). Os resultados demonstraram que a postura carpado gera menor quantidade de momento angular e número revoluções comparada à técnica tradicional (95,7 e 106,2 $\mathrm{kgm}^{2} / \mathrm{s}$; e 2,00 e 2,22 rev/s, respectivamente). 


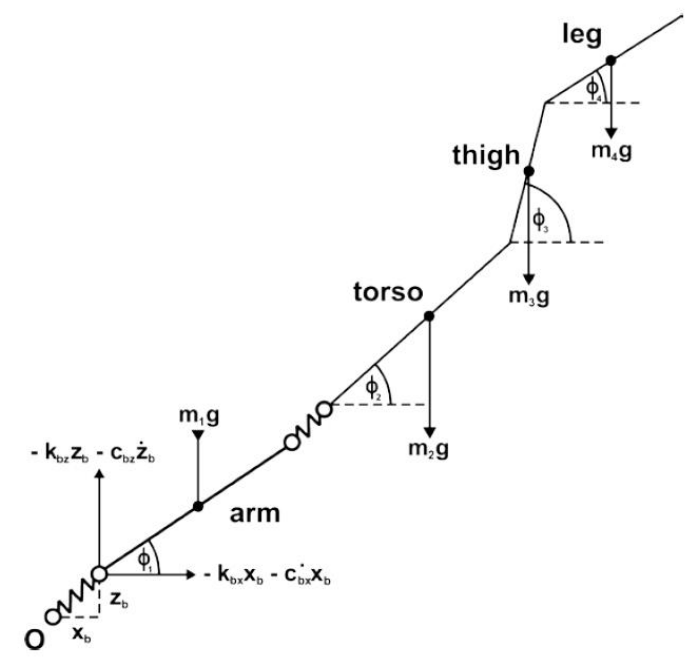

Figura 11. Diagrama de corpo livre das forças atuantes nos 4 segmentos corporais (membros superiores, tronco, coxa e perna) (HILEY; YEADON, 2003a).

Em outro estudo, Hiley e Yeadon (2003b) identificaram diferentes janelas de lançamento nas técnicas de giro gigante tradicional e carpado para saída em duplo mortal estendido com pirueta. Essa janela representa o intervalo temporal para o aproveitamento do impulso obtido na fase de balanço que precede a saída. As saídas de 8 finalistas dos Jogos Olímpicos de Sydney 2000 na técnica carpado e outras 3 de ginastas na técnica tradicional foram analisadas. Margens de erro de lançamento foram simuladas a partir de um modelo planar de 4 segmentos (perna, coxa, tronco e membros superiores).

Foram observados maiores intervalo de tempo ( $88 \mathrm{a} 157 \mathrm{~ms}$ ) e arco de balanço (226 a $268^{\circ}$; sendo ângulo zero em 12 horas) para soltar a barra na técnica carpado comparada à tradicional (73 a $84 \mathrm{~ms} ; 118$ a $186^{\circ}$ ). Isso implica em maior margem de erro para o tempo de soltar com quantidade de movimento suficiente para completar o duplo mortal em fase aérea. A Figura 12 representa as posições articulares nas passagens imediatamente acima e abaixo da barra. 


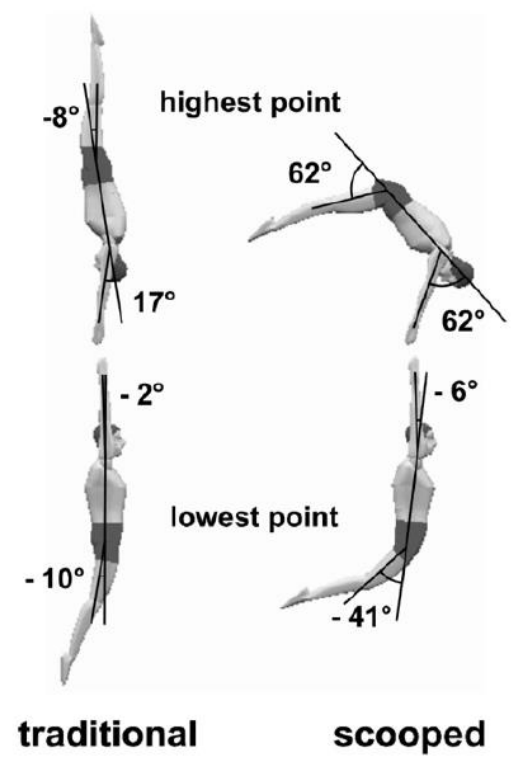

Figura 12. Caraterização angular das técnicas tradicional e carpado durante o giro gigante para saída em duplo mortal estendido com pirueta (HILEY; YEADON, 2003b).

$\mathrm{Na}$ sequência, os autores testaram o potencial de realização de um triplo mortal estendido na saída de barra fixa (HILEY; YEADON, 2005). O modelo de simulação 2D já apresentado (HILEY; YEADON, 2003a) foi utilizado para produzir a quantidade de movimento angular e o tempo de voo necessários para a realização do triplo mortal. Esses critérios de otimização foram calculados considerando os limites realistas da produção de momentos articulares (Tabela 4). Os resultados indicaram uma janela temporal para o lançamento em condições ótimas de $28 \mathrm{~ms}$. Esse intervalo é menor do que o observado entre os ginastas finalistas (55 ms) nas Olímpiadas de Sydney 2000. Assim, embora tecnicamente possível, a saída de triplo mortal estendido requer esforço máximo e tempo preciso de lançamento da barra fixa. 
Tabela 4. Janela de lançamento de cada quantidade de movimento angular, com restrição de momento (redução de 25\%) (HILEY; YEADON, 2005)

\begin{tabular}{|c|c|c|c|c|}
\hline $\begin{array}{c}\text { lower limit on } \\
\text { angular } \\
\text { momentum } \\
\text { (straight saltos) }\end{array}$ & $\begin{array}{c}\text { angle at } \\
\text { start of } \\
\text { window } \\
\left(^{\circ}\right)\end{array}$ & $\begin{array}{c}\text { angle at } \\
\text { end of } \\
\text { window } \\
\left({ }^{\circ}\right)\end{array}$ & $\begin{array}{c}\text { release } \\
\text { window } \\
\left({ }^{\circ}\right)\end{array}$ & $\begin{array}{c}\text { release } \\
\text { window } \\
(\mathrm{ms})\end{array}$ \\
\hline 1.49 & 579 & 641 & 62 & 186 \\
\hline 1.60 & 579 & 640 & 61 & 178 \\
\hline 1.70 & 581 & 633 & 50 & 156 \\
\hline 1.80 & 581 & 624 & 43 & 141 \\
\hline 1.90 & 583 & 617 & 34 & 111 \\
\hline 2.00 & 585 & 614 & 29 & 97 \\
\hline 2.10 & 587 & 612 & 25 & 86 \\
\hline 2.20 & 589 & 611 & 22 & 75 \\
\hline 2.30 & 593 & 610 & 17 & 66 \\
\hline 2.40 & 602 & 611 & 9 & 39 \\
\hline 2.50 & - & - & - & - \\
\hline 2.60 & - & - & - & - \\
\hline
\end{tabular}

* Quantidade de movimento angular normalizada por $2 \pi$ vezes o momento de inércia corporal em torno do centro de massa. ** Ângulo zero em $12 \mathrm{~h}$.

Mais recentemente, esses autores analisaram dois critérios de otimização do giro gigante para o duplo estendido (HILEY; YEADON, 2016): (1) minimização dos momentos articulares ou (2) maximização da janela de lançamento. Foram analisadas 10 saídas de barra de um ginasta de ranking internacional ( 24 anos, $1,73 \mathrm{~m}, 70 \mathrm{~kg}$ ) e os critérios testados por simulação a partir do modelo de 4 segmentos (HILEY; YEADON, 2003b). Os resultados demonstraram que, na presença de um sistema mecânico falível e variável, como são os movimentos humanos, o desempenho ótimo está centrado nas estratégias motoras que maximizam as margens de erro e não na minimização dos esforços articulares (Tabela 5 e Tabela 6). 
Tabela 5. Caraterísticas dos voos e janelas de lançamento para a saída em duplo mortal estendido de um ginasta de elite (HILEY; YEADON, 2016).

\begin{tabular}{lccccc}
\hline & $\begin{array}{c}\text { Flight } \\
\text { Trial } \\
\text { time [s] }\end{array}$ & $\begin{array}{c}\text { Angular } \\
\text { momentum } \\
{[\mathrm{ss}]}\end{array}$ & $\begin{array}{c}\text { Travel }^{+} \\
{[\mathrm{m}]}\end{array}$ & $\begin{array}{c}\text { Release } \\
\text { window } \\
{[\mathrm{ms}]}\end{array}$ & $\begin{array}{c}\text { Average } \\
\text { torque }^{\dagger} \\
{[\mathrm{N} \cdot \mathrm{m}]}\end{array}$ \\
\hline 1 & 1.24 & 1.67 & 2.82 & 64 & 243 \\
2 & 1.25 & 1.65 & 2.84 & 64 & 232 \\
3 & 1.24 & 1.61 & 2.56 & 65 & 243 \\
4 & 1.24 & 1.63 & 2.71 & 45 & 236 \\
5 & 1.24 & 1.61 & 2.66 & 71 & 238 \\
6 & 1.24 & 1.62 & 2.84 & 57 & 246 \\
7 & 1.24 & 1.67 & 2.69 & 69 & 258 \\
8 & 1.22 & 1.59 & 2.55 & 58 & 236 \\
9 & 1.25 & 1.61 & 2.48 & 42 & 242 \\
10 & 1.24 & 1.61 & 2.57 & 35 & 226 \\
Mean & $\mathbf{1 . 2 4}$ & $\mathbf{1 . 6 3}$ & $\mathbf{2 . 6 7}$ & $\mathbf{5 7}$ & $\mathbf{2 4 0}$ \\
Stdev & $\mathbf{0 . 0 1}$ & $\mathbf{0 . 0 3}$ & $\mathbf{0 . 1 3}$ & $\mathbf{1 2}$ & $\mathbf{9}$ \\
\hline
\end{tabular}

Notes: ${ }^{\star}$ Normalised to straight somersaults per flight time.

+ Horizontal distance of the mass centre from the bar on landing.

${ }^{\dagger}$ Average total joint torque at the shoulder, hip and knee for matching simulations based using equation 3 .

Tabela 6. Diferença RMS nos ângulos articulares, deslocamento da barra e ângulos de rotação corporal entre as soluções ótimas e experimentais (HILEY; YEADON, 2016).

\begin{tabular}{lcccccc}
\hline $\begin{array}{l}\text { Optimisation/ } \\
\text { criterion }\end{array}$ & $\begin{array}{c}\text { Shoulder } \\
{\left[{ }^{\circ}\right]}\end{array}$ & $\begin{array}{c}\text { Hip } \\
{\left[{ }^{\circ}\right]}\end{array}$ & $\begin{array}{c}\text { Knee } \\
{\left[{ }^{\circ}\right]}\end{array}$ & $\begin{array}{c}\text { Bar } \\
{[\mathrm{m}]}\end{array}$ & $\begin{array}{c}\text { Rot } \\
\text { angle }\left[{ }^{\circ}\right]\end{array}$ & $\begin{array}{c}\text { Success } \\
{[\%]}\end{array}$ \\
\hline $\begin{array}{l}\text { Local } \\
\text { Min torque }\end{array}$ & 7 & 6 & 5 & 0.01 & 1 & 21 \\
Max window & 4 & 6 & 4 & 0.02 & 2 & 74 \\
Max success & 4 & 4 & 3 & 0.01 & 2 & 98 \\
$\begin{array}{l}\text { Global } \\
\text { Min torque }\end{array}$ & 19 & 20 & 8 & 0.02 & 4 & 12 \\
Max window & 8 & 21 & 7 & 0.04 & 12 & 56 \\
Max success & 8 & 11 & 5 & 0.02 & 3 & 100 \\
\hline
\end{tabular}

Serbest e colaboradores (2018) compararam as variáveis cinemáticas e cinéticas durante o impulso de três diferentes saídas de barra fixa: duplo grupado, estendido com pirueta e duplo estendido; todas em mortal para trás (Figura 13). Tipicamente, esse impulso é obtido a partir do balanço em dois giros gigantes (flips) em torno da barra. Um ginasta de nível nacional (13 anos de idade, 7 anos de experiência) foi a amostra deste estudo. O corpo humano foi modelado por 5 segmentos (antebraço, braço, tronco, coxa e perna), a barra como um sistema de mola e os momentos articulados calculados por dinâmica direta em ambiente SimMechanics (Matlab®).

Foram observados momentos similares no primeiro flip entre as três saídas de barra. Um aumento nos momentos do primeiro para o segundo flip e um maior valor absoluto no punho comparado às demais articulações, também foram comuns. Durante o segundo flip, 
destaca-se um maior pico relativo para quadril e o ombro na saída de duplo mortal estendido (Figura 14).
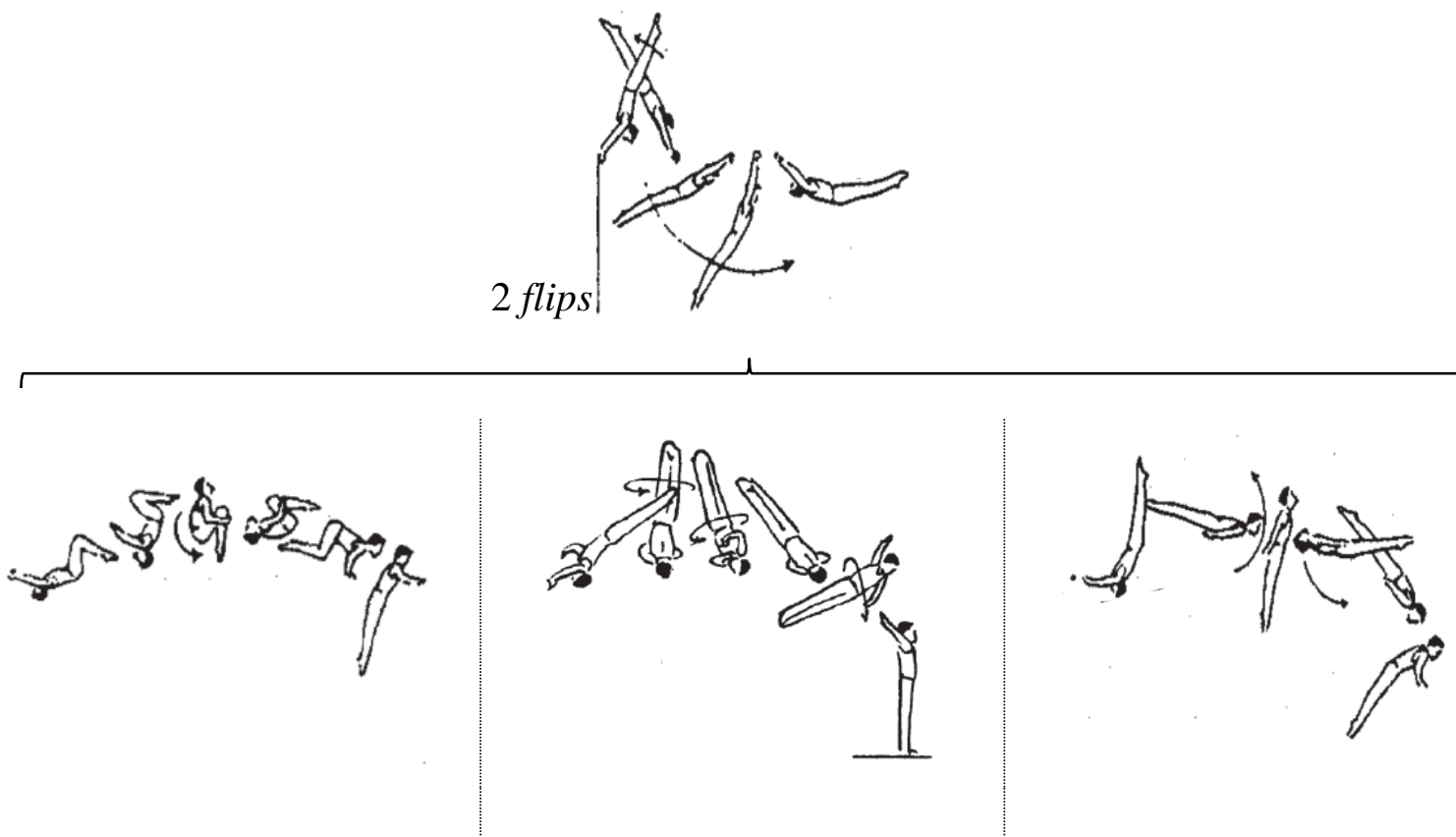

Figura 13. Saída de barra fixa em mortal para trás: giros gigantes (superior), duplo grupado (inferior esquerdo), estendido com pirueta (inferior centro) e duplo estendido (inferior direito) (FIG, 2017).
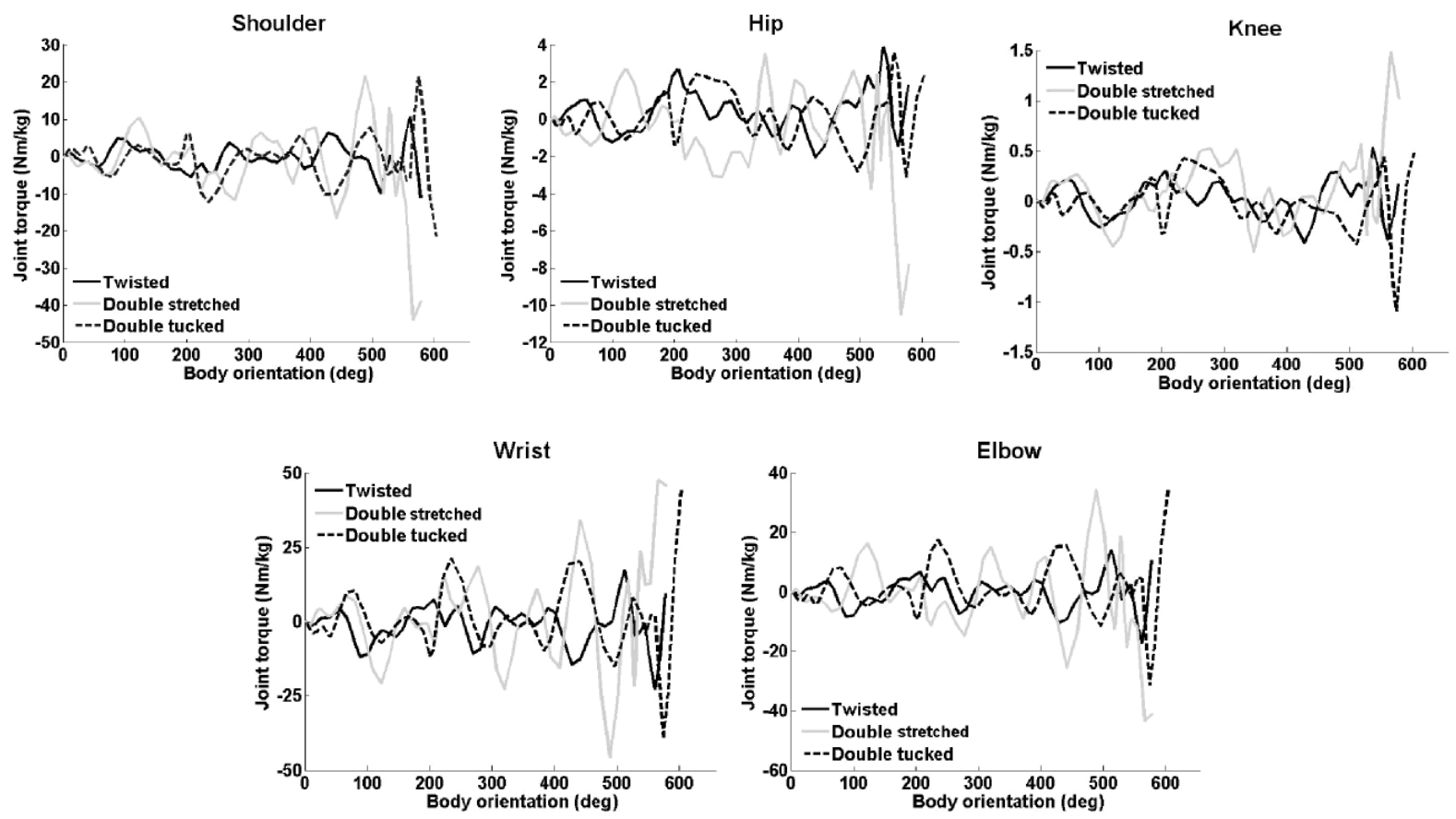

Figura 14. Momentos articulares durante o giro gigante para três saídas de barra em mortal para trás: grupado (double tucked), estendido com pirueta (twisted) e duplo estendido (double stretched) (SERBEST; BERISHA; CILLI, 2018). 


\subsubsection{Elementos de voo}

Durante o voo, algumas estratégias de quadril podem favorecer a finalização dos mortais. Kerwin e colaboradores (1990) investigaram os efeitos desses ajustes posturais para duas saídas de barra: duplo mortal estendido para trás e triplo mortal grupado para trás. As estratégias foram, respectivamente, hiperextensão e abdução de quadril (Figura 15).

Os movimentos de 8 ginastas finalistas das Olímpiadas de Seoul 1992 foram adotados como variáveis de entrada (ângulo articular e quantidade de movimento angular) para a simulação dessas estratégias posturais. Foram analisadas 4 tentativas de cada saída de barra, consideradas com aterrissagem controlada. Baseados em condições realistas de comportamento articular, as alterações provocadas estão resumidas na Tabela 7.

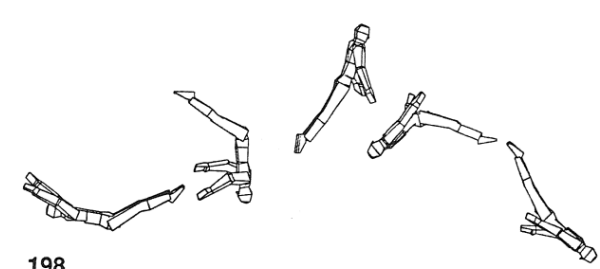

198

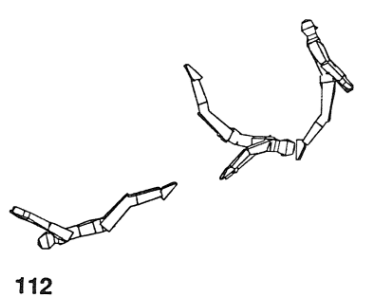

112

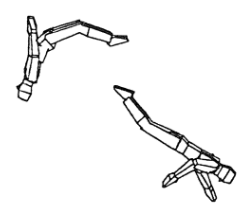

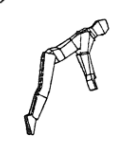

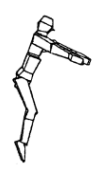

$\mathrm{a}$

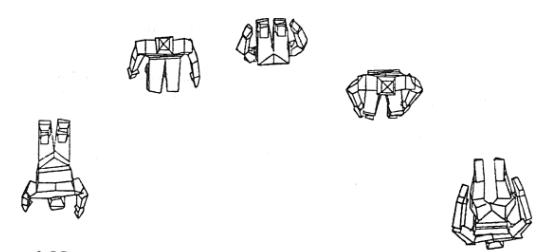

149
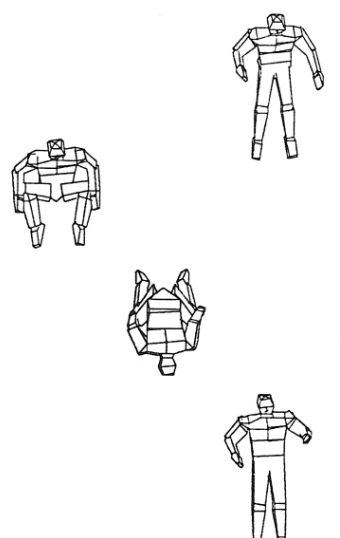

Figura 15. Ajustes posturais de quadril para saídas de barra fixa (KERWIN; YEADON; LEE, 1990): (a) duplo mortal estendido e (b) triplo mortal grupado. 
Tabela 7. Ajuste postural simulado para saída de barra fixa em GA (KERWIN; YEADON; LEE, 1990).

\begin{tabular}{|c|c|c|}
\hline \multirow{2}{*}{ Elemento ginástico } & Período de voo (\%) & Ajuste postural de quadril \\
\hline \multirow{3}{*}{ Duplo mortal estendido para trás } & $\leq 10$ e $\geq 80$ & Ângulo experimental \\
\cline { 2 - 3 } & 20 a 70 & Restrito em 180 graus de extensão \\
\cline { 2 - 3 } & Entre 20 e 30 & $\begin{array}{c}\text { Transição em velocidade angular } \\
\text { experimental }\end{array}$ \\
\cline { 2 - 3 } Triplo mortal grupado para trás & Entre 70 e 80 & $\begin{array}{c}\text { Transição em velocidade angular } \\
\text { experimental }\end{array}$ \\
\cline { 2 - 3 } & Entre 10 e 80 & Ângulo experimental \\
\hline
\end{tabular}

Para o duplo estendido, os autores observaram que a neutralização do quadril em 180 graus reduziu entre 1,5 e $6 \%$ o número de mortais comparado aos movimentos com hiperextensão. No caso do triplo grupado, essa redução chegou a 12\% no número de rotações para um dos ginastas. Em ambos os casos, o efeito provocado pela variação postural foi um aumento no momento de inércia corporal e, considerando o princípio de conversação da quantidade de movimento angular, uma redução da velocidade angular em fase de voo. Assim, dado um mesmo período de voo, os ginastas completaram um menor número de rotações. Entre as posturas estendida e grupada, ainda foram identificadas: maior quantidade de movimento angular (18\%), menor tempo de voo (4\%), menor altura de lançamento (9\%) e menor altura máxima de voo $(9 \%)$; respectivamente (Tabela 8).

Tabela 8. Resultados das saídas de duplo mortal estendido $($ saltos $=2)$ e triplo mortal grupado $($ saltos $=3)$ (KERWIN; YEADON; LEE, 1990).

\begin{tabular}{lccccc}
\hline Competitor & Saltos & $\begin{array}{c}\text { Angular } \\
\text { momentum }\end{array}$ & $\begin{array}{c}\text { Flight } \\
\text { time (s) }\end{array}$ & $\begin{array}{c}\text { Release } \\
\text { height (m) }\end{array}$ & $\begin{array}{c}\text { Maximum } \\
\text { height (m) }\end{array}$ \\
\hline 112 & 2 & 1.57 & 1.23 & 2.07 & 3.45 \\
122 & 2 & 1.41 & 1.26 & 2.59 & 3.73 \\
189 & 2 & 1.47 & 1.25 & 2.54 & 3.69 \\
198 & 2 & 1.68 & 1.28 & 2.34 & 3.68 \\
$M$ & & 1.53 & 1.26 & 2.39 & 3.63 \\
$S D$ & & 0.12 & 0.02 & 0.24 & 0.13 \\
120 & 3 & 1.23 & 1.29 & 2.57 & 3.89 \\
149 & 3 & 1.43 & 1.28 & 2.76 & 3.95 \\
193 & 3 & 1.19 & 1.34 & 2.67 & 4.08 \\
202 & 3 & 1.27 & 1.37 & 2.46 & 4.03 \\
$M$ & & 1.28 & 1.32 & 2.62 & 3.99 \\
$S D$ & & 0.11 & 0.04 & 0.13 & 0.08 \\
\hline
\end{tabular}

${ }^{*}$ Straight somersaults per unit flight time. 
Takei e Dunn (1997) analisaram as propriedades mecânicas da estratégia de kickout para o sucesso da saída de duplo mortal carpado para trás. O kickout consiste em estender quadris e joelhos antes do alinhamento vertical (zero grau) na posição invertida durante o segundo mortal (Figura 16). Essa estratégia sugere antecipação e preparo para uma aterrissagem controlada e segura.

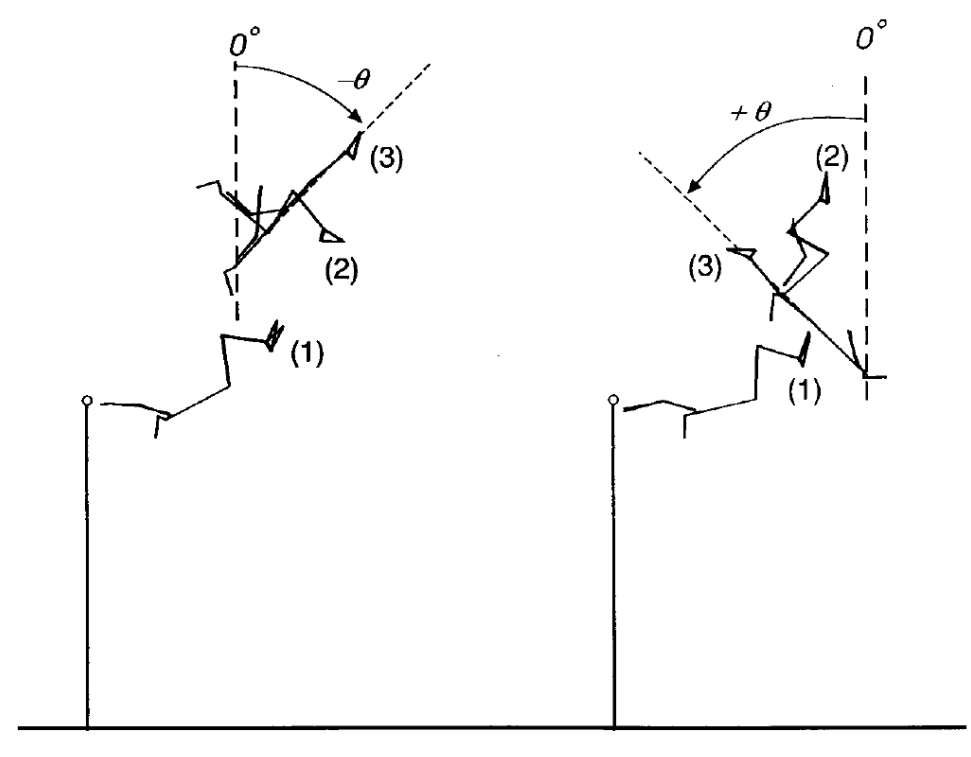

$\mathbf{A}$

B

Figura 16. Kickout (3): (A) posições antecipada e (B) atrasada de extensão articular (joelho e quadril).

Esse estudo teve como amostra 24 saídas de barra (G1, kickout = 12; G2, non-kickout =12) realizadas em campeonatos nacionais no Japão e Estados Unidos. Baseado num modelo biomecânico planar de 12 segmentos (CLAUSTER; MCCONVILLE; YOUNG, 1969) e parâmetros antropométricos de Hay (1993), os autores compararam as características espaçotemporais, o comportamento do centro de massa e a quantidade de movimento angular dos dois grupos. Para favorecer a discriminação das variáveis, o voo foi dividido em três subfases: (1) do lançamento até o instante de máximo grupado; (2) do instante anterior ao momento de kickout e (3) desse último à aterrissagem (Figura 17).

Observou-se que velocidade horizontal do centro de massa e a quantidade de movimento angular foram similares entre os grupos. No entanto, o G1 apresentou dois aspectos fundamentais: (1) maior velocidade vertical do centro de massa no lançamento, logo, maiores altura máxima e tempo de voo; e (2) maior momento de inércia normalizado 
$\left(\mathrm{J}^{*}\right.$ massa $^{-1} *$ estatura $\left.^{-2}\right)$ e, assim, menor velocidade angular e maior tempo de preparo para a aterrissagem (Figura 18).
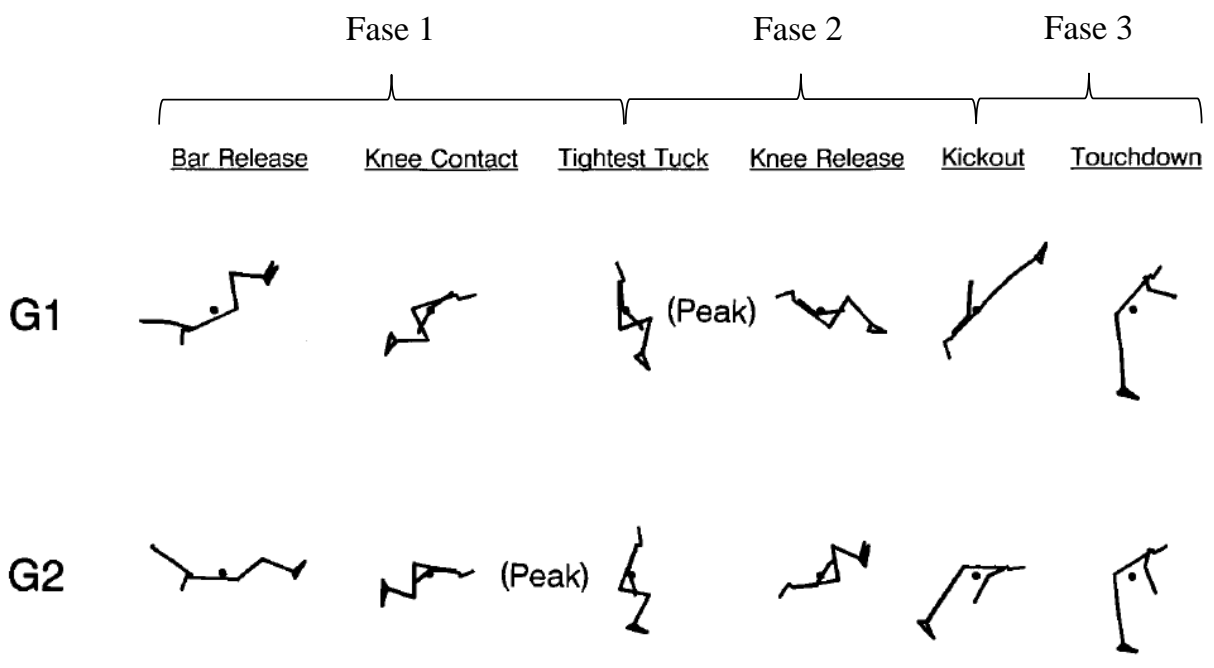

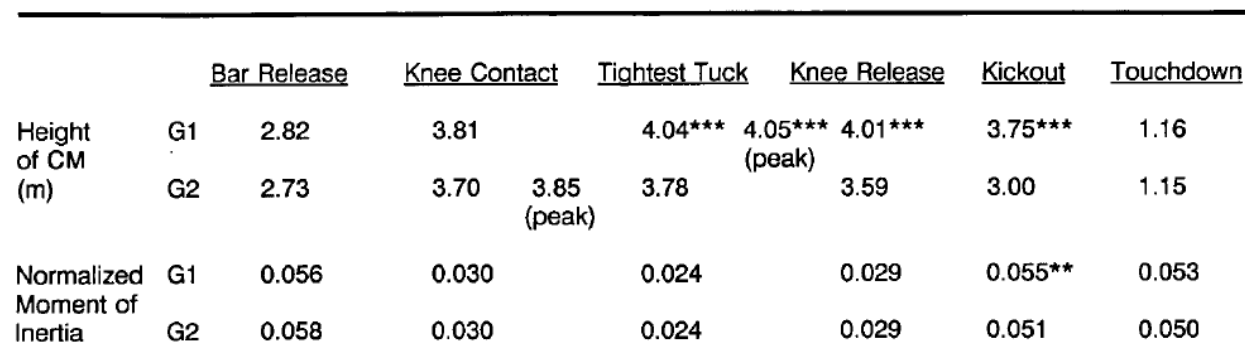

Figura 17. Sequência de posturais corporais e resultados de altura do centro de massa e momento de inércia normalizado na saída de duplo mortal carpado para trás $\left[* * \mathrm{p}<0,005 \mathrm{e}^{* * *} \mathrm{p}<0,001\right]$ (adaptado de TAKEI; DUNN, 1997). 


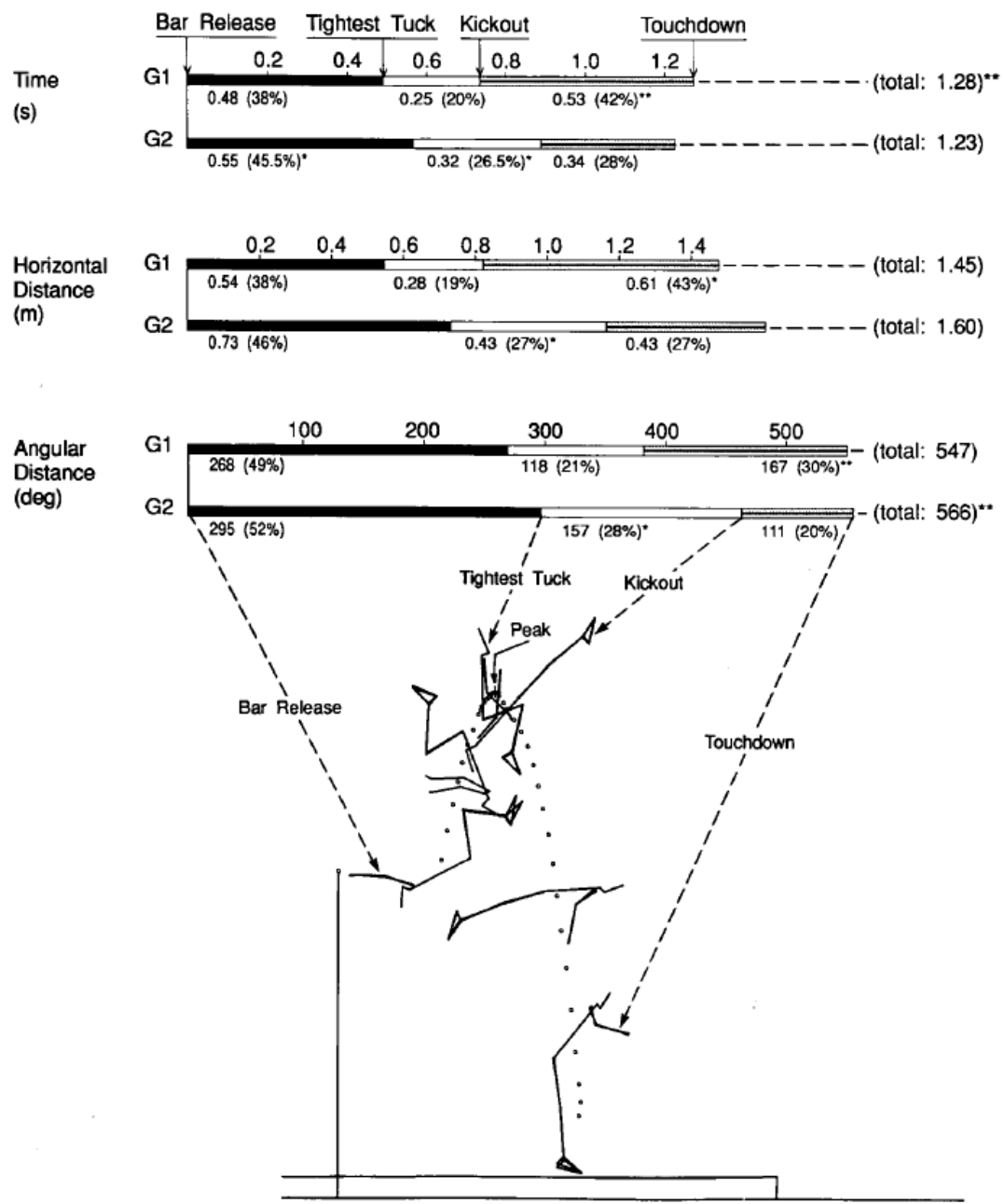

Figura 18. Tempo de voo, distância horizontal do centro de massa e distância angular nas fases da saída de duplo mortal carpado para trás $(* \mathrm{p}<0,005 \mathrm{e} * * \mathrm{p}<0,001)$ (TAKEI; DUNN, 1997).

Em deslocamentos aéreos onde a resistência do ar pode ser desprezada, o movimento translacional do centro de massa é definido no lançamento. No entanto, o movimento rotacional (Figura 19) está amplamente sobre controle do atleta. Yeadon (1997) demonstrou que as piruetas podem ser produzidas por técnicas de decolagem e de voo. Em ambos os casos é necessário que o corpo assuma uma orientação inclinada em relação à vertical durante o voo. 


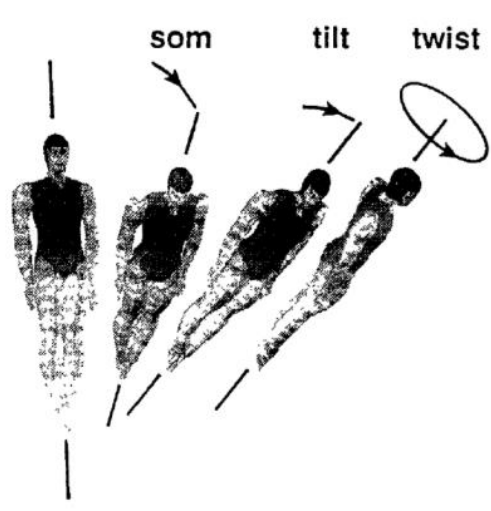

Figura 19. Rotações em mortal (som), inclinação (tilt) e piruetas (twist) (YEADON, 1997).

Na técnica de pirueta por decolagem, uma inclinação do corpo é obtida a partir da segunda metade do mortal (Figura 20, linha superior) e neutralizada ao final do mortal. No entanto, para elementos com aterrissagem em posição invertida ao lançamento ou antes de um mortal completo, como nas saídas de barra em GA e diversos saltos ornamentais, essa mudança de orientação corporal é um efeito indesejado.

Para as piruetas iniciadas em voo, uma vez sem o auxílio das forças de contato, a rotação depende de movimentos assimétricos (direito-esquerdo) de ombro e/ou quadril com efeito contralateral (Figura 20, linha inferior). Por exemplo, em um mortal iniciado com ambos os braços no prolongamento do corpo, o ginasta em fase aérea realiza uma adução do ombro direito resultando na inclinação do corpo para o lado oposto. O mesmo efeito ocorre com ações de desvio dos membros inferiores para a direita (quadris direito abduzido e esquerdo aduzido) devido à conservação do momento angular.

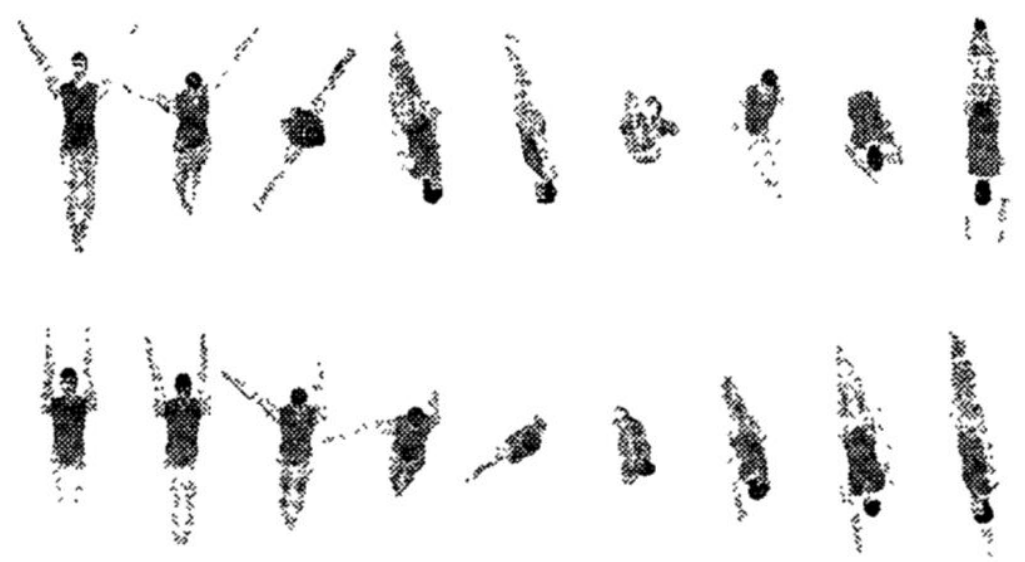

Figura 20. Sequência de movimento para as técnicas de controle de pirueta: decolagem (superior) e assimetria de membros (inferior) (YEADON, 1997). 
Ainda segundo o autor (YEADON, 1997), o potencial de inclinação de ambas as técnicas não é o mesmo. Enquanto, a técnica de lançamento contribui com $6^{\circ}$ de inclinação do corpo, a técnica de assimetria em voo provoca $13^{\circ}$, sendo $7^{\circ}$ devido à participação dos ombros e $6^{\circ}$ em decorrência dos quadris. Uma vez que maiores inclinações podem provocar maior quantidade de piruetas, isso justifica a predominância dessa última técnica entre competidores de elite na saída de argolas de argolas e barra fixa, por exemplo. Assim, os movimentos articulares têm o potencial de iniciar, controlar ou reduzir as rotações do corpo em voo.

\subsection{CHEGADAS E CONDIÇÕES DE ATERRISSAGEM}

No esporte de alto rendimento, as aterrissagens estão entre as habilidades motoras de maior demanda mecânica (MCNITT-GRAY, 2000). Particularmente na GA, essa tarefa é significativamente afetada por fatores como: a altura do salto (MCNITT-GRAY, 1991; MCNITT-GRAY, 1993; MCNITT-GRAY; YOKOI; MILLWARD, 1993; YEOW; LEE; GOH, 2009), o tipo de salto (mortais para frente e para trás) (MCNITT-GRAY et al., 2001), stiffness articular (DEVITA; SKELLY, 1992), as posturas de apoio (mono ou bipodal) (PAPPAS et al., 2007) e as propriedades do solo (suave e rígido) (MCNITT-GRAY; YOKOI; MILLWARD, 1993; 1994).

$\mathrm{Na}$ maioria das modalidades esportivas, o desafio está em maximizar a absorção do impacto recorrendo a diferentes estratégias de frenagem e amortecimento (MARINŠEK, 2010). Ainda que igualmente necessário, na ginástica artística, esse não é o único requisito. Busca-se, antes de tudo, uma aterrissagem sem passos ou queda: uma chegada "cravada". Em termos mecânicos, isso implica numa redução total da quantidade de movimento horizontal, vertical e angular durante a aterrissagem (REQUEJO; MCNITT-GRAY; FLASHNER, 2002). Para tanto, no final da fase de voo, o ginasta necessita controlar o momento de inércia corporal de tal maneira que inicie o contato com o solo em condições de gerar impulso suficiente para zerar a quantidade de movimento.

McNitt-Gray e colaboradores (1998) observaram características invariantes durante a aterrissagem de ginastas em competições olímpicas. Foram analisadas 20 chegadas de 10 ginastas nas saídas de barras paralelas (PB) e barra fixa (HB). Entre essas, 19 foram falhas sendo 8 com rotação excessiva no instante de contato, e consequente salto ou passo para trás, e 11 com rotação incompleta, e assim, passo ou salto para frente. De acordo com os autores, uma taxa de sucesso similar a essa já havia sido observada nos Jogos Olímpicos de 1992. 
$\mathrm{Na}$ chegada de $\mathrm{PB}$, as falhas com recuo foram caraterizadas com maior ângulo de inclinação para o segmento que une as posições do tornozelo ao CM, comparados às falhas com avanço $\left(65-78^{\circ}\right.$ em relação à horizontal e 61-66 , respectivamente). No caso das chegadas de barra fixa, essa diferenciação foi menos definida ( $73^{\circ}$ sucesso; $79-86^{\circ}$ falha com recuo; e $69-80^{\circ}$ falha com avanço). Os ângulos de quadril foram de 23 a $35^{\circ}$ maiores nas chegadas de HB. Entre os ângulos de joelho, nenhuma diferença significativa foi observada.

Os resultados acima sugerem uma relação entre aumento da velocidade vertical de impacto e aumento do ângulo de quadril na chegada. Entretanto, esses resultados não foram observados nas aterrissagens de ginastas femininas para diferentes alturas (MCNITT-GRAY; YOKOI; MILLWARD, 1993). Isso, provavelmente, porque os ângulos de quadril na chegada de HB foram menores, em média, 30 graus.

Depois do contato com o solo foi observada uma consistente relação angular entre joelho e quadril em 9/10 sujeitos. Para os autores, isso indica que o sucesso da aterrissagem independe do padrão de controle articular ou da velocidade vertical de colisão. Além disso, esses resultados também sugerem que os músculos bi ou poli articulares são os principais responsáveis pela coordenação e distribuição de cargas na aterrissagem.

Requejo e colaboradores (2002; 2004) usaram abordagens experimentais e de modelagem para testar as seguintes hipóteses: (1) ao final da fase de voo, os ginastas não modificam as estratégias de membros inferiores em condições de sucesso ou falha nas aterrissagens; e (2) as ações de ombro devem ser suficientes para promover condições de contato que assegurem aterrissagens de sucesso.

Saídas de paralelas assimétricas em duplo mortal para trás $(n=10$, sendo 5 sucessos e 5 falhas com rotação em excesso) de ginastas nos Jogos Olímpicos de 2000, foram registradas. O período de $1 / 2$ rotação $(\sim 0,2 \mathrm{~s})$ imediatamente anterior à colisão foi analisado. Os parâmetros antropométricos de Zatsiorsky ajustados por DeLeva (1996) foram adotados. As equações de movimento de 5 segmentos em 2D foram formuladas pelo método de Lagrange e a dinâmica simulada em ambientes ADAMS (Mechanical Dynamics) e Matlab/Simulink (Mathworks).

Os autores identificaram um momento de ombro cinco vezes menor nas condições de sucesso. Esse ajuste representou uma redução de $14,9^{\circ}$ na posição de aterrissagem, segmento que representa a diferença de posição do tornozelo ao CM (Figura 21 e Figura 22). As modificações de momentos no pescoço, joelho e quadril não resultaram em ângulos realistas de aterrissagem. 


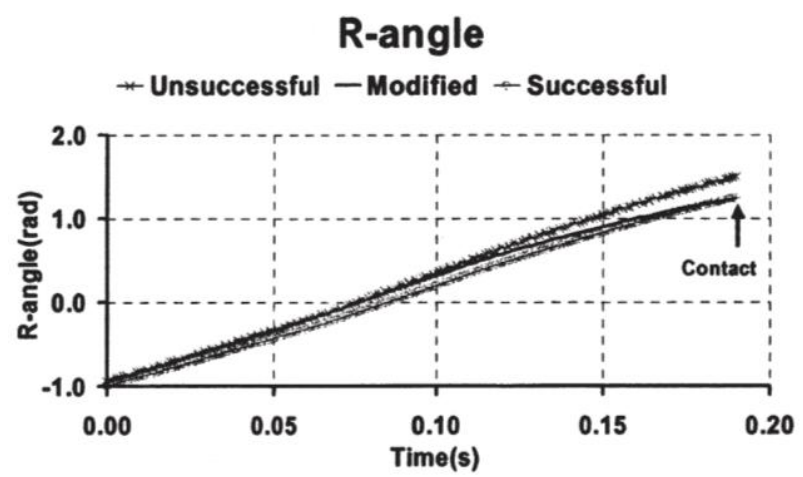

Figura 21. Posição angular nas chegadas de paralelas assimétricas em três condições: falha, sucesso e modificada para o sucesso em função do momento nos ombros (REQUEJO; MCNITT-GRAY; FLASHNER, 2002).

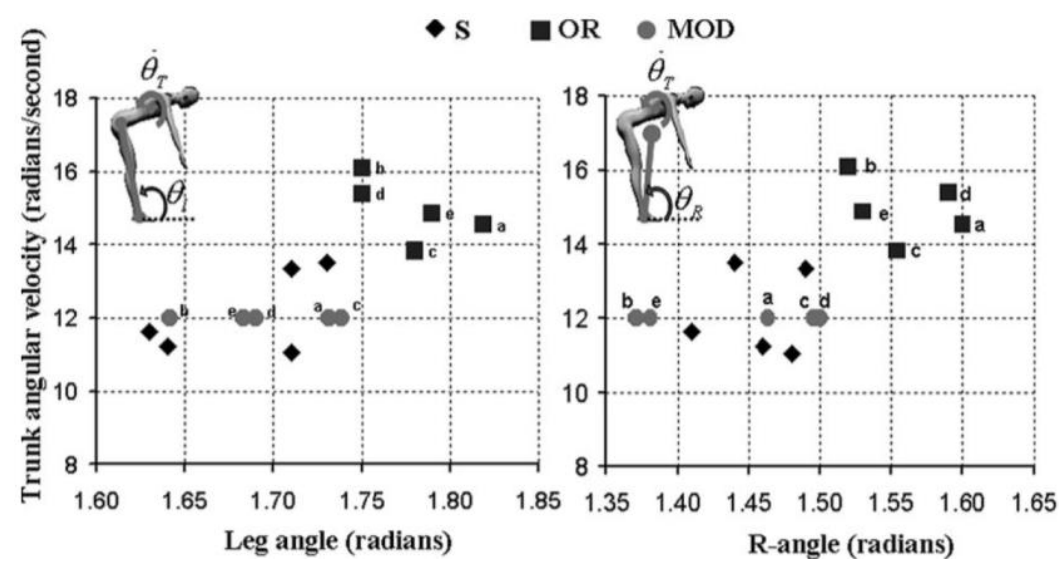

Figura 22. Cinemática da aterrissagem na saída de paralelas assimétricas. Dados experimentais (esquerda) e simulação de controle modificada (direita) para satisfazer as condições de sucesso (R-angle) (REQUEJO; MCNITT-GRAY; FLASHNER, 2004).

Com foco nas condições (sucesso ou falha) de aterrissagem, Heinen e Nicolaus (2016) investigaram a dinâmica do salto mortal grupado para frente. Precedido por corrida de aproximação e impulso sobre o trampolim, o salto foi descrito em três fases: (1) lançamento, (2) voo e (3) aterrissagem (Figura 24). A fase de voo ainda subdividida em: (2a) alcance da posição grupada, (2b) permanência em postura grupada e (2c) retorno à posição estendida. 


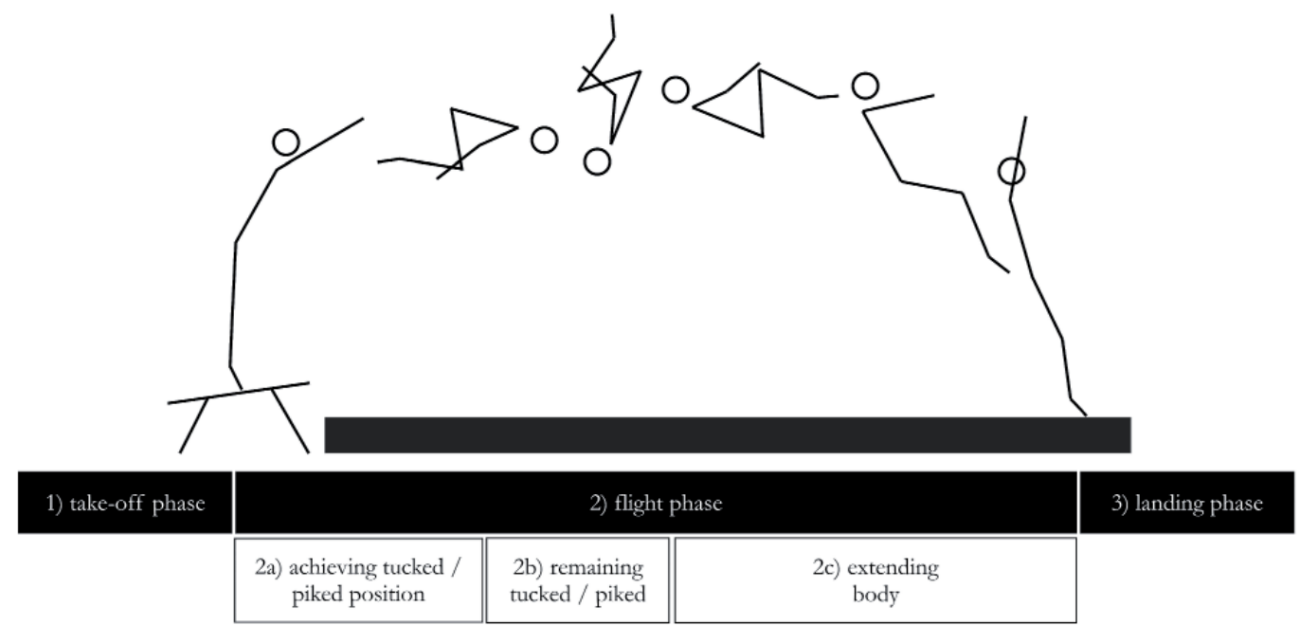

Figura 23. Fases e sequência de movimentos para o mortal grupado para frente (HEINEN; NICOLAUS, 2016).

Uma variação angular típica de 305 a $325^{\circ}$ de rotação em fase aérea foi assumida como condição de sucesso para a simulação das variáveis preditivas. Esse procedimento foi realizado em duas etapas: (1) definição da quantidade de movimento angular de maior sucesso $\left(\mathrm{H}_{\mathrm{s}}\right)$; e (2) definição das estratégias de voo com base na variação do momento de inércia $(\mathrm{J})$ para $\mathrm{H}_{\mathrm{s}+}$ (Tabela 9 e Figura 24):

Tabela 9. Parâmetros de entrada para a simulação das possibilidades de sucesso para aterrissagem de mortal grupado para frente (adaptado de HEINEN; NICOLAUS, 2016).

\begin{tabular}{|c|c|c|c|}
\hline Variável & Fase de voo & Intervalo & Discretização \\
\hline $\mathrm{H}(\mathrm{Nms})$ & 2 & $20 \mathrm{a} 60$ & 1,0 \\
\hline \multirow{3}{*}{$\mathrm{J}\left(\mathrm{kgm}^{2}\right)$} & $2 \mathrm{a} \mathrm{e} 2 \mathrm{c}$ & $11,4 \mathrm{a} 14,4$ & 0,1 \\
\cline { 2 - 4 } & $2 \mathrm{~b}$ & $2,4 \mathrm{a} 4,6$ & 0,1 \\
\hline \multirow{3}{*}{$\Delta \mathrm{t}(\mathrm{ms})$} & 2 & 800 & - \\
\cline { 2 - 4 } & $2 \mathrm{a}$ & $170 \mathrm{a} 230(21,25 \mathrm{a} 28,75 \%)$ & - \\
\cline { 2 - 4 } & $2 \mathrm{~b}$ & $0 \mathrm{a} 460(0 \mathrm{a} 57,50 \%)$ & - \\
\cline { 2 - 4 } & $2 \mathrm{c}$ & $(13,75 \mathrm{a} 78,75 \%)$ & \\
\hline
\end{tabular}
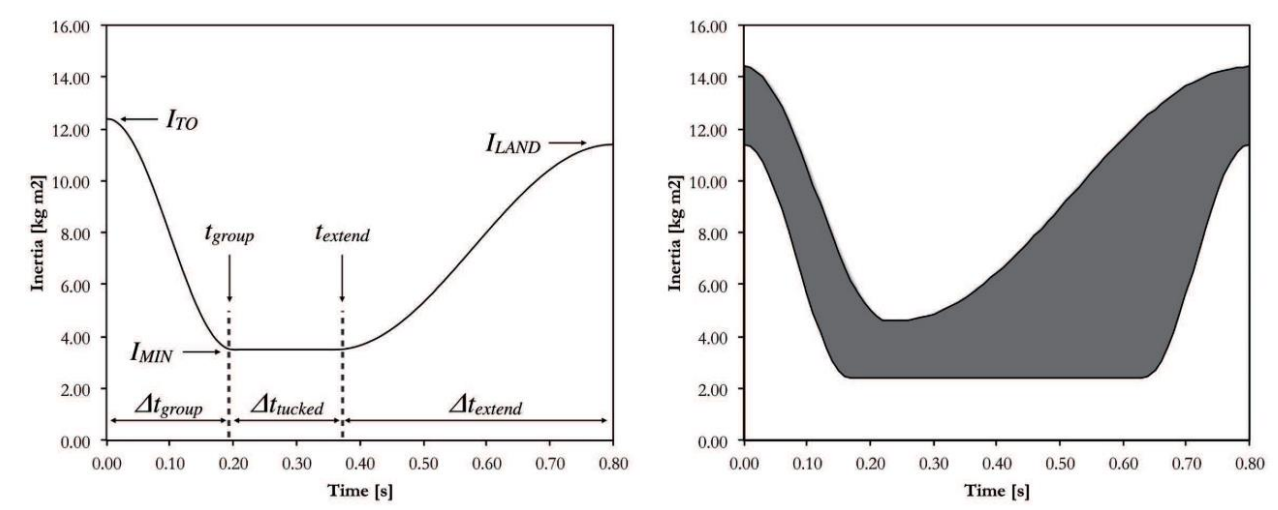

Figura 24. Limites críticos para a subdivisão das fases de voo (esquerda) e intervalo de momento de inércia assumido pelo corpo durante a simulação do mortal grupado para frente (HEINEN; NICOLAUS, 2016). 
Do total de observações simuladas de H (acima de 10 milhões), apenas 6,41\% resultaram em posição de sucesso. Entre essas, o valor de maior potencial de sucesso $(13,79 \%)$ ocorreu em 39 Nms. Dez opções de movimento representaram as condições de maior sucesso, sendo somente duas dessas (1 e 6) com 100\% de chance (Figura 25). Nesses casos, observou-se maior momento de inércia para as fases de alcance da posição grupada (2a) e retorno à posição estendida (2c); e maior tempo de voo grupado (posição $2 b$ ) e maior tempo de voo durante extensão (2c). Esses achados sinalizam um melhor aproveitamento das posições extremas (estendido e grupado) para o sucesso das chegadas de mortal para frente no solo.

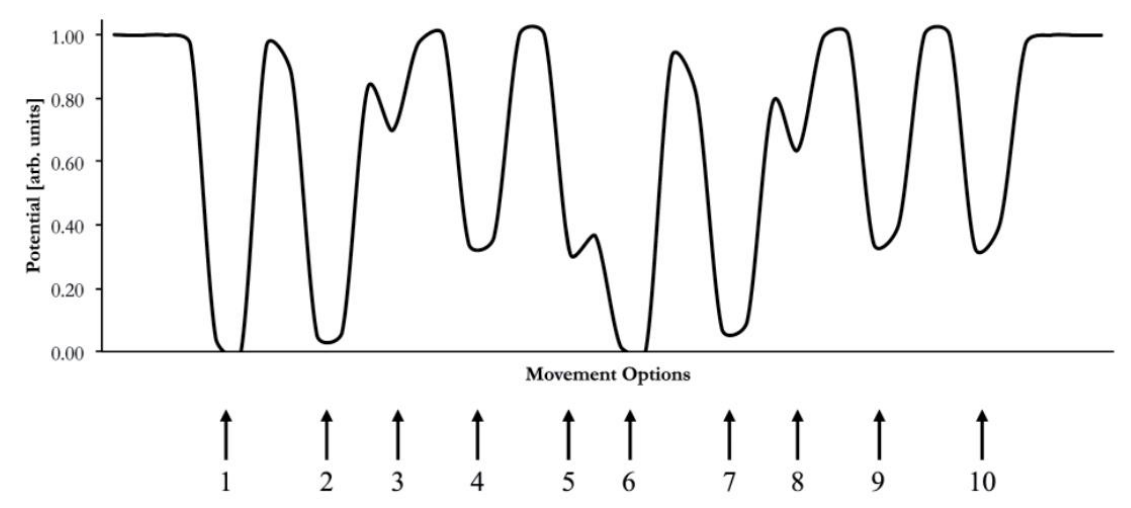

Figura 25. Projeção do potencial de aterrissagem ( com quantidade de movimento de 39 Nms (HEINEN; NICOLAUS, 2016).

Considerando as consequências mecânicas para o sucesso da aterrissagem em GA, dois aspectos de natureza neuromotora precisam ser destacados. Primeiro, a contribuição vestíbulo-ocular para orientação corporal na chegada de um elemento ginástico. Enquanto a velocidade angular da cabeça durante mortal grupado para trás pode atingir picos de $750 \%$ (BERTHOZ; POZZO, 1994), o reflexo vestíbulo-ocular é limitado a 350\% (PULASKI; ZEE; ROBINSON, 1981). Para o salto mortal para trás, Berthoz e Pozzo demonstraram que após uma rotação $235^{\circ} \mathrm{em}$ fase aérea a cabeça reduz a velocidade angular de $270^{\circ} / \mathrm{s}$ para $100 \%$, por $0,15 \mathrm{~s}$, enquanto o tronco permanece em $230 \%$ s. De acordo com os autores, nesse período de estabilização relativa o sistema vestíbulo-ocular contribui com orientação corporal para a aterrissagem no solo (Figura 26). 


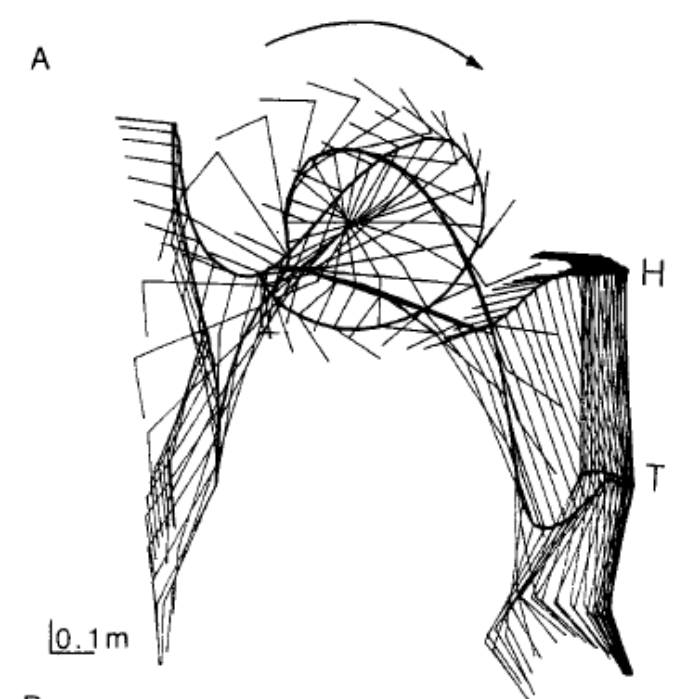

B

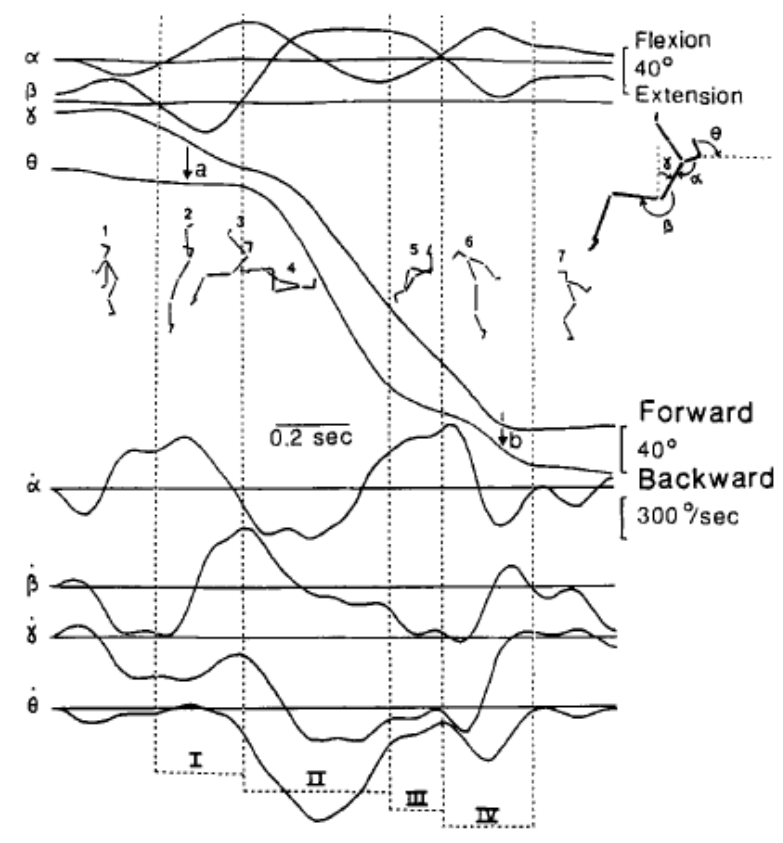

Figura 26. (A) representa a sequência de movimentos durante o mortal para trás. (B) deslocamentos e velocidades angulares do pescoço $\left(\alpha\right.$ e $\left.\alpha^{\prime}\right)$, quadril $\left(\beta\right.$ e $\left.\beta^{\prime}\right)$, tronco $\left(\gamma\right.$ e $\left.\gamma^{\prime}\right)$ e cabeça $\left(\theta\right.$ e $\left.\theta^{\prime}\right)$. O movimento foi dividido em 4 fases considerando os períodos de estabilização relativa da cabeça (I e III) (BERTHOZ; POZZO, 1994).

Esses achados corroboram com as investigações de Davlin e colaboradores (2001a; 2001b). Em dois estudos, os autores testaram os efeitos da oclusão visão na cinemática e nas condições de aterrissagem para o salto mortal grupado para trás. Dez ginastas de nível competitivo (11,6 $\pm 2,7$ anos; não elite) foram avaliadas aterrissando em tapetes sobre blocos de espuma. As condições de aterrissagem foram pontuadas em (FIG, 2017): 0 - controladas corretamente; 1, passo grande ou múltiplos pequenos passos; 2, múltiplos grandes passos ou contato das mãos no solo. 
O primeiro estudo (DAVLIN; SANDS; SHULTZ, 2001a) incluiu as condições visuais: plena, periférica (limitada em $100^{\circ}$ ), focal (limitada em $60^{\circ}$ ) e ocluída. Para as condições ocluídas as ginastas utilizaram óculos de natação modificados. No segundo estudo (DAVLIN; SANDS; SHULTZ, 2001b), foram outras 4 condições visuais: plena $(n=5)$, ocluída na $1^{\mathrm{a}}$ metade do mortal $\left(\mathrm{n}=5\right.$, do impulso à posição invertida), ocluída na $2^{\mathrm{a}}$ metade do mortal ( $\mathrm{n}=5$, da posição invertida à aterrissagem) e ocluída $(\mathrm{n}=5)$. As visões parciais decorreram da interrupção da luz ambiente controlada por sensor infravermelho na posição invertida. Nas duas investigações os resultados foram queda de desempenho progressivo a perda de informação visual (Tabelas 10, Tabela 11 e Figura 27).

Tabela 10. Cinemática e condições de aterrissagem para mortal grupado para trás com variação do campo visual (vision - normal; peripheral - restrito em $100^{\circ}$ ou $60^{\circ}$; no vision - vedado) (DAVLIN; SANDS; SHULTZ, 2001a).

\begin{tabular}{|c|c|c|c|c|c|c|c|c|}
\hline \multirow[t]{3}{*}{ Measure } & \multicolumn{2}{|c|}{ Vision } & \multicolumn{4}{|c|}{ Pcriphcral Vision } & \multicolumn{2}{|c|}{ No Vision } \\
\hline & \multirow[t]{2}{*}{$M$} & \multirow[t]{2}{*}{ SD } & \multicolumn{2}{|c|}{$100^{\circ}-1$} & \multicolumn{2}{|c|}{$60^{\circ}$} & \multirow[t]{2}{*}{$M$} & \multirow[t]{2}{*}{$S D$} \\
\hline & & & $M$ & $S D$ & $M$ & $S D$ & & \\
\hline Flight time, msec. & 661.0 & 42.5 & 663.0 & 45.8 & 661.0 & 44.2 & 665.0 & 41.0 \\
\hline Initiation of closing time, $\%$ & 5.6 & 2.1 & 5.2 & 8.3 & 5.1 & 5.6 & 5.1 & 1.5 \\
\hline Angle, deg. & 130.0 & 10.8 & 129.0 & 12.6 & 130.0 & 10.7 & 127.0 & 10.4 \\
\hline Peak closing velocity time, \% & 15.3 & 8.8 & 16.2 & 2.2 & 15.9 & 1.8 & 15.3 & 2.5 \\
\hline Angle, deg. & 98.0 & 8.5 & 98.0 & 13.3 & 99.0 & 9.1 & 97.0 & 11.2 \\
\hline Vclocity, $\%$ sec. & -603.0 & 78.2 & -606.0 & 81.8 & -586.0 & 69.9 & -609.0 & 87.5 \\
\hline Initiation of opening time, \% & 33.7 & $\begin{array}{r}10.2 \\
4.8\end{array}$ & 32.1 & 4.0 & 30.3 & 2.5 & 31.4 & 5.1 \\
\hline Angle, deg. & 54.0 & 10.0 & 57.0 & 8.6 & 58.0 & 5.3 & 55.0 & 9.9 \\
\hline Peak opening velocity time, $\%$ & 70.8 & 3.4 & 70.4 & 3.6 & 67.2 & 11.4 & 69.4 & 3.3 \\
\hline Angle, deg. & 115.0 & 8.5 & 114.0 & 7.9 & 108.0 & 9.3 & 116.0 & 11.2 \\
\hline Velocity, $\% / s e c$. & 625.0 & 89.8 & 591.0 & 105.7 & 574.0 & 78.3 & 623.0 & 94.6 \\
\hline Landing balance & 0.8 & 0.3 & 0.9 & 0.3 & 1.0 & 0.3 & 1.3 & 0.3 \\
\hline
\end{tabular}

Tabela 11. Tempo de estabilização da aterrissagem no salto mortal para trás com variação visual temporal (vision - normal; first half - normal na $1^{\mathrm{a}}$ metade do voo; second half - normal na $2^{\mathrm{a}}$ metade do voo; no vision vedado) (DAVLIN; SANDS; SHULTZ, 2001b).

\begin{tabular}{lcc}
\hline Condition & $M$ & $S D$ \\
\hline Vision & 0.78 & .26 \\
Vision first half & 1.08 & $.30^{*}$ \\
Vision second half & 1.00 & $.40^{*}$ \\
No vision & 1.30 & $.25^{*}$ \\
\hline
\end{tabular}

*Significantly different from the vision condition $(p<.05)$. 

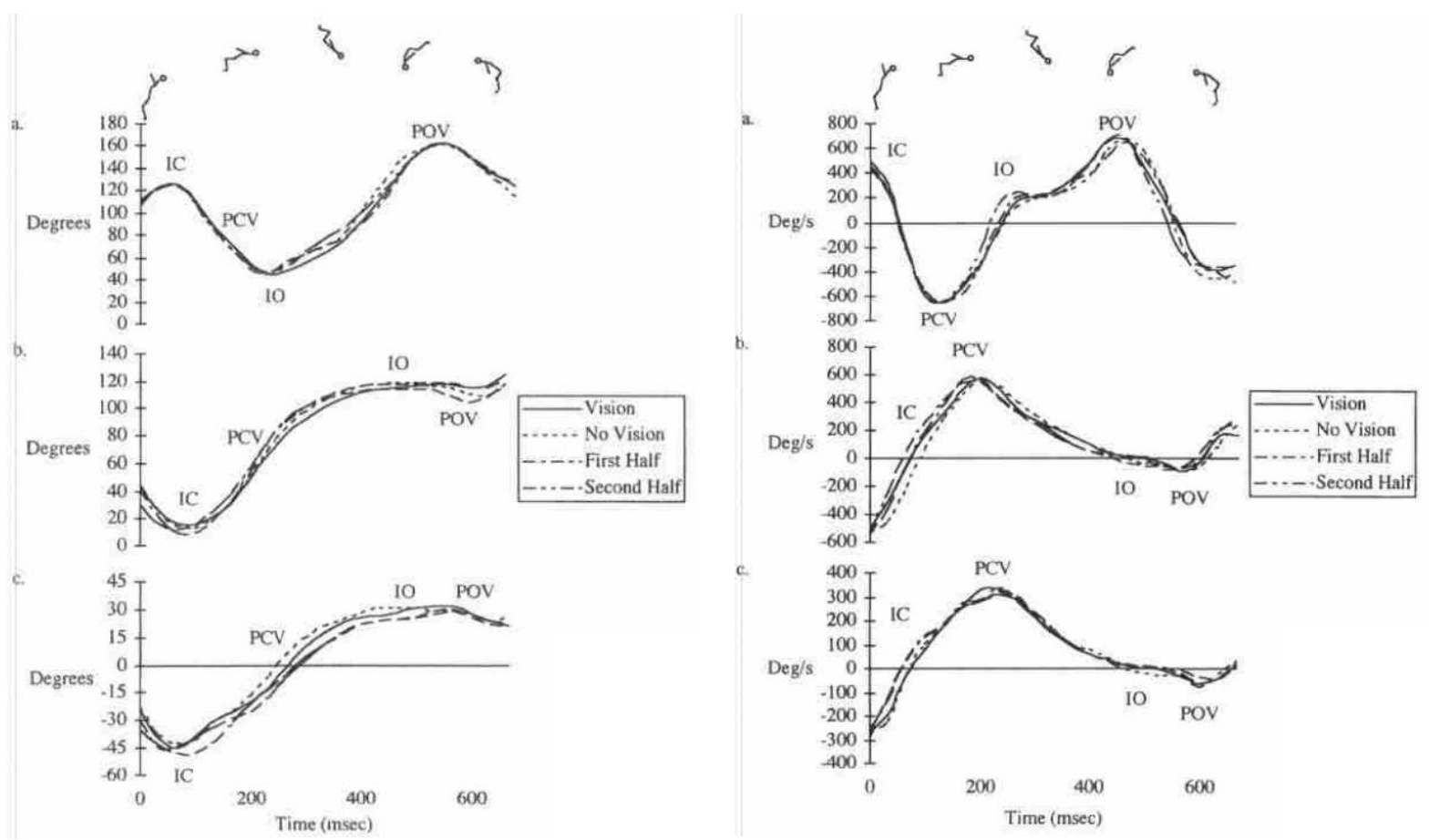

Figura 27. Ângulo e velocidade angular do (a) joelho, (b) quadril e (c) tronco durante o salto mortal para trás com variação visual temporal (vision - normal; first half - normal na $1^{\mathrm{a}}$ metade do voo; second half - normal na $2^{\mathrm{a}}$ metade do voo; no vision - vedado) (DAVLIN; SANDS; SHULTZ, 2001b).

O segundo aspecto neuromotor de destaque para aterrissagens em GA é o controle de movimentos (feedback e feedforward) para colisão. Em virtude do curto tempo para absorção de impacto, o padrão de ativação muscular para aterrissagens é sempre pré-programado (DYHRE-POULSEN; SIMONSEN; VOIGT, 1991). Essa pré-ativação muscular, ou ajuste postural antecipatório, inicia cerca de 150 a 200 ms antes do contato inicial. Considerando um mesmo músculo, independente da altura da queda, esse padrão temporal não altera (DUNCAN; MCDONAGH, 2000). Picos mais expressivos de ativação muscular, ou ajustes posturais compensatórios, ocorrem entre 50 e 200 ms após o contato seguido de queda progressiva. Em ambos os casos, pré e pós-impacto, a intensidade de ativação muscular modifica em resposta à maior ou menor demanda de absorção (DYHRE-POULSEN; SIMONSEN; VOIGT, 1991; ARAMPATZIS; MOREY-KLAPSING; BRÜGGEMANN, 2003) (Tabela 12, Figura 28 e Figura 29). 
Tabela 12. Comparação das latências EMG (ms) para três condições de aterrissagens (DUNCAN; MCDONAGH, 2000).

\begin{tabular}{|c|c|c|c|c|c|c|}
\hline & $\begin{array}{c}1 \\
0 \cdot 45 \mathrm{~m} \text { landing }\end{array}$ & $\begin{array}{c}2 \\
0 \cdot 70 \mathrm{~m} \text { landing }\end{array}$ & $\begin{array}{c}3 \\
P(1 \text { vs. 2) }\end{array}$ & $\begin{array}{c}4 \\
\text { Surprise landing }\end{array}$ & $\begin{array}{c}5 \\
P(1 \text { vs. } 4)\end{array}$ & $\begin{array}{c}6 \\
P(2 v s .4)\end{array}$ \\
\hline Gastrocnemius & $153 \pm 54$ & $208 \pm 37$ & $0 \cdot 001 *$ & $170 \pm 41$ & $0 \cdot 240$ & $0 \cdot 004^{*}$ \\
\hline Soleus & $148 \pm 67$ & $207 \pm 50$ & $0 \cdot 005^{*}$ & $176 \pm 39$ & $0 \cdot 110$ & $0 \cdot 007 *$ \\
\hline Tibialis anterior & $179 \pm 77$ & $225 \pm 43$ & $0 \cdot 046^{*}$ & $192 \pm 50$ & $0 \cdot 476$ & $0 \cdot 0003 *$ \\
\hline Rectus femoris & $206 \pm 61$ & $234 \pm 60$ & $0 \cdot 040^{*}$ & $192 \pm 70$ & $0 \cdot 375$ & $0 \cdot 005^{*}$ \\
\hline Biceps femoris & $163 \pm 61$ & $212 \pm 37$ & $0 \cdot 006^{*}$ & $183 \pm 58$ & $0 \cdot 053$ & $0 \cdot 03^{*}$ \\
\hline
\end{tabular}

Values are means \pm s.D. of determinations from 10 subjects. $*$ Significant difference $(P<0 \cdot 05$, Student's two-tailed $t$ test for paired values).

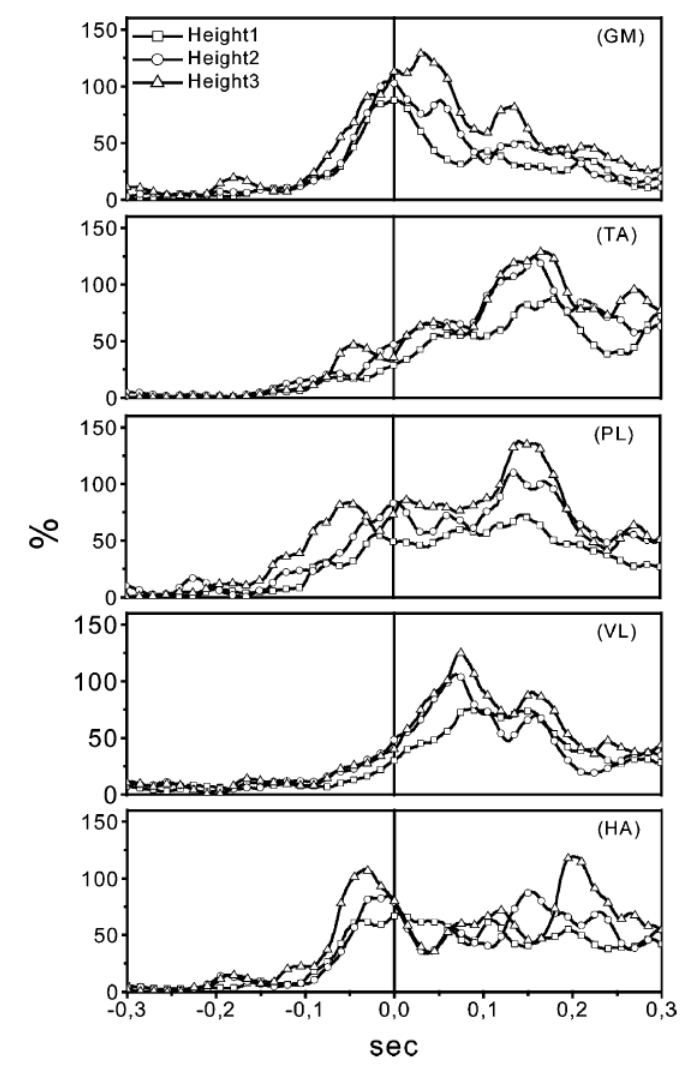

Figura 28. Ativação EMG normalizada durante aterrissagens em 3 alturas (1,0,1,5 e 2,0 m). A linha vertical representa o tempo de contato com o solo. GM - gastrocnêmio medial, TA - tibial anterior, PL - fibular longo, VL - vasto lateral e HA - isquiotibiais (ARAMPATZIS; MOREY-KLAPSING; BRÜGGEMANN, 2003). 


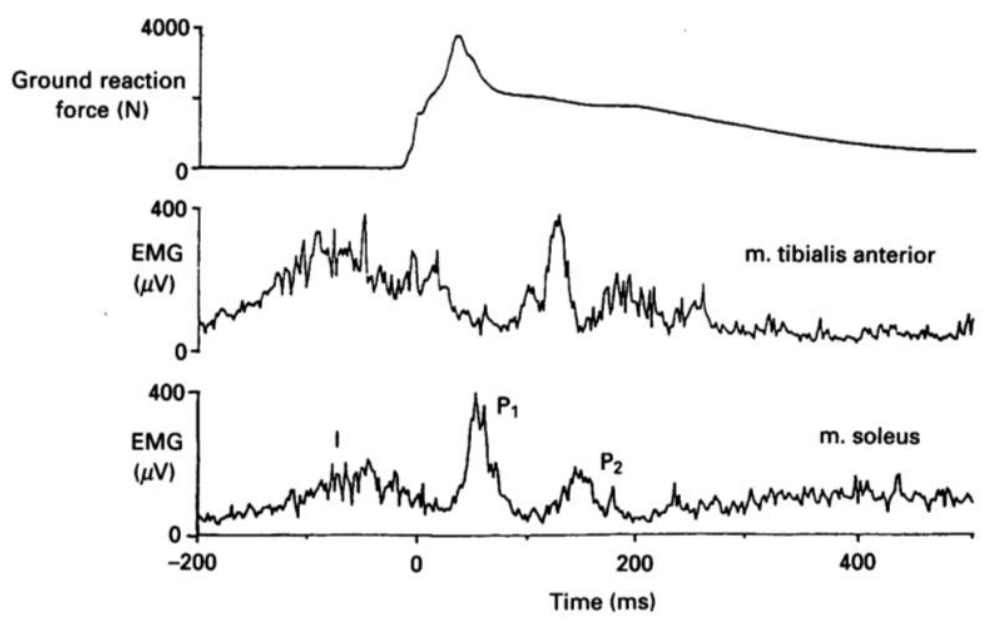

Figura 29. Padrão de atividade muscular durante aterrissagem em profundidade (0,6 m) (Adaptado de DYHREPOULSEN; SIMONSEN; VOIGT, 1991).

Sheets e Hubbard (2007) identificaram regiões de contorno para o equilíbrio dinâmico nas aterrissagens de mortal simples e duplo mortal, ambos estendidos e para trás, nas barras assimétricas. De acordo com os autores, quando as velocidades angulares de colisão foram baixas, a ginasta quase sempre foi capaz de manter o equilíbrio nas aterrissagens, desde que o CM estivesse sobre a base de apoio no instante de contato com o solo. No entanto, quando o corpo atingiu o solo com maior velocidade angular, como no caso do duplo mortal, fez-se necessário uma chegada com maior inclinação em relação à vertical, projetando o CM para fora da base de apoio na colisão (Figura 30).

Além disso, o equilíbrio dinâmico dependeu da produção de um impulso rotacional para reposicionar o CM sobre a base de apoio, ao final da aterrissagem. Os autores também observaram que com maior velocidade angular, a janela de ângulo de aterrissagem aumentava, mas, por outro lado, a janela temporal de impulso compensatório diminuía. Com maior quantidade de movimento em fase aérea, o duplo mortal exigiu maior velocidade horizontal de lançamento e maior contribuição do momento linear horizontal na fase de impulso para aterrissagem. 


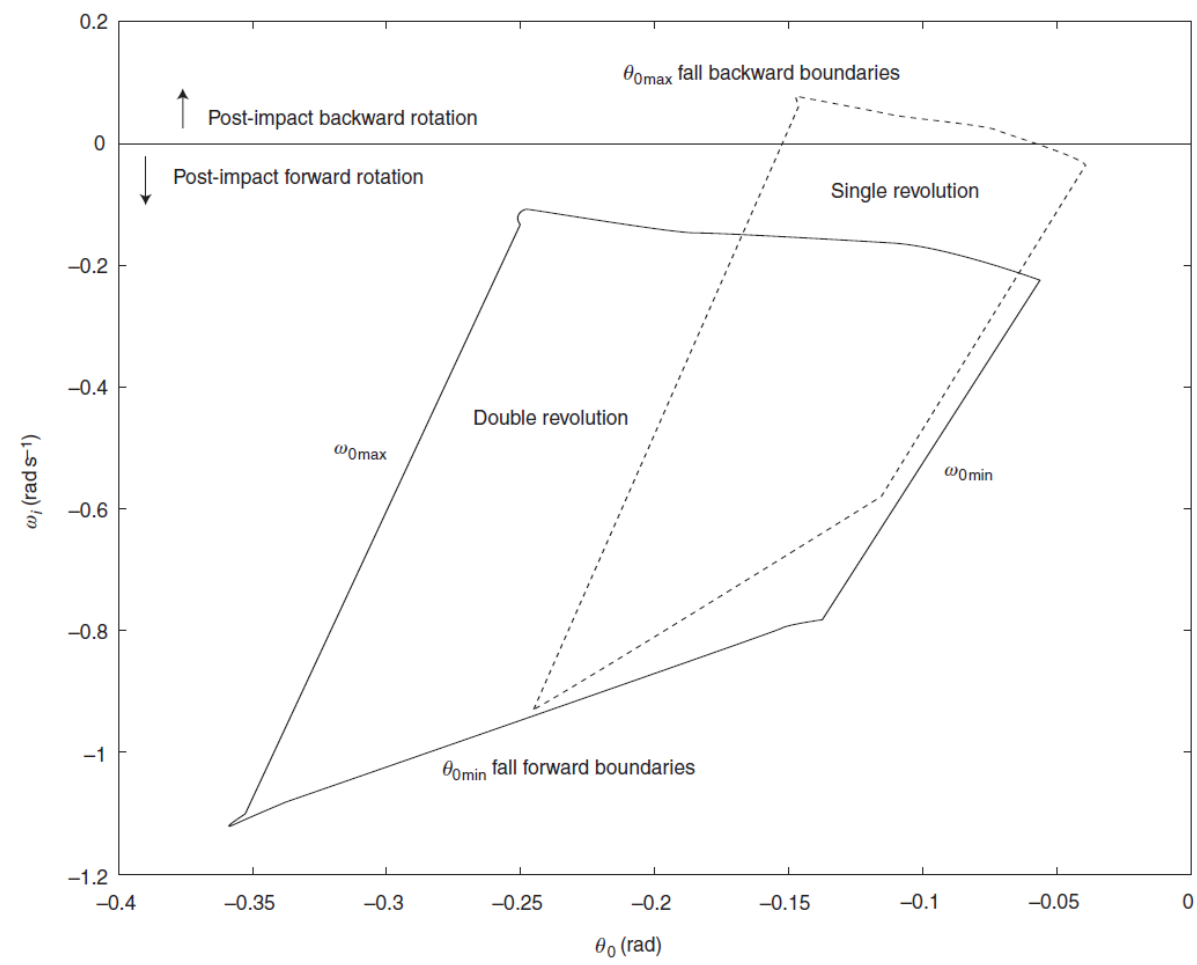

Figura 30. Regiões de velocidade angular pós-impacto $\left(\omega_{\mathrm{i}}\right)$ resultantes de ângulo corporal de pré-impacto $\left(\theta_{0}\right)$ para as condições de equilíbrio nas aterrissagens de barras assimétricas, em mortal simples e duplo mortal (SHEETS; HUBBARD, 2007).

Num estudo com saída de trave em mortal para trás, Gittoes e colaboradores (2013) observaram que o equilíbrio nas aterrissagens possui alta dependência da capacidade de compensar a quantidade de movimento linear do touchdown. Comparando as saídas de mortal simples nas posturas grupado e carpado (Figura 31), esses autores encontraram uma predominância das posições angulares de joelho, variando em 19,8\% (tornozelo = 10,9\%; quadril $=17,9 \%$ ), e das velocidades angulares de quadril 30,9\% (tornozelo $=13,6 \%$; joelho $=$ $15,4 \%)$. Isso sugere uma limitação do tornozelo como estratégia de ajuste da orientação corporal e uma forte dependência de quadril, quando considerado a variação de altura máxima de voo. 


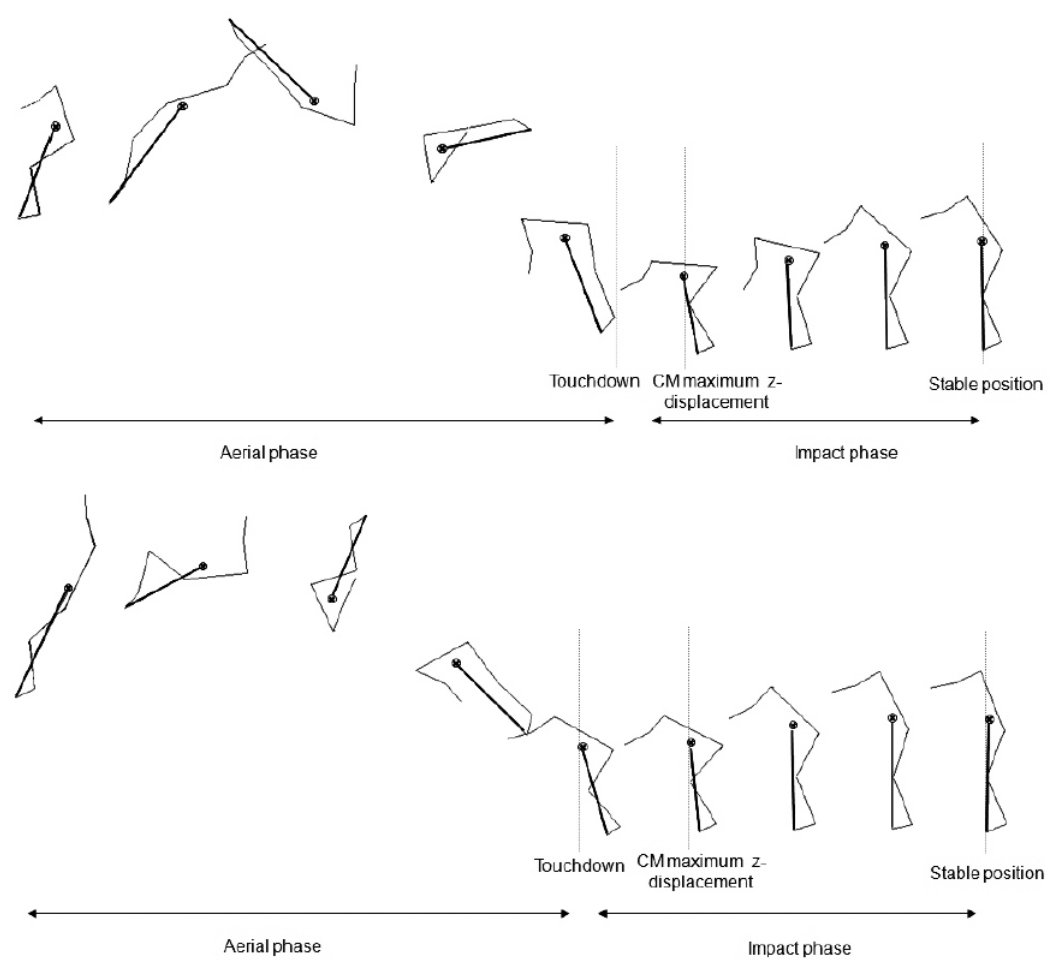

Figura 31. Fases aérea e de impacto na saída de trave em mortal para trás: carpado (superior) e grupado (inferior). Orientação corporal representada pelo segmento que une o centro articular metatarsofalangeano ao centro de massa $(\otimes)$ (GITTOES; IRWIN; KERWIN, 2013).

Os estudos abordados até aqui favorecem a compreensão de diferentes fatores biomecânicos associados ao duplo mortal estendido na barra fixa. Com destaque às fases de lançamento e voo, pode-se afirmar que a caracterização da saída de barra envolve: (1) estreita janela de lançamento (57 ms), (2) baixo ângulo de lançamento (352 graus), (3) alta quantidade de movimento angular (> $\left.65 \mathrm{kgm}^{2} / \mathrm{s}\right)$, (4) elevados picos de momento (> $400 \mathrm{Nm}$ e $>520 \mathrm{Nm}$, respectivamente para quadril e ombro), (5) alto momento de inércia e, consequente, (6) baixa velocidade angular.

A literatura abordada também nos permite algumas afirmações para as condições de aterrissagem com sucesso. Entre essas, podemos observar: baixa taxa de sucesso em competições (1/20) e diferenciação angular indefinida para condições de aterrissagem nas saídas de barra fixa (sucesso: $73^{\circ}$; falhas: 69 a $86^{\circ}$ ), perfis de sucesso para quantidade de movimento angular (39 Nms) e deslocamento angular (305-325 $)$ nos mortais para frente no solo, e padrão temporal regular de ajuste postural antecipatório nas aterrissagens (entre 150$200 \mathrm{~ms}$ ).

Conforme discutido na introdução deste estudo, as penalidades para falhas nas aterrissagens têm efeito significativo no pódio de um ginasta. E apesar das elucidações acima, pouco se conhece sobre o comportamento biomecânico para chegadas de sucesso na barra 
fixa; sobretudo, com diferenciação entre os tipos de falha (recuo ou avanço) e as condições suficientes para o sucesso (sem passo ou queda). Este trabalho propõe uma exploração dos fatores biomecânicos que caracterize nas saídas em barra fixa uma aterrissagem de sucesso, uma chegada "cravada". 


\section{MATERIAIS E MÉTODOS}

Para investigar o comportamento biomecânico das chegadas em ginástica artística, este estudo adota modelos teóricos e experimentais in loco do movimento de duplo mortal estendido na barra fixa (DSBS - Double Salto Backward Stretched). Ao final deste capítulo, a Figura 40 apresenta um resumo dos procedimentos adotados nessa investigação.

\subsection{CASUÍSTICA}

A amostra deste estudo foi composta por 7 ginastas $(63,5 \pm 6,7 \mathrm{~kg}, 1,67 \pm 0,04 \mathrm{~m}) \mathrm{de}$ elite com participação voluntária expressa em Termo de Consentimento Livre e Esclarecido (Anexo I) aprovado pelo Comitê de Ética da EEFE-USP (Anexo II, Plataforma Brasil CAAE 60049516.0.0000.5391). Esses atletas representam os titulares em barra fixa nos últimos 2 anos da seleção brasileira de ginástica artística masculina.

Para caracterizar os aspectos biomecânicos que definem a habilidade esportiva (nível de confiança $=90 \%$ ) (DISS, 2001), os ginastas foram instruídos a realizar o DSBS (Figura 32), sem passos ou queda na aterrissagem. Foram consideradas válidas as saídas com simetria bilateral (i.e., membros direito e esquerdo continuamente alinhados durante todo o movimento), sem deslocamento lateral na chegada ao solo.

\subsection{PROCEDIMENTOS EXPERIMENTAIS}

Previsto no Código de Pontuação da FIG (2017), o DSBS é um elemento do grupo C (0,3 pontos) que consiste em balanço na barra (giro gigante), dupla rotação em torno do eixo médio-lateral durante o voo na postura quasi-ortostática (estendida) e aterrissagem (ou chegada). A escolha pelo DSBS foi motivada por duas conveniências metodológicas: (1) por pertencer a uma família de saídas ginásticas restritas a movimentos bidimensionais, o que simplifica os procedimentos experimentais e o modelo físico-matemático; e (2) por favorecer a uniformidade amostral, uma vez que trata-se de um elemento de grande familiaridade para o grupo experimental. 
Para efeitos de modelagem, a análise dessa habilidade motora foi dividida em duas fases: (1) barra (movimentos pendulares), (2) aérea (movimentos de voo) (Figura 33). Foram fixados marcadores para o rastreamento dos seguintes pontos anatômicos e técnicos: maléolo lateral, extremidades lateral da linha articular do joelho, trocânter maior do fêmur, linha axilar posterior e processo estiloide; além de duas marcas num fio prumo para definir o plano de calibração. A Figura 34 ilustra a configuração do ambiente de coleta.

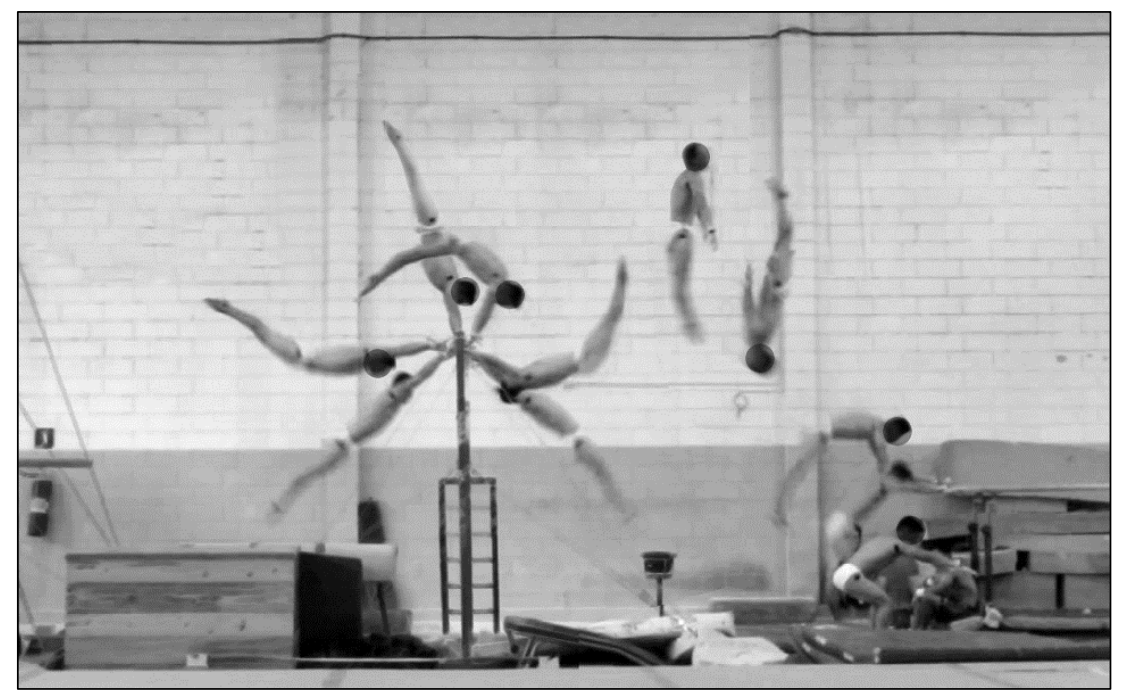

Figura 32. Sequência de movimentos para a saída de barra fixa em duplo mortal estendido para trás (DSBS): giro gigante (balanço em barra fixa), lançamento, voo (rotação em torno do $\mathrm{CM}$ ) e chegada (ou aterrissagem).

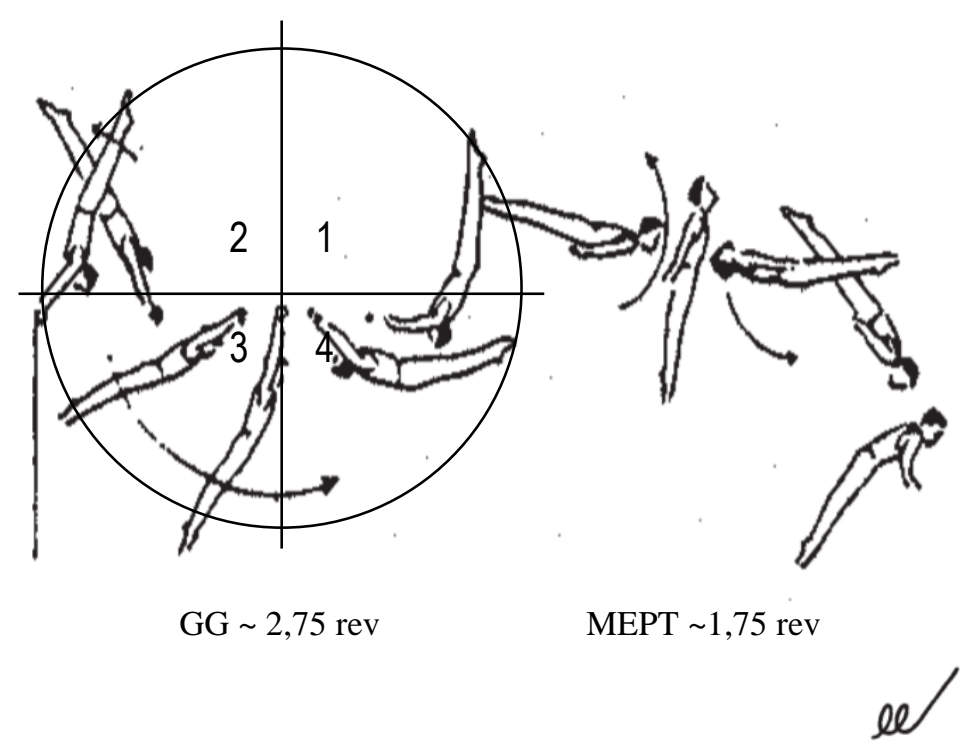

Figura 33. Saída de barra em DSBS (FIG, 2017). Quadrantes da fase de barra ( $1 \mathrm{a} 4^{\mathrm{a}}$ ) e rotações no plano sagital em ambas as fases: GG - giro gigante; MEPT - mortal estendido para trás). 
Os dados foram amostrados em $100 \mathrm{~Hz}$ e a reconstrução 2D das coordenadas segmentares espaciais ( $\mathrm{X}$ e Y; ântero-posterior e vertical, respectivamente) foi obtida por Fractional Linear Transfomation (FLT) (ROBERTSON; CALDWELL, 2004). Assim, as distâncias entre os marcadores foram escalonadas pela razão da distância entre os pontos controle na tela da câmera e as medidas físicas de referência correspondentes. Os dados brutos de posição foram suavizados por filtro digital Butterworth de $4^{\mathrm{a}}$ ordem, passa-baixa com frequência de corte de $8 \mathrm{~Hz}$, sem atraso de fase. Esse procedimento foi realizado nos dados originais de posição, antes de estimar a primeira derivada por diferenças finitas para cômputo das velocidades. O mesmo filtro foi novamente aplicado aos dados de velocidade, antes da nova diferenciação para estimava das acelerações, como estratégia de minimização de ruídos (OKAZAKI; TEIXEIRA; RODACKI, 2007) nos momentos articulares decorrentes dos artefatos de movimento. Parâmetros dessa grandeza (4 a $12 \mathrm{~Hz}$, entre $4^{\mathrm{a}}$ e $5^{\mathrm{a}}$ ordem) têm sido observados na literatura para filtragem de movimentos ginástico de mesma natureza (BRÜGGEMANN et al., 1994; BRÜGGEMANN et al., 1994; ARAMPATZIS; BRUGGEMANN, 1999; REQUEJO; MCNITT-GRAY; FLASHNER, 2004). Posterior a esses estudos, Okazaki et al. (2006) observaram um melhor ajuste para os dados cinemáticos amostrados a $100 \mathrm{~Hz}$ em frequência de corte a $8 \mathrm{~Hz}$.

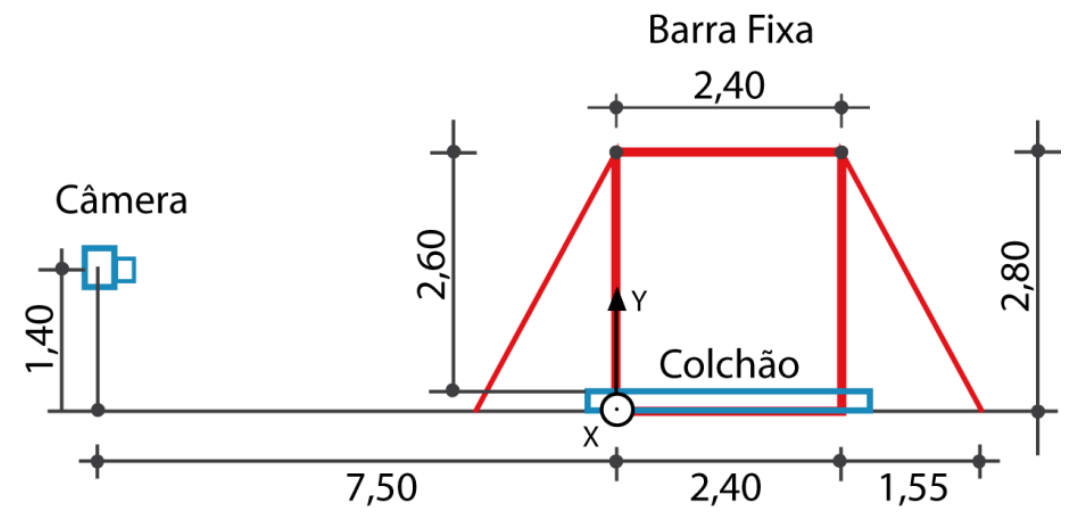

Figura 34. Posição da câmera (m), posição do colchão $(\mathrm{m})$, dimensões da barra fixa $(\mathrm{m})$ e sistema de referência global (X, Y).

\subsection{EQUIPAMENTOS}

A coleta de dados ocorreu em quatro Centros de Treinamentos em Ginástica Artística da região sudeste do Brasil. A análise dos dados foi resultado da integração de esforços entre o Laboratório de Biomecânica da Escola de Educação Física e Esporte (EEFE), o Laboratório 
de Biomecatrônica da Escola Politécnica (EP), ambos na Universidade de São Paulo, e o Centro Universitário FEI em São Bernardo do Campo, SP. Para o registro dos dados experimentais foram utilizados: uma câmera infravermelho $(100 \mathrm{~Hz}$, acurácia $<1 \mathrm{~mm}, \mathrm{FOV}=$ 46,2 x 34,7 , OptiTrack, NaturalPoint) (Figura 35a) com ambientação MR3 (Noraxon), um conjunto de marcadores retrorreflexivos $(n=7)$ (Figura 35b) e um fio de prumo de dimensões físicas conhecidas. O rastreamento e a reconstrução das coordenadas segmentares foram obtidos por meio do software Tracker@ e o processamento das variáveis dinâmicas e as simulações em ambiente MatLab ${ }^{\mathrm{TM}}$.

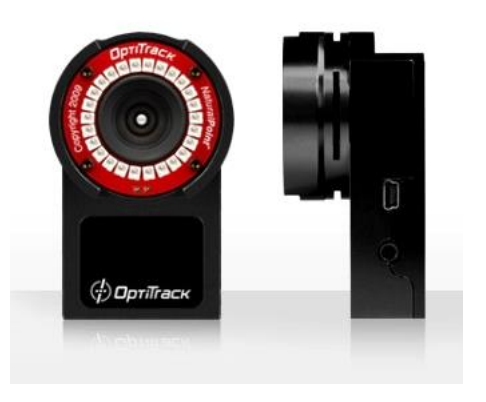

a

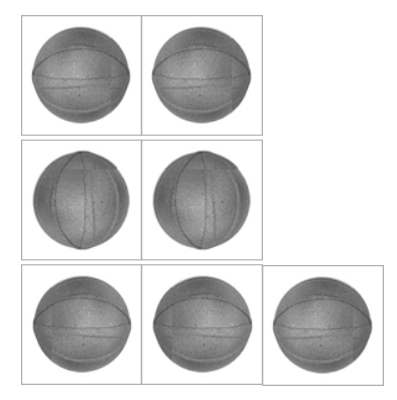

b

Figura 35. Hardwares do sistema para análise cinemática: (a) câmera OptiTrack: Flex3 e (b) marcadores retrorreflexivos.

\subsection{MODELAGEM BIOMECÂNICA}

\subsubsection{Parâmetros antropométricos}

Em virtude da similaridade amostral (ginastas), o presente estudo adotou o modelo antropométrico de Yeadon (1990) (Tabela 13) para escalonar, de acordo com a massa e a estatura, os parâmetros segmentares de cada sujeito.

Tabela 13. Parâmetros antropométricos segmentares de referência (HILEY; YEADON, 2016).

\begin{tabular}{|c|cccc|}
\hline & perna-pé* & coxa $^{*}$ & tronco-cabeça & membro superior* \\
\hline$m[\mathrm{~kg}]$ & 8,38 & 16,68 & 36,42 & 8,42 \\
\hline$l[\mathrm{~m}]$ & 0,40 & 0,40 & 0,52 & 0,57 \\
\hline$l_{C M}[\mathrm{~m}]$ & 0,23 & 0,17 & 0,17 & 0,32 \\
\hline$J\left[\mathrm{kgm}^{2}\right]$ & 0,21 & 0,24 & 1,77 & 0,28 \\
\hline
\end{tabular}

Legenda: $m$ - massa do segmento, $l$ - comprimento do segmento, $l_{C M}$ - distância longitudinal do CM segmentar considerando a articulação mais próxima do eixo de rotação da barra e $J$ - momento de inércia em relação ao respectivo CM. *Dados referentes a ambos os lados. 


\subsubsection{Cinemática do Duplo Mortal Estendido para Trás}

A partir das coordenadas dos centros articulares no movimento de DSBS foram determinados o comprimento e a orientação espacial de cada segmento corporal:

$$
\begin{aligned}
& \vec{s}=C_{P}-C_{D}, \\
& \theta_{S}=\tan ^{-1}\left[\left(C_{P Y}-C_{D Y}\right) /\left(C_{P X}-C_{D X}\right)\right] .
\end{aligned}
$$

onde os pontos $C_{P}$ e $C_{D}$ representam as articulações proximal e distal, respectivamente; $\vec{s}$ é o vetor que define segmento e $\theta_{S}$ descreve a orientação do segmento em movimento plano.

O CM segmentar foi determinado por uma razão do comprimento longitudinal do mesmo (Tabela 13), com origem na articulação proximal. Na sequência, com base na massa segmentar e posição do CM segmentar, a posição do CM corporal foi calculada por (NIGG; HERZOG, 2009):

$$
\vec{r}_{C M}=\frac{1}{m} \sum_{i=1}^{n} m_{i} \vec{r}_{i}
$$

onde $m_{i}$ é a massa e $\vec{r}_{i}$ é a posição do CM do i-ésimo segmento e $n$ é o número de segmentos $(n=4)$.

O corpo do ginasta foi modelado por um sistema multicorpo plano composto por quatro segmentos rígidos conectados por juntas de revolução ideais, em 6 graus de liberdade (Figura 36). Ainda que os segmentos do corpo humano não sejam perfeitamente rígidos, tal simplificação foi adotada para tornar solucionáveis as equações de movimento aplicadas ao modelo biomecânico (AMADIO et al., 1996; YEADON; KING, 2008; NIGG; HERZOG, 2009). 


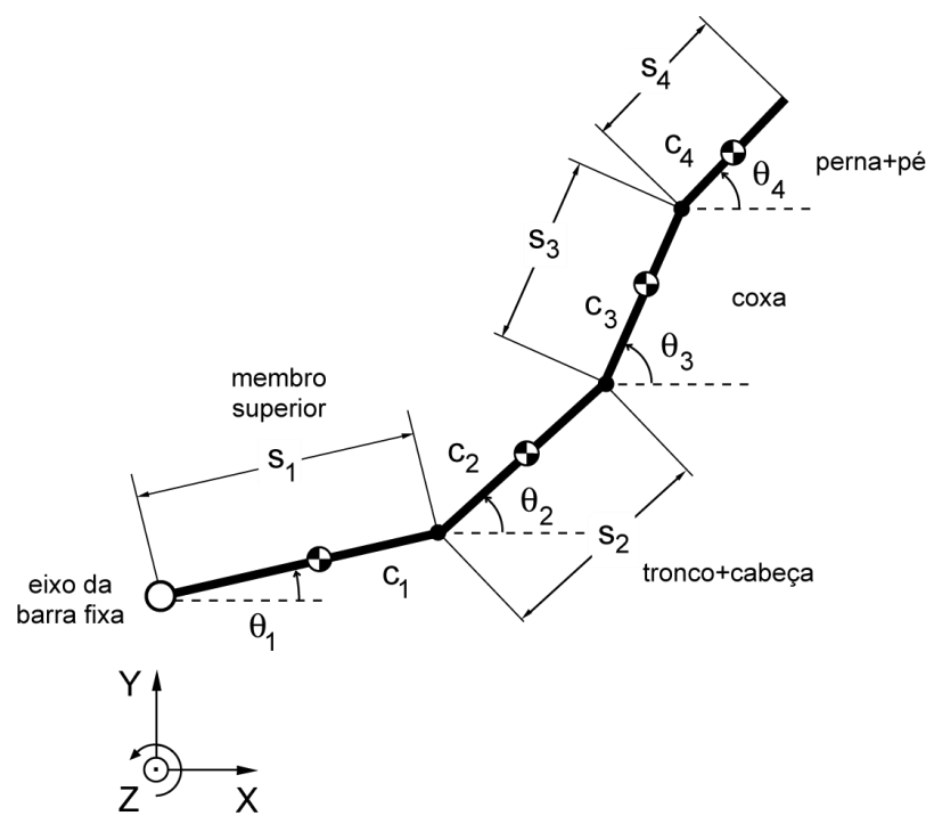

Figura 36. Modelo cinemático 2D para saída de barra em DSBS.

As velocidades e acelerações (lineares e angulares) foram obtidas pela diferenciação de primeira e segunda ordens, respectivamente, do vetor posição em relação ao tempo:

$\vec{v}=\dot{\vec{r}}=\frac{d \vec{r}}{d t}$,

$\vec{a}=\ddot{\vec{r}}=\frac{d^{2} \vec{r}}{d t^{2}}$,

$\omega=\dot{\theta}=\frac{d \theta}{d t}$,

$\alpha=\ddot{\theta}=\frac{d^{2} \theta}{d t^{2}}$.

onde $\vec{v}$ é a velocidade do CM, $\vec{r}$ é a posição do $\mathrm{CM}, \omega$ é a velocidade angular do corpo, $\theta$ é o ângulo entre a direção longitudinal do segmento e o plano horizontal, $\omega$ é a velocidade angular e $\alpha$ é a aceleração angular do corpo. 


\subsubsection{Cinética do Duplo Mortal Estendido para Trás}

\subsubsection{Quantidade de movimento e energia mecânica}

Considerando o corpo simétrico em relação ao plano de referência (XY), a quantidade de movimento linear $\left(\vec{Q}_{i}\right)$ e quantidade de movimento angular $(H)$ em relação ao CM para cada segmento foram definidas por (FRANÇA; MATSUMURA, 2011):

$$
\begin{aligned}
& \vec{Q}_{i}=m_{i} \vec{v}_{i}, \\
& H_{S_{C M}, i}=J_{i} \omega_{i}, \\
& H_{C M}=\left.\sum_{i=1}^{n}\left(\vec{r}_{i}-\vec{r}_{C M}\right)^{\wedge} \vec{Q}_{i}\right|_{z}+\sum_{i=1}^{n} H_{S_{C M}, i},
\end{aligned}
$$

onde $\vec{Q}_{i}$ é a quantidade de movimento linear do segmento, $m_{i}$ é a massa do segmento, $\vec{v}_{i}$ é a velocidade do centro de massa do segmento, $H_{S_{C M} i}$ é a quantidade de movimento angular do segmento em relação ao próprio $\mathrm{CM}, J_{i}$ é o momento de inércia do segmento em relação ao $\mathrm{CM}$ do mesmo segmento, $\omega_{i}$ é a velocidade angular do segmento, $H_{C M}$ é a quantidade de movimento angular de todo o corpo em relação ao $\mathrm{CM}, \vec{r}_{i}$ é o vetor posição de centro de massa de cada segmento e $\vec{r}_{C M}$ é o vetor posição do centro de massa corporal.

A energia mecânica total do sistema foi definida pela soma das energias potencial gravitacional e cinética dos segmentos:

$$
\begin{aligned}
& U_{i}=m_{i} g r_{y, i}, \\
& K_{i}=\frac{1}{2} m_{i} v_{i}^{2}, \\
& E_{m}=\sum_{i=1}^{n}\left(U_{i}+K_{i}\right),
\end{aligned}
$$


onde $U_{i}$ é a energia potencial de cada segmento, $m_{i}$ é a massa do segmento, $g$ é a aceleração gravitacional, $r_{y, i}$ é a posição vertical do CM de cada segmento, $K_{i}$ é a energia cinética de cada segmento, $v_{i}$ é o módulo da velocidade do segmento e $E_{M}$ é a energia mecânica do sistema (corpo).

\subsubsection{Solução por dinâmica inversa}

Baseado no método de dinâmica inversa, as soluções das equações de movimento 2D (16) a (18) ocorreram de forma sucessiva a partir dos resultados obtidos de forças e momentos articulares para o segmento mais distal da cadeia cinemática (CAMARGO-JUNIOR, 2012) (Figura 37 e Figura 38). Como estratégia para minimizar os efeitos da propagação de incerteza na cinética articular (CAMARGO et al., 2013), foram adotadas abordagens bottom-up para o joelho e o quadril durante todo o período, e para o ombro, bottom-up na fase de interação com a barra e top-down na fase aérea.

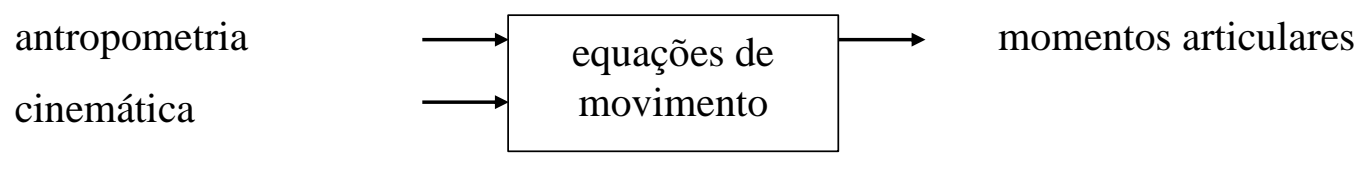

Figura 37. Solução por dinâmica inversa.

Aplicando-se o Teorema do Movimento do Baricentro (TMB) e o Teorema do Momento Angular (TMA) para problemas bidimensionais, obtivemos as seguintes equações:

$$
\begin{aligned}
& m \dot{\vec{v}}=\vec{F}, \\
& J_{C M} \dot{\omega}=M_{C M}, \\
& F_{X, i+1}=m_{i} a_{X, i}+F_{X, i}, \\
& F_{Y, i+1}=m_{i} a_{Y, i}+F_{Y, i}+m_{i} g,
\end{aligned}
$$




$$
\begin{aligned}
& M_{i+1}=J_{C M, i} \dot{\omega}_{i}+M_{i}-F_{X, i+1}\left[c_{i} \cdot \operatorname{sen}\left(\theta_{i}\right)\right]+F_{Y, i+1}\left[c_{i} \cdot \cos \left(\theta_{i}\right)\right]+F_{X, i}\left[\left(s_{i}-c_{i}\right) \operatorname{sen}\left(\theta_{i}\right)\right]- \\
& -F_{Y, i}\left[\left(s_{i}-c_{i}\right) \cos \left(\theta_{i}\right)\right]
\end{aligned},
$$

onde $m$ é a massa do corpo, $\dot{\vec{v}}$ é a aceleração do CM, $\vec{F}$ é a força resultante, $J_{C M}$ é o momento de inércia do corpo em relação ao respectivo CM, $\dot{\vec{\omega}}$ é a aceleração angular, $\vec{M}_{C M}$ é o momento resultante em relação ao $\mathrm{CM}, F_{i+1}$ é a força de reação proximal, $F_{i}$ é a força de reação distal, $a_{i}$ é a aceleração do CM do segmento, $g$ é a aceleração gravitacional, $M_{i+1}$ é o momento articular proximal, $M_{i}$ é o momento articular distal, $J_{C M, i}$ é o momento de inércia segmentar, $\dot{\omega}_{i}$ é a aceleração angular segmentar, $c_{i}$ é distância do CM em relação à extremidade proximal do segmento e $s_{i}$ é o comprimento do segmento.
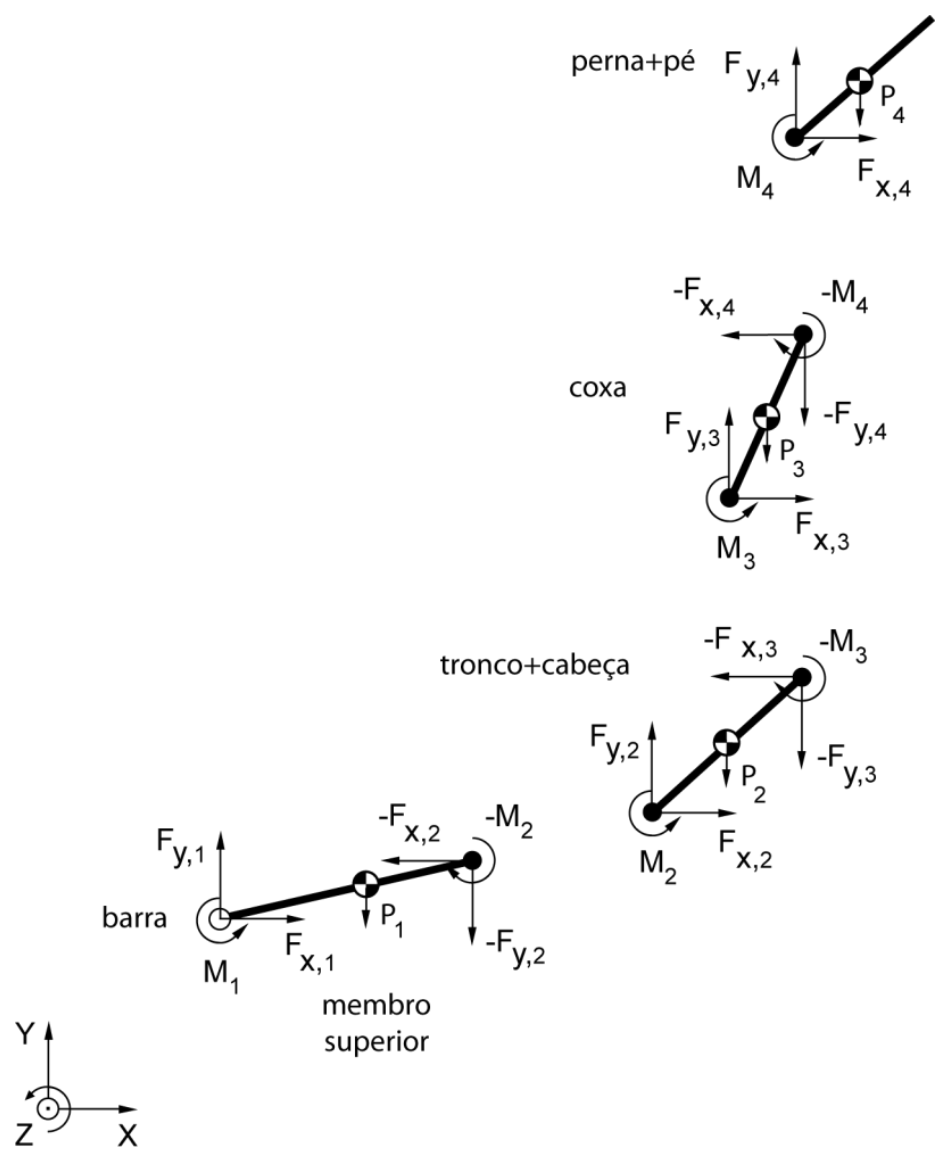

Figura 38. Diagrama de corpo livre para o modelo de DSBS.

A dinâmica do DSBS foi caracterizada por variáveis nos domínios do tempo em termos de média e pico para a fase de impulso, o instante de lançamento, a fase de voo e o instante de pré-impacto. Para a análise das configurações biomecânicas do DSBS, as 
condições de chegada foram categorizadas em: (S) sucesso, quando não houve a necessidade de passo ou queda na aterrissagem; $(\mathrm{Fb})$ falha para trás, quando houve recuo após o contato com o solo; ou (Ff) falha para frente, em situações de avanço anterior após o contato.

\subsection{MODELO ANALÍTICO DE ATERRISSAGEM}

Nesta seção, propõe-se um modelo simples de aterrissagem visando fornecer uma abordagem analítica para a interpretação da influência das variáveis medidas experimentalmente sobre o sucesso da chegada de barra fixa. Utilizando como inspiração o trabalho de Millard et al. (2009), representa-se o sistema como um único corpo rígido durante a chegada do DSBS e o impacto é modelado como uma colisão perfeitamente inelástica.

A Figura 39 reúne os três instantes determinantes $\left(\mathrm{t}^{-}, \mathrm{t}^{+}\right.$e $\left.\mathrm{t}_{\mathrm{f}}\right)$ em que o corpo é representado pela posição do CM e por um segmento que liga esse ponto ao tornozelo, na finalização do elemento ginástico. Nessa figura, a configuração da esquerda $\left(\mathrm{t}^{-}\right)$representa $\mathrm{o}$ sistema no instante imediatamente anterior à colisão. Nesse instante, o corpo apresenta componentes da velocidade do CM, tanto na direção perpendicular ao segmento, quanto na direção longitudinal, enquanto o componente rotacional é caracterizado pela quantidade de movimento angular do sistema. A configuração ao centro $\left(\mathrm{t}^{+}\right)$representa o sistema no instante imediatamente posterior à colisão perfeitamente inelástica do tornozelo com o solo. Nessa condição, uma articulação $\mathrm{O}$ é formada entre o tornozelo e o solo, e o vetor velocidade do CM passa a ser perpendicular ao segmento compondo movimento de pêndulo invertido. A velocidade do CM e a velocidade angular do segmento nesse instante $\left(\mathrm{t}^{+}\right)$podem ser calculadas por meio do tratamento da colisão, assumindo-se a conservação da quantidade de movimento angular em relação ao tornozelo $\left(\mathrm{H}_{\mathrm{o}}\right)$ durante a colisão, como será explicado adiante. Em t $\mathrm{t}_{\mathrm{f}}$, por sua vez, representa-se a condição final ideal, com o sistema em repouso e o CM posicionado sobre a articulação do tornozelo. Essa condição representa uma aterrissagem bem-sucedida e é atingida a partir da configuração $\left(\mathrm{t}^{+}\right)$por desaceleração em resposta à ação da força peso. 

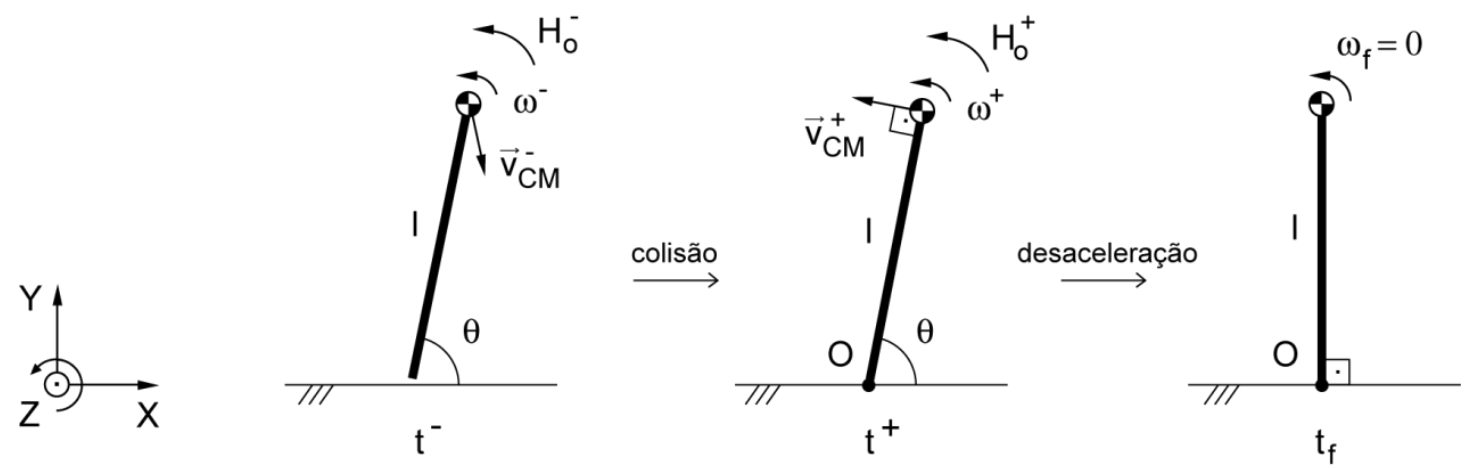

Figura 39. Modelo biomecânico de aterrissagem em DSBS.

Dessa maneira, a quantidade de movimento angular do sistema mecânico foi determinada em relação ao ponto de colisão $(O)$, em torno do qual ocorre a conservação da quantidade de movimento angular, uma vez que o momento gerado pelas forças impulsivas de reação do solo durante a colisão é nulo (MILLARD et al., 2009). Assim, a quantidade de movimento angular em relação ao ponto de contato $O$ no instante imediatamente posterior à colisão $\left(H_{o}{ }^{+}\right)$é igual à quantidade de movimento angular no instante imediatamente anterior à colisão $\left(H_{o}{ }^{-}\right)$:

$H_{o}^{-}=H_{o}^{+}$,

com:

$H_{o}^{-}=\left.\left(\vec{r}_{C M}-\vec{r}_{o}\right) \wedge m \vec{v}\right|_{z}+H_{C M}^{-}$,

onde $\vec{r}_{C M}$ é a posição do centro de massa corporal; $\vec{r}_{o}$ é a posição do centro articular do tornozelo; $m$ é massa do corpo; $\vec{v}$ é o vetor velocidade do centro de massa; e $H_{C M}^{-}$é a quantidade de movimento angular, em relação ao centro de massa corporal no instante imediatamente anterior à colisão.

Considerando o sistema um pêndulo invertido, logo após a colisão a quantidade de movimento angular em relação ao tornozelo pode ser escrita como:

$H_{o}^{+}=J_{o} \omega^{+}$ 
onde $J_{o}$ é o momento de inércia do corpo em relação ao tornozelo logo após o contato e $\omega+$ a velocidade angular no mesmo instante.

Após a colisão, o sistema de pêndulo invertido é desacelerado sob a ação da força peso até atingir, em uma condição de aterrissagem bem-sucedida, a configuração vertical (CM sobre o tornozelo) com velocidade angular no instante $t_{f}, \omega_{f}=0$. Considerando uma condição de sucesso, para a qual energia cinética no instante $t_{f}$ é nula, num sistema de pêndulo invertido, no qual a energia mecânica se conserva, tem-se:

$$
\begin{aligned}
& E_{M}=K^{+}+U^{+}=U_{f}+\not \chi_{f} 0\left(\omega_{f}=0\right) \\
& \frac{1}{2} J_{o} \omega^{2}+m g l \sin \left(\theta^{-}\right)=m g l .
\end{aligned}
$$

Das equações (21) e (23), eliminando-se $\omega_{f}$, tem-se que:

$$
\frac{1}{2} J_{o}\left(\frac{H_{o}^{+}}{J_{o}}\right)^{2}+m g l \sin \left(\theta^{-}\right)=m g l \text {. }
$$

E das equações (19), (20) e (23), com eliminação de $H_{o}{ }^{+}$, tem-se que as condições imediatamente anteriores à colisão devem satisfazer a seguinte equação escalar $(k)$ para garantir uma aterrissagem bem-sucedida:

$$
k=k\left(m, l, J_{o}, \theta^{-}, v_{X}^{-}, v_{Y}^{-}, H_{C M}^{-}\right)=0 .
$$

onde $\theta^{-}$é o ângulo de chegada; $l$ é a distância entre o centro articular do tornozelo e o centro de massa corporal; $m$ é a massa corporal; $v_{x}^{-}$é a componente horizontal da velocidade do CM imediatamente antes do contato; $v_{y}^{-}$é a componente vertical da velocidade do CM imediatamente antes do contato; $H_{C M}^{-}$é a quantidade de movimento angular do corpo em relação ao centro de massa. 
A expressão (25) evidencia a importância dessas quatro variáveis dependentes do instante imediatamente anterior ao contato para uma aterrissagem bem-sucedida. Em outras palavras, é a combinação adequada dessas variáveis, de acordo com a equação (21), que garantirá uma aterrissagem bem-sucedida.

Os dados experimentais preliminares mostram que as aterrissagens ocorrem geralmente com ângulos $\theta$ muito próximos de $90^{\circ}$. Nesse caso, a equação (23) mostra que para um aterrissagem bem-sucedida, $\omega+\sim 0$ e, portanto,

$\mathrm{H}_{\mathrm{o}}^{+} \sim 0$

De (26) e (19), para a aterrissagem $\operatorname{com} \theta \sim 90^{\circ}$,

$\mathrm{H}_{\mathrm{o}}^{-} \sim 0$

E assim, aterrissagens bem-sucedidas requerem uma pequena quantidade de movimento angular em relação ao tornozelo, imediatamente antes do contato com o solo. Das equações (27) e (19) decorre ainda que:

$H_{o}^{-}=\left.\left(\vec{r}_{C M}-\vec{r}_{o}\right) \wedge m \vec{v}\right|_{z}+H_{C M}^{-} \sim 0$

Esse último resultado é importante porque mostra que, para manter um $\mathrm{H}_{\mathrm{o}}{ }^{-}$baixo, é necessário que haja um equilíbrio entre as contribuições dos dois termos. O primeiro termo é tipicamente negativo, representando a contribuição da velocidade (predominantemente a horizontal) antes da colisão, enquanto o segundo é tipicamente positivo, representando a contribuição de $H_{C M}{ }^{-}$antes da colisão. Se o primeiro termo exceder o segundo em magnitude, $H_{o}{ }^{-}$torna-se negativo e o corpo tende a girar para frente após a colisão, com passos para frente. Por outro lado, se o segundo termo exceder o primeiro em magnitude, o corpo tende a girar para trás após a colisão, com falha relacionada a passos para trás. 


\subsection{ANÁLISE ESTATÍSTICA}

A dinâmica do DSBS foi caracterizada em termos de média ( \pm desvio padrão) e picos (máximo e mínimo), no domínio tempo (KURZ; STERGIOU, 2004). Para os instantes críticos foram identificados os intervalos de confiança $(\alpha=0,05)$ e os limites superior e inferior que configuram as diferentes condições de chegada de barra (BUSSAB; MORETTIN, 2010).

O potencial explicativo das variáveis selecionadas no pré-impacto, $\mathrm{X}\left(v_{x}, v_{y}, \theta\right.$, $\omega$ e $\left.H\right)$, foi definido com base na Análise de Componentes Principais (PCA) para cada sujeito e condição (sucesso ou falha). Para diminuir o efeito das diferenças de escala e magnitude nos resultados de PCA, o conjunto de variáveis $\mathrm{X}$ foi normalizado na média das tentativas:

$$
X_{R}^{\prime}=\frac{X_{R}}{\bar{X}},
$$

onde $X_{R}$ é o valor de cada explicativa, $\bar{X}$ é a média das variáveis de mesma escala e $X_{R}^{\prime}$ é a variável normalizada, com $R=5$.

O processamento em PCA implica numa transformação ortogonal, $\mathrm{M}$, da matriz $\mathrm{X}_{\mathrm{RC}}$ para que a matriz resultante $\mathrm{Y}_{\mathrm{RC}}$ torne-se diagonalizada. Nesse processo, os elementos de $\mathrm{M}$ são os autovalores e os elementos de $\mathrm{Y}_{\mathrm{RC}}$ são os autovetores (ou componentes principais) (MANLY, 2004; MOCHIZUKI; AMADIO, 2007):

$$
\begin{gathered}
X_{R C}=\left[\begin{array}{cccc}
x_{11} & x_{12} & \ldots & x_{1 C} \\
x_{21} & & & \ldots \\
\ldots & & & \ldots \\
x_{R 1} & \ldots & \ldots & x_{R C}
\end{array}\right], \\
M=\left[\begin{array}{llll}
A_{1} & A_{2} & \ldots & A_{n}
\end{array}\right]^{T}, \\
Y_{R C}=\left[\begin{array}{cccc}
y_{11} & y_{12} & \ldots & y_{1 C} \\
y_{21} & & & \ldots \\
\ldots & & & \ldots \\
y_{R 1} & \ldots & \ldots & y_{R C}
\end{array}\right],
\end{gathered}
$$


$X_{R C}=M \cdot Y_{R C}$,

onde o índice ${ }_{R}$ representa a tentativa de aterrissagem $(\mathrm{R}=49)$ e o índice ${ }_{C}$ corresponde ao conjunto de variáveis explicativas analisadas $(\mathrm{C}=5)$.

$O$ resultado disso foi uma redução dimensional de $X_{R C} \rightarrow Y_{R C}$, na qual: (1) a quantidade de variância de cada PC é igual ao próprio autovalor, (2) cada PC maximiza a variância explicada a partir da matriz de correlação e (3) os PC não são correlacionados (MANLY, 2004; MOCHIZUKI; AMADIO, 2007).

Por fim, com base na variância contabilizada de cada $\mathrm{PC}_{\mathrm{n}}$, indicada pelo próprio autovalor, a contribuição relativa de $\mathrm{PC}_{\mathrm{n}}(\lambda)$ na variabilidade total do conjunto foi definida por:

$\lambda_{n}=\frac{A_{n}}{\sum_{n=1}^{C} A_{n}}$.

onde $A_{n}$ é o autovalor que compõe a matriz $M$ e o índice ${ }_{C}$ corresponde ao conjunto de variáveis explicativas analisadas $(\mathrm{C}=5)$.

O fluxograma a seguir apresenta uma síntese de todo o procedimento metodológico adotado nesta investigação (Figura 40): 


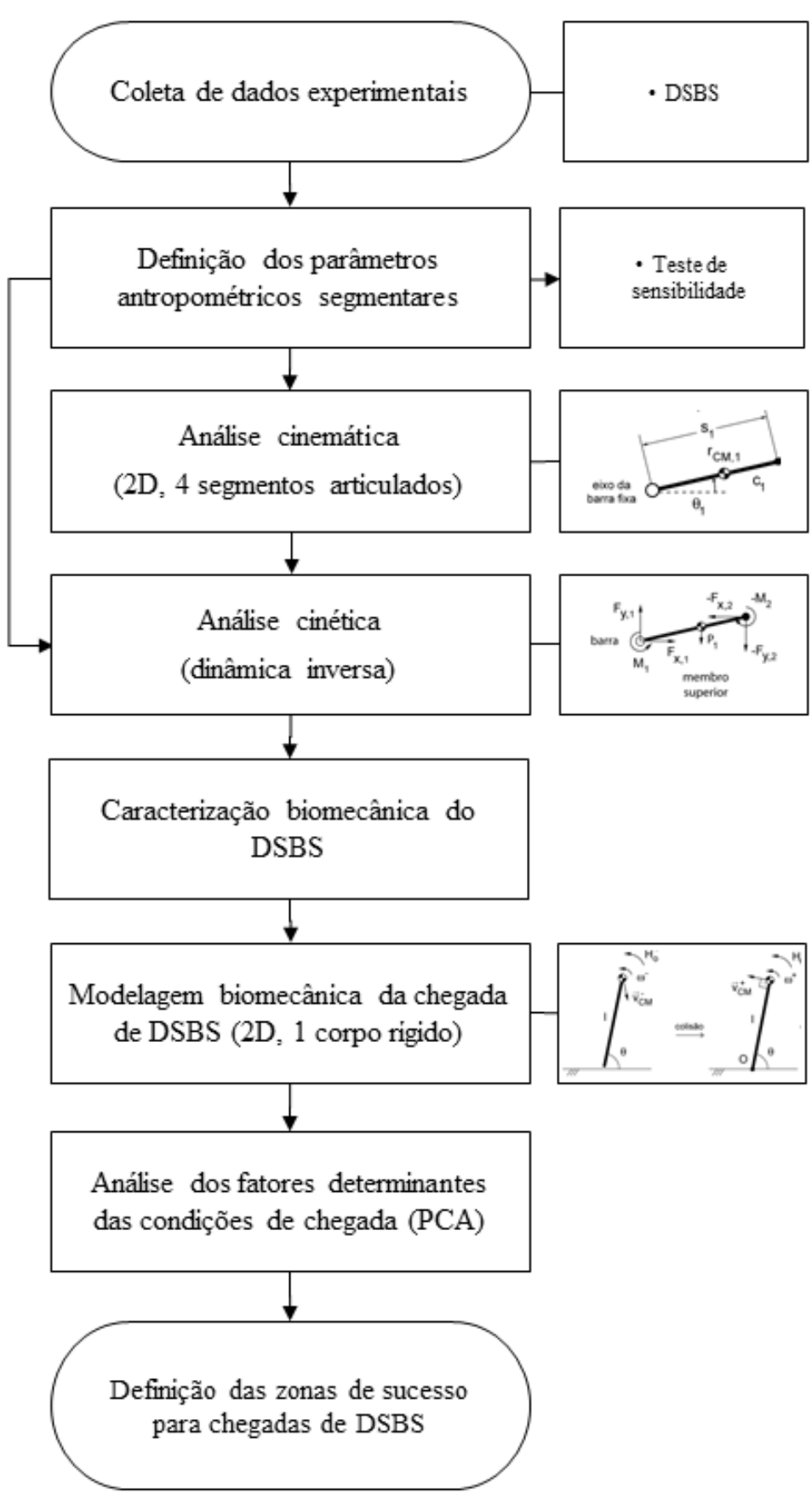

Figura 40. Etapas de desenvolvimento do estudo. Legenda: (DSBS) Double Salto Backward Stretched, (2D) bidimensional e (PCA) Principal Component Analysis. 


\section{RESULTADOS E DISCUSSÃO}

As saídas de aparelho ginástico consistem em uma habilidade de alta complexidade. Uma manifestação disso é a baixa taxa de sucesso nas aterrissagens. McNitt-Gray e colaboradores (1998) apresentaram 5\% de acerto nas finalizações de paralelas e barra fixa em competições olímpicas. Na presente investigação, em 49 finalizações de barra fixa em DSBS foi observado sucesso (aterrissagem sem passo ou queda) em $43 \%$ das tentativas. E ao considerar uma única saída de barra de cada ginasta, como numa competição, o percentual de sucesso reduziu para 14\%. O mesmo percentual encontrado por Heinen e Nicolaus (2016) para as chances de sucesso em mortais para frente no solo com saída de trampolim. Uma vez que as saídas de barra são habilidades automatizadas pela rotina de treinamento, o efeito do acúmulo de tentativas no percentual de sucesso em ginastas de elite sugere uma estreita fronteira para os fatores biomecânicos que configuram a chegada em DSBS.

\subsection{PERFIL BIOMECÂNICO DESCRITIVO DA SAÍDA DE BARRA FIXA EM DUPLO MORTAL ESTENDIDO}

Investigado por diferentes pesquisadores (KERWIN; YEADON; LEE, 1990; BRÜGGEMANN et al., 1994; SMITH, 1998; ARAMPATZIS; BRUGGEMANN, 1998; ARAMPATZIS; BRUGGEMANN, 1999; YEADON; HILEY, 2000; HILEY; YEADON, 2001; HILEY; YEADON, 2003a; HILEY; YEADON, 2003b; HILEY; YEADON, 2005a; HILEY; YEADON, 2016); SERBEST; BERISHA; CILLI, 2018), os movimentos em giro gigante que precedem a saída de barra fixa têm por objetivo gerar velocidade (linear e angular), energia mecânica e quantidade de movimento angular suficientes para o lançamento.

Para essa fase de movimento, a técnica carpado foi a opção adotada por todos os ginastas que compõem a amostra dessa pesquisa. Conforme discutido anteriormente, apesar dessa técnica apresentar uma menor quantidade de movimento angular para o lançamento, a postura carpado permite maior janela temporal de lançamento (88-157 ms). E isso implica numa maior margem de acerto associada à saída do aparelho (HILEY; YEADON, 2003b).

As propriedades biomecânicas que compõem os elementos ginásticos de voos ginásticos (YEADON, 1990b, 1990a, 1990c; YEADON; ATHA; HALES, 1990; KERWIN; 
YEADON; LEE, 1990; BRÜGGEMANN et al., 1994; YEADON, 1997; TAKEI; DUNN, 1997b; SMITH, 1998; YEADON; HILEY, 2014; YEADON; HILEY, 2018) e os efeitos dessas propriedades nas condições de aterrissagem (REQUEJO; MCNITT-GRAY; FLASHNER, 2002, 2004; SHEETS; HUBBARD, 2007; HEINEN; NICOLAUS, 2016; GITTOES et al., 2011; GITTOES; IRWIN; KERWIN, 2013; SERBEST, K; BERISHA, M. ÇILLI, 2019; SERBEST; BERISHA; CILLI, 2018) têm sido relatadas com alta dependência do aparelho ginástico e tipo de salto adotados. Para a saída de barra fixa, esses saltos diferem na postura (grupado, carpado ou estendido), na quantidade de mortais (simples, duplo ou triplo), no sentido da rotação dos mortais (para frente ou para trás) e na combinação com piruetas (ausente, simples ou dupla). Para a ideal interpretação das características biomecânicas que governam a saída de barra, faz-se necessário a contextualização desses fatores na sequência temporal de execução dos movimentos. Nas análises a seguir, adotou-se como marcos na linha do tempo, os eventos: giro girante, lançamento, voo e chegada (ou aterrissagem).

Foram observadas fases com períodos consistentes intra e inter-sujeitos durante o DSBS. O impulso em giro gigante representou $78,4 \pm 0,7 \%$ do período $(4,13 \pm 0,17 \mathrm{~s})$ e o voo $21,6 \pm 0,7 \%(1,19 \pm 0,04)$ (Tabela 14). Alguns eventos característicos foram destacados abaixo no percentual do período do movimento (Figura 1 e Figura 42):

(0 -54) giro gigante em postura estendida: início em apoio na barra fixa $\left(\theta=90^{\circ}\right)$ e finalização após um arco de $585^{\circ}$, na metade do $4^{\circ}$ quadrante;

(54-70) giro gigante em postura carpado: pico de flexão de quadril e extensão e ombro em $62 \%$ do período, arco de $225^{\circ}$;

(70-78) movimento "chicote": ação flexo-extensora de quadril e ombro com início após $810^{\circ}$ (entre o 2 e $3^{\circ}$ quadrantes) e arco de $180^{\circ}$;

(78) lançamento: início do movimento aéreo após um arco pouco acima de $1120^{\circ} \mathrm{com}$ referência de zero grau no plano horizontal (entre quadrantes $4 \rightarrow 1$ );

(78-100) duplo mortal estendido: voo com rotação de $630^{\circ}$ em torno do centro de massa;

(100) chegada: instante de pré-impacto na aterrissagem. 


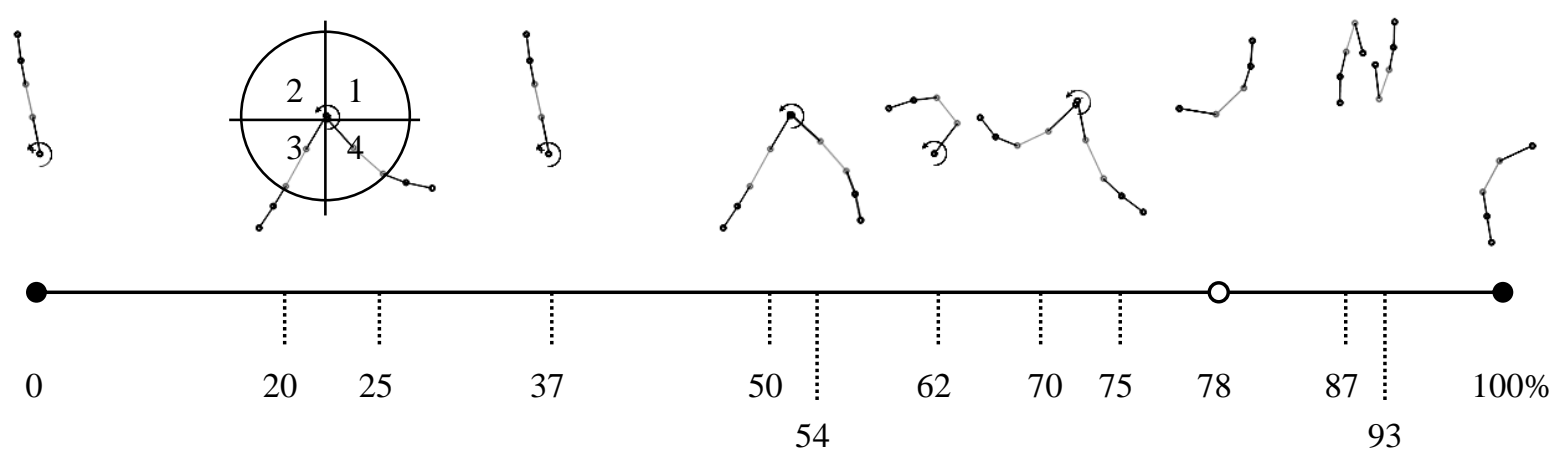

Figura 41. Sequência de movimentos para a saída de DSBS no percentual do período: início do primeiro giro gigante (0), início do segundo giro gigante (37), postura carpado sobre a barra (62), lançamento (79), duplo mortal (79-100) e pré-impacto (100).

Tabela 14. Fases e subfases, ciclos de movimento, posições e posturas características do DSBS.

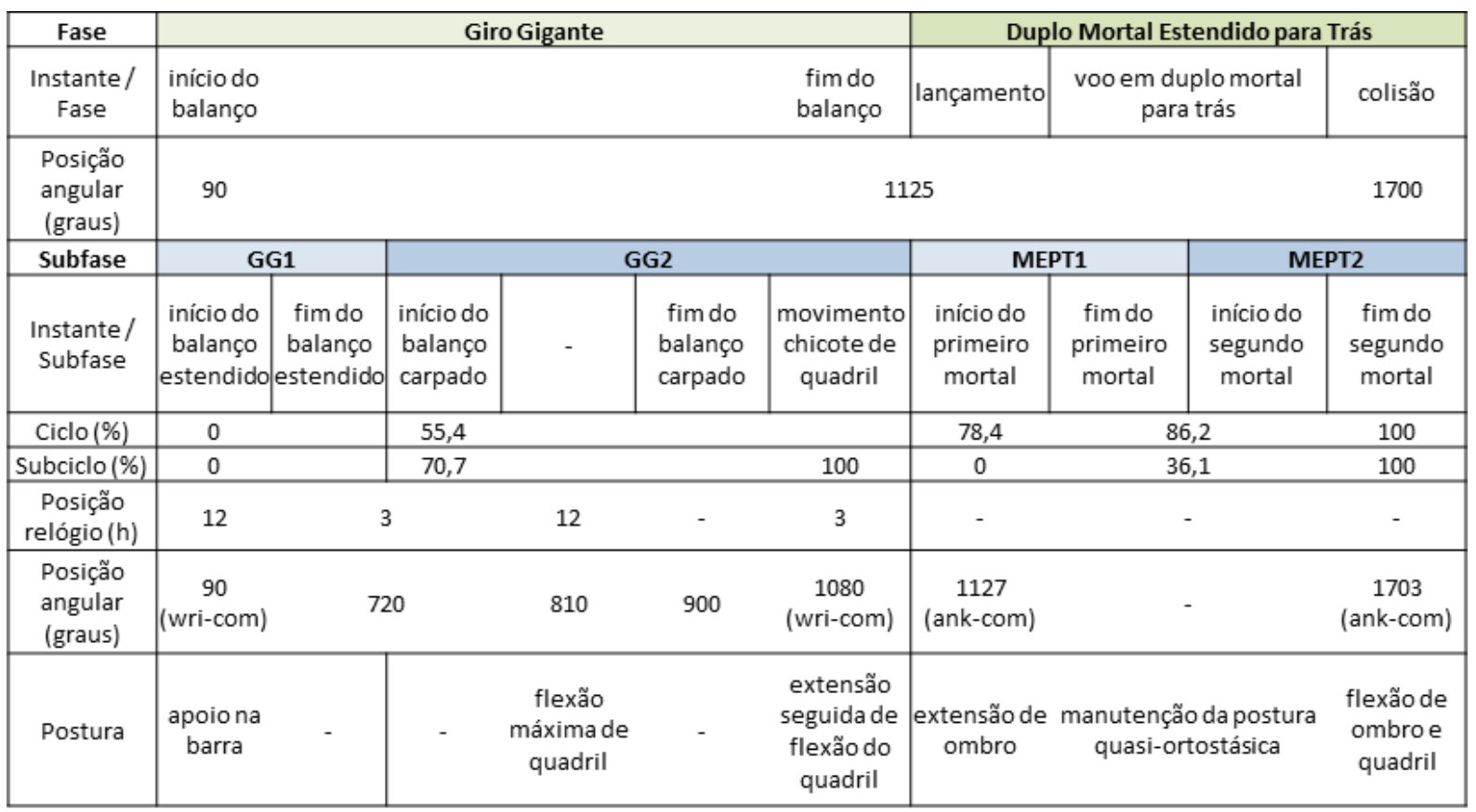

Legenda: (GG1) primeiro giro gigante; (GG2) segundo giro gigante; (MEPT1) primeiro mortal estendido para trás; (MEPT2) segundo mortal estendido para trás; (wri-com) segmento que une o centro articular do punho ao centro de massa corporal; (ank-com) segmento que une o centro articular do tornozelo ao CM.

Durante o balanço, o centro de massa descreveu trajetória circular nos primeiros $720^{\circ}$ de rotação, seguido por forma quasi-triangular (vértices em 3h, 9h e 5h, aprox.) no impulso carpado. Após o lançamento o CM assumiu um previsível comportamento parabólico (Figura 43). Essas trajetórias representam, respectivamente, o movimento pendular para o início do impulso, as ações de tração da barra para acúmulo de energia e aumento da velocidade angular, e um comportamento típico de lançamento de projétil durante o voo. Com velocidade 
angular inicial média de 67 \% e picos de 720 \% próximo ao lançamento, os ginastas realizaram 2,75 giros $\left(\Delta \theta=990^{\circ}\right)$ nessa fase de impulso.
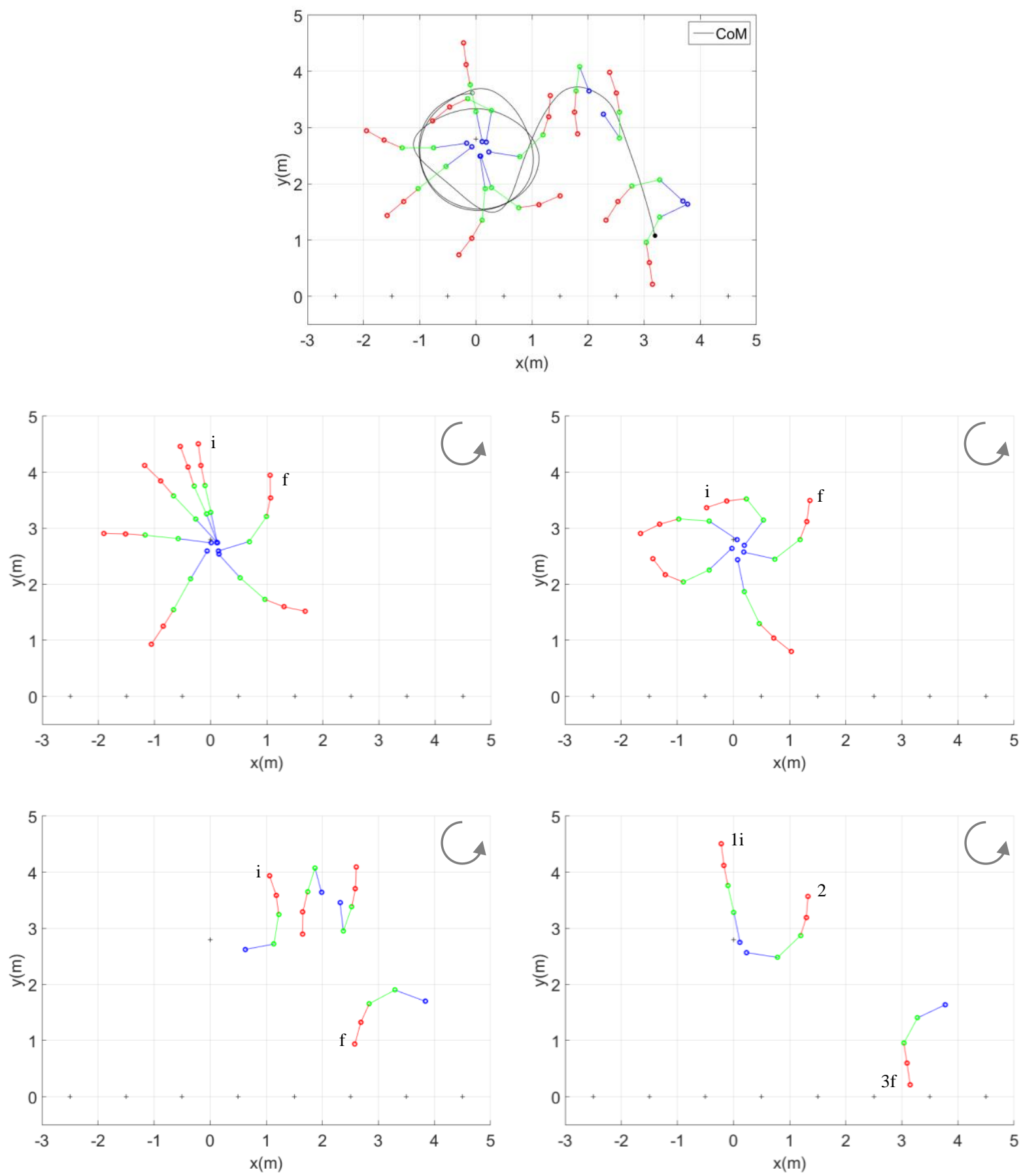

Figura 42. Representação segmentar e trajetória do centro de massa (CoM) durante o DSBS (superior). Primeira subfase do giro gigante: postura quasi-estendida; período de 630 graus com rotação de 0 à $3 \mathrm{~h}$ no sentido antihorário (centro-esquerda). Segunda subfase do giro gigante: postura carpado (entre 3 e 9 h); período de 360 graus com rotação iniciando em $3 \mathrm{~h}$ no sentido anti-horário (centro-direita). Fase de voo: rotação em torno do CM; período de 630 graus (inferior-esquerda). Posturas de início do giro gigante (1), lançamento (2) e chegada (3) (inferior-direita). Legenda: (i) posição inicial e (f) final da sequência de movimentos. 

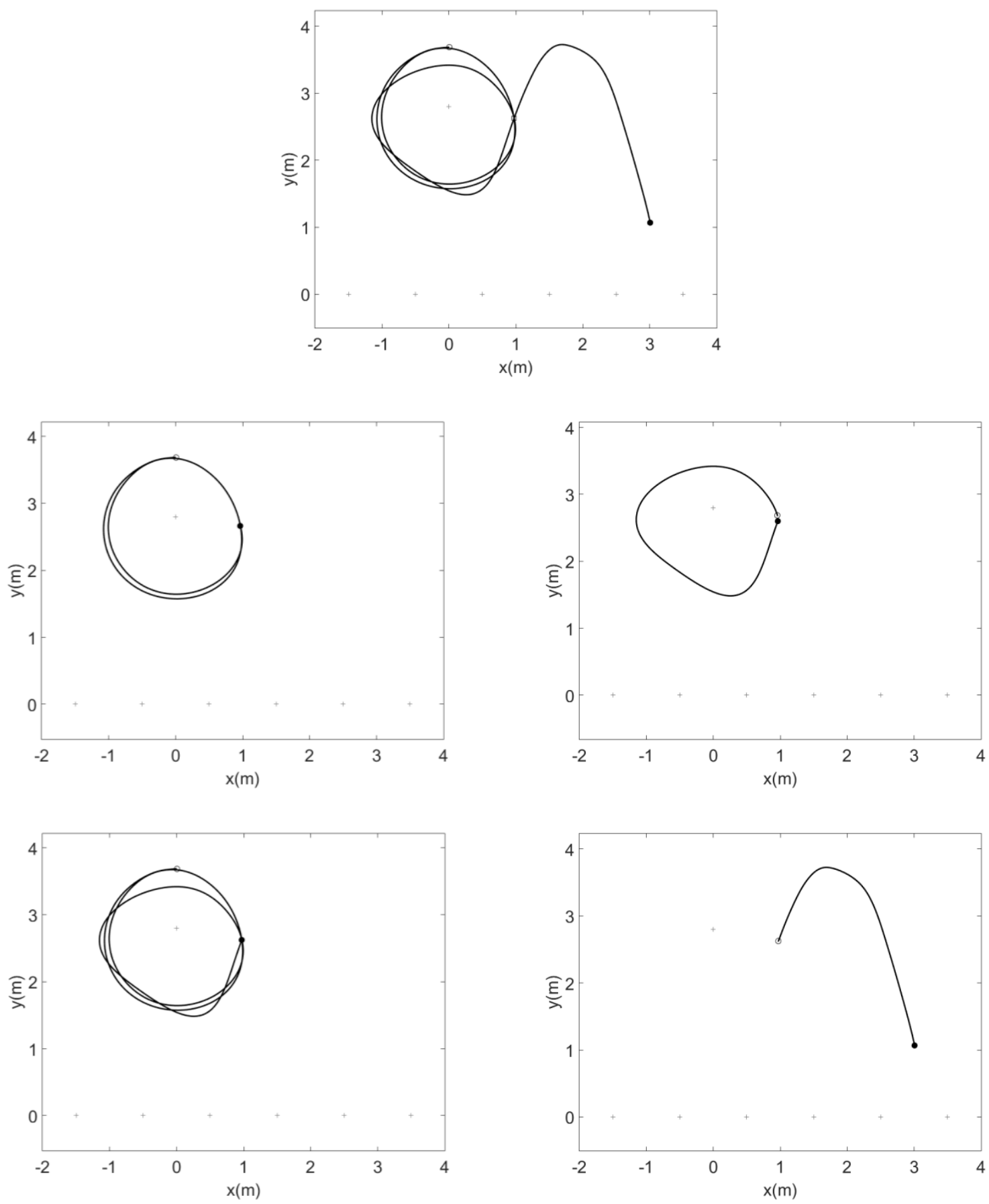

Figura 43. Trajetória do CM (média) durante o DSBS (superior). Primeira subfase do giro gigante (centroesquerda). Segunda subfase do giro gigante (centro-direita). Fase completa de giro gigante (inferior-esquerda). Fase de voo (inferior-direita). Legenda: (०) posição inicial e (•) final da sequência de movimentos.

Esse comportamento do CM provocado pela técnica carpado no o giro gigante já havia sido observado por (HILEY; YEADON, 2003b) que apontaram uma deformação da barra até $0,16 \mathrm{~m}$ durante o período. No presente estudo, no entanto, foram observados deslocamentos de até $0,23 \mathrm{~m}$ em relação ao eixo barra. A explicação para essa diferença pode estar em alguns fatores: na diferença de massa entre os ginastas avaliados, na velocidade de 
rotação em torno da barra pela ação centrífuga ou na diferença de tensão dos cabos de fixação da barra fixa selecionada por cada ginasta dentro de uma margem de segurança préestabelecida (FIG, 2017). Em investigações com giro gigante nas barras assimétrica (modalidade feminina), Sevrez e colaboradores (2009) encontraram variações de quase 0,10 $\mathrm{m}$ na aproximação do $\mathrm{CM}$ em relação à barra durante o impulso.

Smith (1998) demonstrou que, para a saída de barra com velocidade angular fixa em $114,6 \%$, os ângulos de lançamento mais próximos a $90^{\circ}$ (linha gravitacional $=0^{\circ}$ ) permitem altura máxima de voo de $3,85 \mathrm{~m}$ e, consequentemente, maior tempo de voo (1,31 s) comparado a ângulos menores. Contudo, esse ângulo de saída está muito próximo ao limite de segurança para o ginasta não colidir com a barra. Assim, uma alternativa foi aumentar a velocidade angular de lançamento (171,9\%) para um tempo de voo correspondente (1,32 s) num ângulo de $65^{\circ}$. Porém, isso diminui a janela de lançamento e aumenta a demanda de impulso durante a aterrissagem. No caso deste estudo, partindo do mesmo referencial, em média o ângulo de lançamento foi de $80^{\circ}$ para cumprir um arco de $630^{\circ}$, num de voo de $1,19 \mathrm{~s}$ (Figura 44 e Figura 45). Isso representa uma velocidade média de quase 530\%. Essa diferença de velocidade angular justifica-se pela especificidade dos saltos observados que, no caso do autor (mortal simples estendido e mortal duplo grupado) exigem menor demanda rotacional comparados ao DSBS.

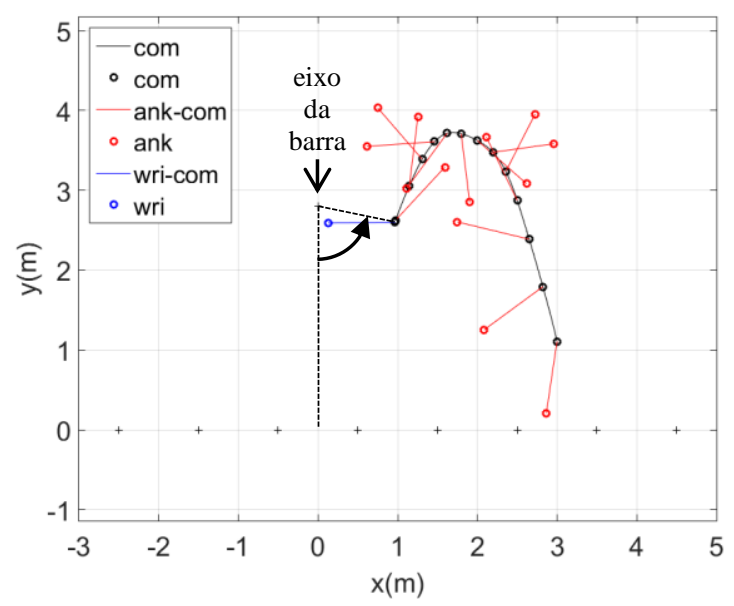

Figura 44. Movimento rotacional (média) do corpo representado por: (1) wri-com, segmento que une o centro articular do punho (azul) ao centro de massa (preto) no instante de lançamento; (2) ank-com, segmento que une o centro articular do tornozelo ao centro de massa durante a fase aérea. 


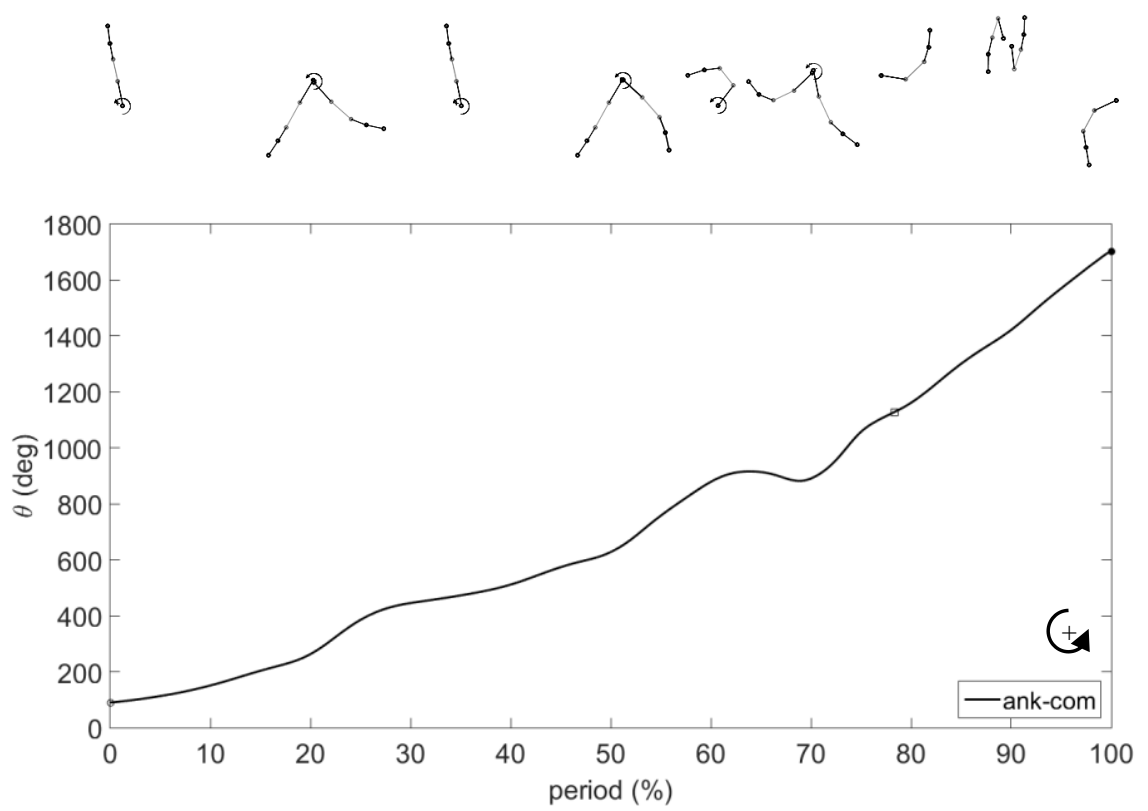

Figura 45. Posição angular (média) do corpo durante o DSBS. Legenda: (ank-com) segmento que une o centro articular do tornozelo ao centro de massa; ( $\square$ ) instante de lançamento.

A velocidade tangencial durante o giro gigante atingiu picos de $6,0 \mathrm{~m} / \mathrm{s}$ aos $90 \%$ do período do giro gigante. A velocidade horizontal variou entre $-4,2$ e $5,5 \mathrm{~m} / \mathrm{s}$ nessa mesma

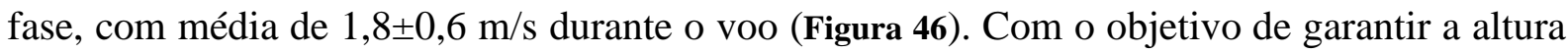
necessária para a realização do duplo mortal, a velocidade vertical oscilou entre -4,5 e 5,8 m/s

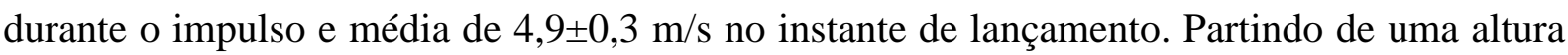
de 2,6 m do colchão, o ginasta atingiu o solo com uma velocidade vertical de $-7,3 \mathrm{~m} / \mathrm{s}$.
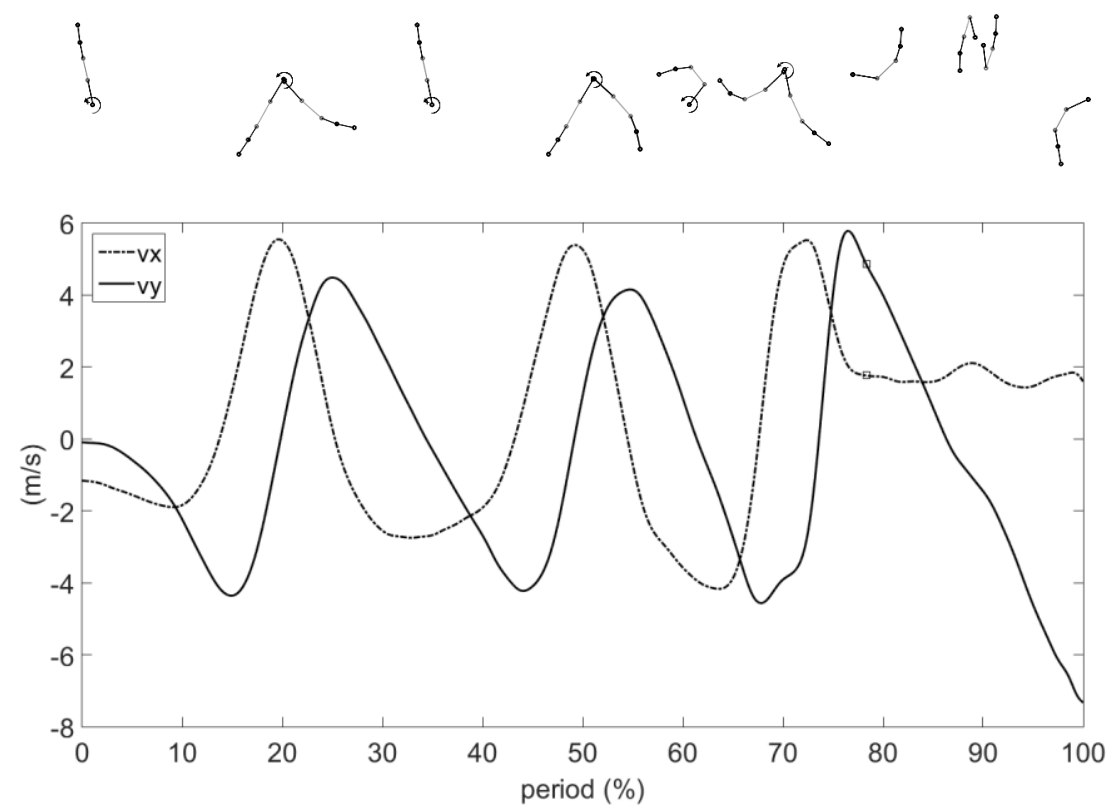

Figura 46. Velocidade linear (média) no período de DSBS. Legenda: (vx) velocidade horizontal do CM; (vy) componente vertical do CM; ( $\square$ ) instante de lançamento. 
As movimentações articulares mais significativas no giro gigante ocorreram durante o último balanço (Figura 47). Entre 50 e $70 \%$ do período de barra, pode-se observar um sincronismo entre as ações de ombro e quadril que provocam aumento, seguido por diminuição do momento de inércia do corpo, na busca por impulso para o lançamento. Nessa fase o ginasta realiza um balanço carpado sobre a barra (de 3 a 9 h, em sentido anti-horário), seguido por um movimento "chicote" de quadril (extensão seguida de flexão articular) que permite tracionar a barra na posição de $9 \mathrm{~h}$ e acumular energia para o lançamento.

Após o pico da postura carpado que ocorre em $810^{\circ}$ (transição: $1^{\circ} \rightarrow 2^{\circ}$ quadrante, (Figura 42, centro-direita), no próximo arco de $180^{\circ}$ o ginasta flexiona os ombros e estende os quadris entre o $2^{\circ}$ e $3^{\circ}$ quadrante provocando nova tração na barra e aumento do momento de inércia. Na sequência, prestes ao lançamento, o ginasta inverte as ações. Estende os ombros e flexiona os quadris, diminuindo o momento de inércia para ganho de velocidade angular. Ao longo da fase de giro gigante, os picos de energia mecânica observados foram de 2259 a 2831 J (Figura 51).

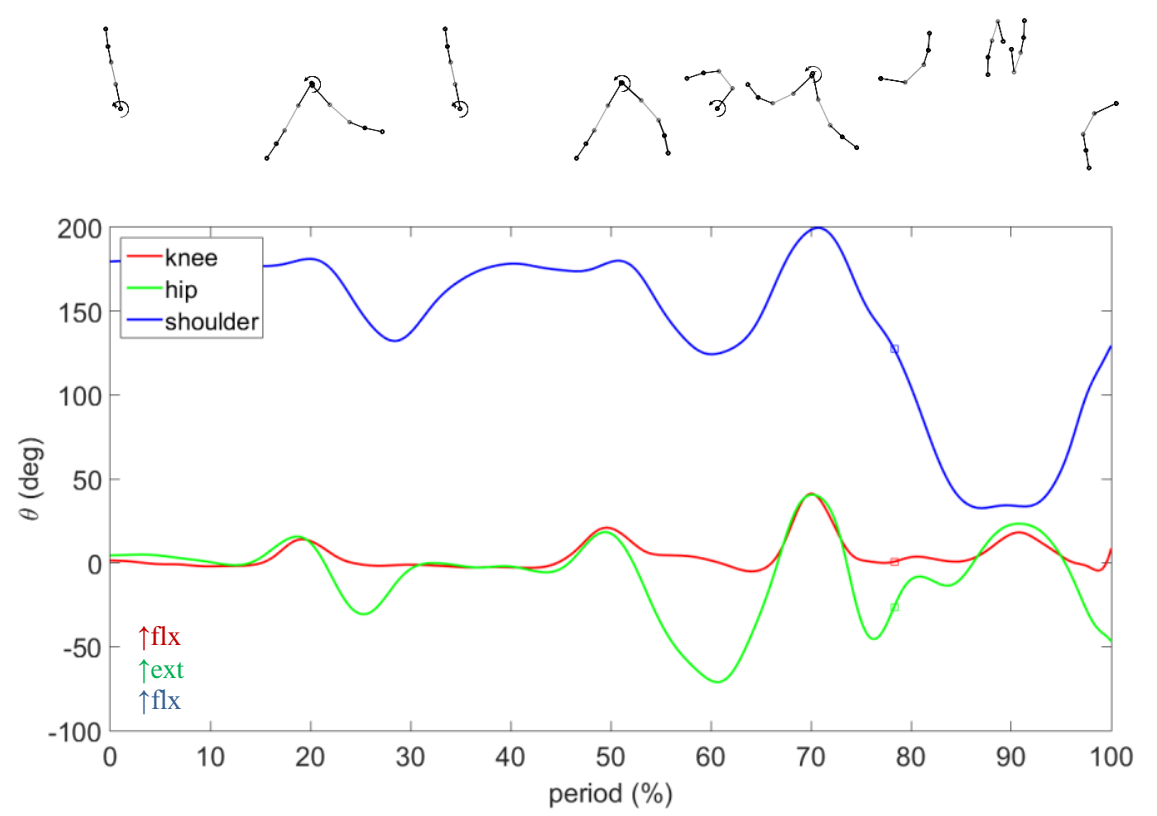

Figura 47. Ações articulares (médias) no DSBS: (1) instante de máxima flexão de quadril e máxima extensão de ombro; (2) instante de máxima extensão de quadril e máxima flexão de ombro. Legenda: ( $\uparrow$ flx) ação flexora; ( $\uparrow$ ext) ação extensora; ( $\square$ ) instante de lançamento.

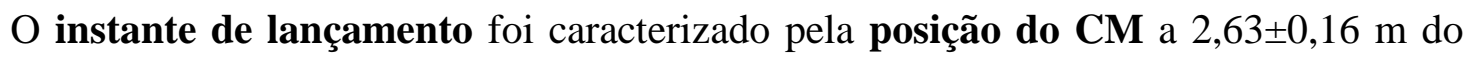
solo (ou 2,43 m em relação ao nível do colchão) e um afastamento da barra fixa de $0,97 \pm 0,17$ m. Isso representou um ângulo de saída praticamente paralelo à horizontal para o segmento que define as posições do CM em relação ao punho (wri-com), depois de $1128 \pm 14^{\circ}$ de rotação 
em torno do eixo da barra (ou $348^{\circ}$ no último balanço com zero alinhado à horizontal) (Figura 44). As componentes de velocidade linear ( $v x$; vy) nesse instante foram $1,76 \pm 0,59 \mathrm{~m} / \mathrm{s}$ e $4,87 \pm 0,36 \mathrm{~m} / \mathrm{s}$, respectivamente. Kerwin e colaboradores (1990) encontraram resultados similares para a posição vertical de lançamento $(2,39 \mathrm{~m}$ em relação ao colchão, presumidamente) durante o DSBS. Brüggemann e colaboradores (1994) já haviam relatado posições de lançamento $\left(352 \pm 30^{\circ}\right.$ em relação à horizontal) e componentes de velocidade semelhantes $(1,34 \pm 0,67 ; 4,04 \pm 0,10 \mathrm{~m} / \mathrm{s})$.

A quantidade de movimento angular de lançamento é um fator determinante para o desenvolvimento dos movimentos rotacionais na fase de voo. Foi encontrado um resultado médio de $82,8 \pm 16,5 \mathrm{kgm}^{2} / \mathrm{s}$ entre as tentativas, o que corresponde à faixa de valores relatados na literatura para o mesmo tipo de saída de barra fixa: $65,1 \pm 16,0 \mathrm{kgm}^{2} / \mathrm{s}$ (BRÜGGEMANN et al., 1994), 68,9 $\pm 9,4 \mathrm{kgm}^{2} / \mathrm{s}$ (ARAMPATZIS; BRUGGEMANN, 1999) e $81,6 \mathrm{kgm} / \mathrm{s}$ (HILEY; YEADON, 2003a). Os valores para o DSBS são apontados como os mais elevados comparados a outros tipos de saída: $51,7 \pm 5,2 \mathrm{kgm}^{2} / \mathrm{s}$ (duplo mortal carpado para trás com pirueta) (TAKEI; DUNN, 1997b); 46,6 $\pm 6,7 \mathrm{kgm}^{2} / \mathrm{s}$ (duplo mortal carpado para trás com pirueta) e 47,6 $\pm 4,1 \mathrm{kgm}^{2} / \mathrm{s}$ (triplo mortal carpado para trás com pirueta) (HILEY; YEADON, 2003a). Para rotações no eixo médio-lateral, isso representa uma direta relação entre o aumento do momento de inércia e dificuldade em realizar os mortais na postura estendido.

Desprezada a resistência do ar na trajetória do CM, as velocidades lineares e a quantidade de movimento angular durante o voo são definidas no lançamento. Durante DSBS,

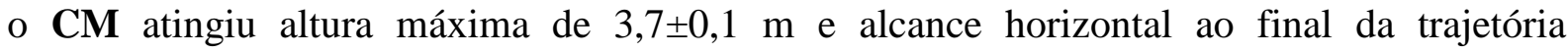
parabólica de 3,0 $\pm 0,4 \mathrm{~m}$ (Figura 43). Ginastas que optaram por uma saída antecipada da barra atingiram maior alcance horizontal devido ao aumento da componente horizontal de velocidade.

O controle da velocidade angular durante a fase aérea é obtido por meio da variação do momento inércia, que por sua vez é resultado da aproximação ou afastamento dos segmentos em relação ao CM. E uma vez que as ações de diversas articulações estão restritas por questões de configuração da técnica para o DSBS, em voo esse controle ficou restrito às ações flexo-extensora de ombro (ao longo do período) e quadril (nos primeiros 45 e nos últimos $180^{\circ}$ de rotação). Heinen e colaboradores (2016) exploraram esse controle de voo para o salto mortal grupado no solo. Nessa postura corporal, as ações flexo-extensora (joelho, quadril e ombro) foram exploradas com variações no momento de inércia corporal de $12 \mathrm{kgm}^{2}$ durante a fase aérea. 
Nossos resultados demonstram uma ação extensora de ombro até a posição neutra nos primeiros $37 \%$ do período de voo (entre 78,2 e $86,4 \%$ do período total), seguido de flexão nos últimos $34 \%$ (últimos 7,7\% do período total). No caso do quadril, após o lançamento ocorreu uma hiperextensão com pico de $23,4 \pm 5,7^{\circ}$ e uma ação flexora iniciada no último quarto de voo. No touchdown, as posições angulares para ombro e quadril foram, respectivamente: $127,8 \pm 7,0$ e $23,4 \pm 5,7$. Ainda que em menor período de tempo, um dos ginastas apresentou acentuada flexão de joelho $\left(58,9 \pm 6,2^{\circ}\right)$ durante o voo, elevando a média do pico para $18,4 \pm 3,7^{\circ}$. Os demais ginastas mantiveram o joelho próximo à posição neutra.

Yeadon e colaboradores (2014) demonstraram o efeito das ações articulares no controle das rotações em fase aérea. Num estudo realizado com saltos mortais em trampolim, os autores demonstraram que uma redução de $2^{\circ}$ na flexão máxima de quadril provoca uma diminuição de $39^{\circ}$, nas piruetas, e $14^{\circ}$ nos mortais. Enquanto que um aumento de $2^{\circ}$ graus na flexão máxima de quadril gerou um aumento de $78^{\circ}$ nas piruetas e $6^{\circ}$ nos mortais. Também foram observadas as seguintes consequências da variação da quantidade de movimento angular em saltos mortais: redução de $2 \%$ em $\mathrm{H}$ representou diminuição de 23 e $13^{\circ}$ na finalização de pirueta e mortal, respectivamente; e aumento de $2 \%$, ganhos de 31 e $10^{\circ}$ aos mesmos movimentos rotacionais.

Na presente investigação, como será discutido adiante, os efeitos dessa sequência de ações articulares podem corrigir ou até inverter as condições de falha associada ao ângulo de chegada, exigindo um passo para frente após o impacto, ao invés de para trás, por exemplo.

Os picos das velocidades articulares destacam o papel das demandas mecânicas em dois instantes de transição do DSBS: pré-lançamento (joelho: 286,4 $\pm 107,0$; quadril: 364,3 \pm 128 ,7; ombro: 257,0 $\pm 106,2$ ) e pré-colisão (joelho: $260,6 \pm 114,0$; quadril: $268,4 \pm 48,6$; ombro: $343,1 \pm 52,3)$. Próximo ao lançamento, esse aumento de velocidade permite diminuição do momento de inércia e aumento da velocidade angular do corpo na saída da barra. De acordo com Sevrez e colaboradores (2009), essa rápida atuação articular flexo-extensora durante o giro gigante compensa a perda de energia decorrente do atrito das mãos em contato com a barra. Quando próximo à aterrissagem, as estratégias são mais variadas. No geral, busca-se por aumento do momento de inércia para reduzir a velocidade de rotação de chegada. Porém, enquanto em alguns ginastas (S1 e S3) predominam as ações de quadril para essa desaceleração, em outros (S2, S3, S4, S6 e S7) isso ocorreu devido às ações dos ombros (Figura 48). 

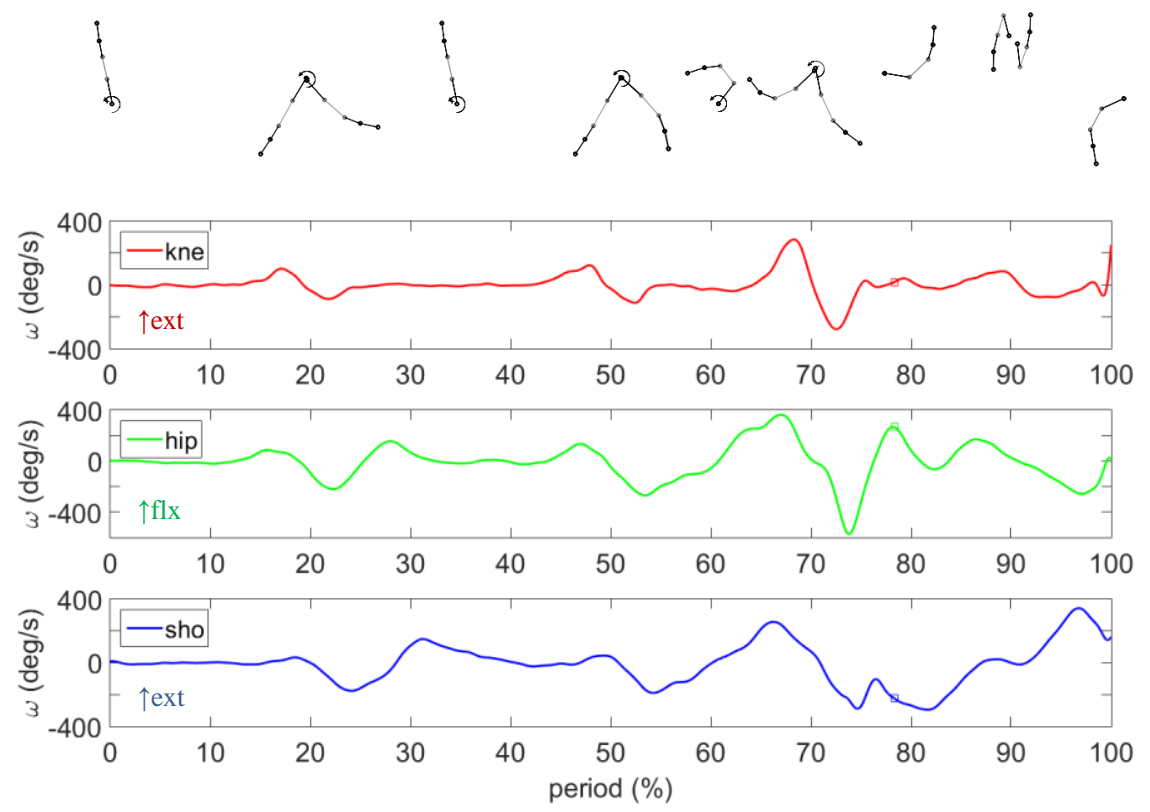

Figura 48. Velocidades articulares (médias) durante o DSBS. Legenda: (kne) joelho, (hip) quadril e (sho) ombro; ( $\uparrow$ flx) ação flexora; ( $\uparrow e x t)$ ação extensora; (口) instante de lançamento.

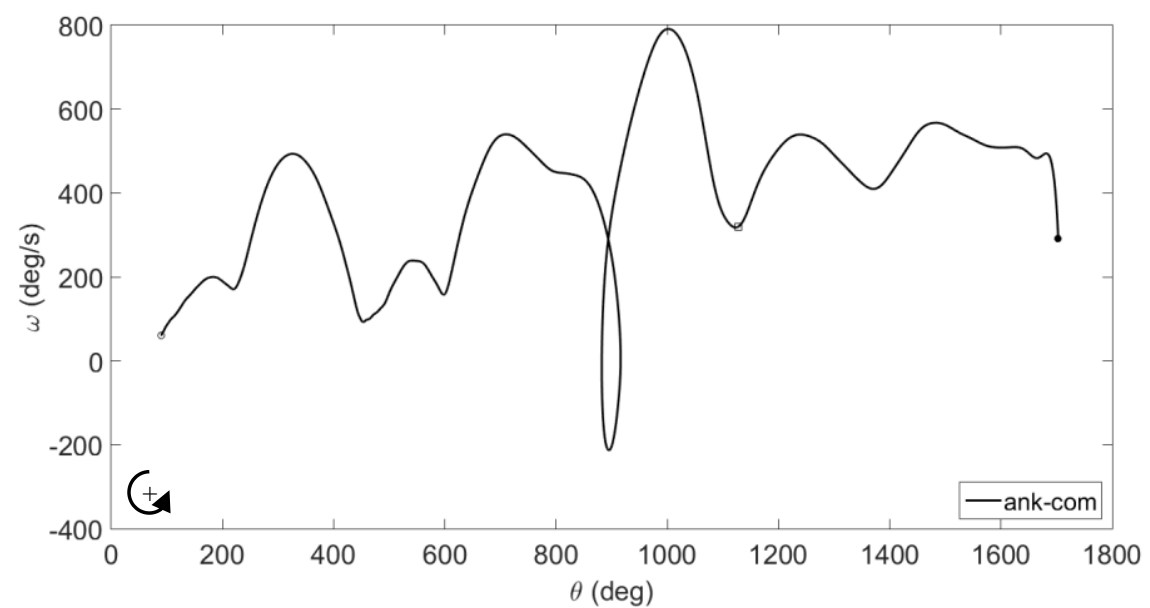

Figura 49. Velocidade angular (média) do corpo em função da posição angular durante o DSBS. Legenda: (ankcom) segmento que une o centro articular do tornozelo ao centro de massa; ( $)$ posição inicial e (•) final da sequência de movimentos; ( $\square$ ) instante de lançamento. 

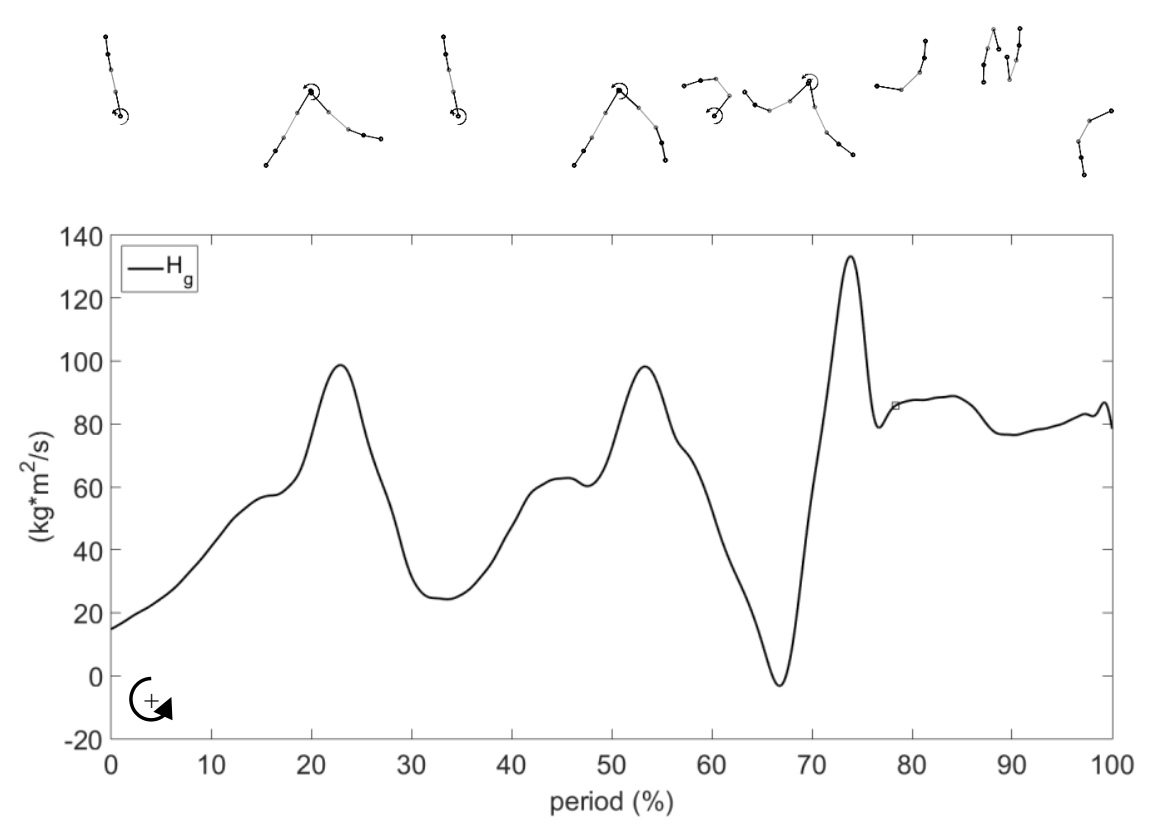

Figura 50. Quantidade movimento angular (média) em relação ao centro de massa durante o DSBS. Legenda: $\left(\mathrm{H}_{\mathrm{g}}\right)$ quantidade de movimento angular em relação ao centro de massa; $(\square)$ instante de lançamento.

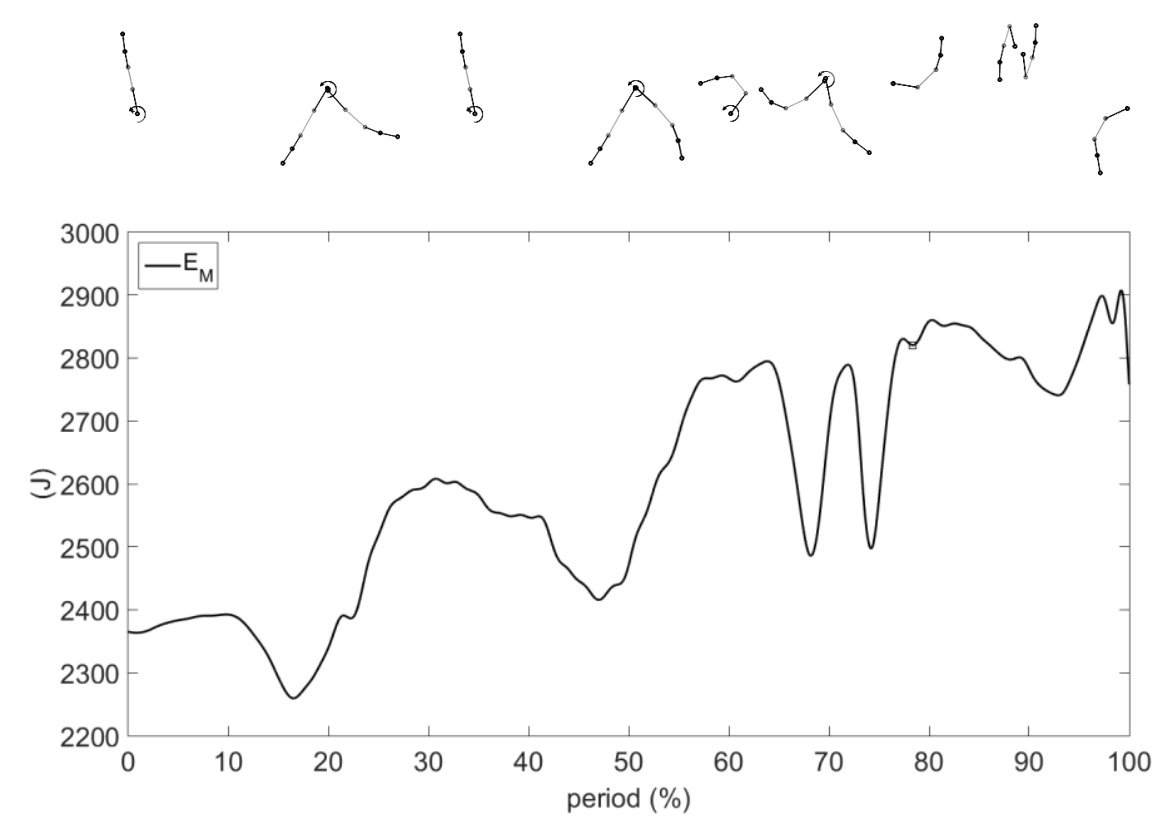

Figura 51. Energia mecânica (média) durante o DSBS. Legenda: (๑) instante de lançamento.

Em correspondência às ações articulares, as maiores demandas de momento resultante ocorreram nos últimos $270^{\circ}$ antes do lançamento. Nesse período foram observados picos: extensor de joelho de $1,0 \pm 0,4 \mathrm{Nm} / \mathrm{kg}$, flexor de quadril de $2,3 \pm 0,9 \mathrm{Nm} / \mathrm{kg}$, e extensor de ombro de 6,1 $22,5 \mathrm{Nm} / \mathrm{kg}$ (993, 1043 e $1057^{\circ}$ antes do lançamento, respectivamente) (Figura 52). Também no caso dos picos de momento articular, observou-se uma consistência temporal inter-sujeitos com uma sutil tendência de solicitação sequencial nas demandas de joelho, quadril e ombro, respectivamente (Tabela 15). 
Esses resultados de pico de momento foram similares aos demonstrados por Arampatizs e Brüggemann (1999) para quadril (2,8 Nm/kg) e ombro $(4,0 \mathrm{Nm} / \mathrm{kg})$ na técnica carpado de giro gigante. Serbest e colaboradores (2018) encontraram picos de momento de joelho $(1,0 \mathrm{Nm} / \mathrm{kg})$ similares, porém momentos de quadril $(10,5 \mathrm{Nm} / \mathrm{kg})$ e ombro $(38,8$ $\mathrm{Nm} / \mathrm{kg}$ ) muito superiores. Um fator que pode ter contribuído para essa expressiva diferença foi a diferença entre amostras. Esses autores analisaram um ginasta de 13 anos de idade, sendo razoável supor que ginastas de elite possam realizar o movimento de saída com maior aproveitamento da elasticidade da barra e maior eficiência articular.

Tabela 15. Percentual do período de DSBS para instante de pico de momento articular $(\tau)$. Diferença de instantes entre articulações adjacentes.

\begin{tabular}{cccccc}
\hline Sujeito & $\tau$-joelho & $\tau$-quadril & $\begin{array}{c}\Delta \text { (quadril- } \\
\text { joelho) }\end{array}$ & $\tau$-ombro & $\begin{array}{c}\Delta \text { (ombro- } \\
\text { quadril) }\end{array}$ \\
\hline 1 & 72,4 & 74,2 & 1,8 & 74,5 & 0,3 \\
2 & 74,7 & 75,1 & 0,4 & 75,5 & 0,4 \\
3 & 74,2 & 74,7 & 0,5 & 75,1 & 0,4 \\
4 & 71,2 & 73,7 & 2,5 & 74,0 & 0,3 \\
5 & 73,9 & 74,5 & 0,6 & 75,4 & 0,9 \\
6 & 73,2 & 74,7 & 1,5 & 75,2 & 0,5 \\
7 & 74,0 & 74,2 & 0,2 & 74,4 & 0,2 \\
\hline média & 73,4 & 74,4 & 1,1 & 74,9 & 0,4 \\
DP & 1,2 & 0,5 & 0,9 & 0,6 & 0,2 \\
\hline
\end{tabular}

Os momentos articulares durante o voo foram menos expressivos quando comparados à fase de impulso, especialmente no caso do ombro $(1,1 \pm 0,2 \mathrm{Nm} / \mathrm{kg})$. Quadril e joelho apresentaram picos extensores $(0,9 \pm 0,6 \mathrm{Nm} / \mathrm{kg}$ e $0,7 \pm 0,1 \mathrm{Nm} / \mathrm{kg}$, respectivamente) nos últimos 5\% do período de voo (99\% do total) (Figura 52). 

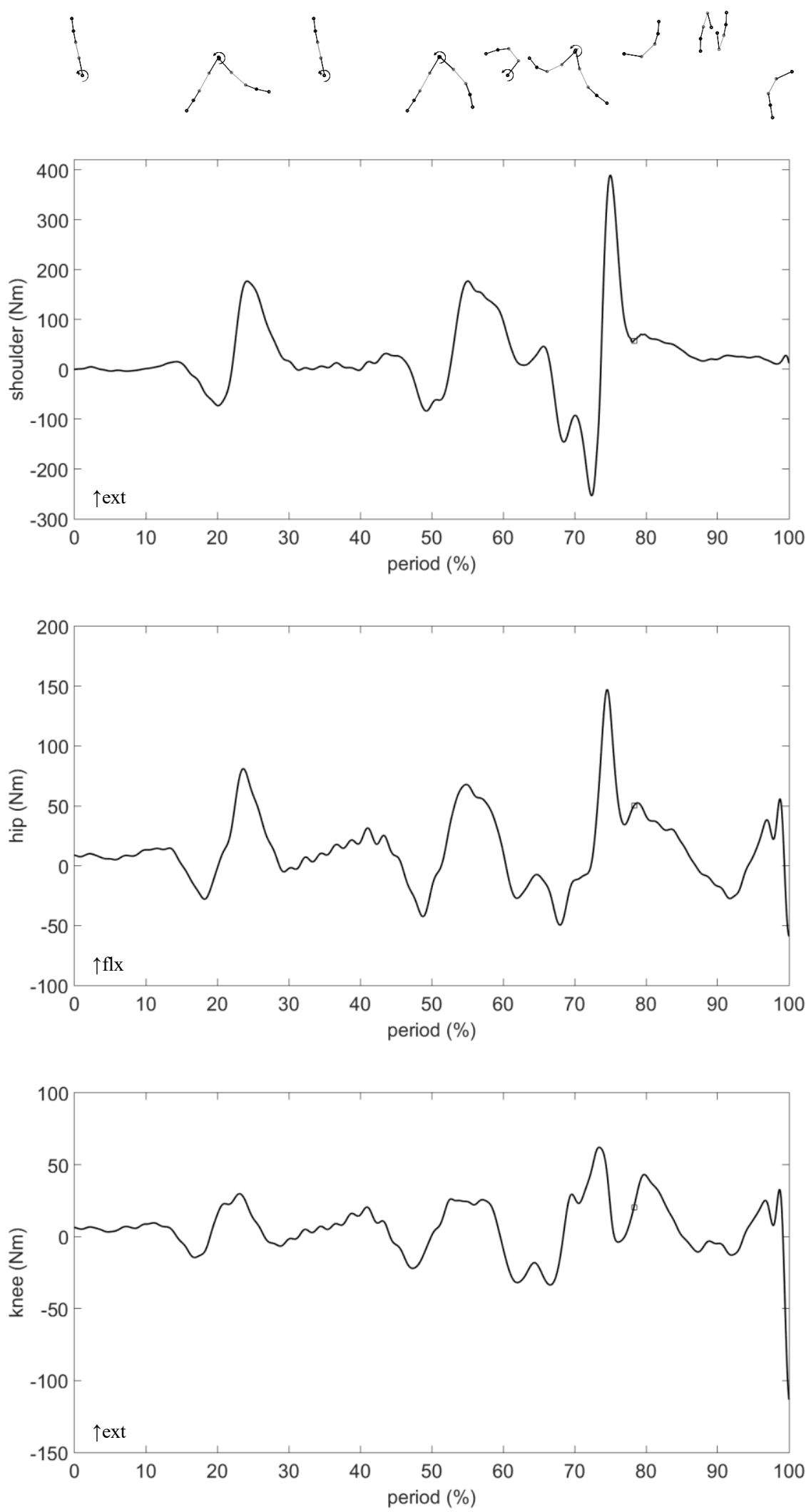

Figura 52. Momentos articulares (médios) durante o DSBS: ombro (superior), quadril (centro) e joelho (inferior). Legenda: ( $\uparrow f l x)$ ação flexora; ( $\square$ ) instante de lançamento.

No instante de pré-colisão foi observado um ângulo de inclinação corporal (ankcom) de $83,0 \pm 3,8^{\circ}$ e uma velocidade angular de $291,7 \pm 53,7^{\circ} / \mathrm{s}$. Se por um lado a baixa 
variabilidade de inclinação indica uma estreita faixa entre sucesso e falha, por outro lado, a alta variabilidade da velocidade angular sinaliza a diversidade de condições de chegada. As posições articulares de pré-impacto foram: joelho fletido em $0,5 \pm 3,0^{\circ}$, quadril fletido em $44,4 \pm 7,7^{\circ}$ e ombro fletido em $127,8 \pm 13,7^{\circ}$, com destaque para uma abrupta ação flexora de joelho nos últimos $5 \%$ do período de voo (aprox. $50 \mathrm{~ms}$ ) e início das desacelerações de quadril e ombro, $6 \%$ do fim do período (cerca de $70 \mathrm{~ms}$ ).

Assim, assumindo como critério de tentativa válida a finalização de DSBS em apoio bipodal, define-se abaixo o perfil biomecânico dessa saída de barra fixa (Figura 53):

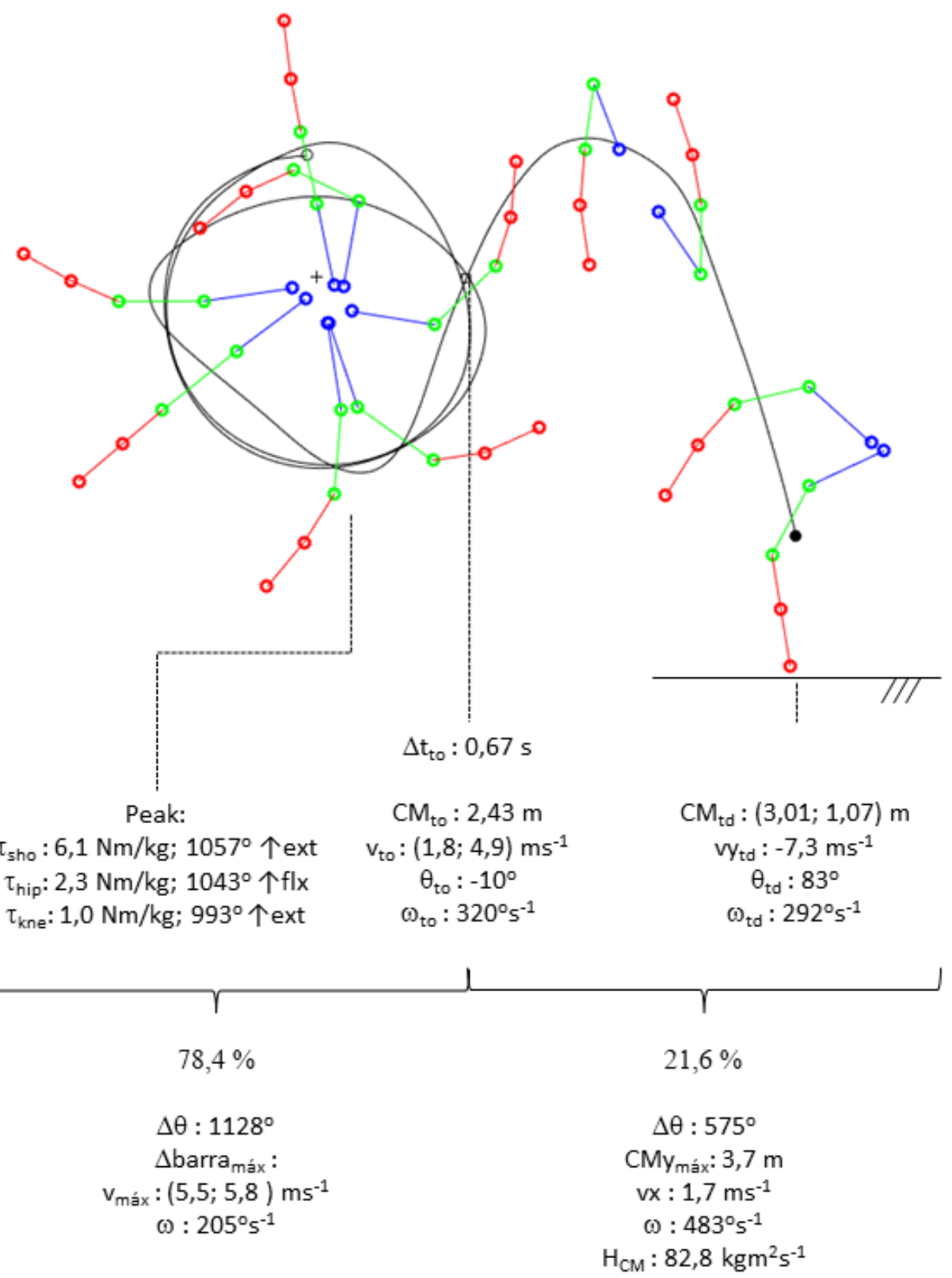

Figura 53. Perfil biomecânico do DSBS baseado em instantes críticos. 
Os comportamentos médios $( \pm \mathrm{DP})$ das variáveis biomecânicas que caracterizaram o DSBS, de cada sujeito em 7 tentativas, foram reunidos abaixo (Figura 54 a Figura 63):
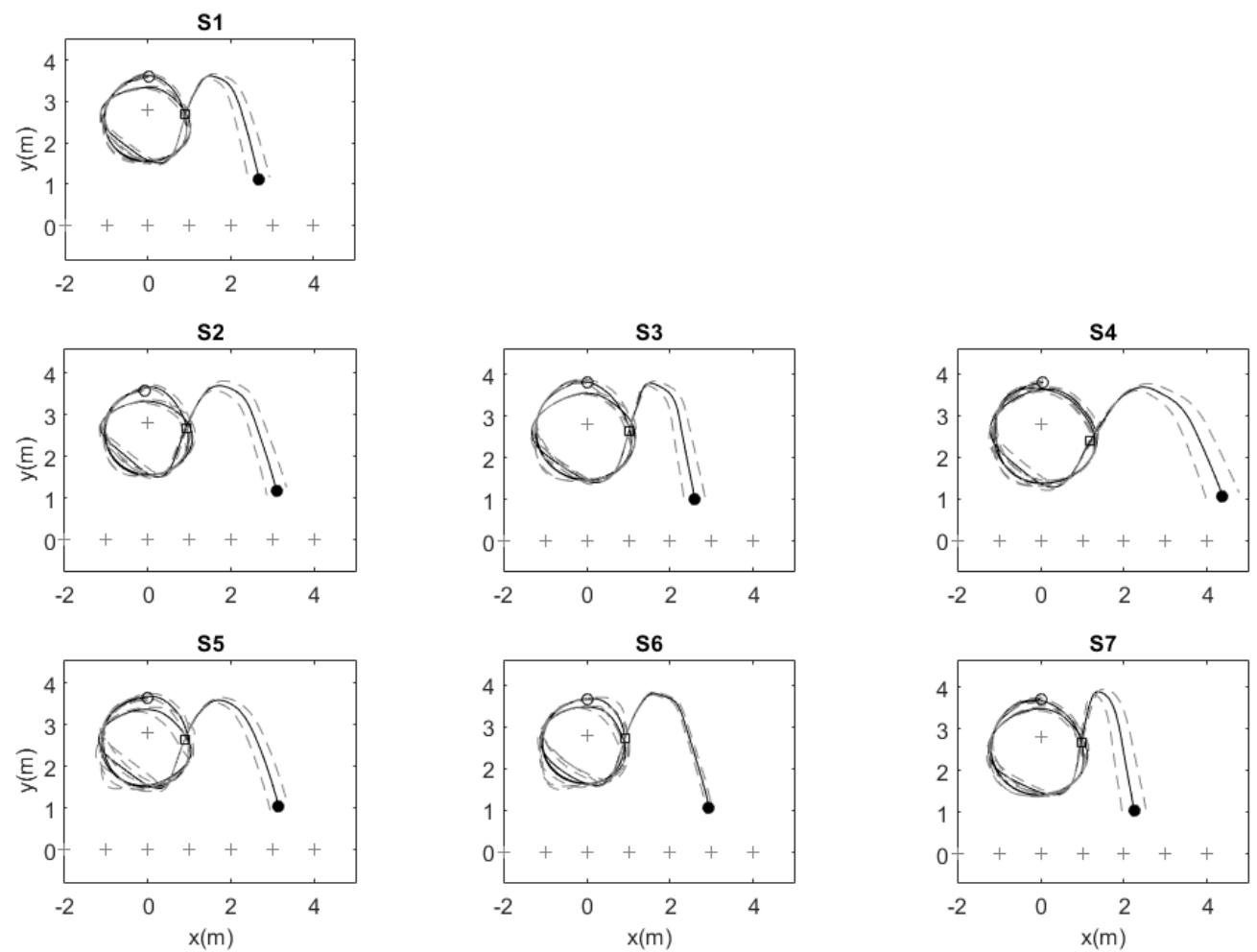

Figura 54. Trajetória do CM (média \pm desvio padrão) no período de DSBS de cada sujeito. Legenda: (०) posição inicial e $(\bullet)$ final da sequência de movimentos.
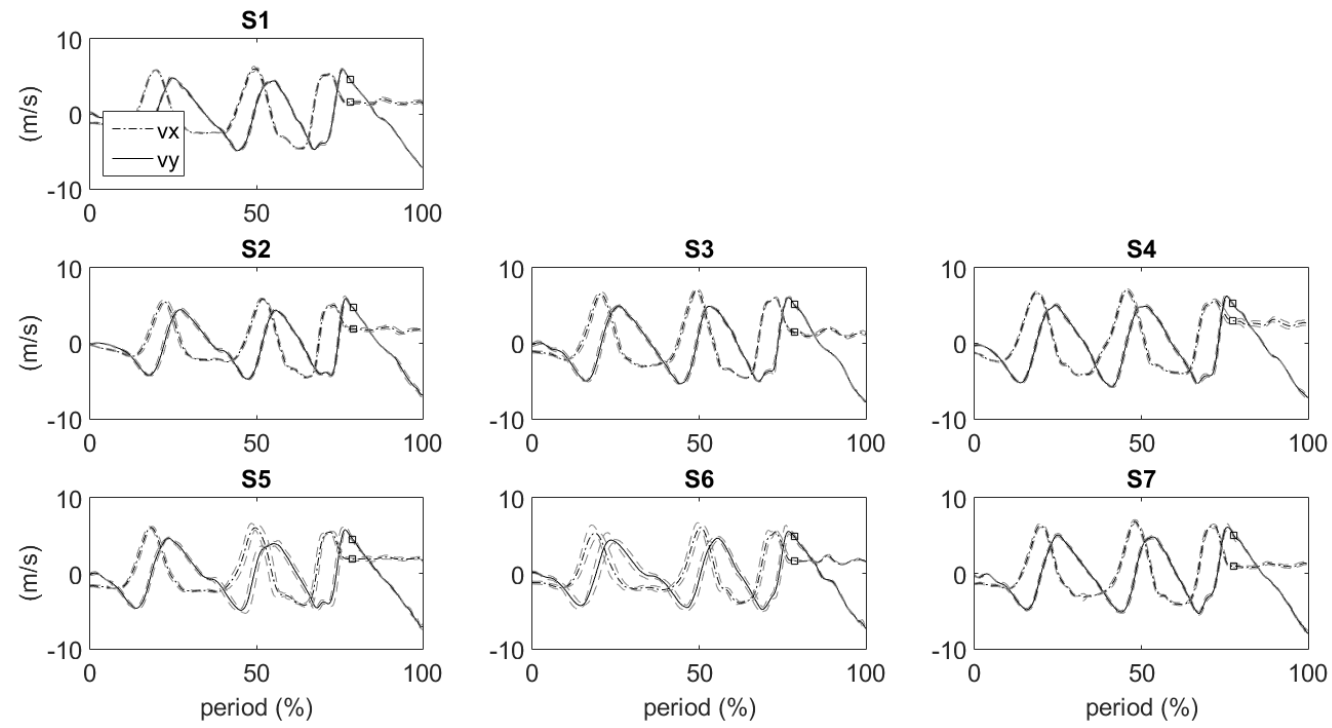

Figura 55. Velocidade linear do CM (média \pm desvio padrão) no período de DSBS de cada sujeito. Legenda: ( $\square$ ) instante de lançamento. 

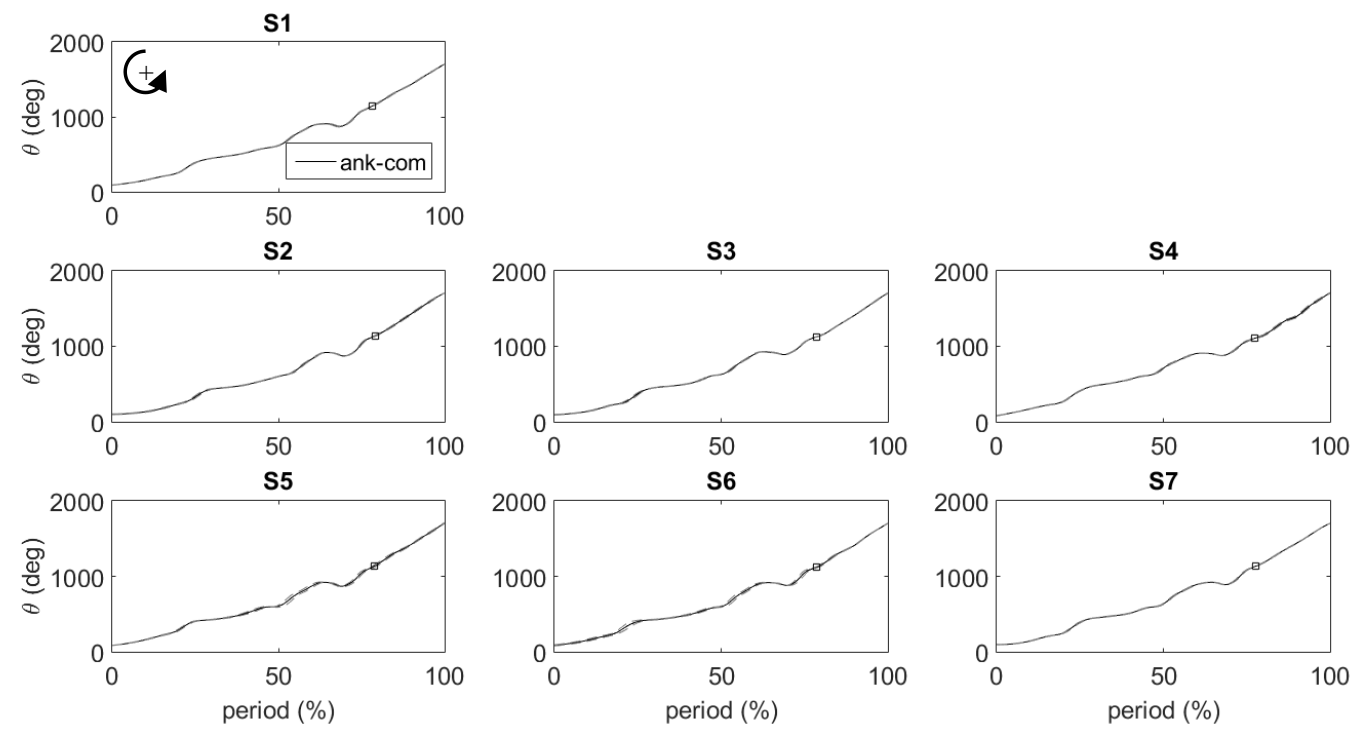

Figura 56. Histórico da posição angular do corpo (média \pm desvio padrão) no período de DSBS de cada sujeito. Legenda: (ank-com) segmento que ume o centro articular do tornozelo ao CM; ( $\square$ ) instante de lançamento.
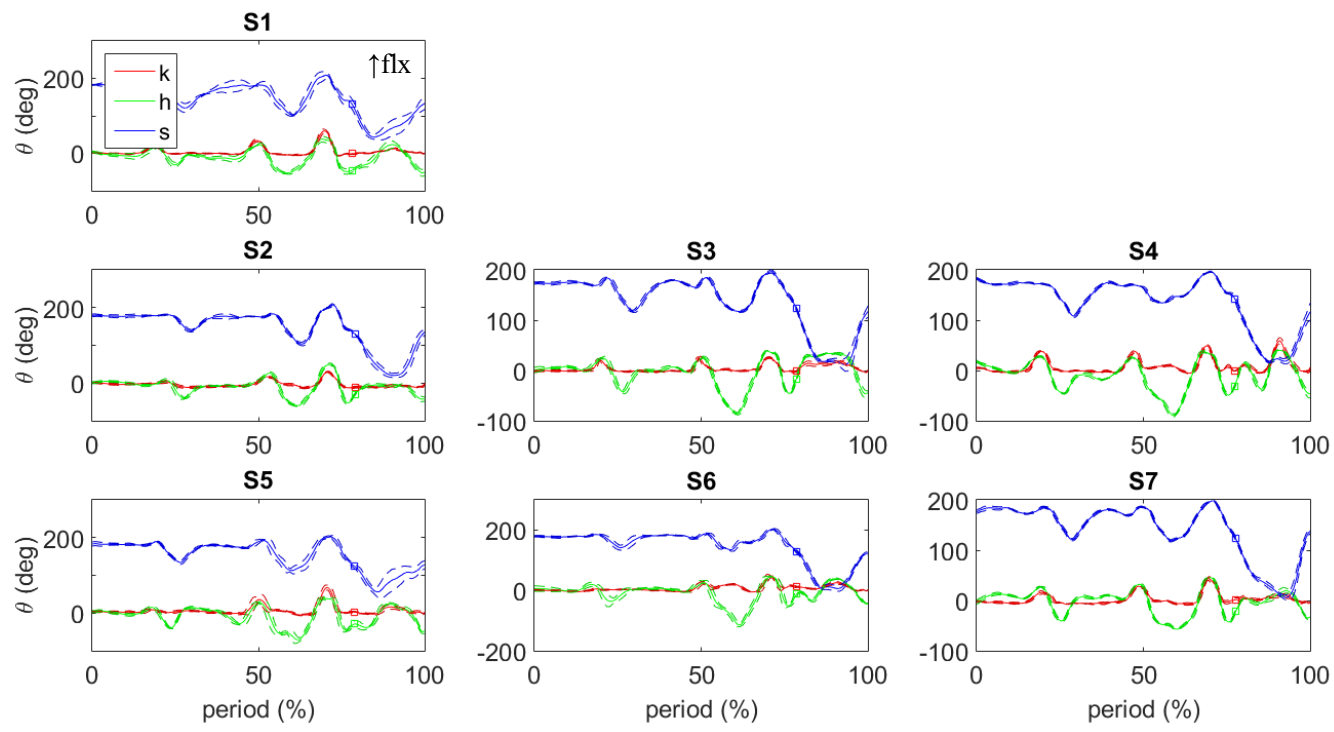

Figura 57. Posição articular (média \pm desvio padrão) no período de DSBS de cada sujeito. Legenda: (k) joelho, (h) quadril e (s) ombro; ( $\uparrow$ flx) ação flexora; ( $\square$ ) instante de lançamento. 

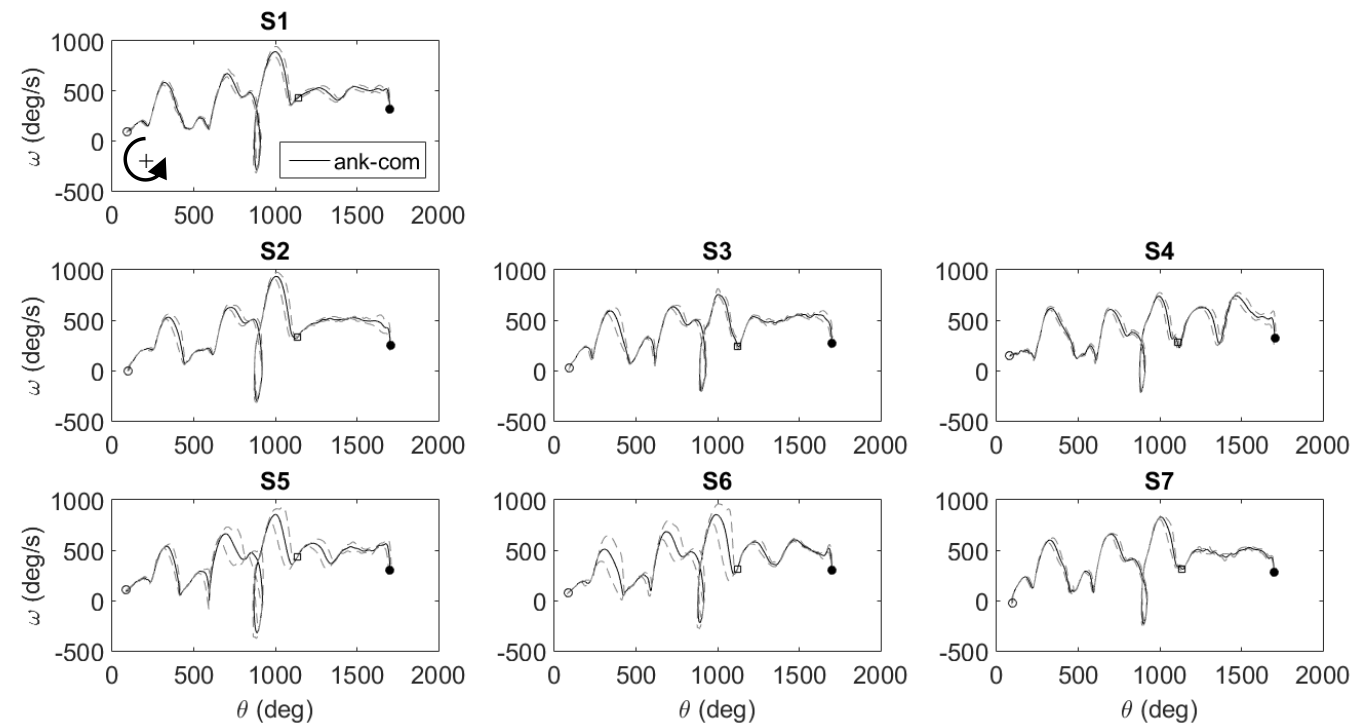

Figura 58. Velocidade angular do corpo (média \pm desvio padrão) em função da posição angular, no período de DSBS de cada sujeito. Legenda: (ank-com) segmento que une o centro articular do tornozelo ao centro de massa; (०) posição inicial e $(\bullet)$ final da sequência de movimentos; ( $\square$ ) instante de lançamento.
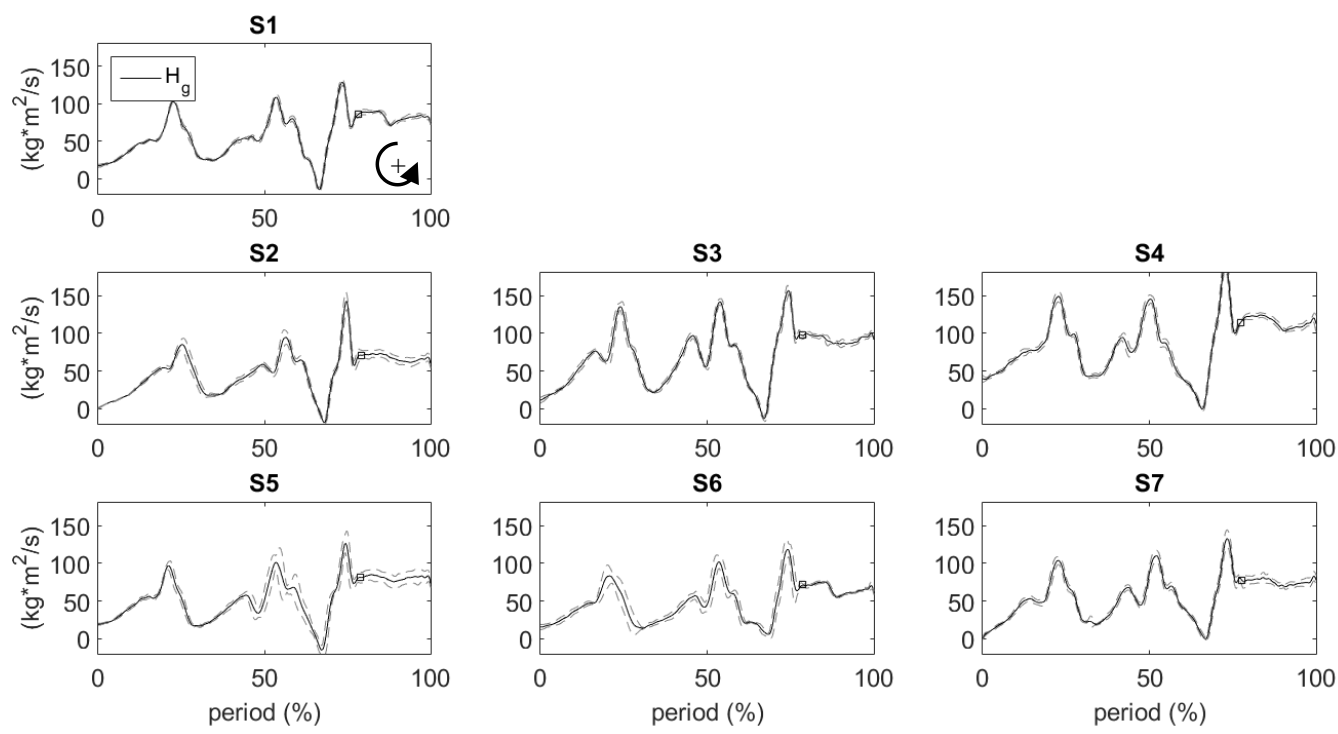

Figura 59. Quantidade de movimento angular $\left(\mathrm{H}_{\mathrm{g}}\right)$ em relação do centro de massa (média \pm desvio padrão) no período de DSBS de cada sujeito. Legenda: () instante de lançamento. 

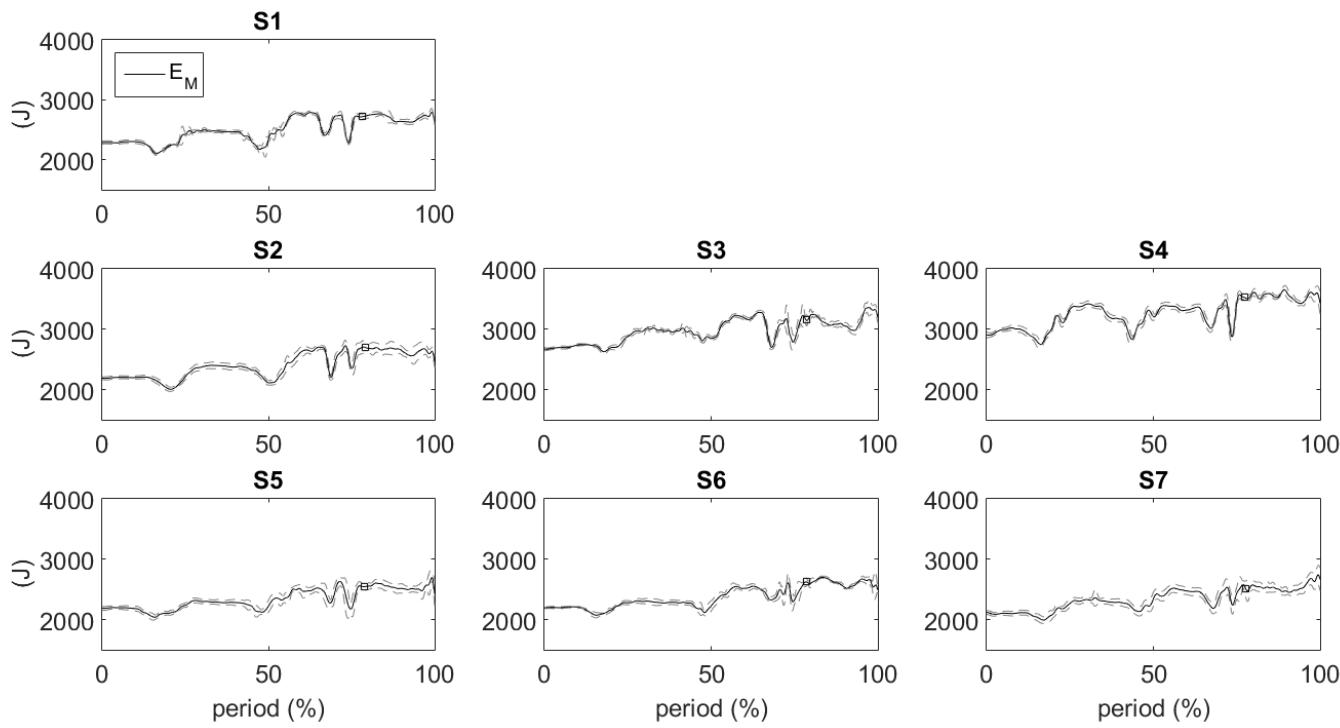

Figura 60. Energia mecânica (média \pm desvio padrão) no período de DSBS de cada sujeito. Legenda: ( $\square$ ) instante de lançamento.
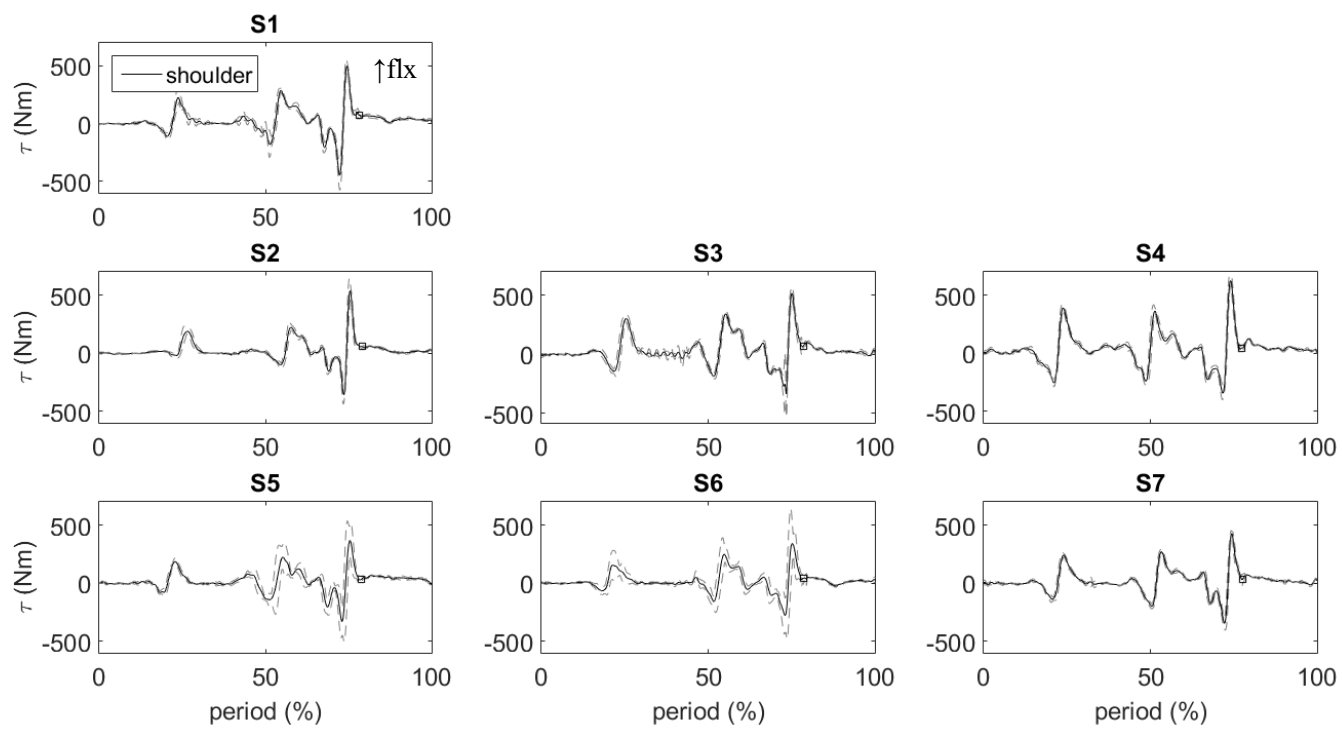

Figura 61. Momento de ombro $(\tau)$ (média \pm desvio padrão) no período de DSBS de cada sujeito. Legenda: ( $\uparrow$ flx) ação flexora; $(\square)$ instante de lançamento. 

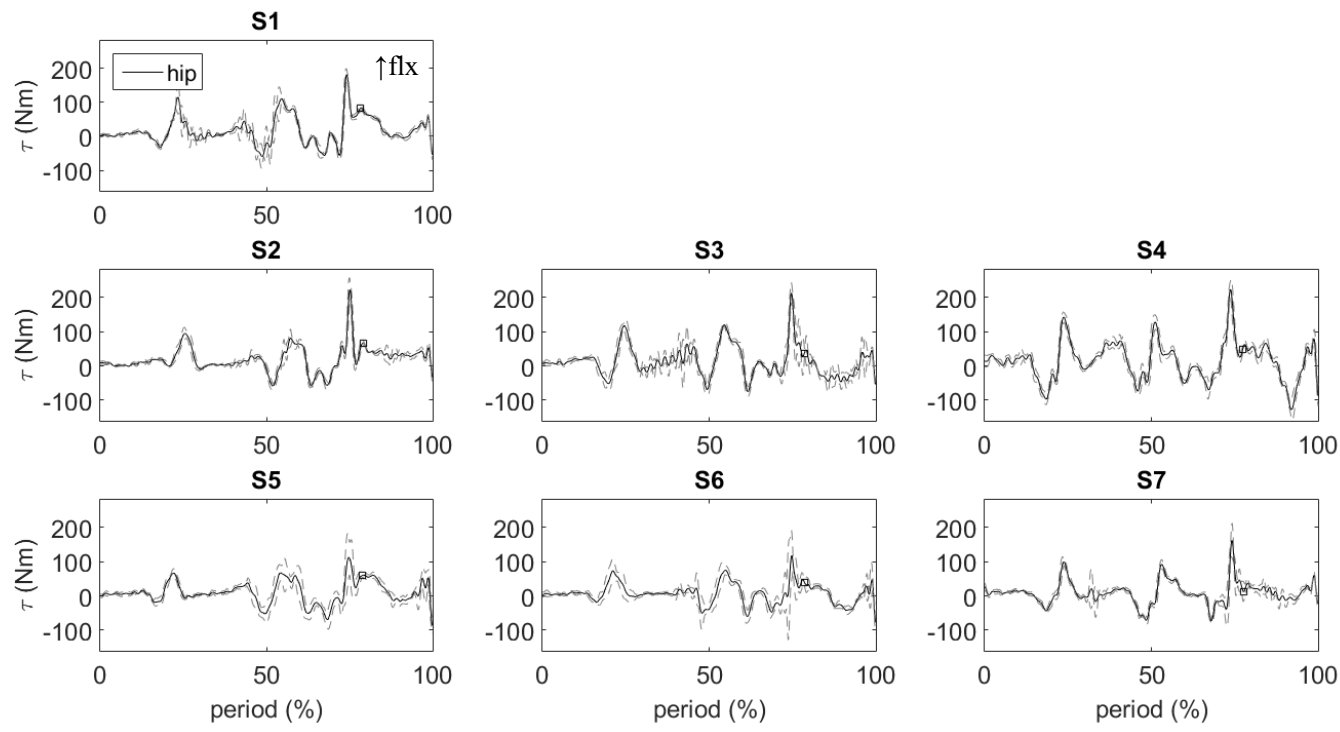

Figura 62. Momento de quadril ( $\tau$ ) (média \pm desvio padrão) no período de DSBS de cada sujeito. Legenda: ( $\uparrow$ flx) ação flexora; (口) instante de lançamento.
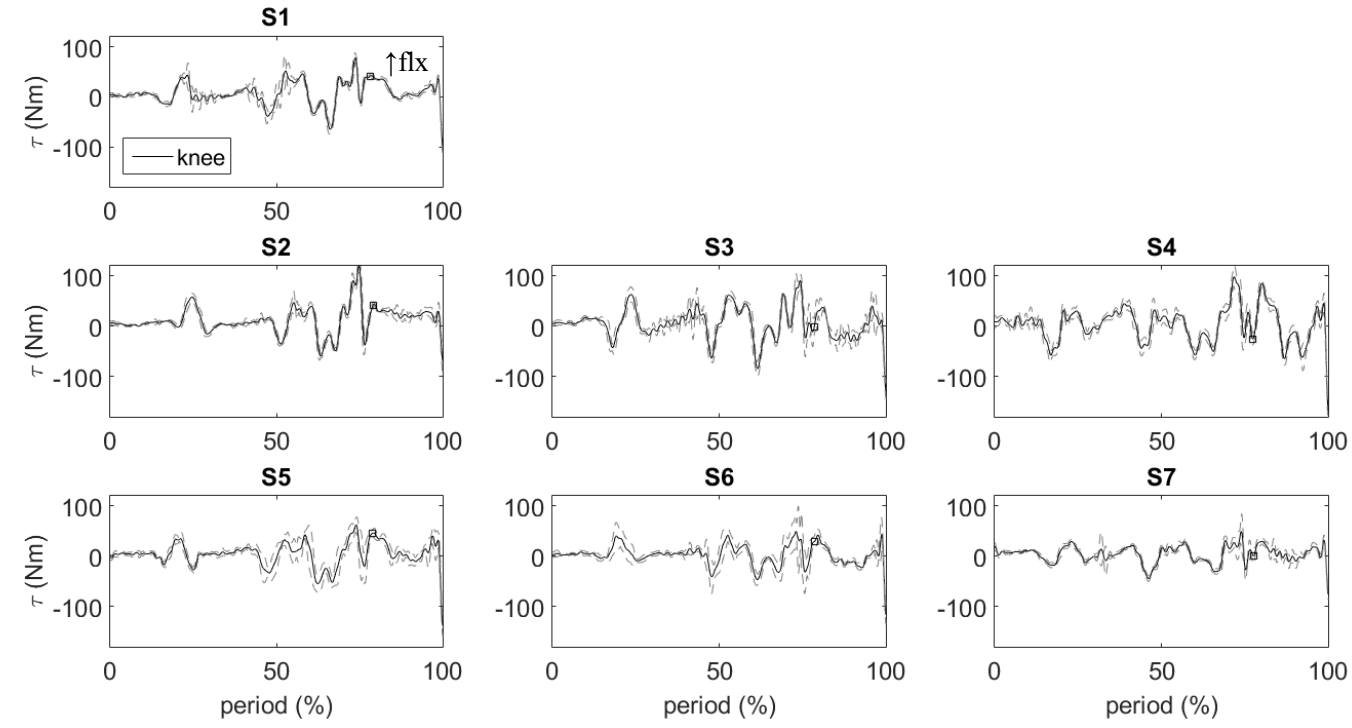

Figura 63. Momento de joelho $(\tau)$ (média \pm desvio padrão) no período de DSBS de cada sujeito. Legenda: ( $\uparrow$ flx) ação flexora; ( $\square$ ) instante de lançamento.

\subsection{CONDIÇÕES DE ATERRISSAGEM DO DUPLO MORTAL ESTENDIDO PARA TRÁS SEGUNDO MODELO ANALÍTICO}

Diante de 109 variáveis biomecânicas analisadas e numerosas possibilidades de combinação das mesmas, quais fatores determinam a aterrissagem de DSBS em condições de atingir o repouso sem a necessidade de passos na chegada? Selecionadas com base no modelo 
analítico, a hipótese alternativa foi concentrada em cinco variáveis para o instante de précolisão: $\mathrm{vx}^{-}, \mathrm{vy}^{-}, \theta^{-}, \omega^{-} \mathrm{e} \mathrm{H}_{\mathrm{o}}^{-}$. A análise de componentes principais revelou que a variabilidade dessas variáveis foi responsável por $45 \%$ dos casos de discriminação das condições de chegada (sucesso ou falha) no PC1, 76\% acumulados em PC1 e PC2, 91\% de PC1 a PC3 e praticamente o total de casos até PC4 (Tabela 16).

Em PC1, destaca-se a contribuição da quantidade de movimento angular $(0,64)$, seguida por velocidade angular $(0,56)$, ângulo de aterrissagem $(0,42)$ e velocidade horizontal $(0,36)$. Em PC2, foram predominantes, respectivamente, as contribuições das velocidades horizontal $(0,63)$ e vertical $(-0,59)$. No terceiro componente a velocidade vertical aumenta a importância relativa $(0,78)$. E por fim, em PC4 a velocidade angular $(0,81)$ torna-se preponderante (Figura 64 a Figura 66 e Tabela 17).
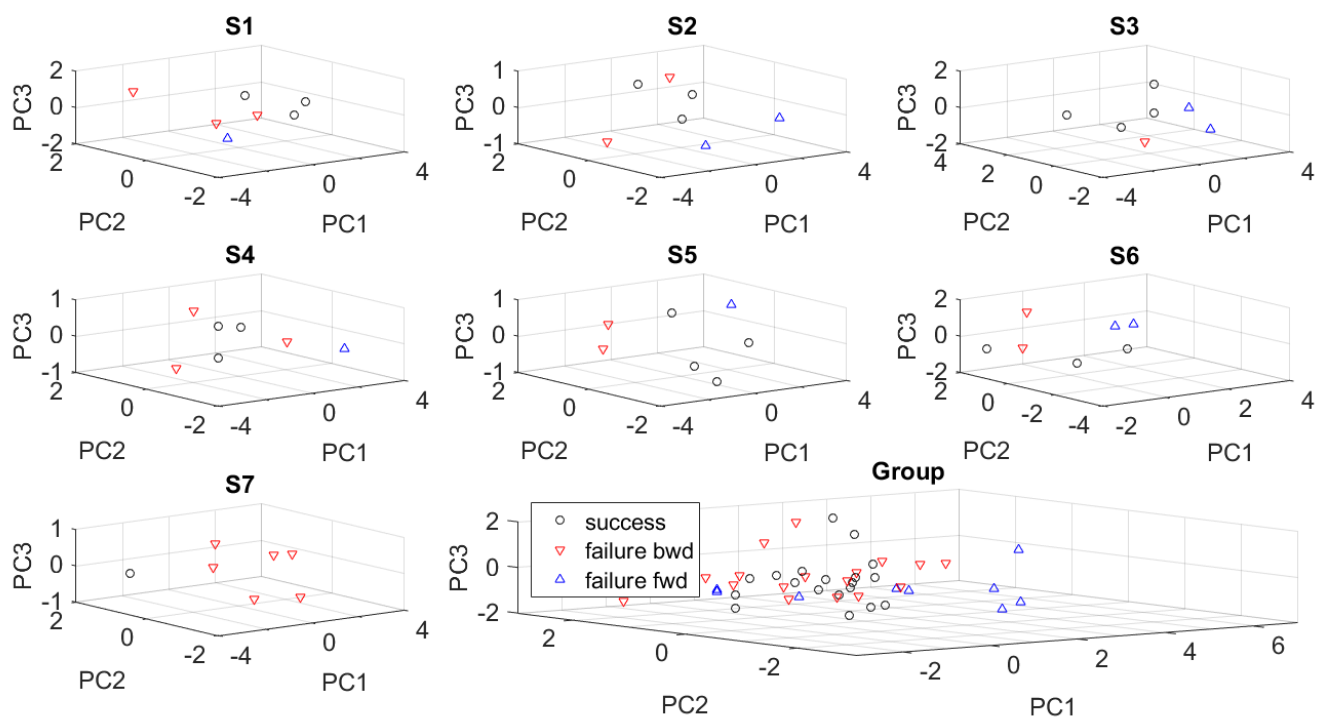

Figura 64. Análise de componentes principais para condições de sucesso ou falha (7 sujeitos (S), em 7 tentativas cada) nas saídas de barra fixa em duplo mortal estendido, considerando 77 variáveis biomecânicas. 

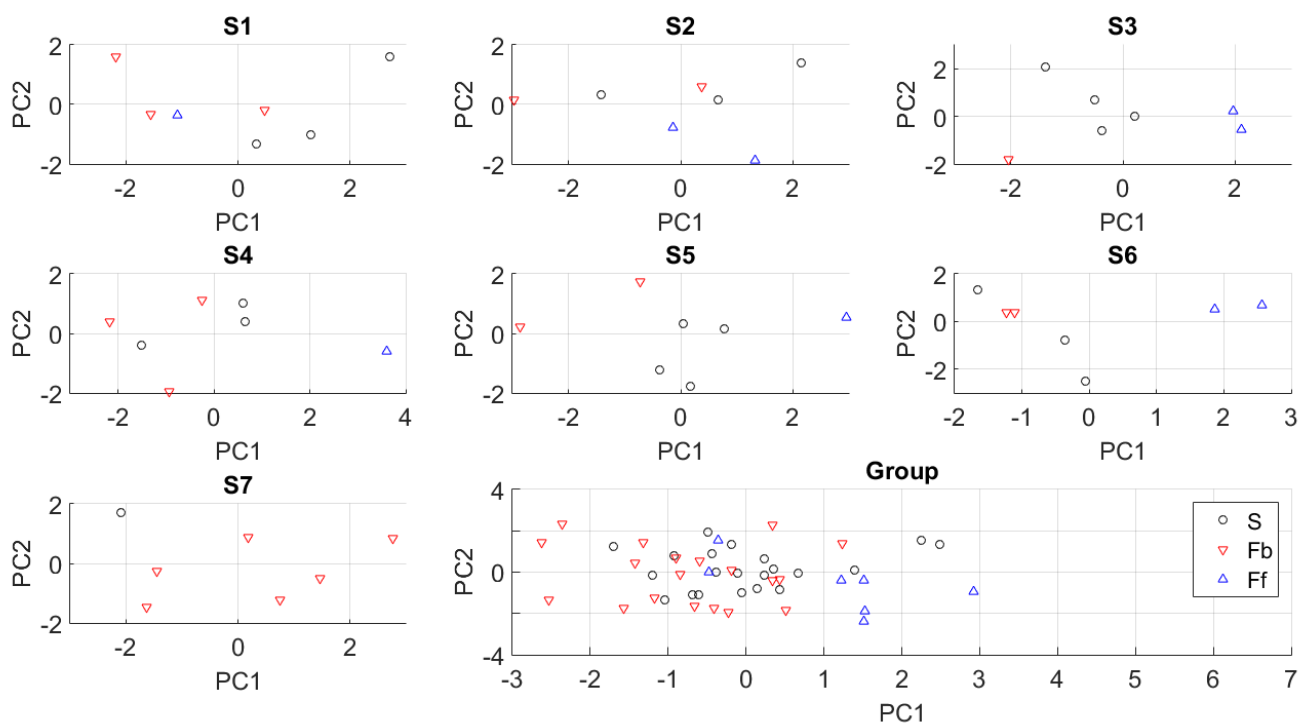

Figura 65. Componentes Principais 1 e 2 para condições de sucesso ou falha nas saídas de barra fixa em duplo mortal estendido. Legenda: $(\mathrm{S})$ sucesso, $(\mathrm{Fb})$ falha com deslocamento para trás e (Ff) falha com deslocamento para frente.
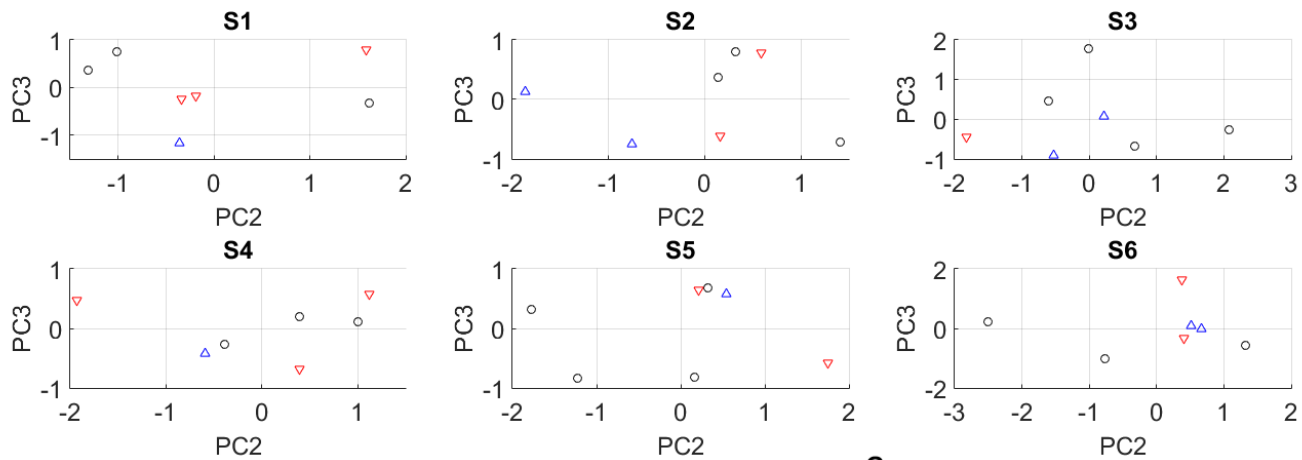

S5
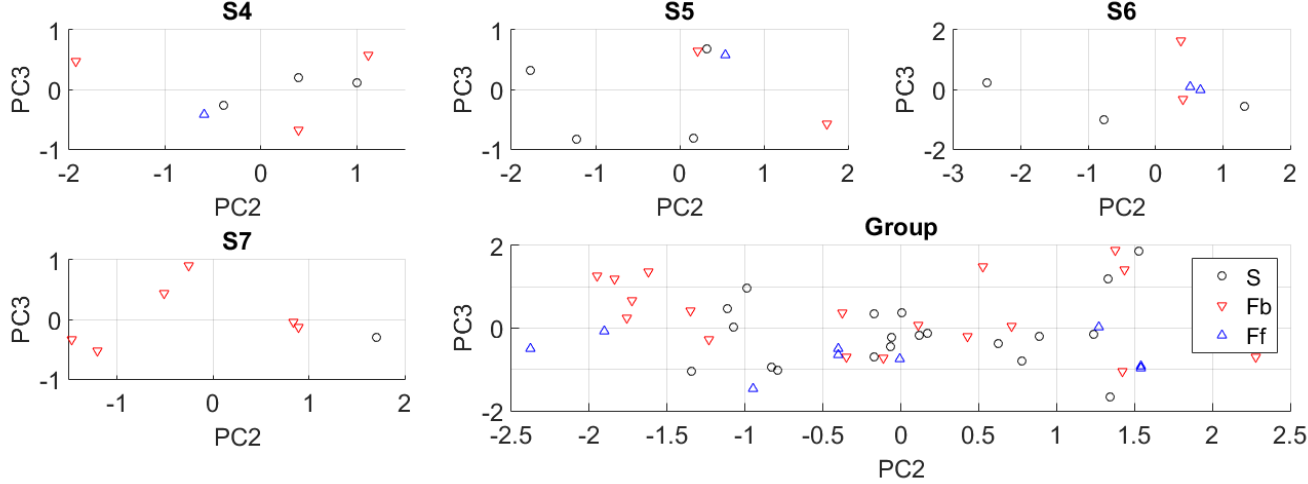

Figura 66. Componentes Principais 2 e 3 para condições de sucesso ou falha nas saídas de barra fixa em duplo mortal estendido. Legenda: $(\mathrm{S})$ sucesso, $(\mathrm{Fb})$ falha com deslocamento para trás e (Ff) falha com deslocamento para frente.

Tabela 16. Resultados da proporção acumulada na PCA para as variáveis que configuram a hipótese de pesquisa (velocidade linear, ângulo do corpo, velocidade angular e quantidade de movimento angular).

\begin{tabular}{ccccc}
\hline PC1 & PC2 & PC3 & PC4 & PC5 \\
\hline 0,451 & 0,757 & 0,910 & 0,992 & 1,000 \\
\hline
\end{tabular}


Tabela 17. Resultados da contribuição da variabilidade de cada variável nos eixos que compõem o espaço multidimensional na PCA.

\begin{tabular}{cccccc}
\hline Variáveis & PC1 & PC2 & PC3 & PC4 & PC5 \\
\hline vx $^{-}$ & 0,36 & 0,63 & 0,32 & $-0,05$ & 0,60 \\
vy $^{-}$ & $-0,01$ & $-0,59$ & 0,78 & $-0,04$ & 0,21 \\
$\theta^{-}$ & 0,42 & $-0,48$ & $-0,51$ & $-0,30$ & 0,49 \\
$\omega^{-}$ & 0,56 & $-0,13$ & $-0,02$ & 0,81 & $-0,12$ \\
$\mathrm{H}_{\mathrm{o}}^{-}$ & 0,61 & 0,06 & 0,19 & $-0,50$ & $-0,58$ \\
\hline
\end{tabular}

Legenda: (vx) velocidade horizontal, (vy) velocidade vertical, $(\theta)$ ângulo do corpo, ( $\omega$ ) velocidade angular do corpo, $\left(\mathrm{H}_{\mathrm{o}}\right)$ quantidade de movimento angular em relação ao tornozelo e ( $\left.{ }^{\circ}\right)$ instante imediatamente anterior à colisão.

Diante da capacidade discriminativa das variáveis que compõem essa simplificação do sistema mecânico para aterrissagem de DSBS (Figura 39), o modelo biomecânico de chegada (equações 19 a 25) foi adotado para análise das configurações determinantes de sucesso. Pressuposta a condição de repouso $\left(\omega_{f}=0\right)$ para um sistema de pêndulo invertido, um conjunto de relações destaca-se entre as variáveis determinantes (Figura 67), onde os resultados de $\mathrm{H}_{\mathrm{o}}{ }^{-}<0 \mathrm{kgm}^{2} / \mathrm{s}$ foram considerados offset associados às medidas experimentais, preservando o significado interpretativo do intervalo relativo $\Delta \mathrm{H}_{\mathrm{o}}{ }^{-}$. Para $\mathrm{H}_{\mathrm{o}}{ }^{-}$variando entre 29,3 e -76,1 $\mathrm{kgm}^{2} / \mathrm{s}$, ângulos de colisão abaixo de 79,6 $6^{\circ}$ graus não apresentaram quantidade de movimento angular suficiente para impedir um deslocamento para frente. Por outro lado, $\theta^{-}$ acima de $87,4^{\circ}$ provocaram, quase sempre, deslocamentos para trás. Essa região de $\mathrm{H}_{\mathrm{o}}{ }^{-}$e $\theta^{-}$ representou as condições necessárias $85,7 \%$ dos casos de sucesso nas chegadas (Figura 67).

$\mathrm{Na}$ faixa de configurações acima, foi uma combinação das velocidades lineares e angulares que definiu as condições suficientes para uma chegada ideal após o DSBS (Figura 68). Quando próximo ao limite superior de $\theta^{-}\left(>83,2^{\circ}\right)$, velocidades angulares inferiores a $332,9 \%$ foram compensadas por maiores velocidades horizontais $(\geq 1,62 \mathrm{~m} / \mathrm{s})$ e/ou maiores velocidades verticais $(<-7,53 \mathrm{~m} / \mathrm{s})$. Por outro lado, quando no limite inferior de $\theta$, foram as maiores velocidades angulares (> 253,14\% ) associadas às menores velocidades horizontais (< 1,62 m/s) e/ou menores velocidades verticais (> -7,22 m/s) que garantiram a posição estacionária ao final da fase de colisão (Figura 69 e Figura 70). 


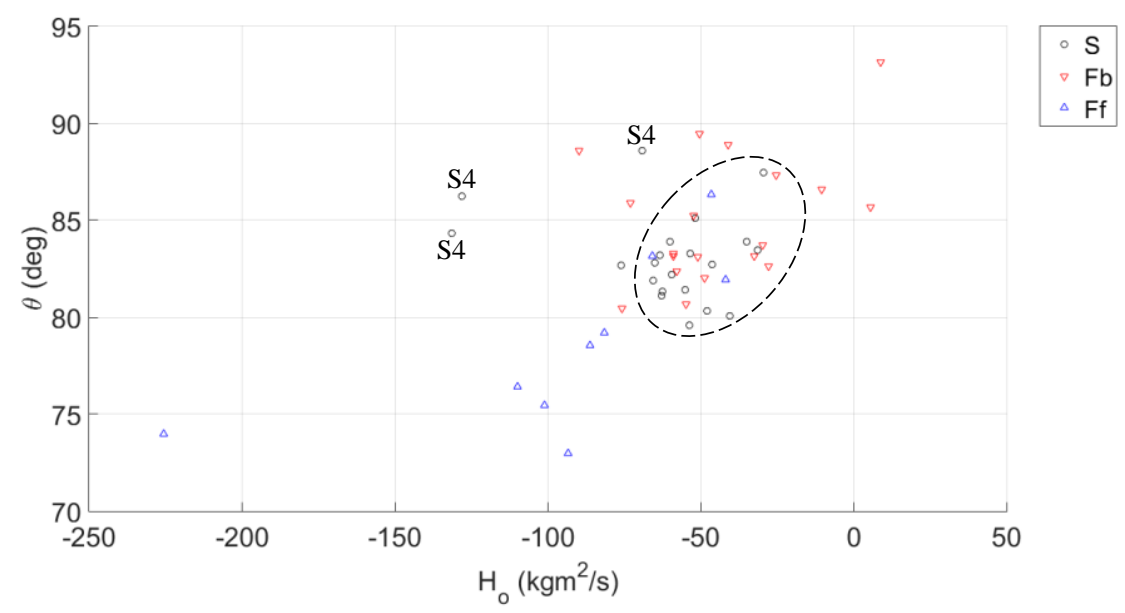

Figura 67. Ângulo de aterrissagem $(\theta)$ em relação à quantidade de movimento angular $\left(\mathrm{H}_{\mathrm{o}}\right)$ em relação ao eixo de controle (tornozelo) para o impulso estacionário. Conjunto representativo das configurações de sucesso (área tracejada). Legenda: $(\mathrm{S})$ sucesso, $(\mathrm{Fb})$ falha com deslocamento para trás; $(\mathrm{Ff})$ falha com deslocamento para frente e (S4) caso particular de sucesso.

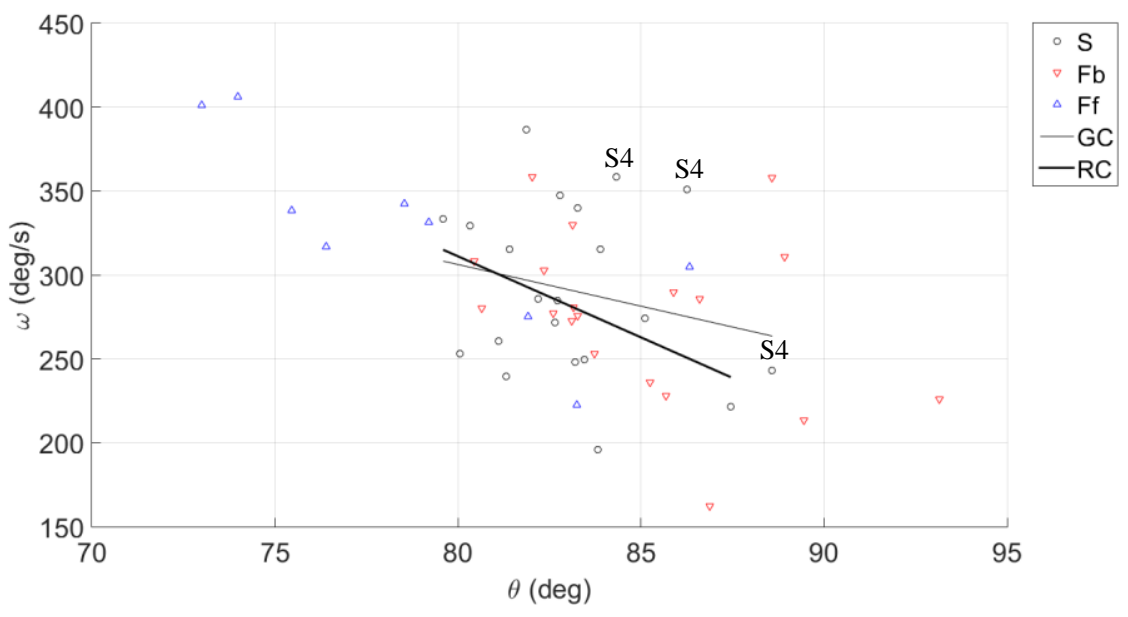

Figura 68. Velocidade angular $(\omega)$ em relação ao ângulo $(\theta)$ de pré-impacto. Linha de tendência associada ao sucesso da aterrissagem. Legenda: $(\mathrm{S})$ sucesso, $(\mathrm{Fb})$ falha com deslocamento para trás, $(\mathrm{Ff})$ falha com deslocamento para frente, (GC) linha de tendência central para o sucesso com caso particular (S4) e (RC) linha de tendência central para o sucesso somente com casos regulares. 


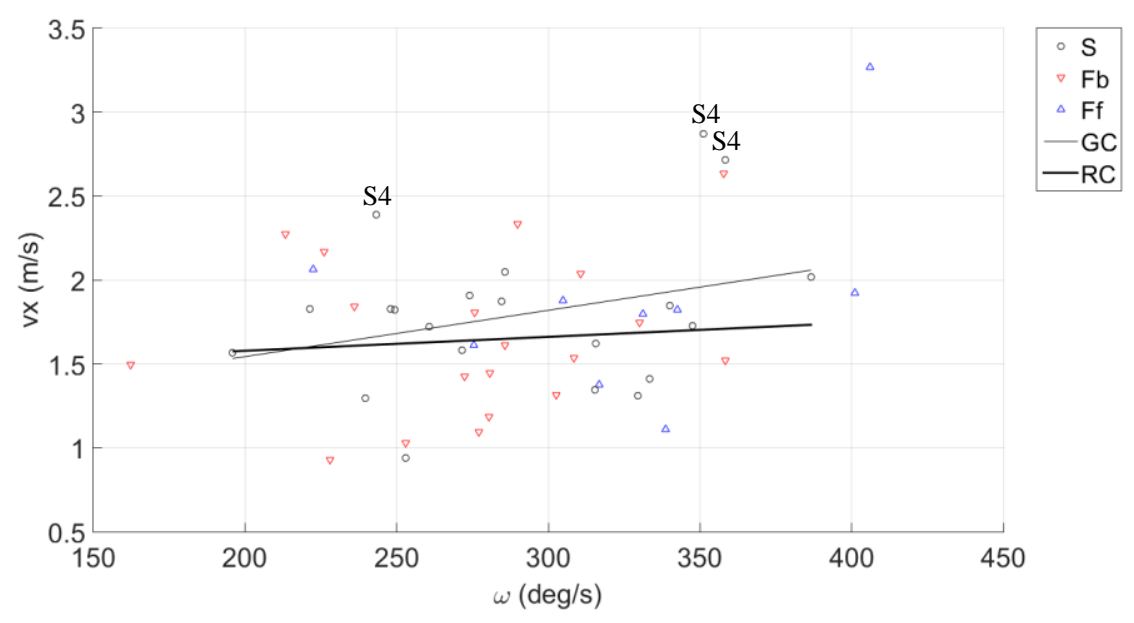

Figura 69. Velocidade horizontal $(\mathrm{vx})$ em relação à velocidade angular $(\omega)$ no pré-impacto. Linha de tendência associada ao sucesso da aterrissagem. Legenda: $(\mathrm{S})$ sucesso, $(\mathrm{Fb})$ falha com deslocamento para trás, $(\mathrm{Ff})$ falha com deslocamento para frente, (GC) linha de tendência central para o sucesso com caso particular (S4) e (RC) linha de tendência central para o sucesso somente com casos regulares.

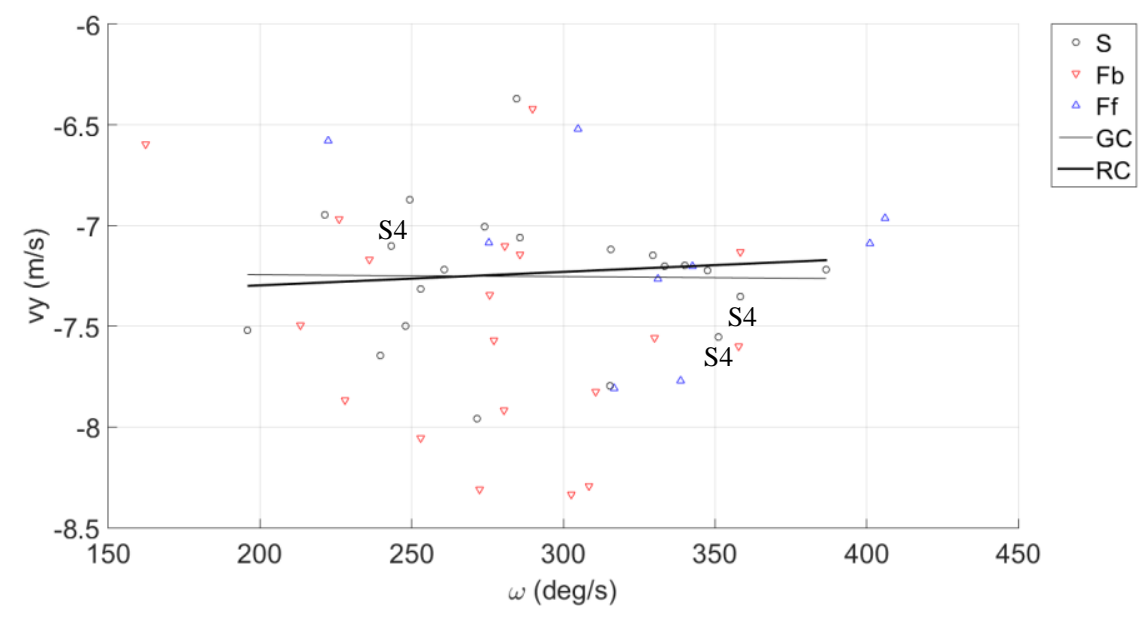

Figura 70. Velocidade vertical (vy) em relação à velocidade angular ( $\omega)$ no pré-impacto. Linha de tendência associada ao sucesso da aterrissagem. Legenda: $(\mathrm{S})$ sucesso, $(\mathrm{Fb})$ falha com deslocamento para trás, (Ff) falha com deslocamento para frente, (GC) linha de tendência central para o sucesso com caso particular (S4) e (RC) linha de tendência central para o sucesso somente com casos regulares.

Um caso particular ocorreu com o ginasta 4 (S4). Em todas as tentativas, incluindo as três condições de sucesso, uma acentuada flexão de joelho em fase aérea representa uma falha de execução para o DSBS. Essa estratégia técnica foi acompanhada de um comportamento atípico em fase aérea (pico de $\mathrm{H}_{\mathrm{o}}{ }^{-}=-131,3 \mathrm{kgm}^{2} / \mathrm{s}$ ) nas variáveis biomecânicas que configuram o sistema. Apesar de válida, a saída de barra apresentada nessas condições provoca desconto na nota por falha de execução. Dessa maneira, sugere-se que a adoção dessa estratégia seja ponderada. 
As relações entre as variáveis que compõem a hipótese desta pesquisa, de cada sujeito, no instante imediatamente anterior à aterrissagem de DSBS, foram reunidas abaixo (Figura 71 a Figura 75, Tabela 18):
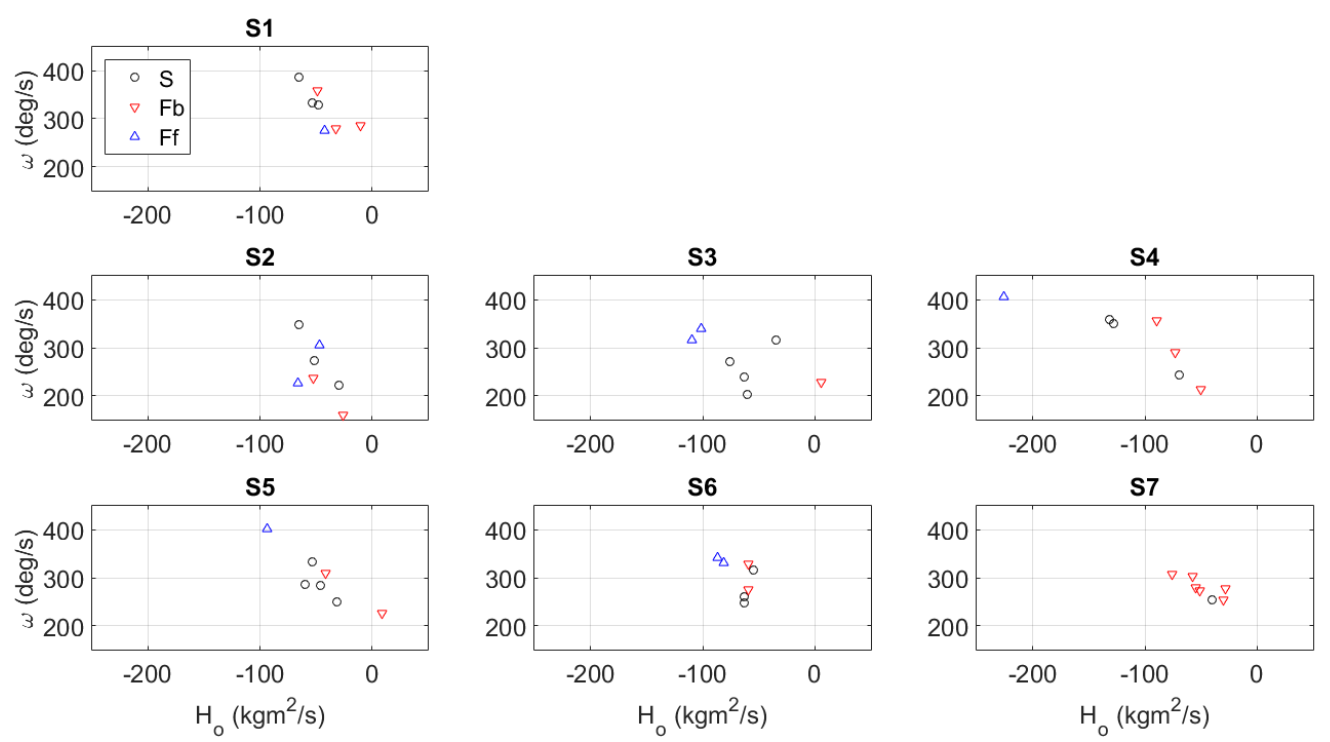

Figura 71. Velocidade angular $(\theta)$ em relação à quantidade de movimento angular $\left(\mathrm{H}_{\mathrm{o}}\right)$ no pré-impacto, de cada sujeito. Legenda: $(\mathrm{S})$ sucesso, $(\mathrm{Fb})$ falha com deslocamento para trás e (Ff) falha com deslocamento para frente.
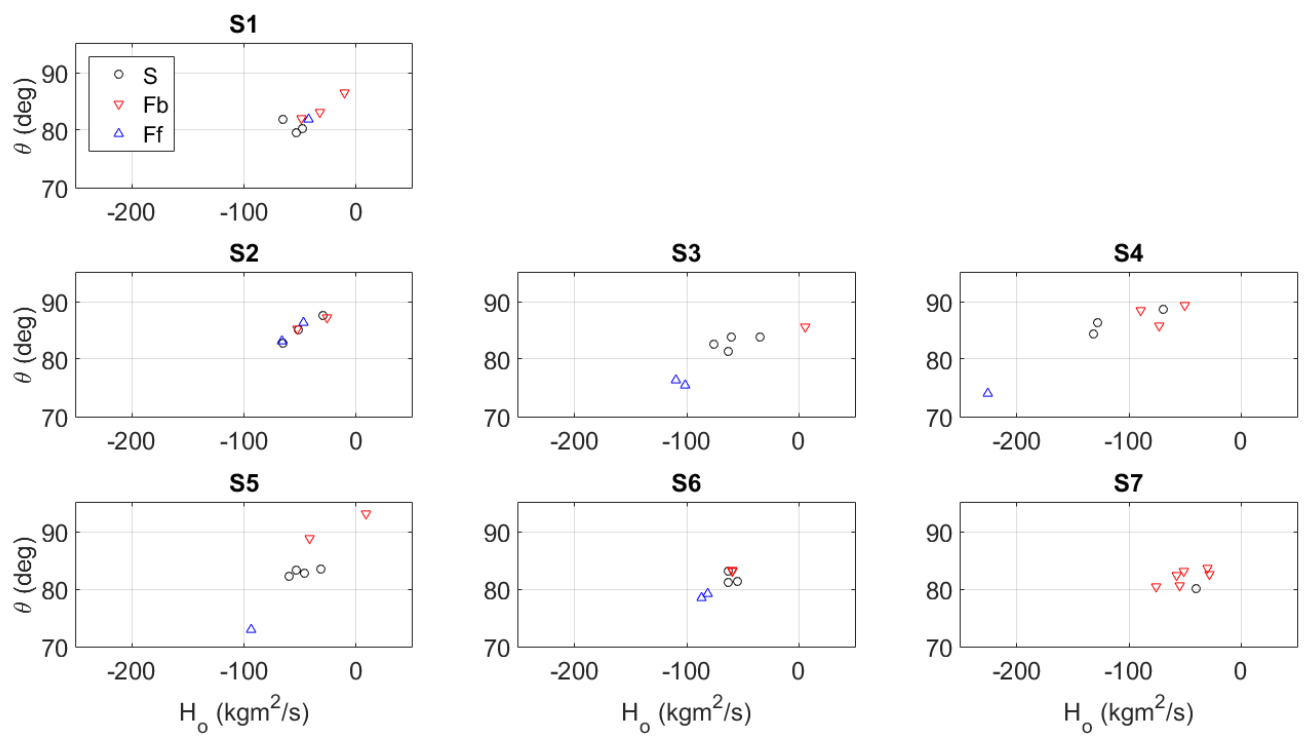

Figura 72. Ângulo de aterrissagem $(\theta)$ em relação à quantidade de movimento angular $\left(\mathrm{H}_{\mathrm{o}}\right)$ no pré-impacto, de cada sujeito. Legenda: $(\mathrm{S})$ sucesso, $(\mathrm{Fb})$ falha com deslocamento para trás e (Ff) falha com deslocamento para frente. 

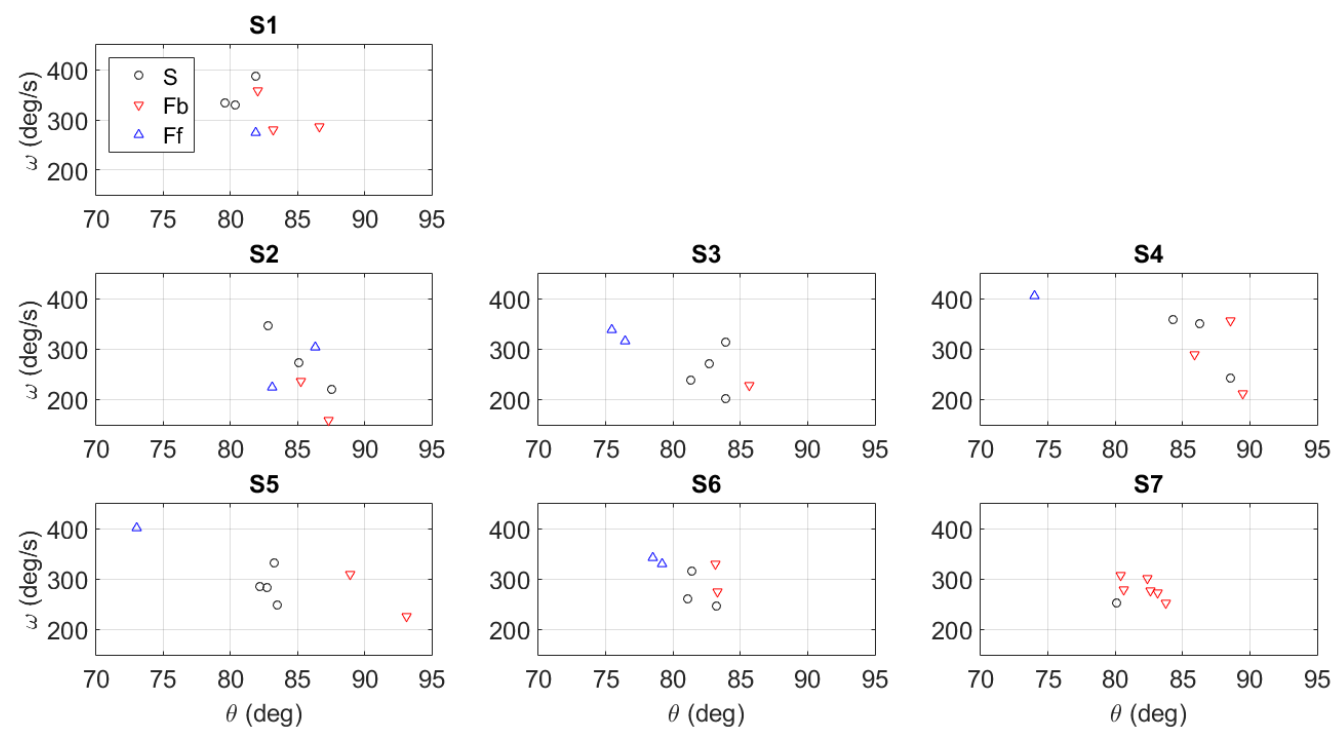

Figura 73. Velocidade angular $(\omega)$ em relação ao ângulo $(\theta)$ no pré-impacto, de cada sujeito. Legenda: (S) sucesso, $(\mathrm{Fb})$ falha com deslocamento para trás e $(\mathrm{Ff})$ falha com deslocamento para frente.
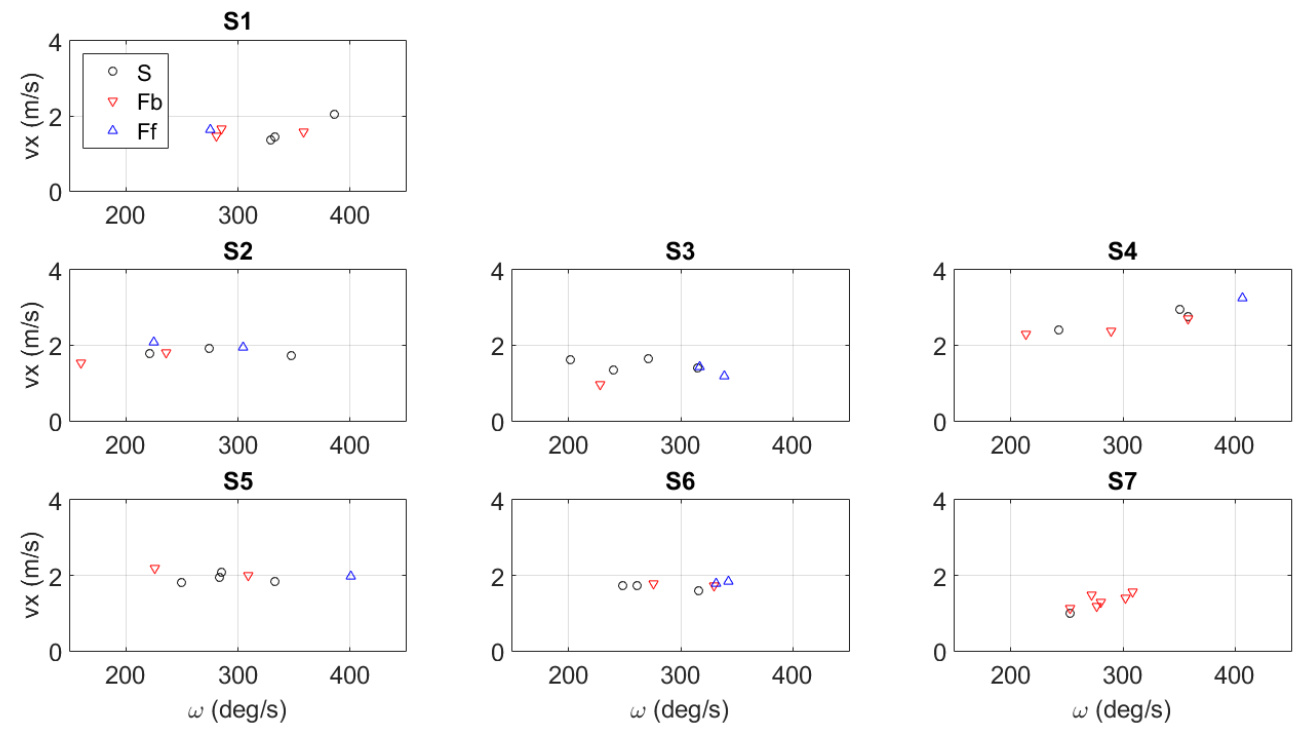

Figura 74. Velocidade horizontal (vx) em relação à velocidade angular ( $\omega)$ no pré-impacto, de cada sujeito. Legenda: $(\mathrm{S})$ sucesso, $(\mathrm{Fb})$ falha com deslocamento para trás e $(\mathrm{Ff})$ falha com deslocamento para frente. 

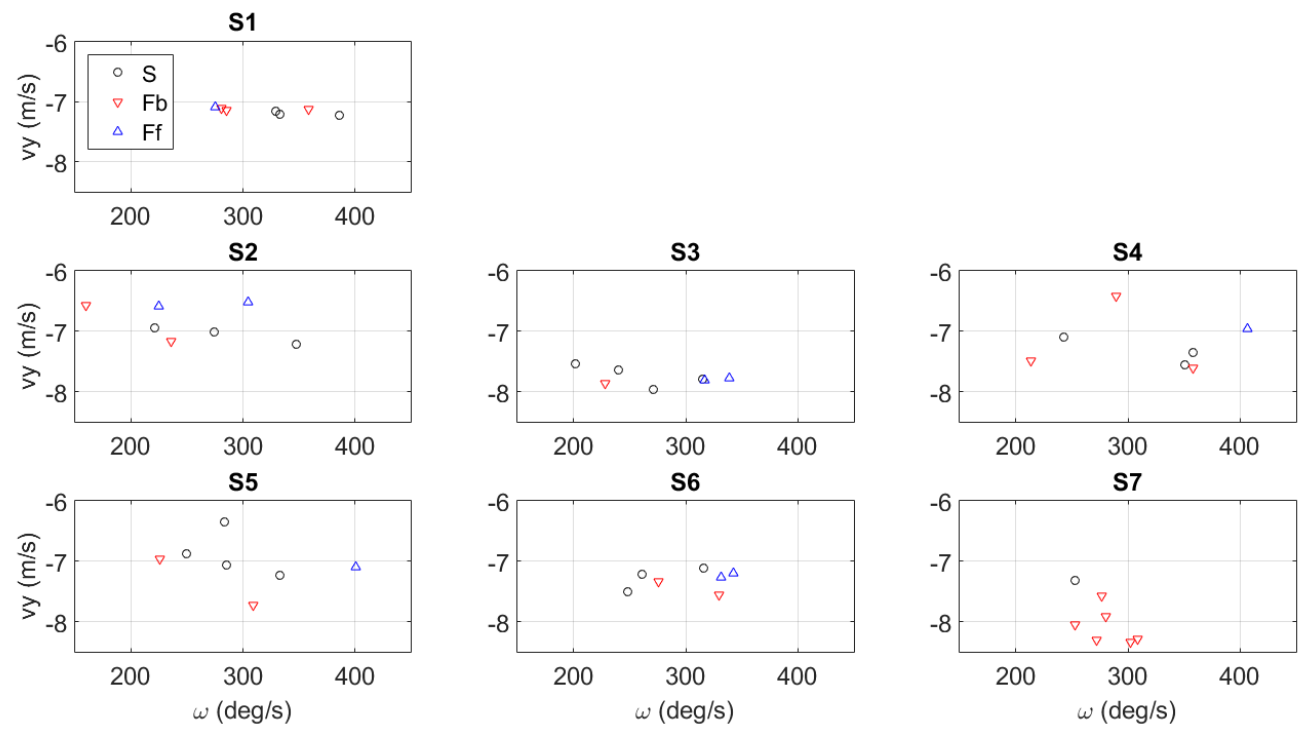

Figura 75. Velocidade vertical (vy) em função da velocidade angular ( $\omega$ ) no pré-impacto, de cada sujeito. Legenda: $(\mathrm{S})$ sucesso, $(\mathrm{Fb})$ falha com deslocamento para trás e $(\mathrm{Ff})$ falha com deslocamento para frente.

O conjunto de resultados obtidos para as variáveis que compõem a hipótese alternativa deste estudo nos 18 casos típicos de sucesso foram resumidos em termos de máximo, mínimo, média, desvio-padrão, intervalo de confiança e limites superior e inferior (Tabela 18). Os resultados individuais para as aterrissagens bem-sucedidas de DSBS $(n=21)$, incluindo o caso particular, no instante de pré-impacto foram reunidos na Tabela 19.

Tabela 18. Resumo dos fatores determinantes de sucesso para aterrissagem de DSBS.

\begin{tabular}{cccccc}
\hline & $\begin{array}{c}\mathbf{v x}^{-} \\
(\mathrm{m} / \mathrm{s})\end{array}$ & $\begin{array}{c}\mathbf{v y}^{-} \\
(\mathrm{m} / \mathrm{s})\end{array}$ & $\begin{array}{c}\boldsymbol{\theta}^{-} \\
\left(^{\circ}\right)\end{array}$ & $\begin{array}{c}\omega^{-} \\
(\% / \mathrm{s})\end{array}$ & $\begin{array}{c}\mathbf{H}_{\mathbf{o}}^{-} \\
\left(\mathrm{kgm}^{2 /} \mathrm{s}\right)\end{array}$ \\
\hline máximo & 2,05 & $-6,35$ & 87,52 & 386,58 & $-29,35$ \\
mínimo & 0,94 & $-7,96$ & 79,59 & 201,50 & $-76,08$ \\
média & 1,65 & $-7,24$ & 82,58 & 286,10 & $-53,29$ \\
desvio padrão & 0,29 & 0,37 & 1,91 & 48,68 & 12,83 \\
IC* & 0,15 & 0,18 & 0,95 & 24,21 & 6,38 \\
limite inferior & 1,50 & $-7,42$ & 81,63 & 261,89 & $-59,67$ \\
limite superior & 1,80 & $-7,06$ & 83,53 & 310,31 & $-46,91$ \\
\hline
\end{tabular}

* IC - intervalo de confiança (95\%). Offset: $\mathrm{H}_{\mathrm{o}}^{-}<0$.

Assim, no intervalo dos limites inferior e superior para os fatores determinantes de sucesso nas aterrissagens de DSBS, as condições necessárias e suficientes foram resumidas em (Figura 76): 


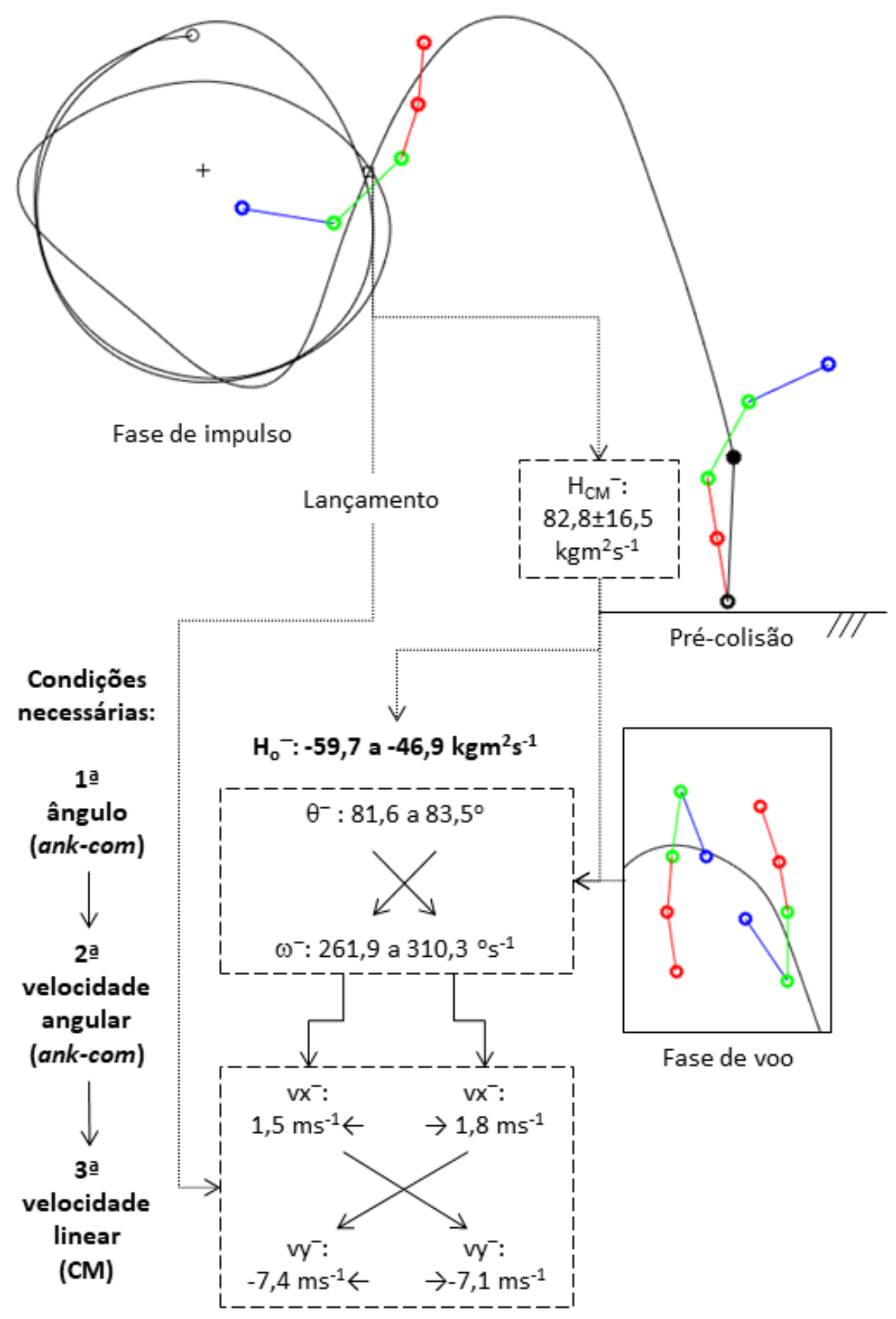

Figura 76. Esquema representativo das condições necessárias para aterrissagem de DSBS, sem passo ou queda.

Como casos típicos de interpretação do modelo de aterrissagem para o DSBS, foram selecionados os exemplos a seguir. Para o S3 as condições de sucesso foram claramente definidas, tanto pelo intervalo $\mathrm{H}_{\mathrm{o}}{ }^{-}\left(-76,1 \mathrm{a}-35,0 \mathrm{kgm}^{2} / \mathrm{s}\right)$, quanto pela faixa angular de $81,3 \mathrm{a}$ $83,9^{\circ}$. Assim, o ginasta atingiu logo no primeiro nível de verificação as condições biomecânicas necessárias para uma aterrissagem de sucesso. Para o S5, no entanto, somente a combinação dos intervalos de $\mathrm{H}_{\mathrm{o}}{ }^{-}\left(-59,5 \mathrm{a}-31,5 \mathrm{kgm}^{2} / \mathrm{s}\right)$ e $\theta^{-}\left(82,2\right.$ a $\left.83,5^{\circ}\right)$ possibilitou uma chegada bem-sucedida. 
Tabela 19. Variáveis atribuídas à hipótese alternativa para o instante de pré-impacto.

\begin{tabular}{|c|c|c|c|c|c|}
\hline sujeito & $\begin{array}{c}\mathbf{V \mathbf { x } ^ { - }} \\
(\mathrm{m} / \mathrm{s}) \\
\end{array}$ & $\begin{array}{c}\mathbf{v y}^{-} \\
(\mathrm{m} / \mathrm{s})\end{array}$ & $\begin{array}{l}\theta^{-} \\
\left({ }^{\circ}\right)\end{array}$ & $\begin{array}{c}\omega^{-} \\
(\% / s)\end{array}$ & $\begin{array}{c}\mathbf{H}_{\mathbf{o}}^{-} \\
\left(\mathrm{kgm}^{2} / \mathrm{s}\right)\end{array}$ \\
\hline \multirow{3}{*}{1} & 2,02 & $-7,22$ & 81,88 & 386,58 & $-65,43$ \\
\hline & 1,41 & $-7,20$ & 79,59 & 333,48 & $-53,64$ \\
\hline & 1,31 & $-7,15$ & 80,34 & 329,43 & $-47,95$ \\
\hline \multirow{3}{*}{2} & 1,73 & $-7,22$ & 82,80 & 347,62 & $-65,08$ \\
\hline & 1,91 & $-7,01$ & 85,10 & 274,20 & $-51,66$ \\
\hline & 1,82 & $-6,95$ & 87,52 & 221,39 & $-29,35$ \\
\hline \multirow{4}{*}{3} & 1,57 & $-7,53$ & 83,90 & 201,50 & $-60,11$ \\
\hline & 1,58 & $-7,96$ & 82,66 & 271,64 & $-76,08$ \\
\hline & 1,34 & $-7,80$ & 83,90 & 315,27 & $-35,02$ \\
\hline & 1,30 & $-7,64$ & 81,32 & 239,69 & $-62,65$ \\
\hline \multirow{3}{*}{4} & 2,39 & $-7,10$ & 88,59 & 243,21 & $-69,25$ \\
\hline & 2,87 & $-7,55$ & 86,25 & 351,14 & $-128,10$ \\
\hline & 2,72 & $-7,35$ & 84,32 & 358,49 & $-131,33$ \\
\hline \multirow{4}{*}{5} & 1,88 & $-6,35$ & 82,70 & 283,49 & $-46,23$ \\
\hline & 1,85 & $-7,23$ & 83,29 & 332,89 & $-53,47$ \\
\hline & 1,82 & $-6,87$ & 83,46 & 249,45 & $-31,50$ \\
\hline & 2,05 & $-7,06$ & 82,19 & 285,75 & $-59,52$ \\
\hline \multirow{3}{*}{6} & 1,62 & $-7,12$ & 81,41 & 315,55 & $-54,97$ \\
\hline & 1,72 & $-7,22$ & 81,10 & 260,84 & $-62,77$ \\
\hline & 1,83 & $-7,50$ & 83,20 & 247,90 & $-63,31$ \\
\hline 7 & 0,94 & $-7,31$ & 80,06 & 253,14 & $-40,53$ \\
\hline máximo & 2,87 & $-6,35$ & 88,59 & 386,58 & $-29,35$ \\
\hline mínimo & 0,94 & $-7,96$ & 79,59 & 201,50 & $-131,33$ \\
\hline
\end{tabular}

Já no caso do S2, a combinação dos intervalos $\mathrm{H}_{\mathrm{o}}{ }^{-}\left(-65,1\right.$ a $\left.-29,3 \mathrm{kgm}^{2} / \mathrm{s}\right)$ e $\theta^{-}(82,8$ a $\left.87,5^{\circ}\right)$ não foi suficiente para definir uma chegada de sucesso. Foi necessária a análise em segundo nível dos fatores determinantes de chegadas de sucesso $\left(\omega^{-}\right.$no intervalo $\left.\theta\left(\mathrm{H}_{\mathrm{o}}\right)^{-}\right)$. De início, nota-se que nesse caso os intervalos de $\theta$ foram maiores que nos ginastas anteriores. No limite superior de $\theta$, foi uma redução $\omega$ de $126,2 \%$ s o fator determinante para o sucesso na aterrissagem.

O mesmo ocorreu com o ginasta S6 para um ângulo de chegada de 81,1 e $81,4^{\circ}$. Nesse último caso, a redução de $\omega$ (de 315 para $248 \%$ s). Um último caso exemplar foi o S1. Num ângulo de aterrissagem de $81,9^{\circ}$, foi a combinação em terceiro nível de um menor $\mathrm{H}_{\mathrm{o}}$ com uma velocidade vertical mais acentuada (> -7,2 m/s) a configuração necessária para o sucesso na aterrissagem $\left(\mathrm{v}^{-}\right.$no intervalo $\left.\omega\left(\theta, \mathrm{H}_{\mathrm{o}}\right)^{-}\right)$.

Sheets e Hubbard (2007) já haviam destacado a importância da posição angular e da velocidade angular apropriadas para atingir um aterrissagem bem-sucedida de barras 
assimétricas, em mortal para trás simples e duplo. Esses autores definiram regiões de equilíbrio com base na $\mathrm{H}$ em relação ao centro de massa $\left(69,52 ; 123,67 \mathrm{kgm}^{2} / \mathrm{s}\right.$, mortal simples e mortal duplo, respectivamente) para as condições de pré-impacto. Esses mesmos autores também apontaram uma tendência de ampliação nas janelas angulares para aterrissagens com maior velocidade angular. No presente estudo, isso foi observado comparando os casos de $\mathrm{S} 1\left(\Delta \theta^{-}=3,2^{\circ} ; \Delta \omega^{-}=57,2^{\circ} / \mathrm{s}\right)$ e $\mathrm{S} 2\left(\Delta \theta^{-}=4,6 ; \Delta \omega^{-}=153,1^{\circ} / \mathrm{s}\right)$.

No entanto, como no caso de S3, grandes variações de velocidade angular $\left(\Delta \omega=113,8^{\circ} / \mathrm{s}\right)$ também foram suportadas para um consistente ângulo de aterrissagem $\left(83,9^{\circ}\right)$ com compensações para as elevadas rotações por redução na quantidade de movimento angular $\left(\mathrm{H}_{\mathrm{o}}^{-}=-35,0 \mathrm{kgm}^{2} / \mathrm{s}\right)$, redução da velocidade horizontal $(\Delta \mathrm{vx}=0,23 \mathrm{~m} / \mathrm{s})$ e aumento da velocidade vertical $(\Delta \mathrm{vy}=0,23 \mathrm{~m} / \mathrm{s})$. Esse último exemplo revela, por um lado, a alta consistência na realização de movimentos complexos, e por outro, a grande variabilidade técnica para as orientações corporais em equilíbrio dinâmico entre os ginastas de elite. Num estudo com saídas de trave, Gittoes e et al. (2013) demonstraram que essas estratégias de controle da orientação corporal nas chegadas de trave dependem fundamentalmente das ações de quadril, joelho e tornozelo, nessa ordem de predominância. A investigação desses autores foi pautada na determinação dos deslocamentos do CM, do ângulo corporal e dos ângulos articulares no período de colisão. Cuk e Marinsek (2013) apontaram a velocidade vertical como o principal determinante de sucesso para aterrissagens nos elementos de solo. No contexto dos autores, um maior número de falhas nas aterrissagens para saltos com rotação nos eixos transverso e longitudinal do corpo ocorreram quando havia uma diferença de velocidades vertical superior a $0,1 \mathrm{~m} / \mathrm{s}$ entre os quadris durante a colisão.

No contexto deste estudo, as abordagens acima citadas permitem uma linha de continuidade para as interpretações do fenômeno da aterrissagem em ginástica artística, visto que o período de colisão excede a proposta dessa pesquisa. E pelo mesmo motivo, uma das principais contribuições desta investigação reside na definição de fatores determinantes que representam as condições de sucesso na chegada de barra fixa, sem a necessidade de exposição ao impacto da aterrissagem. Com base em marcadores de desempenho nos instantes pré-colisão, os treinadores e a equipe multidisciplinar podem definir estratégias de intervenção com menor sobrecarga por colisão e maior domínio das alternativas mecânicas de correção.

Como exemplo de aplicação desse conteúdo, ilustra-se o caso do ginasta 7 (S7) que apresentou a menor taxa de sucesso (1/7, sendo essa na última tentativa). Manifestando um 
lançamento com elevado ângulo de saída, baixa velocidade horizontal e ângulo de incidência próximo ao limite superior, a tendência de deslocamento para trás após a chegada fica previsível. Como primeira meta, sugere-se o aumento do ângulo de saída e, o consequente, aumento da velocidade horizontal na chegada. Uma vez na faixa de maior potencial de sucesso $\left(\mathrm{H}_{\mathrm{CM}} \leq 80,1 \mathrm{kgm}^{2} / \mathrm{s}\right.$, no lançamento; $\mathrm{vy}^{-} \leq-7,3 \mathrm{~m} / \mathrm{s}$, na pré-colisão), o ginasta torna-se apto para as sessões de treinamento fora do fosso de aterrissagem. Isso privaria o ginasta de 5 outras ações com erros técnicos sistemáticos acompanhados de impacto nas aterrissagens com baixo aproveitamento.

Destaca-se entre as limitações deste estudo, a representação do centro articular do ombro como um ponto fixo à borda axilar com o ombro flexionado. Essa região anatômica foi adotada por representar o ponto médio de mobilidade flexo-extensora do ombro, em arcos extremos durante o DSBS, e muito próximo ao ponto médio para os instantes críticos (lançamento e pré-colisão) compreendidos nesta abordagem.

A restrição da região tóraco-lombar como um segmento rígido também foi entendida como uma limitação deste estudo. Em algumas fases do DSBS, essa mobilidade pode provocar alterações no momento de inércia e, consequentemente, afetar os resultados de quantidade de movimento e de momento articular. Com a estratégia de dinâmica inversa por dupla abordagem (bottom-up e top-down) os efeitos dessa propagação de incerteza nas resultantes articulares foram minimizados.

Além disso, a remoção de artefatos de movimento provocado pelas vibrações dos marcadores fixados na pele pode não ter sido suficiente a uma frequência de corte em $8 \mathrm{~Hz}$. Ainda que compreendida na faixa de frequências para investigações de mesma natureza (BRÜGGEMANN et al., 1994; ARAMPATZIS; BRUGGEMANN, 1999; BRÜGGEMANN et al., 1994; REQUEJO; MCNITT-GRAY; FLASHNER, 2004), isso pode ter influenciado particularmente a segunda derivada da posição dos segmentos e, então, os resultados de pico de momento articular. No entanto, essa frequência de corte representou o limite inferior para a eliminação dos efeitos de borda for filtragem recursiva nos instantes que antecipam a colisão. Assim, a frequência de corte adotada preservou o coerente movimento uniformemente variado do CM corporal em fase de voo.

Assim, entende-se que as limitações identificadas nesta investigação podem afetar os valores normativos para o perfil biomecânico do DSBS, mas não compromete a validade do modelo de chegada bem como as intepretações que deste decorreram. Como trabalhos futuros, pretende-se explorar as combinações articulares de controle articular para chegadas de sucesso em DSBS, testar o potencial de transferência dessa proposta de abordagem das 
chegadas outros tipos de saída (incluindo rotações no eixo longitudinal) e rotinas de aparelho; e, ainda, mensurar o potencial de mudança de estado nas taxas de sucesso para chegadas em ginástica artística.

Em linhas gerais, as demandas mecânicas de cada fase incluem atingir impulso e quantidade de movimento angular suficientes para o lançamento e controlar as rotações em fase aérea a fim de aterrissar em pé, sem queda ou a necessidade de passos no solo. Foram identificados como fatores de contorno para uma aterrissagem bem-sucedida: a quantidade de movimento angular em relação ao ponto de contato do solo, o ângulo de chegada e as velocidades angular e linear; organizadas em níveis de interpretação hierárquicos. 


\section{CONCLUSÕES}

A presente investigação permitiu a elucidação de fatores biomecânicos que configuram a aterrissagem de sucesso (i.e., sem passos ou queda) na saída de barra fixa, em ginástica artística. Um perfil da saída de barra em duplo mortal estendido foi caracterizado em termos cinemático e cinético com base numa amostra de ginastas de ranking internacional, sob condições experimentais in loco. O modelo biomecânico adotado foi capaz de discriminar as condições de chegada (sucesso ou falha). Assim, foi possível uma simplificação do fenômeno, inicialmente representado por quatro corpos rígidos articulados, analisado em múltiplas subfases por 109 variáveis biomecânicas, num sistema de um corpo rígido por cinco variáveis determinantes: velocidade linear (horizontal e vertical), ângulo corporal, velocidade angular do corpo e quantidade de movimento angular. Em confirmação à hipótese alternativa, o modelo analítico proposto demonstrou uma alta sensibilidade para ângulo de aterrissagem do corpo no solo, no qual variações superiores a sete graus tornam improvável uma chegada em condições de repouso, e uma significativa influência da quantidade de movimento angular, da velocidade angular e das velocidades lineares para as chegadas de Duplo Mortal Estendido para Trás, na rotina de barra fixa. Espera-se, com esses achados, contribuir com o desenvolvimento de estratégias de controle e correção das habilidades de saída de barra, em condições de menor risco de lesões por impacto e maior domínio dos fatores biomecânicos de intervenção. 


\section{REFERÊNCIAS}

AMADIO, A. C. et al. Fundamentos biomecânicos para a análise do movimento humano. São Paulo: Laboratório de Biomecânica, Escola de Educação Física - USP, 1996.

AMARAL, L.; SANTOS, P.; FERREIRINHA, J. Caracterização do perfil lesional em ginástica artística feminina: um estudo prospectivo das ginastas portuguesas de competição ao longo de uma época desportiva. Rev Port Cien Desp, v. 9, n. 1, p. 43-51, 2009.

ARAMPATZIS, A.; BRUGGEMANN, G. P. A mathematical high bar-human body model for analysing and interpreting mechanical-energetic processes on the high bar. Journal of biomechanics, v. 31, n. 12, p. 1083-1092, dez. 1998.

ARAMPATZIS, A.; BRUGGEMANN, G. P. Mechanical energetic processes during the giant swing exercise before dismounts and flight elements on the high bar and the uneven parallel bars. Journal of biomechanics, v. 32, n. 8, p. 811-820, ago. 1999.

ARAMPATZIS, A.; BRÜGGEMANN, G. P. Mechanical energetic processes during the giant swing exercise before dismounts and flight elements on the high bar and the uneven parallel bars. J Biomech, v. 32, n. 8, p. 811-820, 1999.

ARAMPATZIS, A.; MOREY-KLAPSING, G.; BRÜGGEMANN, G. P. The effect of falling height on muscle activity and foot motion during landings. Journal of Electromyography and Kinesiology, 2003.

ATIKOVIC, A.; SMAJLOVIC, N. Relation between vault difficulty values and biomechanical parameters in men's artistic gymnastics. Science of Gymnastics Journal, v. 3, n. 3, p. 91-105, 2011.

BERTHOZ, A.; POZZO, T. Head and Body Coordination during Locomotion and Complex Movements. In: Interlimb Coordination. [s.l: s.n.].

BRUGGEMANN, G.-P. Biomechanical and Biological Limits in Artistic Gymnastics. International Society of Biomechanics in Sports, 2005.

BRÜGGEMANN, G.-P. Sport-related spinal injuries and their prevention. In: ZATSIORSKY, V. M. (Ed.). . Biomechanics in sport: performance enhancement and injury prevention. London: Blackwell Science, 2000. p. 550-576.

BRÜGGEMANN, G. P. et al. Approach to a biomechanical profile of dismounts and release regrasp skills of the high bar. Journal of Applied Biomechanics, v. 10, n. 3, p. 291-312, 1994.

BUSSAB, W. DE O.; MORETTIN, P. A. Estatística básica. 6. ed. São Paulo: Saraiva, 2010.

CAMARGO-JUNIOR, F. Análise da propagação de incertezas no método de dinâmica inversa tridimensional para membro inferior durante a marcha em diferentes velocidades. [s.1.] Universidade de São Paulo, 2012.

CAMARGO, F. et al. Influence of center of pressure estimation errors on 3D inverse 
dynamics solutions during gait at different velocities. Journal of Applied Biomechanics, 2013.

CLAUSTER, C. E.; MCCONVILLE, J. T.; YOUNG, J. W. Weight, volume, and centre of mass of segments of the human body. Ohio: Aereospace Medical Research Laboratory, 1969.

DAVLIN, C. D.; SANDS, W. A.; SHULTZ, B. B. Peripheral vision and back tuck somersaults. Perceptual and Motor Skills, 2001a.

DAVLIN, C. D.; SANDS, W. A.; SHULTZ, B. B. The role of vision in control of orientation in a back tuck somersault. Motor control, 2001b.

DE LEVA, P. Adjustments to Zatsiorsky-Seluyanov's segment inertia parameters. J Biomech, v. 29, n. 9, p. 1223-1230, 1996.

DESAI, N. et al. Artistic Gymnastics Injuries; Epidemiology, Evaluation, and Treatment. The Journal of the American Academy of Orthopaedic Surgeons, v. 27, n. 13, p. 459-467, jul. 2019.

DEVITA, P.; SKELLY, W. A. Effect of landing stiffness on joint kinetics and energetics in the lower extremity. Med Sci Sports Exerc, v. 24, n. 1, p. 108-115, 1992.

DISS, C. E. The reliability of kinetic and kinematic variables used to analyse normal running gait. Gait Posture, v. 14, n. 2, p. 98-103, 2001.

DUNCAN, A.; MCDONAGH, M. J. N. Stretch reflex distinguished from pre-programmed muscle activations following landing impacts in man. Journal of Physiology, 2000.

DYHRE-POULSEN, P.; SIMONSEN, E. B.; VOIGT, M. Dynamic control of muscle stiffness and $\mathrm{H}$ reflex modulation during hopping and jumping in man. The Journal of Physiology, 1991.

FARANA, R.; VAVERKA, F. The effect of biomechanical variables on the assessment of vaulting in top-level artistic female gymnasts in world cup competitions [Vliv

biomechanických proměnných na hodnocení přeskoků vrcholových sportovních gymnastek při závodě světového poháru]. Acta Universitatis Palackianae Olomucensis, Gymnica, v. 42, n. 2, p. 49-57, 2012.

FIG. Code of Points / MAG, 2017.

FRANÇA, L. N. F.; MATSUMURA, A. Z. Mecânica geral. São Paulo: Blucher, 2011.

GITTOES, M. J. R. et al. Whole-body and multi-joint kinematic control strategy variability during backward rotating dismounts from beam. Journal of sports sciences, v. 29, n. 10, p. 1051-1058, jul. 2011.

GITTOES, M. J. R.; IRWIN, G. Biomechanical approaches to understanding the potentially injurious demands of gymnastic-style impact landings. Sports Medicine, Arthroscopy,

Rehabilitation, Therapy and Technology, v. 4, n. 1, 2012.

GITTOES, M. J. R.; IRWIN, G.; KERWIN, D. G. Kinematic landing strategy transference in 
backward rotating gymnastic dismounts. Journal of applied biomechanics, v. 29, n. 3, p. 253-260, jun. 2013.

HAY, J. G. The Biomechanics of Sports Techniques. 4. ed. Englewood Cliffs, N.J: Prentice Hall, 1993.

HEINEN, T.; NICOLAUS, M. Option selection in whole-body rotation movements in gymnastics. Rev Bras Educ Fís Esporte, v. 30, n. 1, p. 29-39, 2016.

HILEY, M. J.; YEADON, M. R. Swinging around the high bar. Physics Education, 2001.

HILEY, M. J.; YEADON, M. R. Optimum technique for generating angular momentum in accelerated backward giant circles prior to a dismount. Journal of Applied Biomechanics, v. 19, n. 2, p. 119-130, 2003a.

HILEY, M. J.; YEADON, M. R. The margin for error when releasing the high bar for dismounts. J Biomech, v. 36, n. 3, p. 313-319, 2003 b.

HILEY, M. J.; YEADON, M. R. Maximal dismounts from high bar. J Biomech, v. 38, n. 11, p. 2221-2227, 2005.

HILEY, M. J.; YEADON, M. R. Investigating optimal technique in the presence of motor system noise: application to the double layout somersault dismount on high bar. Journal of Sports Sciences, v. 34, n. 5, p. 440-449, 2016.

IRWIN, G.; WILLIAMS, G. K. R.; KERWIN, D. G. Ginástica, treinamento e ciência: perspectivas biomecânicas. In: SCHIAVON, L. M. et al. (Eds.). . Ginástica de alto rendimento. Várzea Paulista: Fontoura, 2014. p. 201-217.

KERWIN, D. G.; YEADON, M. R.; LEE, S.-C. Body configuration in multiple somersault high bar dismounts. International Journal of Sport Biomechanics, v. 6, p. 147-156, 1990.

KIRIALANIS, P. et al. Occurrence of acute lower limb injuries in artistic gymnasts in relation to event and exercise phase. Br J Sports Med, v. 37, p. 137-139, 2003.

KURZ, M. J.; STERGIOU, N. Applied dynamic system theory for the analysis of movement. In: STERGIOU, N. (Ed.). . Innovative analyses of human movement. USA: Human Kinetics, 2004. p. 93-119.

MANLY, B. F. J. Multivariate Statistical Methods: a primer. 3. ed. New York: Chpman \& Hall/CRC, 2004.

MARINŠEK, M. Basic landing characteristics and their application in artistic gymnastics. / OSNOVNE ZNAČILNOSTI DOSKOKA IN NJIHOVA UPORABA V GIMNASTIKI. Science of Gymnastics Journal, 2010.

MCNITT-GRAY, J. Kinematics and Impulse Characteristics of Drop Landings From Three Heights. International Journal O F Sport Biomechanics, 1991.

MCNITT-GRAY, J. L. Kinetics of the lower extremities during drop landings from three heights. Journal of Biomechanics, v. 26, n. 9, p. 1037-1046, 1993. 
MCNITT-GRAY, J. L. et al. Invariant features of multijoint control strategies used by gymnasts during landings performed in Olympic competition. Procedings of the Third North American Congress on Biomechanics. Anais...1998

MCNITT-GRAY, J. L. Musculoskeletal loading during landing. In: ZATSIORSKY, V. M. (Ed.). . Biomechanics in sport: performance enhancement and injury prevention. Oxford: Blackwell Science Ltd, 2000. p. 523-549.

MCNITT-GRAY, J. L. et al. Mechanical demand and multijoint control during landing depend on orientation of the body segments relative to the reaction force. Journal of Biomechanics, v. 34, n. 11, p. 1471-1482, 2001.

MCNITT-GRAY, J. L.; YOKOI, T.; MILLWARD, C. Landing strategy adjustments made by female gymnasts in response to drop height and mat composition. Journal of Biomechanics, v. 9, p. 173-190, 1993.

MCNITT-GRAY, J. L.; YOKOI, T.; MILLWARD, C. Landing strategies used by gymnasts on different surfaces. / Strategies de reprise de contact avec le sol utilisees par des gymnastes, sur differents sols. Journal of Applied Biomechanics, 1994.

MCNITT-GRAY, J. L.; YOKOI, T.; MILLWARD, C. Landing Strategies Used by Gymnasts on Different Surfaces. Journal of Applied Biomechanics, 2016.

MILLARD, M. et al. Human foot placement and balance in the sagittal plane. J Biomech Eng, v. 131, n. 12, p. 121001, 2009.

MOCHIZUKI, L.; AMADIO, A. C. A aplicação da análise dos componentes principais para o estudo do controle postural. Revista Brasileira de Educação Física e Esporte, 2007.

NIGG, B. M.; HERZOG, W. Biomechanics of the musculo-skeletal system. 3. ed. New York: John Wiley \& Sons, 2009.

OKAZAKI, V. H. A. OKAZAKI, F. H. A. TEIXEIRA, L. A. Freqüîncia de Amostragem e Intensidade do Filtro na Análise Cinemática. XI Congresso de Ciências do Desporto e Educação Física dos Países de Lingua Portuguesa. Anais...São Paulo: 2006

OKAZAKI, V. H. A.; TEIXEIRA, L. A.; RODACKI, A. L. F. Tipo de filtro e cálculo das derivadas na análise cinemática. XII Congresso Brasileiro de Biomecânica. Anais...São Pedro: 2007

PAPPAS, E. et al. Biomechanical differences between unilateral and bilateral landings from a jump: gender differences. Clin J Sport Med, v. 17, n. 4, p. 263-268, 2007.

PULASKI, P. D.; ZEE, D. S.; ROBINSON, D. A. The behavior of the vestibulo-ocular reflex at high velocities of head rotation. Brain Research, 1981.

REQUEJO, P. S.; MCNITT-GRAY, J. L.; FLASHNER, H. Flight Phase Joint Control Required for Successful Gymnastics Landings. Medicine \& Science in Sports \& Exercise, 2002.

REQUEJO, P. S.; MCNITT-GRAY, J. L.; FLASHNER, H. Modification of landing conditions at contact via flight. Biological Cybernetics, v. 90, n. 5, p. 327-336, maio 2004. 
ROBERTSON, D. G. E.; CALDWELL, G. E. Planar kinematics. In: ROBERTSON, D. G. E. et al. (Eds.). . Research methods in biomechanics. Champaign: Human Kinetics, 2004. p. 934.

SEEGMILLER, J. G.; MCCAW, S. T. Ground Reaction Forces among Gymnasts and Recreational Athletes in Drop Landings. Journal of Athletic Training, v. 38, n. 4, p. 311314, 2003.

SERBEST, K; BERISHA, M. ÇILLI, M. Development a Simulation Model for Dynamic Analysis of High Bar Dismounts. Institute of Electrical and Electronics Engineers (IEEE), 21 jun. 2019

SERBEST, K.; BERISHA, M.; CILLI, M. DYNAMIC ANALYSIS of THREE DIFFERENT HIGH BAR DISMOUNTS in the SIMMECHANICS ENVIRONMENT. Journal of Mechanics in Medicine and Biology, v. 18, n. 3, 2018.

SEVREZ, V. et al. Regulation of pendulum length as a control mechanism in performing the backward giant circle in gymnastics. Human movement science, v. 28, n. 2, p. 250-262, abr. 2009.

SHEETS, A.; HUBBARD, M. A dynamic approximation of balanced gymnastics landings. Sports Engineering, 2007.

SLATER, A. et al. Greater lower limb flexion in gymnastic landings is associated with reduced landing force: a repeated measures study. Sports biomechanics, v. 14, n. 1, p. 45-56, mar. 2015.

SMITH, T. Biomecánica y gymnasia. Barcelona: Paidotribo, 1998.

TAKEI, Y.; DUNN, J. H. A "kickout" double salto backward tucked dismount from the horizontal bar performed by elite gymnasts. J Sports Sci, v. 15, n. 4, p. 411-425, 1997a.

TAKEI, Y.; DUNN, J. H. A "kickout" double salto backward tucked dismount from the horizontal bar performed by elite gymnasts. Journal of sports sciences, v. 15, n. 4, p. 411 425, ago. 1997b.

WINTER, D. A. Biomechanics and motor control of human movement. 4. ed. Waterloo: John Wiley \& Sons, Inc., 2009.

YEADON, M. R. The simulation of aerial movement - II: a mathematical inertia model of the human body. Journal Biomechanics, v. 23, n. 67-74, 1990a.

YEADON, M. R. The simulation of aerial movement-I. The determination of orientation angles from film data. Journal of Biomechanics, 1990b.

YEADON, M. R. The simulation of aerial movement-III. The determination of the angular momentum of the human body. Journal of Biomechanics, 1990c.

YEADON, M. R. The biomechanics of the human in flight. American Journal of Sports Medicine, 1997.

YEADON, M. R.; ATHA, J.; HALES, F. D. The simulation of aerial movement-IV. A 
computer simulation model. Journal of Biomechanics, 1990.

YEADON, M. R.; HILEY, M. J. The mechanics of the backward giant circle on the high bar. Human Moviment Science, v. 19, p. 153-173, 2000.

YEADON, M. R.; HILEY, M. J. The control of twisting somersaults. J Biomech, v. 47, n. 6, p. 1340-1347, 2014.

YEADON, M. R.; HILEY, M. J. The limits of aerial techniques for producing twist in forward 1(1/2) somersault dives. Human movement science, v. 58, p. 97-107, abr. 2018.

YEADON, M. R.; KING, M. A. Computer simulation modelling in sport. In: PAYTON, C. J.; BARTLETT, R. M. (Eds.). . Biomechanical evaluation of movement in sport and exercise. New York: Taylor \& Francis Group, 2008. p. 176-205.

YEOW, C. H.; LEE, P. V; GOH, J. C. Effect of landing height on frontal plane kinematics, kinetics and energy dissipation at lower extremity joints. J Biomech, v. 42, n. 12, p. 19671973, 2009.

ZATSIORSKY, V. M. (ED.). Biomecânica no esporte: performance do desempenho e prevenção de lesão. Rio de Janeiro: Guanabara Koogan, 2004. 


\section{APÊNDICE I - CÓDIGO FONTE}

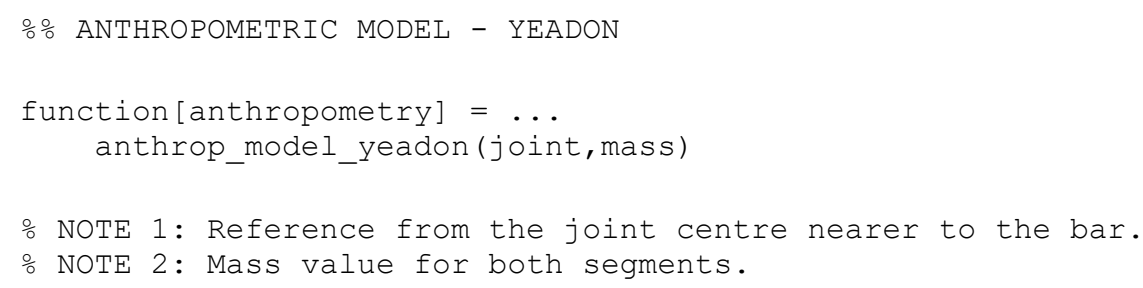


응 Longitudinal CoM position - Proximal [from the joint centre nearer... o...to the bar]

Relative length [\%]

1_com_shank_Y_relative $=$ I_com_foot_shank_Y/I_foot_shank_Y;

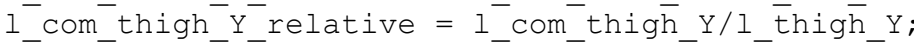

I_com_trunk_Y_relative $=1$ _com_trunk_Y/I_trunk_Y;

l_com_arm_Y_rēlative $=$ I_com_arm_Y/l_arm_Y;

\% Length Scale

1 com shank $=1$ com shank Y relative*l shank;

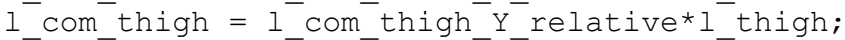

1_com_trunk = 1_com trunk_Y_relative*1_trunk;

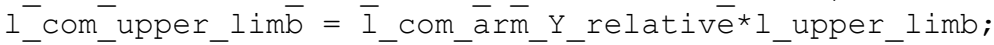

I_com_segment $=$ [1_com_shank, I_com_thigh, I_com_trunk, I_com_upper_limb];

응 Segment inertial moment - CG [from the center of mass of each segment]

for $i=1$

$\mathrm{J} \operatorname{shank}=$

J_foot_shank_Y*(I_shank/I_foot_shank_Y)*(m_foot_shank/mass_foot_shank_Y) ;

$\circ \overline{\mathrm{kgm}} \mathrm{kg}^{\wedge} \overline{\mathrm{c}}$

J_thigh $=J_{-}$thigh_Y*(I_thigh/I_thigh_Y $) *($ m_thigh/mass_thigh_Y $)$;

$\circ\left[\mathrm{kgm}^{\wedge} 2\right]$

J_trunk $=J$ J trunk_Y* (I_trunk/I_trunk_Y $) *($ m_trunk/mass_torso_Y $)$;

$\circ^{-}\left[\mathrm{kgm}^{\wedge} 2\right]$

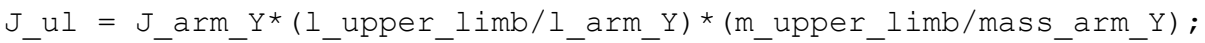

$\circ$

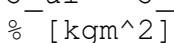

end

J_segment $=\left[J_{-}\right.$shank, J_thigh, J_trunk, J_ul];

\% $\frac{0}{0}$ Center of Mass (CoM_body)

for $i=1$

$r \_s h a n k(i, 1)=$ kne_st $(i, 1)+\left(\operatorname{ank} \_s t(i, 1)-k n e \_s t(i, 1)\right) \cdot{ }^{*}$ __com_shank $(i) ; \%$ proximo-distal

r_thigh $(i, 1)=$ hip_st $(i, 1)+\left(\right.$ kne_st $\left.(i, 1)-h i p \_s t(i, 1)\right) \cdot{ }^{*}{ }_{-}$com_thigh $(i) ; \%$ proximo-distal

$r \_t r u n k(i, 1)=\operatorname{sho} s t(i, 1)+($ hip_st $(i, 1)-\operatorname{sho} s t(i, 1)) \cdot{ }^{*}{ }_{-}$com_trunk $(i) ; \%$ cranio-caudal

$r$ upper $\operatorname{limb}(i, 1)=\operatorname{wri} \operatorname{st}(i, 1)+(\operatorname{sho} \operatorname{st}(i, 1)-$

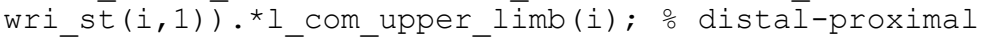

$r \operatorname{shank}(i, 2)=\operatorname{kne} \operatorname{st}(i, 2)+(\operatorname{ank} \operatorname{st}(i, 2)-k n e \operatorname{st}(i, 2)) \cdot{ }^{*} l \operatorname{com} \operatorname{shank}(i) ; \%$ proximo-distal

$r \operatorname{thigh}(i, 2)=$ hip st $(i, 2)+($ kne st $(i, 2)$-hip st $(i, 2)) .{ }^{*}$ com thigh $(i) ; \%$ proximo-distal

$r \operatorname{trunk}(i, 2)=\operatorname{sho} s t(i, 2)+($ hip_st $(i, 2)-\operatorname{sho} s t(i, 2)) \cdot{ }^{*} I_{-}$com_trunk $(i) ; \frac{0}{0}$ cranio-caudal 


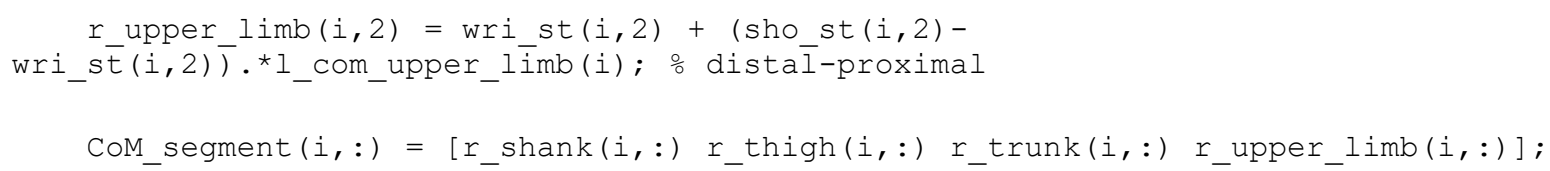

end

응 OUTPUT

anthropometry $=[$ m_segment, I_segment, I_com_segment, J_segment, I_com_body, J_body] ; anthrop_Names $=\{\ldots$

'm_sh', 'm_th','m_tr', 'm_ul',...

'1_sh','1_th','1_tr','1_ul',...

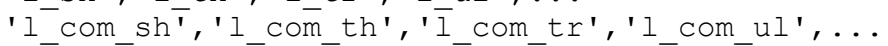

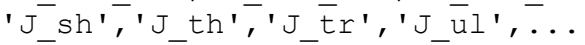

' 1 com boōy', 'J b body'\};

anthropometry = arrāy2table (anthropometry, 'Variable', anthrop_Names);

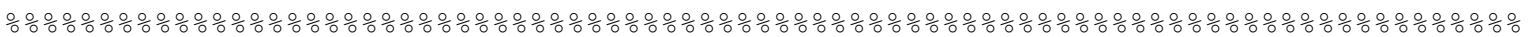

\section{응 2D KINEMATICS / 4 RIGID BODY}

function[historical_time, anthropometry, kma_linear, kma_angular]...

kinematics_2d_4rb(raw_coordinate,raw_initial_time,raw_transition_time,raw_final_tim e, mass)

close all

\section{응 INPUT SELECTION}

samp freq = input('kinematic sampling frequency [Hz]: '); gender = input ('Anthropometric models: Dempster[0], Zatsiorsky[1] or Yeadon[2]? '); apparatus = input ('Apparatus: Rings [0], Table[1], Horizontal bar[2] or Uneven bars [3]? '); 


\section{응 1. EXPERIMENTAL DATA}

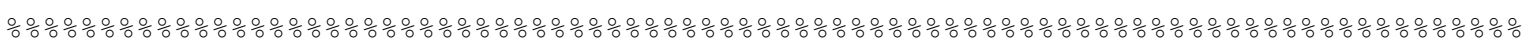

\% 1.1 Struture conversion

raw_coordinate = table2array (raw_coordinate);

ㄴ.2 Unit conversion

scale_cm $=100 ; \%$ for input in centimeters

raw_coordinate $(:, 2:$ end $)=\operatorname{raw} \operatorname{coordinate}(:, 2: \mathrm{end}) . / \mathrm{scale} \mathrm{cm}_{\text {; }}$ [ $\left.\mathrm{cm}\right]$ to $[\mathrm{m}]$

ㄴ.3 Filtering

$d t=1 /$ samp_freq; $\%$ Period $[s]$

joint_filt $=$ matfiltfilt $(d t, 8,4$,raw_coordinate $(:, 2$ :end) ); o data filtered (dt, fēut, order, data)

ㅇ. 1.4 Period

$f i=$ find (raw_coordinate $(:, 1)==$ raw_initial_time);

$\mathrm{ff}=\mathrm{find}\left(\mathrm{raw}{ }_{-} \operatorname{coordinate}(:, 1)==\right.$ raw_final_time);

historical_time $=$ raw_coordinate $(f i-2: f f, 1) ; \%[s]$

joint $=$ joint_filt (fi-2:ff,:); \% filtered joint [m]

1.5 Joint center

ank $=$ joint $(:, 1: 2)$;

kne $=$ joint $(:, 3: 4)$;

hip $=$ joint $(:, 5: 6)$;

sho $=$ joint $(:, 7: 8) ;$

wri $=$ joint $(:, 9: 10)$;

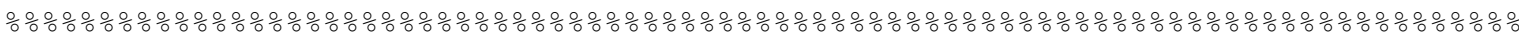

응 2. ANTHROPOMETRIC MODEL

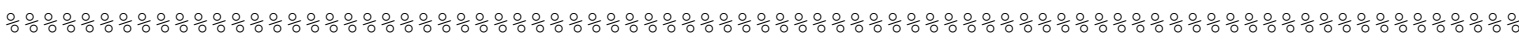

gender = input('Anthropometric models: Dempster[0], Zatsiorsky[1] or Yeadon[2]? ');

응응

if gender $=0$;

응 Dempster (Winter, 2009)

[m_segment_D, I_segment_D, I_com_segment_D, J_segment_D, I_Com_body_D, J_body_D ] $=$ anthrop_model_dempster (joint, mass)

을 $\mathrm{Me}$

Relative Body Mass

m_lower_limb = m_segment_D(1);

m_trunk_head $=$ m_segment_D(2);

$\mathrm{m}$-upper limb $=\mathrm{m}$ segment $\mathrm{D}(3)$;

m_body $=$ [m_lowe $\bar{r} \_$limb m_trunk_head m_upper_limb] ;

\% Segment Longitudinal Length

1 11 = 1_segment_D(1);

1_trunk $=$ I_segment_D (2); 


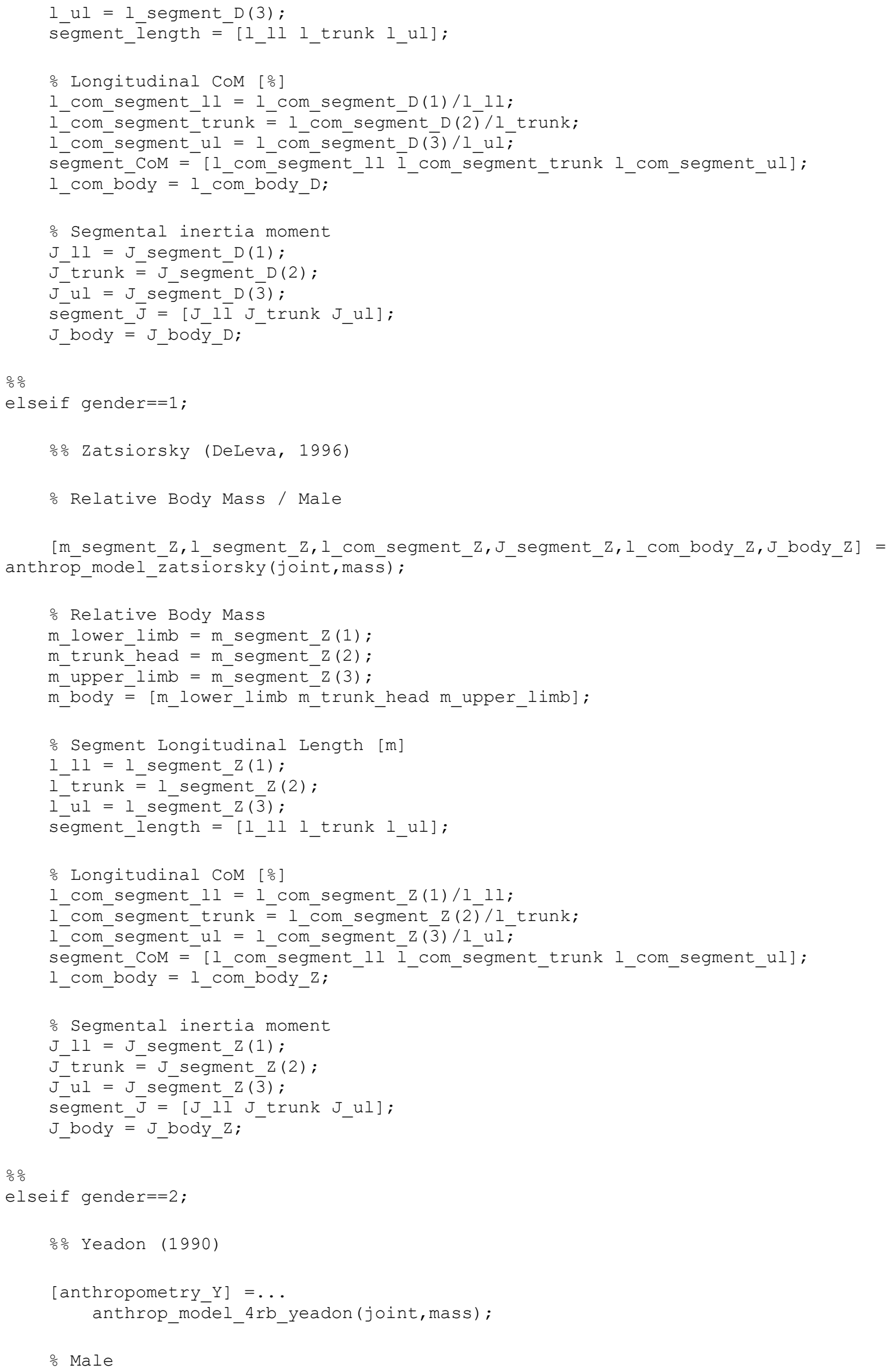


․ Relative Body Mass

$\mathrm{m}$ foot shank = anthropometry $\mathrm{Y}\{:, 1\}$;

m_thigh = anthropometry_Y $\{:, \overline{2}\}$;

$\mathrm{m}$ - trunk head = anthropometry $Y\{:, 3\}$;

m_upper_limb = anthropometry_y $\{:, 4\}$;

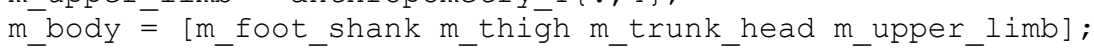

\% Segment Longitudinal Length $[\mathrm{m}]$

1 shank = anthropometry $Y\{:, 5\}$;

1_thigh = anthropometry_Y $\{:, 6\}$;

1_trunk = anthropometry_Y $\{:, 7\}$;

1 ul = anthropometry Y $\{\overline{:}, 8\}$;

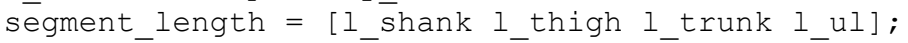

\% Longitudinal CoM (m) - from joint centre nearer to the bar

1_com_shank = anthropometry_y $\{:, 9\}$;

1_com_thigh = anthropometry_Y $\{:, 10\}$;

1_com_trunk = anthropometry_Y $\{:, 11\}$;

1_com_ul = anthropometry_y $\{\overline{\mathbf{:}}, 12\}$;

ségment_CoM = [1_com_shank 1_com_thigh 1_com_trunk 1_com_ul];

1_com_body $=$ ant $\bar{h} r o p o \overline{m e t r y} y\{:, 1 \overline{7}\}$;

\% Longitudinal CoM (\%) - from joint centre nearer to the bar

r_com_shank = anthropometry_Y $\{:, 9\} / I_{-}$shank;

r_com_thigh = anthropometry_y $\{:, 10\} / \overline{1}$ thigh;

r_com_trunk = anthropometry_y $\{:, 11\} / 1$ trunk;

r_com_ul = anthropometry_y $\{\overline{\mathbf{:}}, 12\} / I_{-} u l$;

- Segmental inertia moment - from CG

$J_{-}$shank = anthropometry_Y $\{:, 13\}$;

$\mathrm{J}^{-}$thigh $=$anthropometry_Y $\{:, 14\}$;

$\mathrm{J}_{-}^{-}$trunk = anthropometry_Y $\{:, 15\}$;

$\mathrm{J}_{-}^{-} \mathrm{ul}=$ anthropometry_Y $\{\overline{:}, 16\}$;

ségment_J $=\left[J_{-}\right.$shank J_thigh J_trunk J_ul];

$\mathrm{J}_{-}$body $=$anthropometry_Y $\{:, 18\} \overline{\text {; }}$

end

응응

ㅇ $\mathrm{msh}=\mathrm{m} \operatorname{body}(:, 1)$;

onth $=$ m_body $(:, 2)$;

ontr $=$ m_body $(:, 3)$;

\% m_ul $=m^{-}$body $(:, 4)$;

\% m_body $=\left[m_{-}\right.$sh m_th m_tr m_ul];

을 anthropometry $=$ [m_body, segment_length, segment_CoM, segment_J, CoM_body_Y,

I_com_body, J_body];

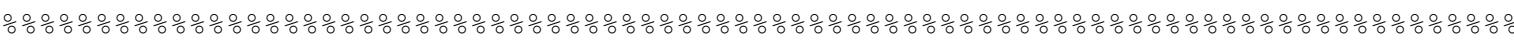

응 3. APPARATUS

ㅇ. 3 SPECIFICATIONS (FIG, 2017-2020)

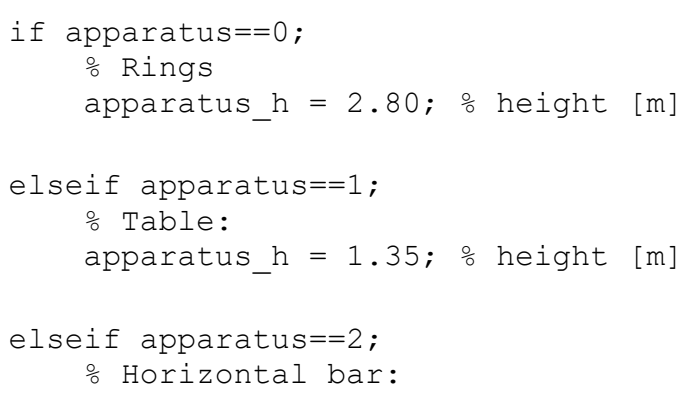


apparatus_h $=2.80 ;$ \% height $[\mathrm{m}]$

elseif apparatus $==3$;

o Uneven bars:

end

apparatus_h $=2.50$; $\frac{\circ}{0}$ height $[\mathrm{m}]$

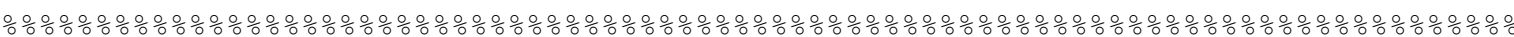

응 4. LINEAR KINEMATICS

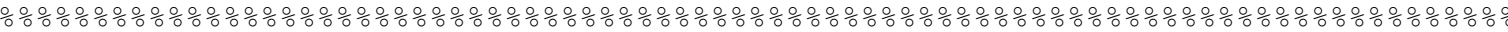

\% 4.1 Calculating the Center of Mass (COM) Position: Segmental (CoM segment) and Total Body (CoM body)

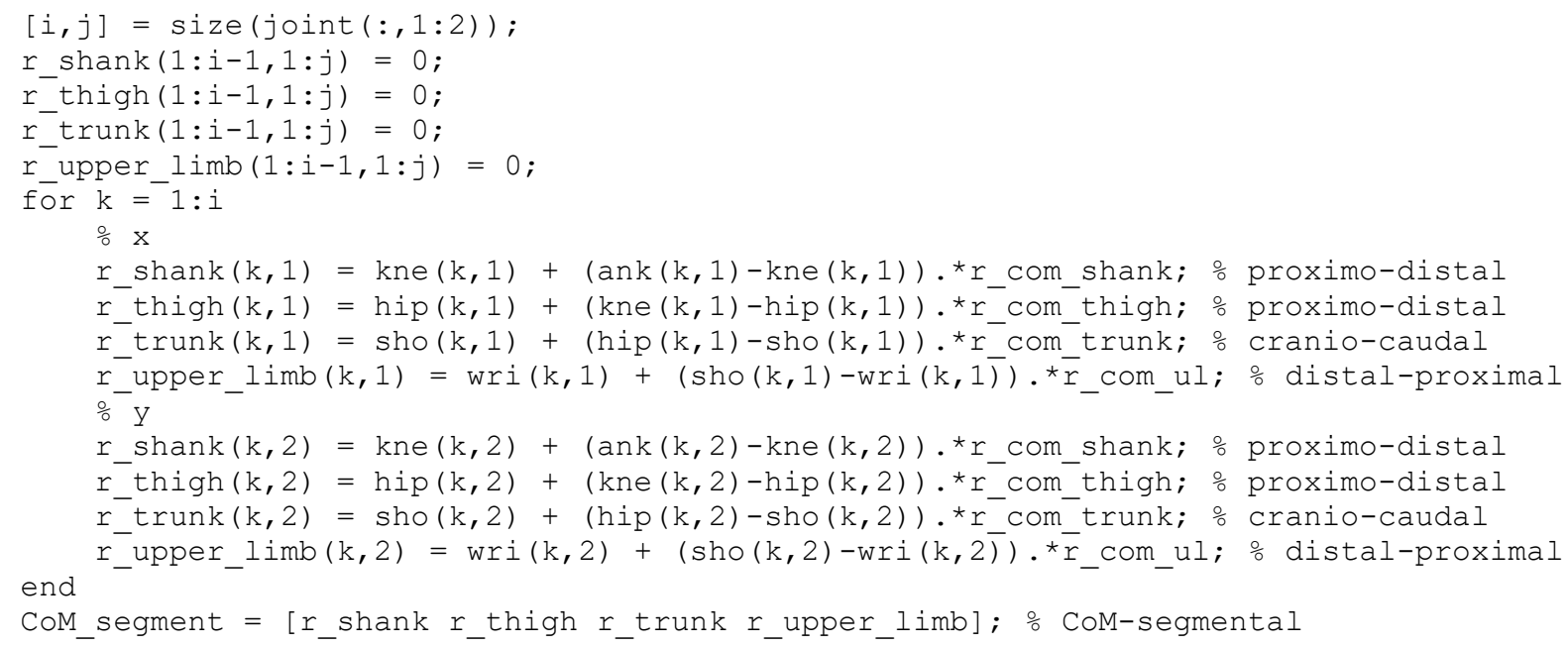

$[i, j]=\operatorname{size}(j \circ i n t(:, 1: 2))$;

CoM_body $(1: i-1,1: j)=0$;

for $k=1: i$

$\operatorname{CoM} \operatorname{body}(k, 1)=\left(m\right.$ foot_shank*r_shank $(k, 1)+m \operatorname{thigh}{ }^{*} \operatorname{thigh}(k, 1)+$

m_trunk_head*r_trunk $(k, 1)+{ }^{-}$m_upper_limb*r_upper_limb $(\mathrm{k}, 1) \overline{)}$. $/$ mass; \% CoMx-body

CoM body $\left(\mathrm{k}^{-}, 2\right)=\left(\mathrm{m}\right.$ foot shank*r $\operatorname{shank}(\overline{\mathrm{k}}, 2)+{ }^{-} \mathrm{m} \operatorname{thigh}{ }^{-} \mathrm{r} \operatorname{thigh}(\mathrm{k}, 2)+$

m_trunk_head*r_trunk $(k, 2)+{ }^{-}$m_upper_limb*r_upper_limb $\left.(k, 2) \bar{l}\right) . /$ mass; $\%$ CoMy-body eñ

o 4.2 Calculating the CoM Linear Velocity (Iinear_vel_CoMs and linear_vel_CoM)

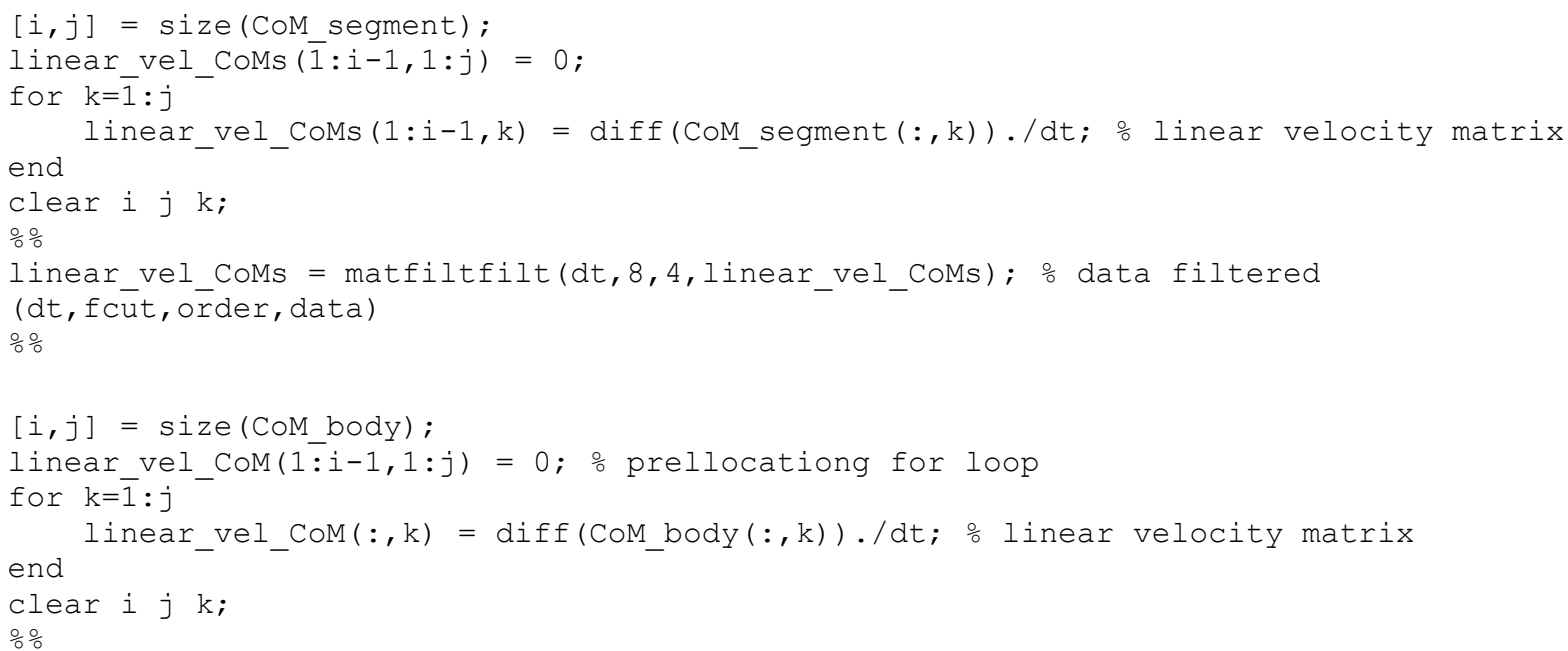




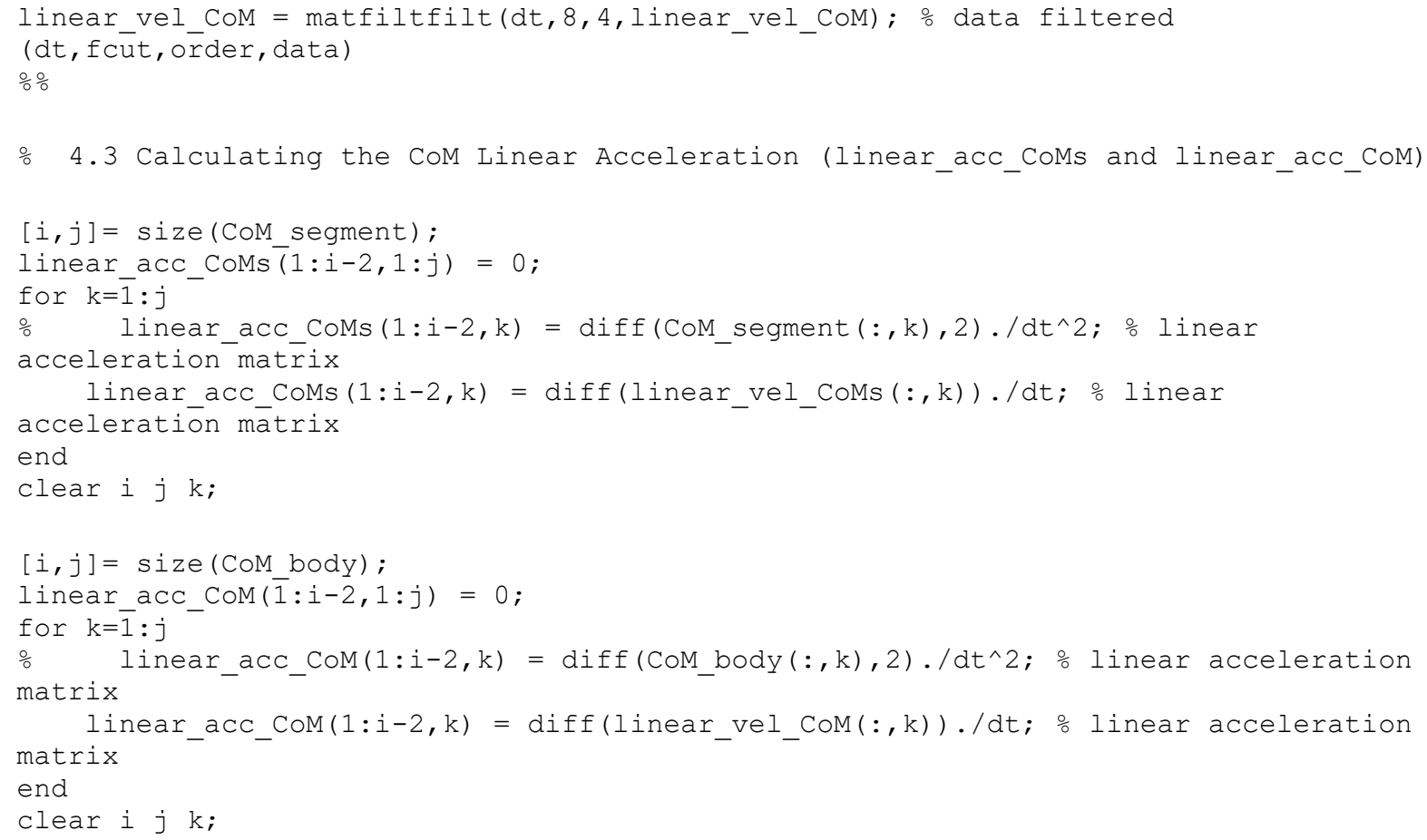


⒌3 Calculating the Angular Acceleration Continuous (angular_acc_seg_continuous) angular_acc_seg_continuous $=\operatorname{diff}($ segmental_angle_continuous, 2$) . / \mathrm{dt}^{\wedge} 2$;

\% 5.4 Calculating the Joint Angles (joint_angle)

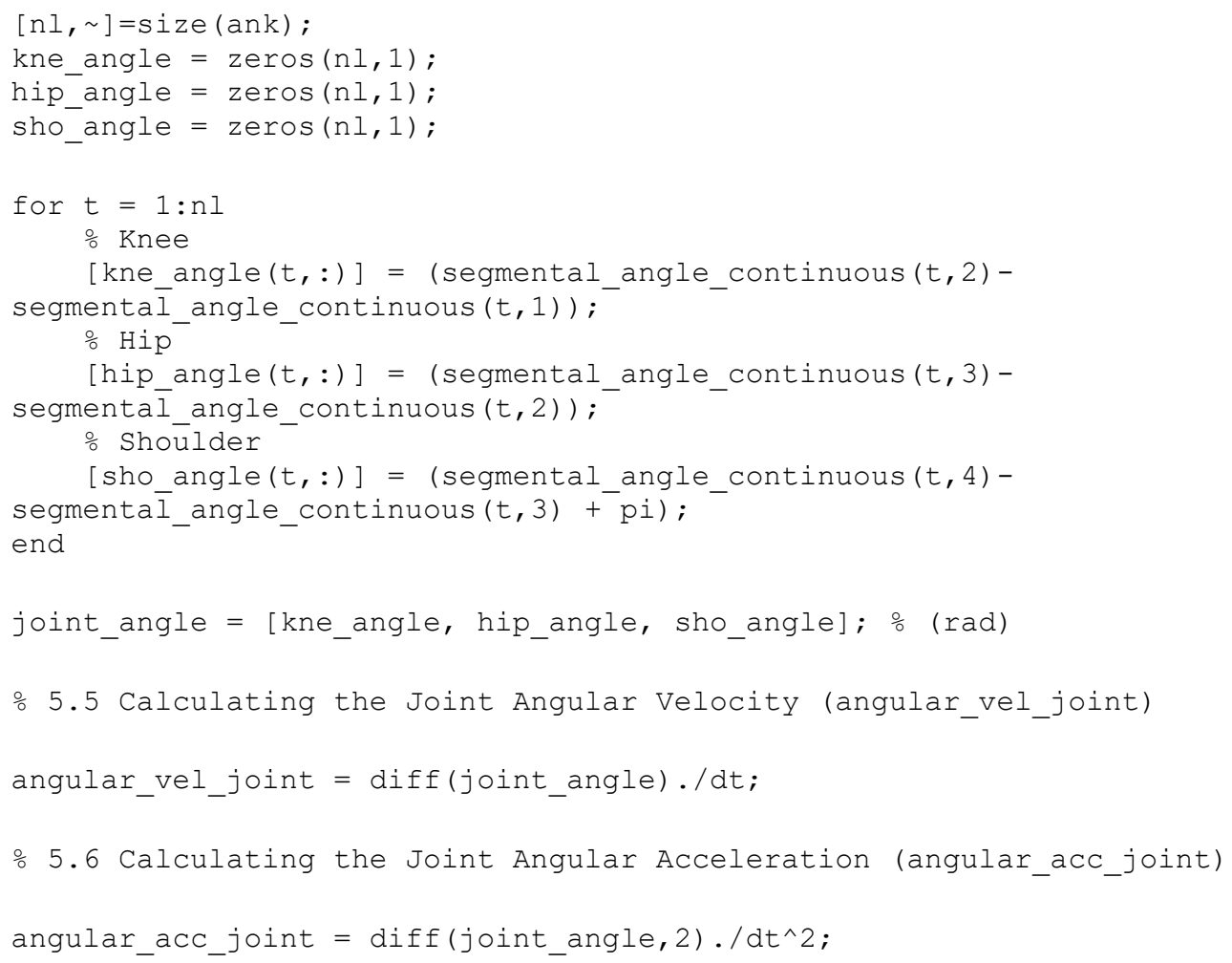


$[\mathrm{nl}, \sim]=\operatorname{size}(\mathrm{ank})$;

theta ank com $=\operatorname{zeros}(\mathrm{nl}, 1)$;

for $t^{-}=1 \overline{: n l}$ end

$[$ theta_ank_com $(t,:)]=$ angle_2d_segment_atan2 $(\operatorname{CoM} b o d y(t,:), \operatorname{ank}(t,:)) ;$

\section{\% 2. Angular Position Continuous}

theta_ank_com_continuous = unwrap (theta_ank_com); $\frac{\circ}{0}$ continuous angle (rad)

\% 3. Angular Velocity

omega_ank_com_continuous =diff(theta_ank_com_continuous)./dt;

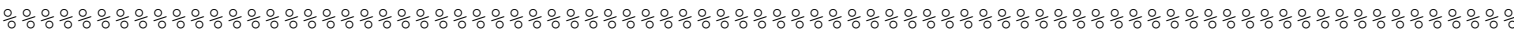

응 OUTPUT TIME VARIABLES:

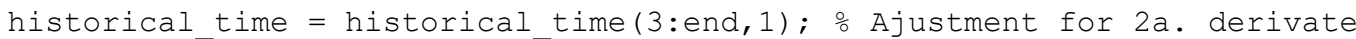
historical time Name $=\{$ 't' $\}$;

historical time ${ }^{-}$array2table(historical_time, 'Variable', historical_time_Name);

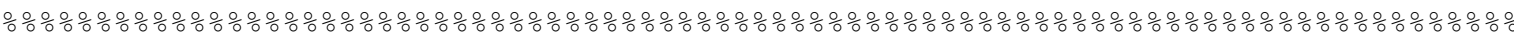

응 OUTPUT ANTHROP VARIABLES:

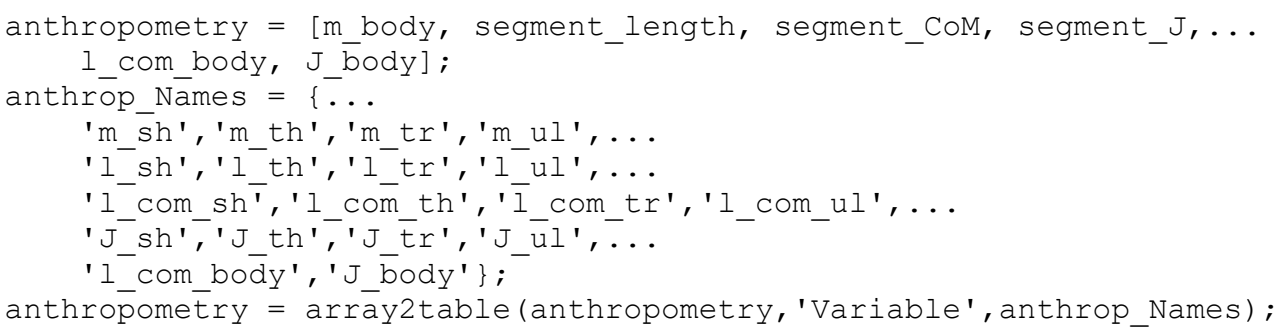

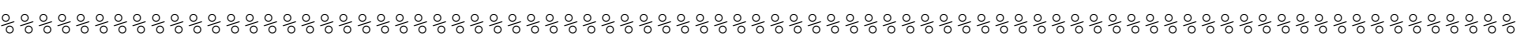

응 OUTPUT KMA VARIABLES:

s joint $=$ joint $(3:$ end, $:)$; \% Joint Center

s_CoMs $=$ CoM_segment $(3:$ end, $:) ;$ o CoM - Segmental Position

$\mathrm{s}$ - CoMb $=$ CoM body $(3:$ end, $:) ;$ \% CoM - Body Position

$\mathrm{v}$ CoMs $=$ linear vel CoMs $(2$ :end, $:) ;$ \% CoM - Segmental Linear Velocity

$\mathrm{v}$ CoMb = linear_vel_CoM (2:end,:); $\frac{\circ}{0}$ CoM - Body Linear Velocity $(\mathrm{x}, \mathrm{y})$

a_CoMs = linear_acc_CoMs; $\frac{\circ}{-} \mathrm{CoM}$ - Segmental Linear Acceleration

a_CoMb = linear_acc_CoM; $\%$ CoM - Body Linear Acceleration

theta joint $=$ joint angle $(3$ :end, $:)$; $\frac{\circ}{0}$ Joint Angle

omega_joint $=$ angular_vel_joint $(2$ :end, $:)$; \% Joint Velocity

alpha joint = angular acc joint; $\%$ Joint Acceleration

theta_seg = segmental_angle( $3:$ end, : ); $\%$ Segmental Angle

theta seg continouos = segmental angle continuous (3:end, :); $\frac{\circ}{\circ}$ Segmental Angle

omega_seg_continouos = angular_vel_seg_continuous $(2$ : end, $:)$; \% Segmental Velocity

alpha_seg_continouos = angular_acc_seg_continuous; 응 Segmental Acceleration

theta ank com = theta ank $\operatorname{com}(3:$ end, $:)$;

theta_ank_com_continuous $=$ theta_ank_com_continuous $(3$ :end, : ) ;

omega ank com continuous = omega ank com continuous $(2$ : end, : $)$;

theta_wri_com $=$ theta_wri_com $(3:$ end, : $)$;

theta wri com continuous $=$ theta wri com continuous $(3$ :end, :);

omega_wri_com_continuous = omega_wri_com_continuous $(2$ : end, $:)$; 


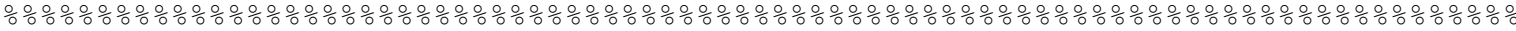

응 COMPLETE TIME MODE

o CAUTION! Output kma_angular: rad for dynamic and deg for statistic

kma_linear $=\left[s_{-}\right.$joint $(:,:), s_{-} \operatorname{CoMs}(:,:), s_{-} \operatorname{CoMb}(:,:), \ldots$

v_CoMs $\left.(:,:), v_{-} \operatorname{CoMb}(:,:), \bar{a} \_\operatorname{CoMs}(:,:), \bar{a} \_\operatorname{CoMb}(:,:)\right]$;

$\mathrm{kma}$ linear Names $=$

$\{$ 'añk_x', 'ànk_y', 'kne_x', 'kne_y', 'hip_x', 'hip_y', 'sho_x', 'sho_y', 'wri_x', 'wri_y', .

'sh_x', 'sh_y','th_x', 'th_y','tr_x', 'tr_y', 'ul_x', 'ul_y', 'cm_x', 'cm_y', ...

'sh_vx', 'sh_vy', 'th_vx', 'th_vy', 'tr_vx', 'tr_vy', 'ul_vx', 'ul_vy', 'cm_vx', 'cm_vy', ...

'sh_ax','sh_ay','th_ax','th_ay', 'tr_ax','tr_ay', 'ul_ax', 'ul_ay', 'cm_ax', 'cm_ay'\};

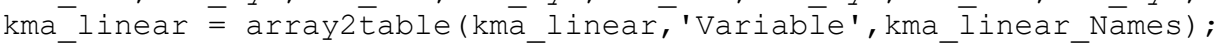

kma_angular $=[$ theta_joint $(:,:)$, omega_joint $(:,:)$, alpha_joint $(:,:), \ldots$

theta_seg_continouos $(:,:)$,omega_seg_continouos $(:,:)$, alpha_seg_continouos $(:,:), \ldots$

theta_ank_com $(:,:)$, theta_ank_com_continuous $(:,:)$, omega_ank_com_continuous $(:,:), \ldots$

theta_wri_com $(:,:)$, theta_wri_com_continuous $(:,:)$, omega_wri_com_continuous $(:,:)]$; kma_añgulār_Names $=$

\{'theta_kne','theta_hip','theta_sho','omega_kne','omega_hip', 'omega_sho', 'alpha_kne ', 'alphā_hip', 'alphā_sho',...

'theta_sh','theta_th', 'theta_tr', 'theta_ul', 'omega_sh', 'omega_th', 'omega_tr', 'omega _ul', 'àlpha_sh', 'àlpha_th', 'àlpha_tr', 'àlpha_ul', ...

'theta ank com', 'theta ank com continuous',' 'omega ank com', ...

'theta_wri_com', 'theta_wri_com_continuous','omega_wri_com'\};

kma_angular $=\bar{a}$ rray2table (kma_angularar, 'Variable', kma_angular_Names) ;

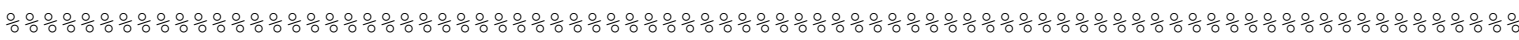

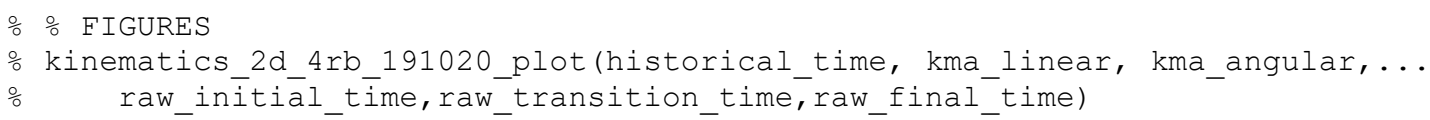

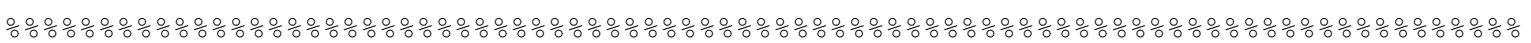

$\div$ 응 TEMPORAL NORMALIZATION

ㅇ [historical time, kma linear, kma angular] =

kinematics_2d_4rb_191022_normalization(historical_time, kma_linear, kma angular,... oraw_initial_time,rāw_transition_time,raw_fiñal_time);

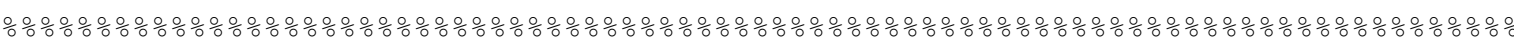

응 2D KINETICS / 4 RIGID BODY

INVERSE DYNAMICS

function[historical_time, anthropometry, kma_linear, kma_angular, kne_linear, kne_angular $]=\ldots$

kinetics_2d_4rb(raw_coordinate,raw_initial_time,raw_transition_time,raw_final_time, mass)

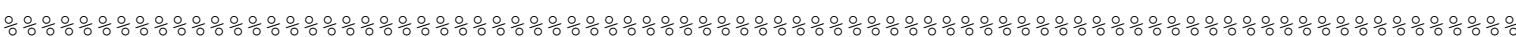

\author{
: SUB-ROTINES : \\ \% anthrop model 4 rb yeadon.m \\ o kinematícs_2d_4rb.m
}




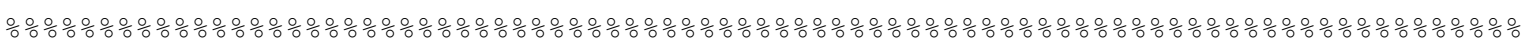

응 INPUT SELECTION

ID_Procedure = input ('ID Procedure: hybrid [0], bottom-up[1], or up-down[2] ? ');

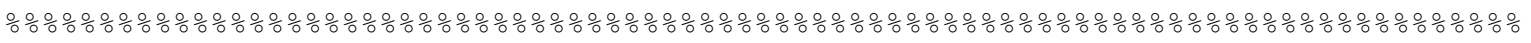

응 EXPERIMENTAL DATA

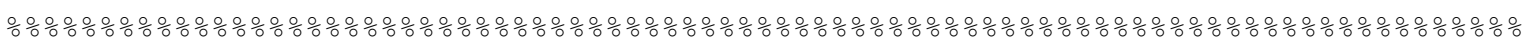

응 1. ANTHROPOMETRIC, TIME AND KINEMATICS (INPUT)

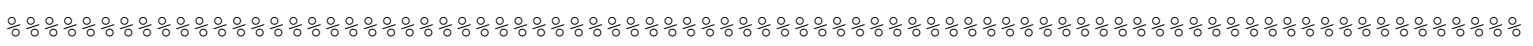

[historical_time, anthropometry, kma_linear, kma_angular]...

$=$

kinematics_2d_4rb_191112(raw_coordinate,raw_initial_time,raw_transition_time,raw_fi nal_time, mass ) ;

1.1 TIME DATA

historical_time = table2array (historical_time);

ti = raw_initial_time;

tt $=$ raw_transition_time;

tf $=$ raw_final_time $\overline{\text {; }}$

$[f i, \sim]=$ find(historical_time $(:, 1)==t i, 1)$;

$[\mathrm{ft}, \sim]=$ find (historical time $(:, 1)==\mathrm{tt}, 1)$;

$[\mathrm{ff}, \sim]=$ find(historical_time $(:, 1)==\mathrm{tf}, 1)$;

take_off_time_r $=\mathrm{ft}$;

\% 1.2 ANTROPOMETRYC DATA

anthropometry = table2array (anthropometry);

m_segment $=$ anthropometry $(:, 1: 4)$;

m_shank $=$ m_segment $(:, 1)$;

m_thigh $=\mathrm{m}^{-}$segment $(:, 2)$;

m_trunk_head $=$ m_segment $(:, 3)$;

m_upper_limb $=$ m_segment $(:, 4)$;

$1^{-}$shank $=$anthropometry $(:, 5)$;

1_thigh = anthropometry $(:, 6)$;

1_trunk = anthropometry $(:, 7)$;

I_ul = anthropometry $(:, 8)$;

I_com_shank = anthropometry $(:, 9)$;

1_com_thigh $=$ anthropometry $(:, 10)$;

1_com_trunk = anthropometry $(:, 11)$;

I_com_ul = anthropometry $(:, 12)$;

J_segment $=$ anthropometry $(:, 13: 16)$;

$\mathrm{J}^{-} \mathrm{sh}=\mathrm{J}$ segment $(:, 1)$;

$\mathrm{J}_{-}^{-}$th $=\mathrm{J}_{-}^{-}$segment $(:, 2)$;

J-trunk $=$ J_segment $(:, 3)$;

J_ul = J_segment $(:, 4)$;

I_com_body = anthropometry $(:, 17)$;

J_body = anthropometry $(:, 18)$;

응 1.3 KINEMATIC DATA 


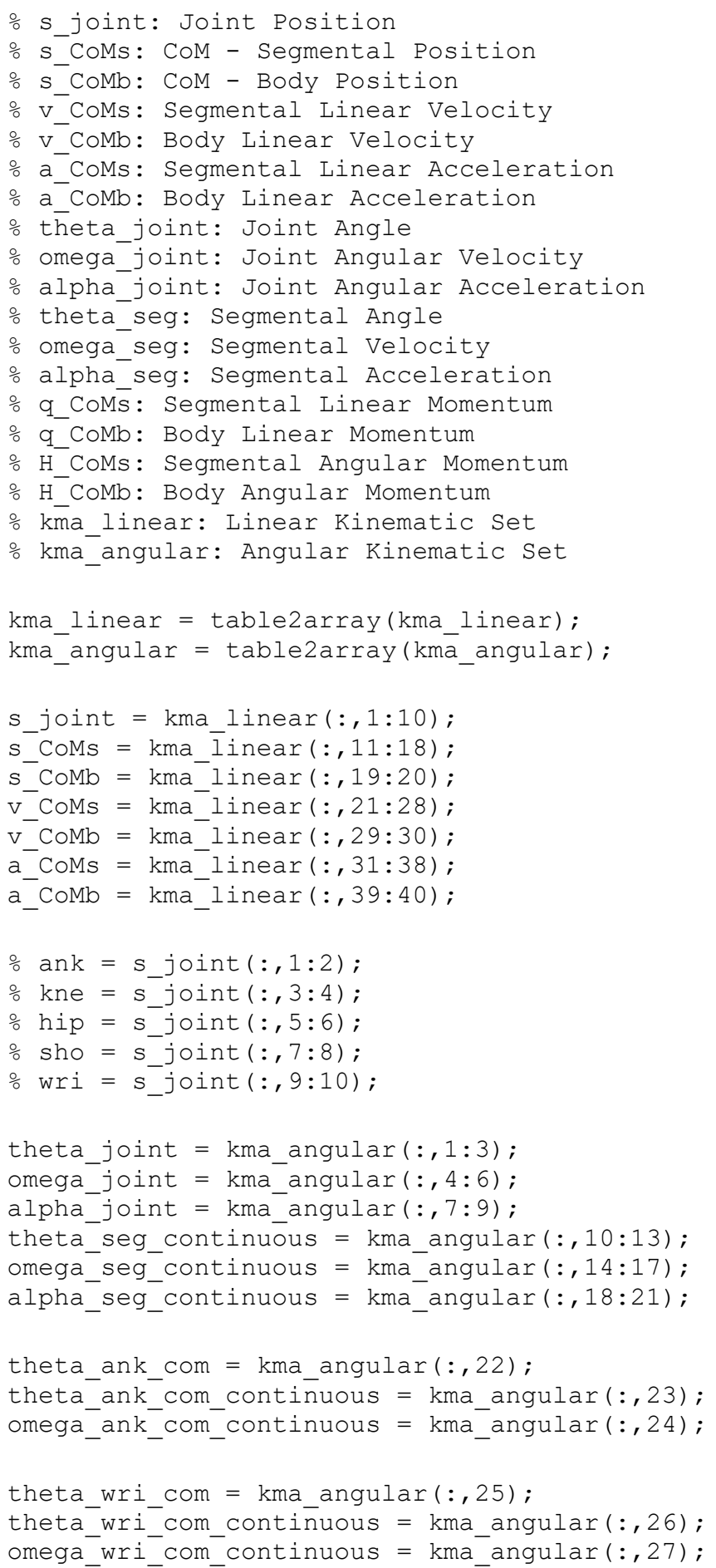

\section{$\because 2$. KINETICS}

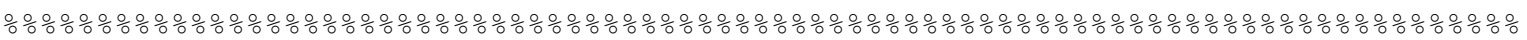

$g=9.81 ; \circ[\mathrm{m} / \mathrm{s}]$

응 LINEAR MOMENTUM (q)

응 Calculate: Segmental Linear Momentum 


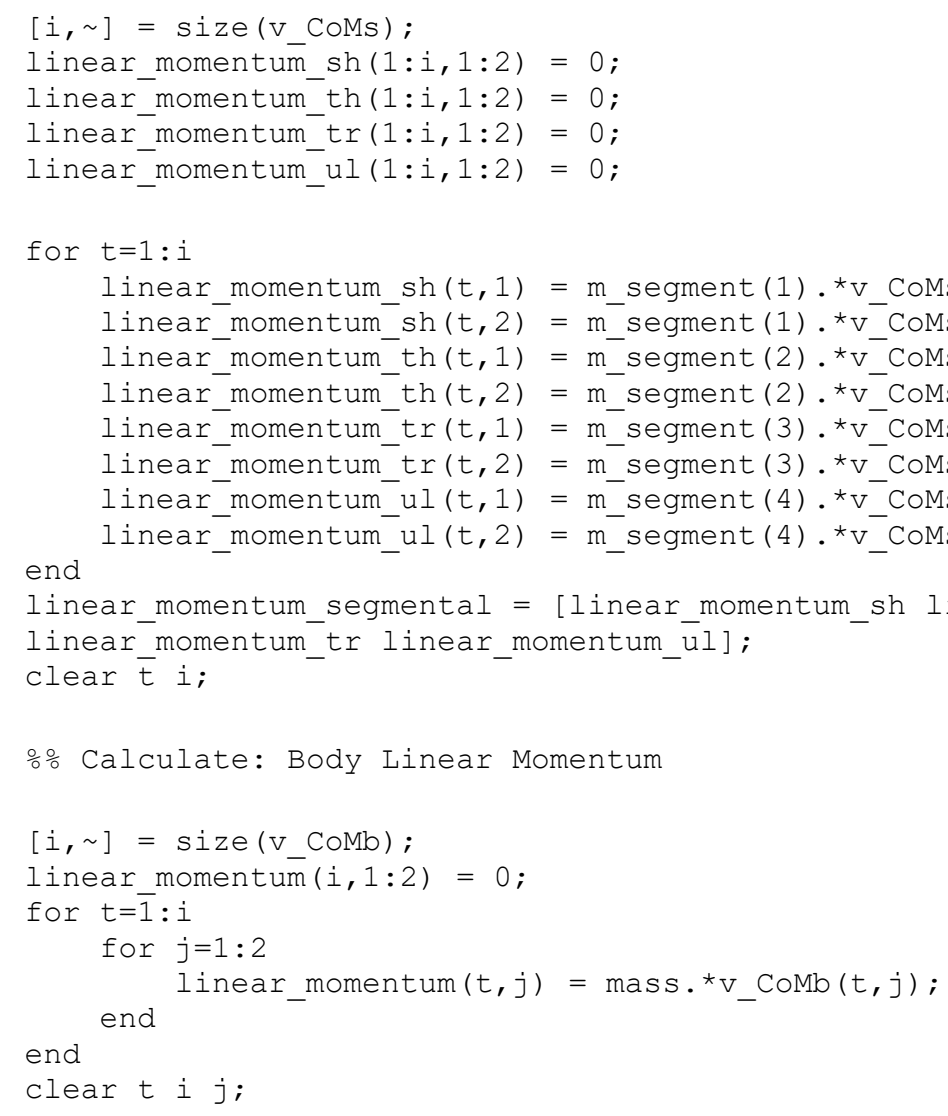

응 ANGULAR MOMENTUM

$\because$ SEGMENTAL

H_sh $(:, 1)=J_{-}$sh*omega_seg_continuous $(:, 1)$;

$\mathrm{H}^{-}$th $(:, 1)=\mathrm{J}^{-}$th ${ }^{*}$ omega_seg_continuous $(:, 2)$;

$\mathrm{H}_{\text {_tr }}(:, 1)=\mathrm{J}_{\text {-trunk}}{ }^{-}$omega_seg_continuous $(:, 3)$;

$\mathrm{H}_{-} \mathrm{ul}(:, 1)=\mathrm{J}_{-} \mathrm{ul}$ omega_seg_continuous $(:, 4)$;

H_S $=\left[H_{-}\right.$Sh H_th H_tr H_ul];

$\therefore$ BODY

[frames, $\sim=\operatorname{size}\left(\mathrm{s}\right.$ CoMs); $\frac{\circ}{0}$ vector dimension

$\mathrm{z}=\operatorname{zeros}($ frames, 1$) \bar{i} \div \mathrm{z}$ coordinates

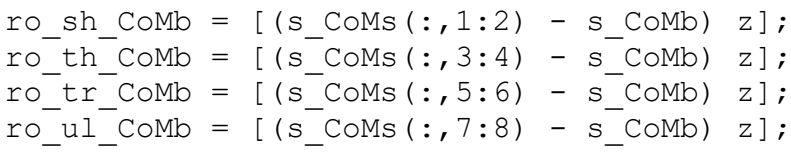

linear momentum shz = [linear momentum sh z]; linear_momentum_thz = [linear_momentum_th z]; linear_momentum_trz $=$ [linear_momentum_tr z]; linear_momentum_ulz=[linear_momentum_ul z];

$\mathrm{H}$ CoM sh $=\operatorname{Cross}(r o$ sh CoMb, linear momentum shz); $\mathrm{H}_{-}^{-} \mathrm{COM}_{-}^{-}$th $=\operatorname{cross}\left(\mathrm{ro}_{-}^{-} \mathrm{th}_{-}^{-} \mathrm{CoMb}\right.$, linear_momentum_thz); $\mathrm{H}^{-} \mathrm{COM}^{-} \mathrm{tr}=\operatorname{cross}\left(\mathrm{ro}^{-} \mathrm{tr}^{-} \mathrm{CoMb}\right.$, linear momentum trz); $\mathrm{H}_{-}{ }_{\mathrm{COM}}{ }_{-} \mathrm{ul}=\operatorname{cross}\left(\mathrm{ro}_{-}{ }^{-}{ }_{-}{ }_{-} \mathrm{COMb}, \mathrm{Iinear}\right.$ momentum_ulz) ;

Hg_body $=\left(H_{-}\right.$CoM_sh $(:, 3)+H_{-} \operatorname{sh}(:, 1)+H_{-}$CoM_th $(:, 3)+H_{-}$th $(:, 1)+\ldots$ 
H_CoM_tr $\left.(:, 3)+\mathrm{H}_{-} \operatorname{tr}(:, 1)+\mathrm{H}_{-} \mathrm{COM} \_u l(:, 3)+\mathrm{H} \_u l(:, 1)\right)$;

ANGULAR MOMENTUM RELATIVE TO THE ANKLE

I_body $=\left[\left(s_{-}\right.\right.$CoMb $-s_{-}$joint $\left.\left.(:, 1: 2)\right), z^{\prime}\right]$

$\mathrm{v}_{-}$body $=\left[\mathrm{v}_{-} \overline{\mathrm{C}} \mathrm{C} \mathrm{Mb}, \mathrm{z}\right]$;

Ho_body_z $=-\operatorname{cross}\left(I_{-}\right.$body, v_body $) \cdot{ }^{*}$ mass;

o Ho_body $=$ Ho_body_z $(:, 3)+$ Hg_body;

Ho_body_gg $\left(1: f \bar{t}-1, \overline{)}=\right.$ Ho_body_z $(1: f t-1,3)+H g \_b o d y(1: f t-1,1)$;

Ho_body_dsbs $(:, 1)=$ Ho_bo dy_z $(\overline{\mathrm{f}} \mathrm{t}: \mathrm{end}, 3)+\operatorname{mean}\left(\overline{\mathrm{H} g \_b o d y}(\mathrm{ff}-20: \mathrm{ff}, 1)\right)$;

Ho_body $=$ [Ho_body_gg; Ho_body_dsbs];

응 KINETICS ENERGY $(k)$

응 Pre-Calculate for Kinetic Energy: Segmental CoM - Scalar Velocity (sv_CoMs)

linear_vel_shCoM $=$ V_CoMs $(:, 1: 2)$;

linear_vel_thCoM $=\mathrm{v}_{-} \operatorname{CoMs}(:, 3: 4)$;

linear vel $\operatorname{trCoM}=\mathrm{v}^{-} \operatorname{CoMs}(:, 5: 6)$;

linear_vel_ulCoM $=v_{-}$CoMs $(:, 7: 8)$;

$[i, \sim]=\operatorname{size}\left(\mathrm{v}_{\mathrm{C}} \mathrm{CoMs}\right)$;

scalar_vel_shCōM(1:i) = 0 ;

scalar vel thCoM $(1: i)=0$;

scalar_vel_trCoM(1:i) = 0 ;

scalar_vel_ulCoM(1:i) = 0 ;

for $t=\overline{1}: i$

scalar_vel_shCoM(t) $=\operatorname{sqrt}($ linear_vel_shCoM(t, 1$) \cdot{ }^{\wedge} 2+$

linear_vel_shCoM(t,2).^2);

scālar_vel_thCoM(t) = sqrt(linear_vel_thCoM $(t, 1) \cdot{ }^{\wedge}+$

linear_vel_thCōM $(t, 2) . \wedge 2)$;

scālar_vel_trCoM(t) $=\operatorname{sqrt}\left(1\right.$ inear_vel_trCoM $(t, 1) \cdot{ }^{2}+$

linear vel $\left.{ }^{-} \operatorname{trC} \bar{M}(t, 2) .^{\wedge} 2\right)$;

scälar vel ulCoM(t) = sqrt(linear vel_ulCoM(t,1).^2+

linear_vel_ulCōM $(t, 2) \cdot \wedge 2)$;

end

sv_CoMs = [scalar_vel_shCoM; scalar_vel_thCoM; scalar_vel_trCoM;

scālar vel ulCoM]';

clear $\bar{t} i$

응 Calculate: Segmental Energy Kinetic

[frames, variable] = size (sv_CoMs);

$\mathrm{k}$ CoMs (frames, variable) = 0 ;

for $f=1$ :frames

for $\mathrm{V}=1$ :variable

$\mathrm{k} \operatorname{CoMs}(\mathrm{f}, \mathrm{v})=\left((1 / 2){ }^{*} \mathrm{~m} \operatorname{segment}(\mathrm{v}) \cdot{ }^{*} \mathrm{SV} \operatorname{CoMs}(\mathrm{f}, \mathrm{v}) \cdot{ }^{\wedge} 2+\right.$

$(1 / 2) * J+\operatorname{se} g m e n t(v) .{ }^{*}$ omega_seg_Continuous $\left.(f, v)^{\wedge} 2\right) ; \%[J]$

end

end

응 Calculate: Body Energy Kinetic

$\mathrm{k} \_\mathrm{CoMb}=\mathrm{k} \_\operatorname{CoMs}(:, 1)+\mathrm{k} \_\operatorname{CoMs}(:, 2)+\mathrm{k}_{-} \operatorname{CoMs}(:, 3)+\mathrm{k} \_\operatorname{CoMs}(:, 4)$;

응 POTENCIAL ENERGY (p)

\% Calculate: Body Potential Energy (p_CoMs)

$[i, j]=\operatorname{size}\left(s_{-} \operatorname{CoMs}(:, 2: 2:\right.$ end $\left.)\right)$;

p_CoMs $(i, j)=\overline{0}$;

for $t=1: i$

$p_{\operatorname{CoMs}}(t, 1)=\mathrm{m} \operatorname{segment}(1) * g .{ }^{*} \mathrm{~S} \operatorname{CoMs}(t, 2) ; \%[\mathrm{~J}]$

p_CoMs $(t, 2)=m_{-}$segment $(2) * g \cdot{ }^{*}{ }_{-} \operatorname{CoMs}(t, 4) ; \%[\mathrm{~J}]$ 
end

ㅇ bottom-up ID:

F_joint_GRS_bottom_up $=$ [Fx_kne1; Fy_kne1; Fx_hip1; Fy_hip1; Fx_shol; Fy_shol;

Fx_wri1; Fy_wril]';

응-down ID:

F_joint_GRS_up_down $=[$ Fx_kne2; Fy_kne2; Fx_hip2; Fy_hip2; Fx_sho2; Fy_sho2;

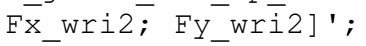

\% hybrid ID:

Fx kne1 2 = [Fx kne1 (1:take off time $r-1$ ), Fx kne2(take off time $r:$ end) ] ;

Fy_kne1_2 = [Fy_kne1(1:take_off_time_r-1), Fy_kne2 (take_off_time_r:end)];

Fx hip1 ${ }^{-} 2=\left[\mathrm{Fx}^{-}\right.$hip1 (1:take off time ${ }^{-}$-1), Fx hip2(take off ${ }^{-}$time $^{-}$r:end)];

Fy_hip1_2 = [Fy_hip1 (1:take_off_time_r-1), Fy_hip2 (take_off_time_r:end)];

Fx_sho1_2 = [Fx_shol(1:take_off_time_r-1), Fx_sho2(take_off_time_r:end)];

Fy_sho1_2 = [FY_shol(1:take_off_time_r-1), Fy_sho2(take_off_time_r:end)];

Fx_wri1_2 = [Fx_wril (1:take_off_time_r-1), Fx_wri2(take_off_time_r:end)];

Fy wril_2 = [Fy wril (1:take off time r-1), Fy wri2 (take off time-r:end)];

F_joint_GRS_hybrid = [Fx_kñe1; Fy_kñe1; Fx_h̄ip1; Fy_hīpl; Fx_shol_2; Fy_sho1_2;

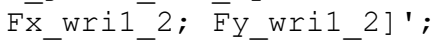

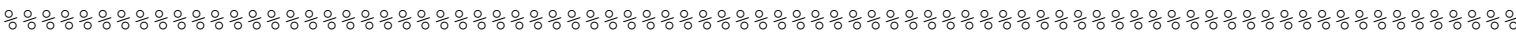

\section{응 JOINT MOMENT}

\% J_ll: lowe limb inertial moment

\% alpha_CoMs: CoM angular acceleration

$\circ$ F joint_GRS: Fx,i-1

: F_joint_GRS: Fy,i-1

or CoMs: level arm, CoM to $\mathrm{F}, \mathrm{i}-1$

\% theta_CoMs: segmental angle

frames $=$ length $(\mathrm{a}$ CoMs $)$

for $i=1$ :frames

응 ВОTTOM-UP:

M knel(i) = J sh*alpha seg continuous $(i, 1)-\ldots$

F_joint_GR $S$ bottom_up $(\bar{i}, 1){ }^{*}$ I_com_shank. ${ }^{*}$ sin (theta_seg_continuous $\left.(i, 1)\right) \ldots$

$+{ }^{-}$_joint_GRS_bottom_up $(i, 2){ }^{\star}{ }^{1}$ _com_shank. ${ }^{\star} \cos ($ the $\bar{t} a$ seg_continuous $(i, 1))$;

Mhipl(i) = J th*alpha seg continuous $(i, 2)+M \operatorname{knel}(i)-\ldots$

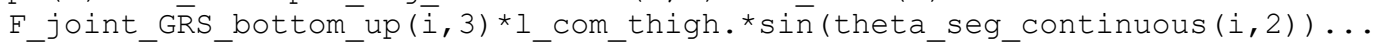

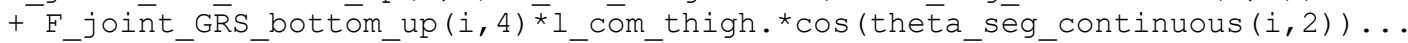

+ F_joint_GRS_bottom_up $(i, 1) *\left(\bar{I}_{\text {t thigh }}-\right.$

1 com thigh). ${ }^{\star} \sin ($ the ta seg_continuous $(\bar{i}, 2)) \ldots$

- F_joint_GRS_bottom_up $(i, 2) *(1$ thigh -

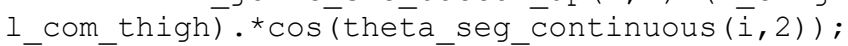

M_sho1(i) = J_trunk*alpha_seg_continuous $(i, 3)+$ Mhipl(i) - ..

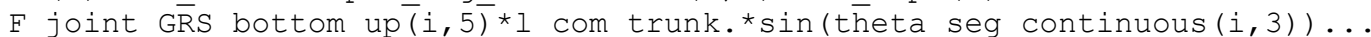

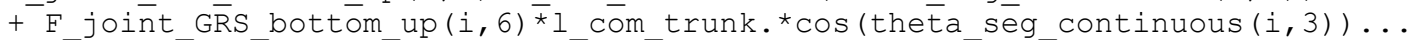

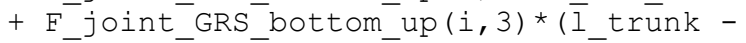

I_com_trunk). ${ }^{*} \sin ($ the ta_seg_continuous $(\bar{i}, 3)) \ldots$

- F_joint_GRS_bottom_up $(i, 4) *(1$ trunk -

I_com_trunk $\overline{)} \cdot{ }^{\star} \cos \overline{(}$ the $\left.\bar{t} a \_s e g \_\overline{c o n t i n u o u s}(\bar{i}, 3)\right)$;

M wril(i) = J ul*alpha seg continuous (i,4) + M shol(i) - ...

F_joint_GR $S$ bottom_up $(\bar{i}, 7){ }^{*}{ }_{-}$com_ul. ${ }^{*} \sin ($ theta_seg_continuous $(i, 4)) \ldots$

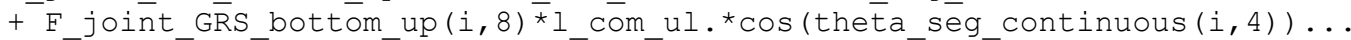

$+F^{-j o i n t}$ GRS bottom up $(i, 5) *\left(\bar{l} u^{-}{ }^{-}\right.$

I_com_ul). ${ }^{*}$ sin (thêta_seg_continuous $(i, 4 \overline{)}) \ldots$ 


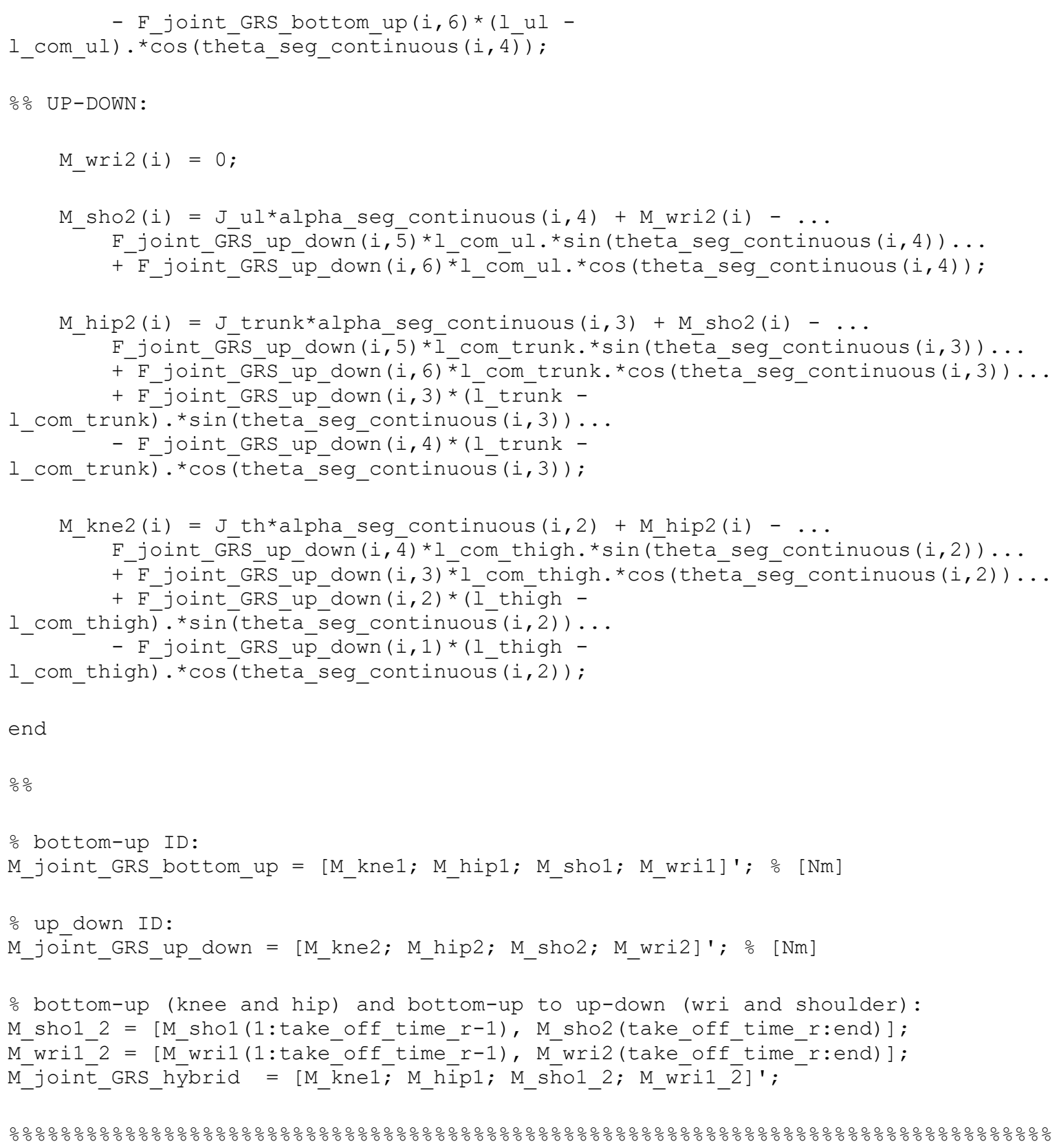


anthropometry = array2table(anthropometry, 'Variable', anthrop_Names);

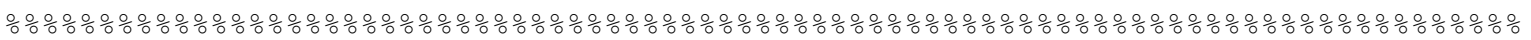

응 OUTPUT KMA VARIABLES:

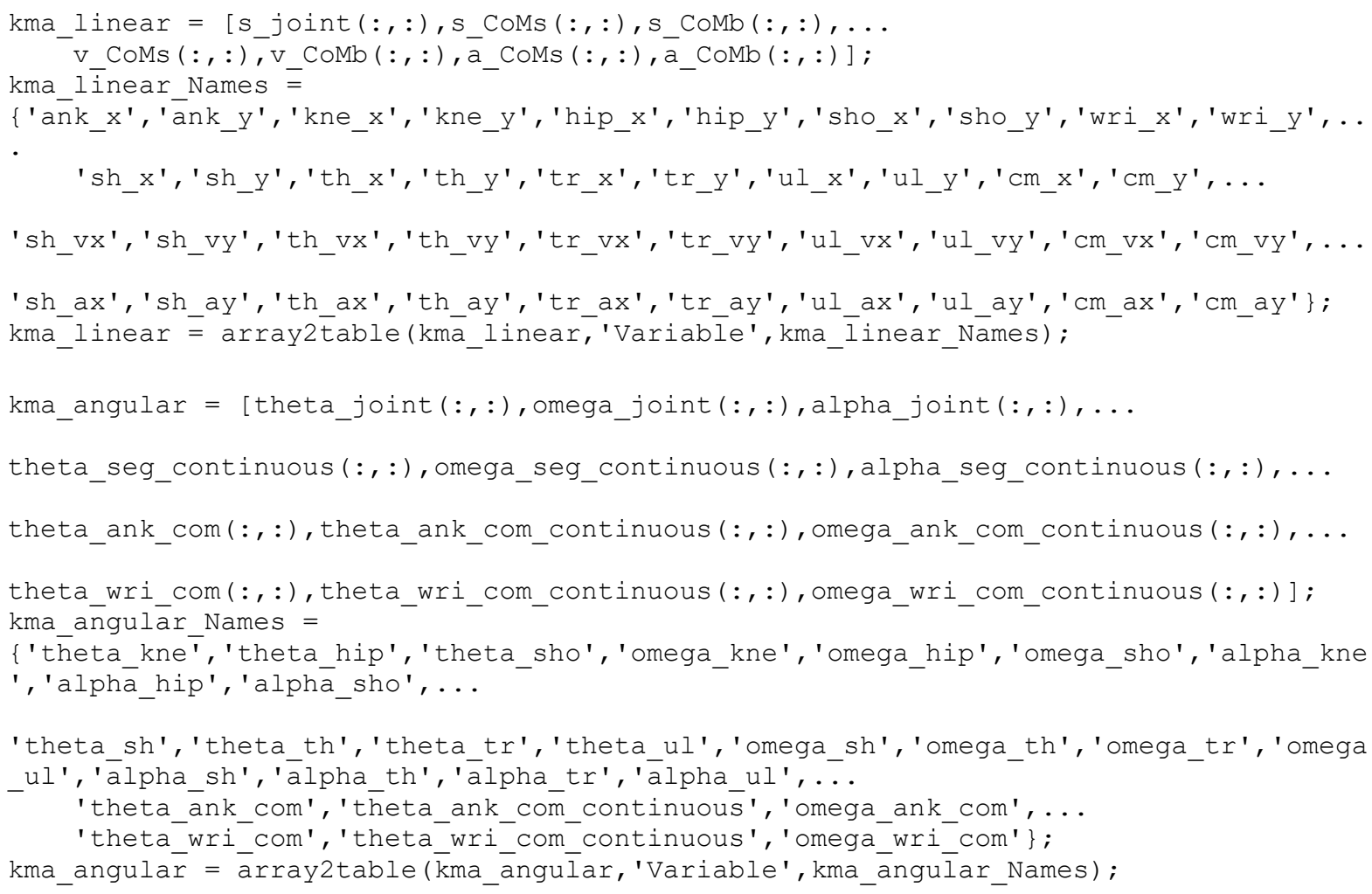

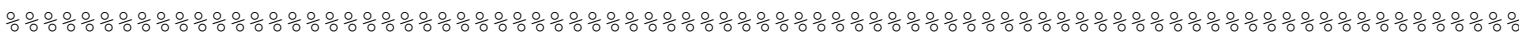

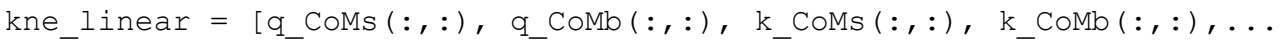

p_CoMs $(:,:), p_{-}$CoMb $(:,:), E_{-} \operatorname{CoMs}(:,:), E_{-} \operatorname{CoMb}(:,:), F_{-}$joint $\left.(:,:)\right]$;

kne linear Names $=$

$\{$ 'Q_sh_x', 'Q_sh_y', 'Q_th_x', 'Q_th_y', 'Q_tr_x', 'Q_tr_y', 'Q_ul_x', 'Q_ul_y', 'Q_body_x' , 'Q_body_y', ... 


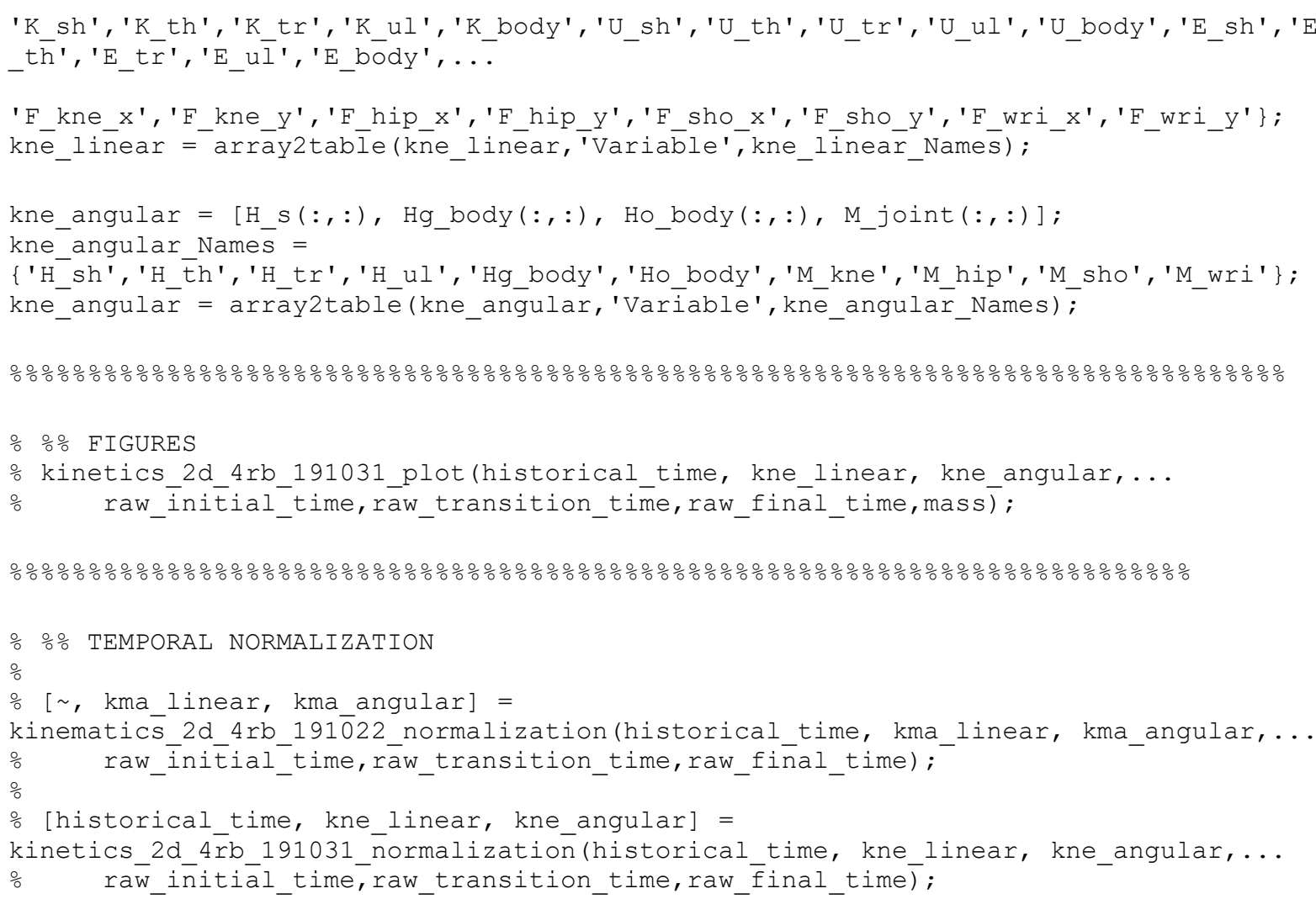




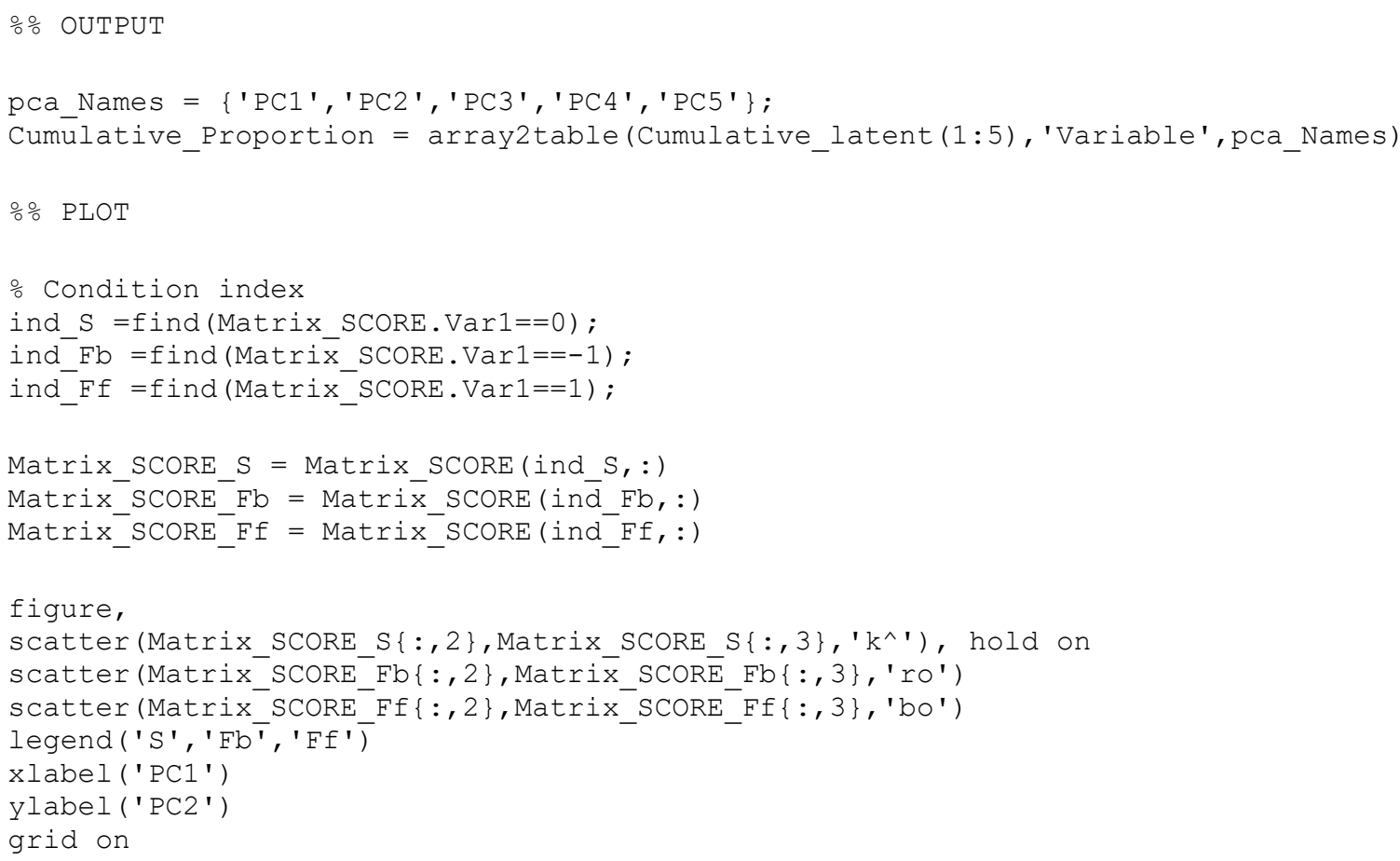




\section{ANEXO I - TERMO DE CONSENTIMENTO LIVRE E ESCLARECIDO \\ I - IDENTIFICAÇÃO DO SUJEITO DA PESQUISA OU RESPONSÁVEL LEGAL \\ 1. DADOS DO INDIVÍDUO \\ Nome completo}

Sexo

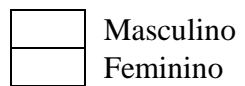

RG

Data de nascimento

Endereço completo

CEP

Fone

e-mail

2. RESPONSÁVEL LEGAL

Nome completo

Natureza (grau de parentesco, tutor, curador, etc.)

Sexo

Masculino

Feminino

RG

Data de nascimento

Endereço completo

CEP

Fone

e-mail

\section{II - IDENTIFICAÇÃO DA PESQUISA CIENTÍFICA}

1. Título do Projeto de Pesquisa

Modelagem dos movimentos para aterrissagens em ginástica artística

2. Pesquisador Responsável

Alberto Carlos Amadio

3. Cargo/Função

Docente

4. Avaliação do risco da pesquisa:

4probabilidade de que o indivíduo sofra algum dano como conseqüencia imediata ou tardia do estudo)
RISCO MÍNIMO $\square$ RISCO MÉDIO

5. Duração da Pesquisa

De 25/11/15 a 30/06/19

\section{III - SOBRE O CONTEÚDO DE PESQUISA CIENTÍFICA:}

O desempenho de um ginasta em qualquer aparelho da modalidade (solo, barra, argolas, salto, paralelas ou cavalo; no caso do masculino) sofre expressiva influência da maneira como aterrissagem é executada. O objetivo deste estudo é investigar as condições mecânicas que permitem a estabilidade corporal para aterrissagem em ginástica artística. Para tanto, será solicitado que você realize cinco tentativas válidas para o salto mortal estendido, a partir de diferentes aparelhos ginásticos. Considerando ser uma habilidade elementar na sua rotina de treinamento, acreditamos que os riscos e/ou desconfortos esperados na aquisição de dados são baixos. Ao término do você e sua equipe técnica receberão um relatório de análise de desempenho com destaque às competências para aterrissagens estáveis em ginástica artística, mesmo que não haja procedimentos alternativos que lhe possam ser vantajosos. 


\section{IV - GARANTIAS DO SUJEITO DA PESQUISA:}

Você poderá, a qualquer tempo, acessar as informações sobre procedimentos, riscos e benefícios relacionados à pesquisa, inclusive para dirimir eventuais dúvidas; terá liberdade para retirar o seu consentimento e deixar de participar do estudo, sem que isto lhe traga prejuízo à continuidade da assistência; terá salvaguarda a confidencialidade, sigilo e privacidade; e poderá contar com a assistência no HU, HCFMUSP e/ou no hospital público mais próximo, por eventuais danos à saúde decorrentes da pesquisa.

\section{V - CONTATO EM CASO DE INTERCORRÊNCIAS CLÍNICAS E REAÇÕES ADVERSAS}

Prof. Dr. Alberto Carlos Amadio

Escola de Educação Física e Esporte - USP

Av. Prof. Mello Moraes, 65 - Cidade Universitária

CEP: 05508-030 - São Paulo - SP

Telefone: (11) 3091-2148

Comitê de Ética em Pesquisa

Escola de Educação Física e Esporte - USP

Av. Prof. Mello Moraes, 65 - Cidade Universitária

CEP: 05508-030 - São Paulo - SP

Telefone: (11) 3091-3097

Hospital Universitário (HU)

Av. Professor Lineu Prestes, 2565 - Butantã - USP

CEP: 05508-000 - São Paulo - SP

Telefone: (11) 3091-9200

Hospital das Clínicas da Faculdade de Medicina da USP (HCFMUSP)

César Av. Dr. Enéas de Carvalho Aguiar, 255 - Cerqueira César

CEP: 05403-000 - São Paulo - SP

Telefone: (11) 2661-0000

\section{VI - OBSERVAÇÕES COMPLEMENTARES:}

Não há.

\section{VII - CONSENTIMENTO PÓS-ESCLARECIDO}

"Declaro que, após convenientemente esclarecido pelo pesquisador e ter entendido o que me foi explicado, consinto em participar do presente Projeto de Pesquisa."

São Paulo,

assinatura do sujeito da pesquisa

ou responsável legal assinatura do pesquisador

(carimbo ou nome legível) 


\section{ANEXO II - TERMO DE COMPROMISSO / COMITE DE ÉTICA LOCAL}

- Plotoformo MINISTERIO DA SAUDE - Consehto Nacional de Saúde - Comissao Nacional de Elica em Pescquisa - CONEF Braril

FOLHA DE ROSTO PARA PESQUISA ENVOLVENDO SERES HUMANOS

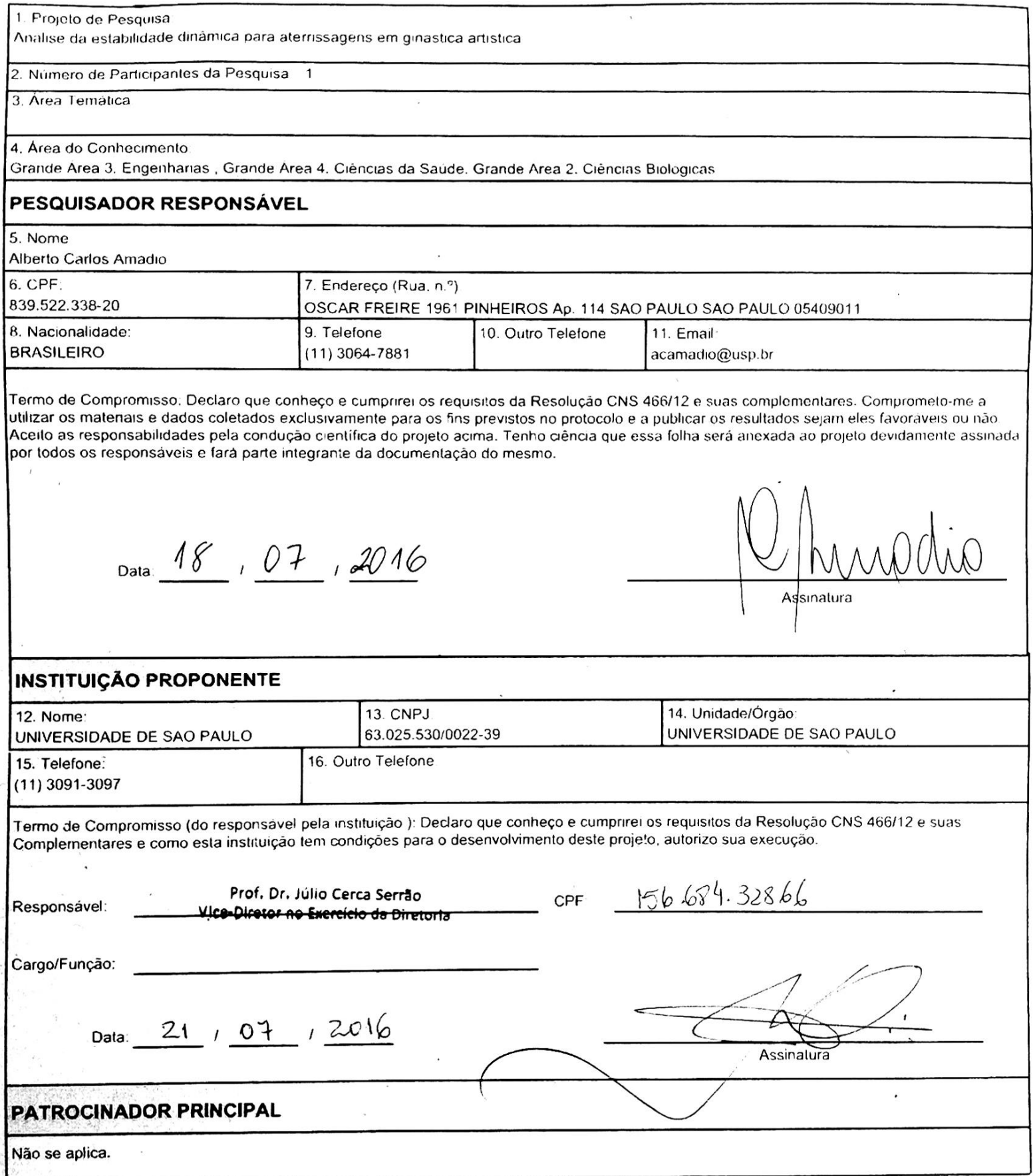

